UNIVERSIDADE DE SÃO PAULO

FACULDADE DE FILOSOFIA, LETRAS E CIÊNCIAS HUMANAS DEPARTAMENTO DE SOCIOLOGIA PROGRAMA DE PÓS-GRADUAÇÃO EM SOCIOLOGIA

ANDRÉ VERETA NAHOUM

Selling "cultures":

The Traffic of Cultural Representations from the

Yawanawa

Versão corrigida

São Paulo 
UNIVERSIDADE DE SÃO PAULO

FACULDADE DE FILOSOFIA, LETRAS E CIÊNCIAS HUMANAS

DEPARTAMENTO DE SOCIOLOGIA

PROGRAMA DE PÓS-GRADUAÇÃO EM SOCIOLOGIA

\section{Selling "cultures": \\ The Traffic of Cultural Representations from the \\ Yawanawa}

Versão corrigida

ANDRÉ VERETA NAHOUM

Tese de doutorado apresentada ao Programa de Pós-Graduação do Departamento de Sociologia da Faculdade de Filosofia, Letras e Ciências Humanas da Universidade de São Paulo, para a obtenção do título de Doutor em Sociologia.

Orientadora: Professora Doutora Nadya Araújo Guimarães

São Paulo 


\begin{abstract}
What are the tensions, alliances, negotiations, and translations underlying the traffic of cultural representations in markets? This research analyzes two economic projects maintained by the Yawanawa, an indigenous population from the southwestern Amazon: one project produces annatto seeds for an American cosmetic firm, and the other involves the public performance of cultural and, notably, spiritual practices. The indigenization of market practices and specific Euro-American categories - such as monetary exchange, environmental protection, and cultural difference - allow cultural elements to be translated into representations of enduring cultures, harmonious lifestyles and good environmental practices. The economic valuation of cultural representations is being used as a new tool in local conflicts that occur internally among leaders and groups in their quest for prestige, loyalty, and material resources, and externally with the region's non-native population and with national initiatives to develop profitable activities in the Amazon. Part of our global market society, the Yawanawa can also employ the demand and valuation of representations associated with their culture to individual projects on the construction of reputation and leadership, and more broadly, to the reassertion of their collective identity as a specific indigenous population with special rights. This research explores market exchange as an arena of complex sociability and conflict. It analyzes how values are created and exchanged within the market in a true cultural economy, and how individual and collective identity projects are constructed, challenged, and sometimes reproduced by the traffic of material and immaterial objects.
\end{abstract}

Keywords: Commodification, culture, markets, indigenous populations, Amazon. 


\section{Resumo}

Quais são as tensões, alianças, negociações e traduções que subjazem ao tráfico de representações culturais no mercado? Esta pesquisa analisa dois projetos de inserção no mercado dos Yawanawá, população indígena do sudoeste amazônico: um projeto para produção de sementes de urucum para uma empresa estadunidense de cosméticos, e outro que envolve a exibição pública de práticas culturais, notadamente espirituais. A indigenização de práticas de mercado e categorias específicas da cultura Euro-Americana - tais como o intercâmbio monetário, a proteção ambiental e a diferença cultural - permitem a tradução de elementos culturais em estilos de vida harmoniosos e boas práticas ambientais. A valorização econômica de representações culturais é utilizada internamente como um novo instrumento em conflitos locais entre líderes e grupos em sua busca por prestígio, lealdade e recursos materiais e, externamente, junto à população regional e nacional não-nativa como contraponto a outras iniciativas para o desenvolvimento de atividades lucrativas na Amazônia. Parte de nossa sociedade global de mercado, os Yawanawa também podem empregar a demanda e valorização de representações associadas à sua cultura em projetos individuais de construção de reputação e liderança, e mais amplamente, para a reafirmação de sua identidade coletiva, como uma população indígena com direitos especiais. Esta pesquisa explora a troca mercantil como uma arena de sociabilidade complexa e conflituosa. Ela analisa como valores são criados e intercambiados no mercado em uma verdadeira economia cultural, e como projetos de identidade individual e coletiva são construídos, questionados e, às vezes, reproduzidos por meio do tráfico de objetos materiais e imateriais.

Palavras-Chave: comodificação, cultura, mercados, populações indígenas, Amazônia. 


\section{Acknowledgments}

As a project developed in different academic institutions and that entailed a multi-site ethnography, the list of people to whom it is indebted, as I am, is obviously a long one. This rich dialogue established in the multiple sites was essential for the development of this work.

First and foremost, this project's contours were defined in constant dialogue and as result of the guidance of my advisors, Professors Beckert and Araújo Guimarães. Both made critical remarks that allowed me to improve it and reminded me of the virtues of pragmatism.

It all began at the Department of Sociology of the University of Sao Paulo, where Professor Nadya Araújo Guimarães accepted and continued to supervise a project with huge de-tours and which required me long periods of absence. I am particularly indebted to the intellectual dialogue I established with her, as well as the constant stimulation and the confidence in the project she revealed. Equally important to the development of this research was the fruitful and stimulating intellectual environment I found at Workshop of Economic and Labor Sociology (Oficina de Sociologia Econômica e do Trabalho), organized by her. Having the chance to discuss my own work at different stages of development was very important, as was discussing the research of colleagues working in cognate fields. This small community of rigorous and demanding readers helped to sharp some of my arguments here. In particular, I would like to thank the members of this group who followed me since the beginning: Murillo de Britto, Ian Prates, Priscila Vieira, Monise Picanço, Ana Carolina Andrada, Jonas Bicev, Jaime Santos Júnior and Gustavo Taniguti. In special, I thank Laura Chartain and Lucas Azambuja, with whom I discussed our research beyond the meetings of the workshop. I am also grateful to my cohort of doctoral students at the Department, with whom I discussed this research at its initial stages, but especially to Frederico Barros, who paired his intellectual support with friendship. The paths this project ended up taking were to some extent defined by the comments I obtained in my qualifying exam in Sao Paulo. I am, in that sense, very grateful to Professors Ricardo Abramovay and Federico Neiburg, who took part in the committee. And beyond the intellectual dialogue, this project is indebted to the Commission of Post-Graduate Studies of the Department of Sociology and its administrative staff, who revealed an unforeseen flexibility that allowed me to remain abroad for long periods, to develop this project in a foreign institution and to present this thesis in English. 
The second institution to which I am thankful for is the Max Planck Institute for the Study of Societies. This research would not exist without the formation and the generous financial support I obtained at the Max Planck, which allowed me to circulate, from Cologne to the Amazon, from the Amazon to the United States, and then back to Cologne. This research was entirely funded by the German Federal Government. But the support I obtained in Cologne was not purely financial. Professor Jens Beckert was, from the first week, an unusually diligent advisor, discussing each step of the conception, development and final writing of this project. Additionally, the constant dialogue with Professor Wolfgang Streeck provided constant intellectual stimulation, much beyond the narrow boundaries of this project, but also in relation to it. Stimulation, support and that portion of merriment that doctoral students require to remain lucid came from incredible colleagues in Cologne. Some since the beginning of this journey, others having arrived at its final stages, they were all nonetheless dependable: Timur Ergen, Philip Mader, Matias Dewey, Maria Luísa Marinho, Marcin Serafin, Jiska Gojowczyk, Irina España Eljaiek, Inga Rademacher, Felipe González, Daniel Mertens, Carolyn Biltoft, Betsy Carter, Azer Kilic, Arne Dressler, Annette Hübschle, Ana Carolina Alfinito Vieira and Aldo Madariaga.

At the institute I also found the most helpful librarians. Susanne Hilbring commands a team working with an almost religious devotion to make available all imaginable bibliographic materials. In particular, I must thank Sebastian Lange for his magic of providing me books about the Amazon that are difficult to obtain even in Brazil. Having to deal with the ordeals of living abroad in a country with a language you do not command and amidst multiple bureaucratic challenges, would not have been possible without the kindness and eagerness to help of Ruth Hanisch.

The Max Planck Institute also allowed me to circulate my ideas and discuss parts or the entirety of this work in academic circles. As a result of this circulation I obtained insightful comments and suggestions. And thus, I am also grateful to the authors of such comments and suggestions: to Professors James Mahoney, Marion Fourcade and Philippe Steiner. Additionally, I thank Professor Viviana Zelizer for suggestions at a very initial stage of this research.

This project also benefited from a short, but instigating research period at the University of California, Berkeley. I thank the kind hospitality of Professor Neil Fligstein and his vibrant research group. I also thank the staff at the Institute for Research on Labor and Employment (IRLE), where I worked during the period in Berkeley. 
My greatest gratitude, however, is to those who gave their time and words, accepting the inconveniences and perils of being observed and researched. My research partners hosted me in their houses and working places, offered me their food and, in many cases, also their trust and friendship. We made culture together: the following pages would be blank without them and, in that sense, this text is also theirs. I am grateful to Biraci Brasil Yawanawa and Joaquim Tashka Yawanawa for authorizing my presence in their indigenous land and for all the Yawanawa for receiving me and accepting yet another outsider scrutinizing their lives. In particular, I must thank Waxy (Luzia) Yawanawa, for all she did to make me feel at home on the shores of the Gregorio River and for the help in getting information I needed. I am equally indebted to Krell Felix Yawa, the most genuinely Yawanawa of all nawas, who provided me remarkable amounts of laughter, anthropological blues and anecdotes of the regional culture while working at Nova Esperança, but also thought me a lot about respect for indigenous cultures.

On the other side of the Americas, I am also very grateful to Aveda Corporation and especially to Mr. Chuck Bennett, for giving me access to the firm and employees involved in the partnership I studied. I thank them for their time and insights.

Many friends in Brazil also deserve recognition for tolerating the temperamental pilgrimage of a doctoral student. In particular, I would like to thank Daniela Fichino, for his virtually therapeutic support, and Juliana Benedetti, for her companionship.

Amidst the turbulent times of dissertation, it would be difficult to carry on without the unconditional support from the kin. I thank Eny, Isidore, Suzana, Daniel and little Helena, who grew side by side to this project, for the uncountable talks, the joy they provided me on the way and for their belief in this project, which made for their sacrifices in conviviality. The support of all these incredible humans in many levels explains the completion and the results of this research, never its flaws.

To my parents, for this journey was also theirs. 
"Diante do amigo europeu, lamentam a má sorte de seus antepassados que não puderam conhecer um povo tão valoroso e ilustre, possuidor de tantas coisas boas" Pero de Magalhães Gandavo, "Historia da prouincia sa(n)cta Cruz a que vulgarme(n)te chamam Brasil, 1576. 


\section{Table of Contents}

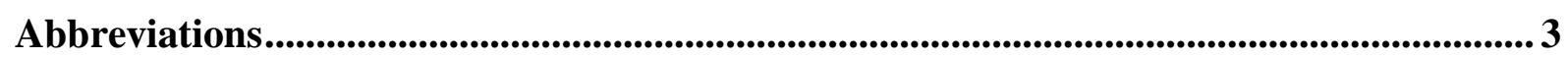

Glossary ......................................................................................................................... 4

List of Tables and Images ................................................................................................................... 7

1. Introduction ..................................................................................................................... 8

Part I .................................................................................................................................

2. Terms of the question: commodities, commodification and "culture" .............................30

2.1. Commodities: a transient phase in the social life of things ........................................... 30

2.2. Commodification as a tensional and negotiated process: towards an enlarged politics of

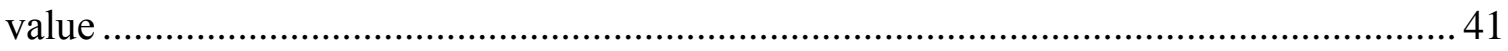

2.3. The mystery of value in cultural representations of otherness ....................................... 61

2.4. The literature on commodification of "cultures": a short review ...................................66

Part II ................................................................................................................................. 70

The Producers.......................................................................................................................... 70

3. "We are like the white-lipped peccaries" "........................................................................ 74

3.1 White-lipped peccaries are good to think: the queixada ritornello ................................ 74

3.2 The nawa contrapunctus: alterity as a constitutive principle of Yawanawa identity ..... 78

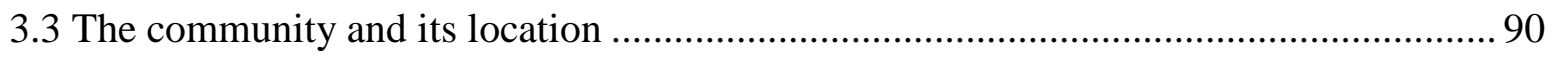

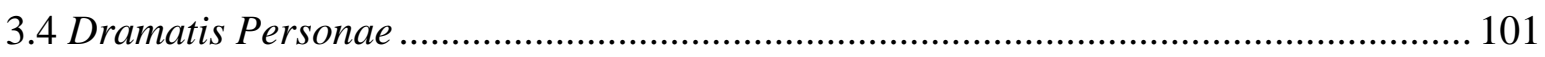

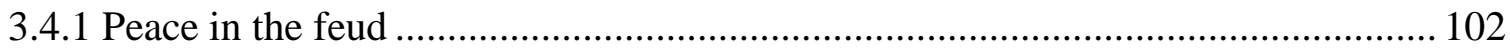

3.4.2 The main characters and their organizations........................................................ 110

4. Permutations of debt: the political and cultural economies of the Yawanawa ........... 117

4.1 Political leadership: the power in the debt and the intermediation between worlds .... 118

4.1.1. The Yawanawa leader: a Big-Man?................................................................. 140

4.2 The production of life amongst the Yawanawa: work, goods and money .................. 149

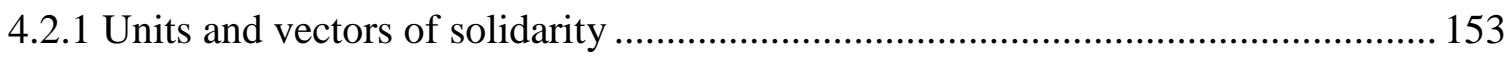

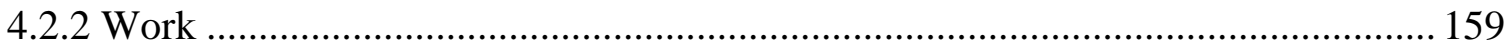

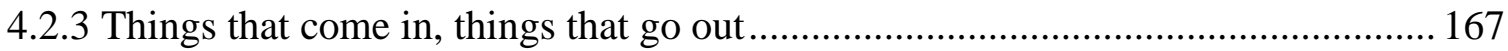

5. From Caboclo Seringueiro to Guardian of the Forest ........................................................ 180

6. An Upper Mississippi Interlude: Beauty is as beauty does .............................................. 195

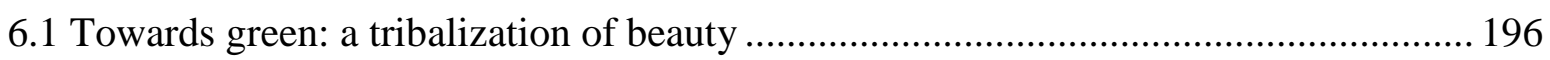

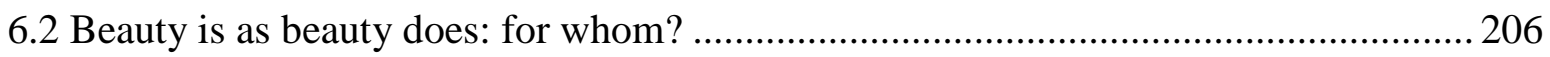




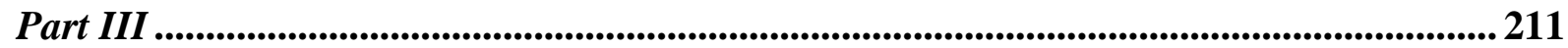

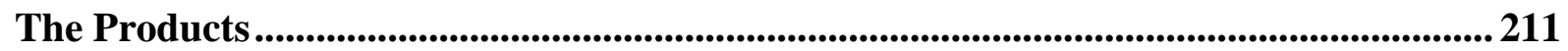

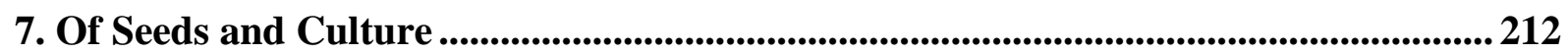

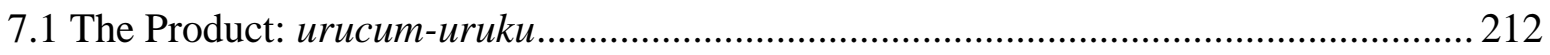

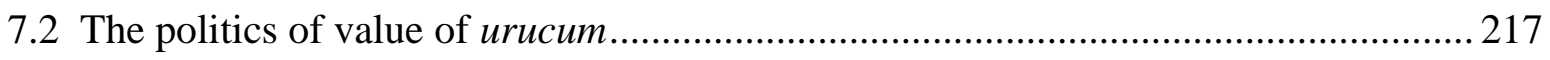

7.3 Producing and selling Uruku ................................................................................ 220

8. Selling the cure, playing Yawanawa.................................................................................... 230

8.1. The Product: Festivals and performances .......................................................... 230

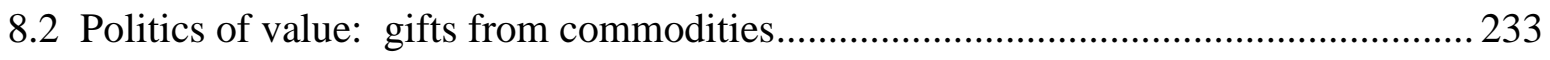

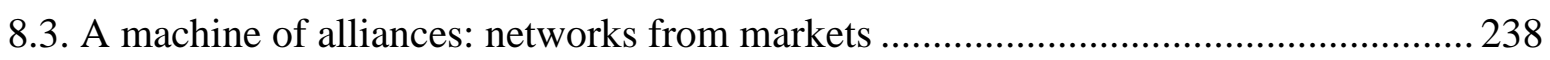

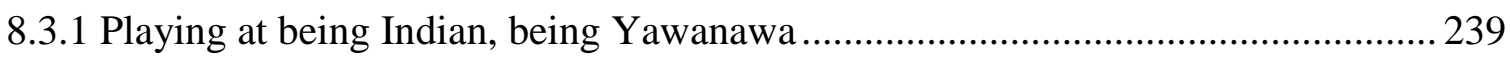

8.3.2 Machines of community, machines of alliances .................................................... 242

8.4 The seeds of "culture": assessing the projects ............................................................ 244

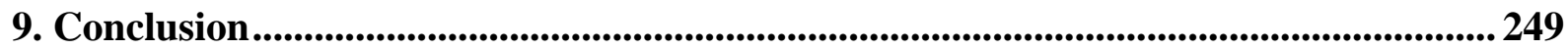

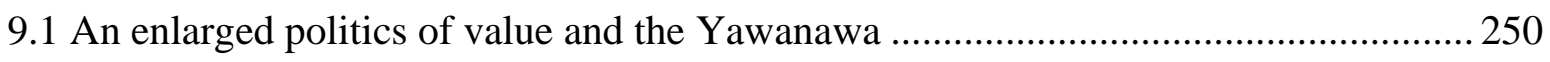

9.2 Instrumentality, dignities and perils of the market: doing business, the Yawanawa way

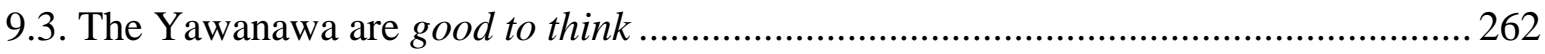

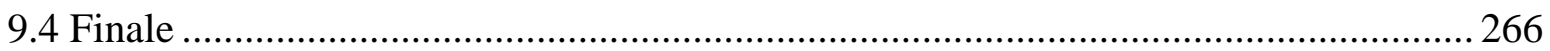

Appendix 1: Interviews at Gregorio River Indigenous Land and key .............................. 270

Appendix 2: Interviews with Aveda employees ........................................................................ 272

References ................................................................................................................................. 273 


\section{Abbreviations}

ASCY = Associação Sociocultural Yawanawa (Yawanawa Sociocultural Association)

$\mathrm{CIMI}=$ Conselho Indigenista Missionário (Missionary Indigenist Council)

CNS = Conselho Nacional dos Seringueiros (National Council of Rubber Tappers)

COOPYAWA = Cooperativa Agroextrativista Yawanawa (Yawanawa Co-op)

COIAB = Coordenação das Organizações Indígenas da Amazônia Brasileira

CPI-ACRE = Comissão Pró-Índio do Acre (Pro-Indian Commission of Acre)

FUNAI = Fundação Nacional do Índio (National Indian Foundation). Federal body responsible for the implementation of Indigenist policies.

MPIVJ = Movimento dos Povos Indígenas do Vale do Juruá (Movement of the Indigenous Populations of the Jurua Valley).

OAEYRG = Organização dos Agricultores e Extrativistas do Rio Gregório (Organization of the Peasants and Extractive Workers of the Gregorio River)

REDD $=$ Reduced Emissions from Deforestation and Forest Degradation

UNCED = United Nations Conference on Environment and Development, also Rio 92

UNCSD = United Nations Conference on Sustainable Development, also Rio+20

UNI-AC = União das Nações Indígenas do Acre e Sul do Amazonas (Union of the Indigenous Nations of Acre and South Amazonas). 


\section{Glossary}

Aliança dos Povos da Floresta = organization created in the mid-1980s encompassing indigenous populations and rubber tappers of Acre. The purpose was to unite them in their struggle to protect their access to forest resources and, consequently, the forest itself, from owners of land that, benefited with tax incentives, planned to transform their newly regularized plots of land into farms and cattle ranches. The movement was short-lived due to differences in goals and clashes amongst leaders, but had a long impact in the politics of Acre. Ayahuasca (also uni) = a psychoactive brew known by multiple names in the Amazon, among which the Hispanicized Quechua term ayahuasca became the most widely employed by nonnative writers and users. Ayahuasca means "vine of the souls". The brew has become an important part of syncretic religious cults (Santo Daime, União do Vegetal and Barquinha), which acquired knowledge on the properties of the brew through natives and non-natives in the Amazon. Among the Yawanawa, the brew is named uni. The brew consists of a combination of the vine Banisteriopsis caapi, containing Monoamine Oxidase Inhibitors (MAOI), and the leaves of any bush that contains DMT ( $N$-dimethyltryptamine), which in the Yawanawa case is the Psychotria Viridis (known as chacruna and rainha - queen - in the region). The combination produces effects on the central nervous system. There are a number of concoctions known and employed following prescriptions in different spiritual rituals and as part of cure procedures that comprise the Yawanawa ethnomedicine. The leaves are thought to carry a powerful spirit that guides the shamans, allowing them to communicate with the personified spirits that inhabit the universe. Consumed as part of a ritual, other drinkers would also be able to have visions. More information on the Ayahuasca and its uses by certain urban religions can be found in McKenna (2004) and Labate/Rae (2010). The uses by Amazonian populations (rubber tappers) are documented in (Pantoja/Conceição 2010).

Caiçuma $=$ A fermented drink of manioc, maze, sweet potatoes or a combination thereof, produced through the contact with saliva of women that chew the cooked vegetables. The preferred caiçuma, drunk by healers and ailing in the process of cure (Gil 1999), is the one made of manioc.

Caucheros $=$ Peruvian gum gatherers, present in the territory of Acre up to the early twentieth century, who normally made incursions into new lands in search of Castilla Elastica (gum) trees. These incursions were normally short, since the goal was to cut the gum trees ant take them to cities of Peru, was gum was extracted, sold and exported. Afraid of native resistance, 
they tended to be violent and this aspect is highlighted by the collective memory or native and non-natives of the region.

Colocações $=$ a socioeconomic unit within the rubber estates (seringais), colocações entail a small forest clearing where a number of houses and gardens were set by the rubber tappers and some rubber trails (estradas de seringal), where the latex was extracted. Scattered along the rubber estates, they constituted nuclei of sociability among the men and their families.

Estradas $($ de seringa $)=$ Trails opened in the forest connecting a number of rubber trees from which the latex was extracted. These trails were granted by the patrons and a rent was deducted from the latex produced. The rent constituted the economic manifestation of the cession of land rights based on the patron's private hold of the land.

Igarapé $=$ a small course of water, tributary of a bigger river.

Kapum = Secretion produced through most parts of the skin of a species of frog, Phyllomedusa bicolor, when stressed. Once the secretion is extracted, the animal is released. The substance is rubbed onto small burned spots of skin and thus reaches the blood system. Its immediate effects are "nausea, swelling, tachycardia, and diarrhea" and it is originally consumed by several Indigenous groups of the Upper Jurua valley to cure men of bad hunting luck, increasing alertness and endurance to hunger and thirst. Oftentimes bad hunting luck is related to a condition that is called panema (see below), a lack of enthusiasm for social activities (Cunha 2009: 49-50).

Mariri $=$ a ritual dance of the Yawanawa culture, performed collectively.

Panema $=$ a general state of being, thought to be carried by the person, which creates an incapacity for action and a lack of enthusiasm. This incapacity is expressed in a failure to hunt or fish that cannot be associated with environmental factors. Product of particular ontologies of nature and their resulting ecologies, it is often associated with the non-observance of positive or negative norms involving fishing, hunting, manipulating the caught animals or consuming them.

Rapé $=$ a mix of crushed and ground ashes of tobacco and leaves, inhaled through the nostrils. Snuff.

Rumé = see rapé.

Saite $=$ a chant sung during rituals or games. Currently, they are also performed for outsiders independently of rituals.

Seringa $=$ latex, rubber.

Seringal $=$ Rubber estate. A plot of land in the Forest held and controlled by a rubber patron. Rubber estates encompassed a number of colocações and their estradas de seringa. They also 
contained a headquarters and at least one warehouse, where the latex was delivered and industrialized goods could be obtained in exchange for rubber. They also have gardens to produce food for the managers and possibly the patron. Before land regularization, most estates were held and claims were backed by purchase contracts, but not necessarily property titles.

Urucum $=$ name employed in the Amazon and taken from the indigenous Tupi language to designate annatto, a natural pigment obtained from the fruit seeds of the Bixa Orellana shrubs.

Uni $=$ see Ayahuasca

Xinay $a=$ an Yawanawa healer who has completed all steps of initiation and learning. 


\section{List of Tables and Images}

Diagram 1: kinship terminology..................................... 81

Map 1: Location of the Gregorio River Indigenous Land in the State of Acre..... 93

Map 2: Gregorio River Indigenous Land - limits and villages (as of 2004)....... 96

Table 1: Leaders and their elements of power............................ 137

Diagram 2: Rubber tapping economy in the Twentieth Century Amazonas........ 184

Image 1: Uruku.................................................. 216

Image 2: Retail area, Aveda Institute, Minneapolis........................ 223

Image 3: Brochure cover: Asian woman covered in bixina powder............. 226

Image 4: Brochure (cont.): The Yawanawa painting code................... 227

Image 5: Brochure (cont.): Information on the partnership................. 228 


\section{Introduction}

This is an account of how elements of culture, signals of difference as appropriated by agents, become commodities and are exchanged, creating connections between different cultures in the market. In other words, it aims at investigating the process of commodification involving representations of culture of distant populations. In recent years there has been an increased interest in products and services purported to convey some form of traditional knowledge from indigenous populations of distant lands. Urban populations and companies have become more interested in the information retained by indigenous populations. Consumers are attracted to their practices, rituals, local medicines, and special production techniques. And indigenous populations have been using this renovated interest to reinvent cultural practices and venture into the market, offering goods and services related to their identity. Besides bringing income and comfort to communities, these activities have been an instrument to reinforce the legitimacy of internal leadership and to advance identity and political claims at the national and international levels.

Preserving the lifestyles and practices of indigenous populations has been increasingly associated with protecting nature and biological diversity. The political debate about ecology has fostered a romantic image of indigenous communities as traditional protectors of nature and experts in the sustainable use of resources, creating new visions of alterity. Their connection with nature has been praised as a model of harmonious lifestyle and a source of wisdom to deal with the malaises of modernity and save the planet from the impeding environmental crisis. They are also often perceived as valiant survivors of the processes of colonization - which they indeed are - and suppliers of an alternative episteme that offers the postmodernist subjects a holistic approach to life in which they can seek inspiration. If the developmental paradigms of the twentieth century provided a justification for assimilationism and condemned Indigenous populations to integrate or perish, the postcolonial, postdevelopmental paradigm (Escobar 1995; Escobar 2008) of the twentieth first calls for a decolonization of the modern episteme through the practices and ontologies of the different other.

But how are representations of culture exchanged in the market, an intrinsically modern arena of exchange? How is the production for the market of indigenous products and cultural practices taking place, and how do consumers in advanced capitalist societies regard these 
products and services? How are supply and demand for these "indigenous" goods constituted? Is "culture" ever alienated? Considering that cultural elements do not originally circulate in the market, how do agents operate the necessary transformations - deviations and qualifications - in order to detach commodities out of cultural edifices?

This research focuses on a particular vernacular use of cultural elements, which embodies an imagined vision of indigenous cultures. The issue here is how "culture" in brackets, as in Cunha's (2009) discussion, i.e., the constructed self-conscious sense of a common identity and patrimony of practices, built upon the return and interpretation of foreign visions of one's identity, is transformed into a commodity. I intend to analyze the exchange of goods that embody a vision of a different society and can thus magically transport consumers to venues that are repositories of a harmonious lifestyle protected from the hassles of modern urban civilization. I am not concerned here with those forms of misappropriation of culture, or biopiracy, but in the rather opposite of those: products, performances, services in which a collective authorship is clear and an essential element of their value. The consumption aims exactly at sharing properties associated with the "culture" that is being represented in exchange.

The exchange process is puzzling because it takes place in the market, so that the market becomes the medium through which cosmogonies and values are exchanged - and to some extent created. Cultures, markers of difference, are in this case the means and the object of exchange. As means, they differentiate populations; as objects they create encounters across cultures. The introduction of cultural elements of indigenous populations into the market evokes fundamental theoretical and practical questions: how cultural elements circulate in the form of commodities, how actors interpret this transition, what is the politics of value, i.e., the negotiation over meanings and values of objects that underlie the circulation of objects, which values are exchanged with the objects and how they are reinterpreted, what points of commensurability are established amongst agents, what are the intentions behind and practical consequences of using the market as an arena for the performance of culture and what expectations are generated? All of these questions can be framed in the more global research question: what are the tensions, alliances, negotiations, expectations and translations underlying the traffic of cultural representations in the market?

In order to understand this phenomenon, it is necessary to approach the actors and their practices, with their own points of view, their meanings, their trajectories and verify how this process is taking place. The decision to take the representations of identity and difference into 
the market cannot be in disconnection with the general entanglements of the carriers and masters of these representations with external institutions, persons and objects. The circulation of cultural representations is, after all, just a fragment of the total circulation of goods, images and power from and to these communities, which defines meanings and expectations regarding exchange in general. Much of the investigation lies, therefore, in understanding how local communities symbolically and materially organize their existence, the scope and meanings of external exchange, the different expectations it generates, the appropriations of external objects and the conditions of expression of difference. This is also important to treat those who offer their signals of difference as agents in the process, with strategies, orientations and goals. Yet this is only half of the picture. For the circulation of such representations requires the demand from another set of agents. They equally bring their conceptions and expectations to this encounter of different desires. Understanding how these goods and practices thought to carry the signs of identity of a different people came to be desired also requires understanding the consumers.

\subsection{An Ethnography of encounter to unveil the indigenization of modernity}

There are clearly two different perspectives in this process, depending on the entry point chosen by the analyst. On the one side, there are heightened cultural consciousness and sense of nativeness, as well as efforts to empower the community. There is the introduction of proprietary notions of culture. And there is a curious process of using the market, objectifying their subjectivity by offering cultural goods and services purported to belong to its "culture", in a strategic step to strengthen their cultural recognition and bring more comfort to the community. In other words, there is an appropriation of instruments regarded as modern in their identity politics that attempt to stress their difference in relation to the same modernity. On the other side, there is a strong association of traditional populations with environmental protection, related to new development discourses that lead to an enchantment of nature and to the notion that we are bound together due to our action on the environment. There is also a quest for authenticity, alternative lifestyles and a similar enchantment of otherness and "culture", thought as repositories of a long derided and lost wisdom, which bestows a magical nature upon cultural traditions of exotic and remote populations. These perspectives reveal the 
opposite vectors of an exchange taking place between two groups of populations that have for a long time been divided between traditional and modern, each appropriating elements of the other. The case here is an instance of what Sahlins (1999: ix) defines as an indigenization of modernity, referring to "the way indigenous peoples appropriate the forces and relations of an encroaching Western capitalism in their own cultural schemes; which is also to say, in their own projects of 'development', according to their historical ideas of good things". However, Sahlins (1999) only looks into the forms through which Indigenous populations appropriate elements of modernity through their local schemes of interpretation, to produce ever more colorful expressions of their different cultures. The opposite is also true: the processes analyzed here suggests that those who thought of themselves as moderns are employing Indigenous symbols, seeking the savant savages to obtain lessons, which are then interpreted according to the cultural schemes of the moderns, to solve problems that are very modern as well. One of the main hypotheses of this work is that images of difference have become much sought after by urban populations and a tool in the hand of savant natives, conscious about the value of their cultural image.

Both these perspectives are analytically relevant. In each of these instances, there are specific processes. This research will approach the question from each of these perspectives, but it concentrates on the meanings, processes, tensions, expectations and relations created amongst the Indigenous producers, as well as in the cultural economy from their perspective. This ethnography of encounter sustains that one must investigate in depth the cultural, historical, social and political aspects of the agents of exchange, in order to understand the social relations and local meanings in which the interactions are inserted. These explain the circulation of objects, their meanings and expectations. The main analytical focus is the producers of "culture" and its products. The reasons are simple: they are considered the weakest, often silenced side of the encounter and yet they are the carriers, masters and subjects of the culture that is being represented and circulating in the market. In so doing, the goal is to address the question of the commodification of "cultures" as a means to investigate the effects of the market on cultural dynamics and expose unexpected results. Unexpected, that is, according to those accounts imbued of a "sentimental pessimism that simply collapses everything in a vision of domination and subjection" (Greenblatt 1991: 152), and awaits, with sorrow, the disappearance of these cultures, or their colonization through its subordination to market exchange. These accounts miss all the creativity of the colonized, their intrepid agency and some oligarchic uses of foreign institutions and objects to reproduce internal structures of power and principles of social differentiation. For a simple principle of economy of research 
and the incapacity to penetrate into the myriad of consumers of these cultural representations, the meanings of these processes for the other side of these interactions, the consumers of "culture" are analyzed with much less depth, without any pretense to actually illuminate the private meanings of their possessions (Richins 1994), and their profound relation with the identities of their carriers (Belk 1988). I offer a detailed account of those sociological, ontological, political and historical aspects of the community that animate the flow of goods, services and power in their relations with outsiders, claiming that these are associated with the circulation of their cultural representations, and a much less detailed account of the consumers.

The object is the encounter and the forms of circulation of cultural representations. Yet, disassembling the parts of the process is an analytical resource to grasp the multiple relationships, negotiations and tensions around objects that connect populations. This procedure serves the purpose of reconstructing some fragments of the chain, in this case mostly about the producers, whereby the market creates linkages, in which culture is the means and the ends, the medium and the object of the dense set of social relations created by and in the market. Reconstructing the parts, the goal is to understand a cultural encounter that takes place in the market.

Despite its distinctive features, native communities ought to be understood as part of a shared world, constituting the same circuits of capital. Aiming at understanding the connections, I investigate the internal meanings of these only because local cultures are the means with which populations engage with the world and common processes (universals). Even producing different responses, in unequal rhythms that vary according to the differential positions of populations and their groups in the distribution of material and symbolical resources, they are part of the same world. In that sense, it is important to abandon some pervasive yet heuristically useless dualisms from social sciences, such as the traditional/modern divide. We are not interested in finding our own past or the seeds of future societal developments in native communities, nor we intend to treat them as traditional, monolithic cultures, in which a conscience collective holds together the entire community harmoniously and produces shared understandings of their present and future. It is a common prejudice in the West to regard these cultures as traditional, rigid and homogeneous, without an internal diversity of dispositions and interests.

These populations not only have myths, but they are historical agents and, thus, have their own histories, which often make some myths more salient than others. The focus here is 
on history and the practices that lead to a permanent renegotiation of meanings. Cultures are relational, defined in the contact with others, fluid and creative, permanently open to invention. Yet each culture has its own devices that allow interpreting these new circumstances and creatively incorporating them. The most stable of all of cultural elements it the structure of possibilities of reception of symbols that mediates the incorporation of new elements and gives meaning to changes (Sahlins 1985).

Each culture has a scheme to classify and interpret processes, relations and objects that flow in and out as a result. But meanings are open to debate. Cultures do not provide a single, necessary or homogeneous meaning as an unequivocal code. Making sense of the world is a process open to the actors, which can use culture and its categories of thought and judgment to advance specific interpretations about the place, role and meaning of institutions, processes and objects. Consequently, even if culture mediates the engagements of a population with difference and change, the expectations, values and interpretations regarding the future remain open to contention. Conflicts and schisms emerge as different interpretations of cultural rules and contingent processes are advanced in the daily life of communities. Particularly important to this work are the ambivalences, tensions and different expectations surrounding the manipulation of values and the interpretation of cultural rules in face of socioeconomic transformations. Situations and interpretations are internally disputed and negotiated, objects discussed and integrated in the cultural apparatus, sometimes with new statuses and meanings. This process is eminently social as well, for this appropriation of external elements and recreation of internal structures is subject to the social position of agents in the community, and it involves creative agency. Culture is not pure ideology and domination, allowing actors to subvert known categories of judgment and thought in novel and unexpected ways.

\subsection{Theoretical Interests}

I believe that investigating the tensions, alliances, negotiations and translations underlying the traffic of cultural representations, in the commodity form, in the market, is good to think about multiple related theoretical questions. The first theoretical interest that animates this research is to understand commodification, not as an inexorable product of ever expanding capitalist forces, but as a process of negotiation of values that allows objects to 
circulate to and from the commodity status. Following the methodological proposal of Appadurai (1986), this research investigates the politics of value behind the movement of objects and their diversions to the commodity state. Commodities are, thus approached not as an ontological property of things, but as a transient state in the social life of a good, which might equally circulate in different regimes of values. Differently than his proposal, however, I hold that the different forms of circulation of goods discussed by theories of exchange (gifts, barter and exchange) remain a valid analytical instrument to differentiate regimes in which exchange takes place according to the social relations in which they are inserted or which they promote and the main orientations underlying exchange. It also attempts to correct his narrow conception of creation of value, confined to the sphere of exchange. Values are equally created in the sphere of production. One of the contentions here is that the politics of value that animates commodification involves not only the meanings of objects during exchange, but also a politics of production. In order to circulate, objects must be produced and, in many cases, with the clear intention of being exchanged. Thus, the circulation of things requires certain dispositions towards labor and exchange, and involves a negotiation on meanings and expectations of productive activities as well.

This analysis here focuses on the traffic of objects different than bulk goods. It analyzes how cultural representations, images of "otherness", circulate in the commodity form. The very appeal of "culture", the Comaroffs aptly assert, "lies in the fact that it seems to resist ordinary economic rationality" (2009: 21). The increased circulation of the object of exchange does not decrease its original value, nor leads to its depletion. More than simply an object which consumption is non-rival, increased circulation reaffirms ethnicity and, consequently, the increase in consumption has actually led to an increase of supply. In fact, as natives all over the world re-enact their recreated traditions and practices, they are the consumers as much as the producers of these forms of ethnicity (ibid.: 26).

Yet "culture" also challenges the economic rationality by offering an alternative to it. The set of practices, rituals and objects that are exchanged are sold as tradition, an original way of life preserved from the market, and consumed as elements of an environmentally friendly, harmonious lifestyle protected from the hassles of urban civilization and even offering a "cure" for its malaises. Projects that are symbols of a new era of indigenous agency incorporating instruments of modernity, transplanted from the Euro-American cultural system, are paradoxically presented as a way to "revert the clock" (Dominique Conseil's speech in AVEDA) of the same modernity. 
Another question is the consequence of attributing economic value to things that were originally out of market, or as Fourcade (2011) puts it, "the feedback loop from monetary valuation to social representations and practices". Money synthesizes different principles of judgment and translates them into an objective equivalent. But, contrary to Simmel's (1978) fears, even when something is priced, as we see in the case of "culture", ordinary categories of judgment of objects do not necessarily fade away and people frequently continue to invoke alternative principles to think about its value. Economic valuation relies on those categories of judgment and, at the same time, affects them, altering the way we relate to priced objects. This takes us to yet another question, which is the relationship between culture and market economy. Traditionally, the market has been seen either as force of corruption and colonization of cultures or, which in fact equates to the same, a force of civilization (Zelizer 1988; Hirschman 1986). And here, the case is particularly rich to overcome this false dualism and replace it for more sophisticated views on that relationship, since in either case the market would destroy the object of exchange.

The main threat when analyzing the encounters of local and global forces that underlies the commodification of culture is to assume that markets are a threat to culture and that this process is imposed from outside, determined by inescapable global processes. Much of the scholarship on this issue, as will be shown, works with that assumption, treating native communities as passive victims of the process. Economic partnerships involving indigenous populations are normally assessed on the basis of their potential to grant self-determination and full empowerment. This is a paradox: albeit rather critical to the market and inferring that neoliberal forces under new developmental discourses impose commodification, menacing the reproduction of culture, they assess the failures of these market-based projects to bring empowerment and self-determination. Markets cannot be at once dangerous and empowering. These studies carry heavy normative assumptions regarding the consequences of market transactions that are not submitted to empirical tests.

Leaving these presuppositions aside, I am interested in understanding the set of social, cultural and political relations and meanings underlying and surrounding the exchange of cultural goods and services, as defined by the involved parties. In that sense, this research is connected to two further theoretical interests. The first is to investigate the nature of the "uneven entanglement of local and global power relations" (Thomas 1991: xi), restituting the roles of "parochial intentions" of "local populations" (Sahlins 1985: viii) in their own history. The dialogue is obviously with World-System Analysis (Wallerstein 1974) which, focusing on 
processes initiated in the center of the World-System and international exchange, mutes peripheral voices and prescribes the disappearance of local particulars or they total subordination to processes of accumulation initiated in the center of the system. In so doing, it is unable to discuss the tensions and conflicts generated in the periphery by entanglements between local and global or to account for the role played by local institutions and projects of power in these processes. There are local forms of control and power mediating and steering global forces for the purposes of local elites that must be unveiled, and beyond the strategic and rational, there are also local forms of creative reinvention of foreign institutions producing unexpected results.

The second is to understand market exchange as part of a cultural economy, in which values are created and exchanged through the circulation of objects and the encounters of their owners. Moving away from a "hostile worlds" type of analysis (Zelizer 2005), the cultural in the economic can be unveiled. The proposal here, which is as much methodological as substantive, is to understand the social, cultural and political dimensions of the market as intimately related dimensions of a single phenomenon. More than simply treating transactions as socially embedded, markets are investigated as spaces in which social, cultural and individual values are exchanged and created, as much as pecuniary values are, in a true cultural economy. A market is an arena for conflicts, tensions and negotiations on many values, symbols and identities. As objects circulate, values are also exchanged and incorporated, according to local schemes.

Markets, as other social arenas, are both produced by and produce a dense set of social relationships, in which agents exchange rights over goods and services. It should produce no surprise to assert that markets are a dense arena of sociability, for as a metaphor or not, they are the primary space for the distribution of material means in modern society and, thus, essential for its reproduction. Essential as they are, however, market exchange fosters other social and symbolic processes not limited to the distribution of material means. The praxis, the material action upon the environment, is not a mere mode of production, but the social action and relations built upon the forces of production, as well as its symbolic representations. It relies on cultural assumptions of external forces and necessity (Sahlins 1988).

The primary focus of analyzes of the market has corresponded to processes underlying material exchange, the creation and destruction of economic value, often equated with price. Yet this is only a partial portrait. Beyond any normative claim for or against a market- 
mediated sociability, things exchanged in markets connect lives. Tensions, contradictions and negotiations of meaning, life projects and even notions of personhood and subjectification take place as value is produced materially and symbolically by agents through labor and exchange. Commodity fetishism, a fundamental analytical category that Marx (1990 [1867]: 163 and ff.) developed to understand the social relations of production, is a powerful way of saying that, under a market society, humans feel connected by mysterious and marvelous things, without recognizing the underlying labor that is necessary to produce them, nor the social relations that production entails. In the end, this could be a mere fetish, but an extremely effective operational device. And as long as the researcher attempts to investigate the relationships, tensions, conflicts and negotiations that remain opaque while the goods are exchanged, no fetishism is reproduced.

The market is not a space of purely economic profit-oriented exchange. It is a complex social space, in which given basic rules of the game, multiple orientations, aspirations and interests can be mobilized and expressed. Part of the investigation becomes, thus, to understand how agents couple their own orientations with market rules, or more broadly, with market action contexts. This leads to the final theoretical interest here, which is to understand the potential uses of market exchange, normally understood as operations of distribution of rights and obligations, as a tool in identity struggles. The observations of the phenomenon of the transformation of cultural elements of indigenous populations of the Brazilian Amazon into commodities, together with some literature on similar cases (Graham 2005; Comaroff/Comaroff 2009), indicate that the market has been chosen by indigenous populations as an arena to seek rights in national politics and to boost processes of cultural revival. All phases of this process - production, exchange and consumption - foster the (re)production of two cultural systems, by means of the exchange of elements of one of these systems, incorporated into the other with new meanings. In other words, by means of the exchange of goods or services carrying indigenous cultural signs, indigenous populations reenact their culture, as do consumers living in the Capitalist West.

The politics of value behind the movement of objects to and from the commodity status (Appadurai 1986) links the reputation of individuals to the outcomes of exchange, and in this way, may act as tools in individual and collective identity projects. But beyond the negotiations, contradictions and tensions that underlie the commodification of an object, there is a politics of value in the social and cultural construction of symbolic relations with objects, which also explain how their consumption by some can serve as a tool in efforts to assert 
ethnicity by others.

There are also particular features of the objects exchanged in this case which allow for the formulation of identity claims based on their exchange in the market. By taking their ethnicity to the market, and selling their "otherness", they increase the external visibility and internal awareness of a selected set of symbols of difference that define their identity. The capitalist culture is a highly complex and differentiated system. Its singularity, as Sahlins (1976) demonstrated in his study about food and clothing habits in the United States, is to be based on the illusion that it is completely run by material rationality. To say that the Western capitalist culture is complex does not imply that indigenous cultures are primitive or simple, but just to recognize that culture under advanced capitalism promotes such a degree of differentiation of lifestyles, that even cultural expressions that are the denial or attempts to circumvent the market culture are tolerated. The critique of modernity, pointing out to its risks and contradictions, or simply the promotion of alternative lifestyles and cultural difference are broad processes underlying these cultural expressions and explaining how the consumption of "otherness", via indigenous cultures can represent culture.

\subsection{Selling culture in the Brazilian Amazon: why the Yawanawa?}

The method here was entirely determined by the conceptions and intentions of this research. Aiming at understanding the circulation of cultural representations as a part of projects of indigenization of modernity, it was fundamental to retrace the circulation and to proceed to an in-depth analysis of the social relations, cultural schemes and political arrangements that guide the engagements of the producers of culture with outsiders in the market. The latter elements, this work sustains, underlie the politics of value in specific diversions of things to the commodity state. Given the period available and the conditions of access, the pragmatic option was to focus the analysis on producers and reconstruct their relations to understand drives, expectations and consequences of circulating elements of their "culture" in market projects. Furthermore, it was necessary to select an object displaying the identity of a population that is circulating or a population that is taking its set of distinctive cultural artifacts and practices into the market.

While looking for interesting instances of the phenomenon, I read about the curious case 
of the Phyllomedusa Bicolor frog. Cunha (2009) used the case in her discussion about the dilemmas involving the acknowledgment by Indigenous populations of their distinctive cultural heritage and the attempts to protect it using intellectual property institutions. In the book, the Yawanawa are briefly mentioned (ibid.: 4), represented by an old man taking part in a meeting to discuss Indigenous intellectual rights, namely on the uses of a secretion of the frog as medicine for bad hunters. Curiously, for any person who had met the Yawanawa, the old man is reported to have said, during the meeting, that $u n i$, the hallucinogenic brew more commonly known by its Quechua name ayahuasca, and popular amongst Southwestern Amazonian Indigenous groups and New Age groups, is not culture. At that point, little I knew about the importance of performances involving the ingestion of such brew for the Yawanawa or other populations of the region. My attention was directed to the information that the Yawanawa maintained business alliances with firms as Aveda (ibid.: 6). I immediately searched on the internet for any information on the population and was impressed with number of available images and videos. These accounted for the volume of representations that were circulating, but also indicated successful strategies in promoting their image and forging alliances with outsiders.

As I gathered more information, the Yawanawa seemed an interesting instance of the phenomenon and good to think about a number of above-mentioned theoretical questions. They have maintained an economic project with a North American firm for twenty years, not without conflicts and interruptions, and have increasingly relied on their cultural representations to obtain material and symbolic resources. Moreover, the Yawanawa are not the pristine, untouched community preferred by classical anthropological ethnographies. They were inserted in the global capitalism at least in the early twentieth century, have maintained stable intercultural encounters with non-natives for a century and developed a pragmatic relationship with work, goods and money. The Yawanawa are not traditionalists and market exchange do not generates moral censure by itself. There are aspects of their ontology that bestow particular meanings to the exchange with others, the Whites and their objects. This language is mobilized to justify some endeavors and guide them to seek allies, but it is seldom invoked. Moreover, most of the symbolic aspects that surround labor are reserved to those activities that entail a relationship with their environment, which are mediated by a particular ecology. And yet they have distinct forms of approaching and developing economic action. Production and exchange amongst the Yawanawa, including the circulation of cultural practices and representations, can only be understood as part of their cultural dynamics, political projects of their leaders, their particular existential strategies and social relations they 
developed over history within the community and with the surrounding populations. The meanings and uses of the market for the Yawanawa are specific and reveal ambivalences and different expectations of the community regarding exchange with outsiders. These particular appropriations of foreign objects and institutions for the reproduction of their cultural and social system render them good to think the commodification of cultures as a strategy in the broader processes of indigenization of modernity. Moreover, they reveal that economic action may assume different meanings, even for populations integrated in the circuits of capital.

There were also pragmatic reasons for the choice. Most Yawanawa speak fluent Portuguese, my native language, and the community normally receives visitors, which was both an opportunity and a challenge for a researcher, further described in the next section.

\subsection{Writing culture with the Yawanawa and beyond: methodological notes}

In order to grasp their own understanding of these processes and the objects involved, I conducted a short fieldwork in the indigenous land which the Yawanawa share with the Katukina, both part of the Pano linguistic group, on the shores of the Gregorio River, in the southern Brazilian Amazon (see figures 1 and 2, chapter 3). The research is an account of the circulation of cultural representations of the Yawanawa, both by means of the traffic of objects that embody such representations, and of persons who attend events in which culture is displayed. I analyze here two specific set of still-running economic activities developed by the Yawanawa in the last two decades. These projects constitute the main source of symbolic resources and generate most of the collective income obtained through economic exchange. The first is a partnership with Aveda Corporation, a firm that manufactures hair and skin care products, makeup and fragrances based in Blaine, Minnesota. This twenty-year long partnership involves the production of annatto seeds, found in the fruits of the Tropical bush Bixa Orellana. These seeds contain Bixin, an orange-red pigment employed as a natural colorant for centuries. In addition to the seeds, the firm purchases the right to employ images and symbols of the Yawanawa in their makeup line named uruku, after the word urucum, the vernacular for annatto seeds in Brazil. The Yawanawa had traditionally employed the pigment, manually extracted from the seeds and mixed with natural oils, to produce body

paintings that are considered symbols of protection and beauty. The second set of economic 
activities analyzed here involves the traffic of ritual elements of the Yawanawa "culture", mainly some spiritual and healing practices. There are two forms of public performance of these rituals: an annual cultural festival, celebrated every October in the main village, Nova Esperança, and presentations by selected members of the community invited to different urban locations. These members are considered legitimate representatives to perform such rituals in a network of allies that the Yawanawa forged in the last years through the intercultural exchange of spiritual practices with new age centers and urban cults. In common, these performances in the village or in cities offer outsiders the possibility to experience and participate in spiritual ceremonies. The festival also encompasses other cultural performances, such as a number of ritual games and dances. The analysis covers the development, challenges, the politics of value underlying production and exchange, and the meanings of these activities for the involved actors.

I believe that the best description of ethnographic work on "cultures" is contained in the visual metaphor employed by Wagner (1981). Brueghel's Dutch proverbs is an apt metaphor, if we could accept the idea that these small characters are also playing for the painter in a combined effort to produce culture. Together with their subjects, ethnographers highlight certain aspects that allow them to organize ideas and make arguments. Just as in the painting, we approach complex fields with unknown characters and relations, selecting those relations and scenes that invoke ideas. Culture is produced in this form, but this is not an exclusive action of the ethnographer. The subjects are equally producing culture in their daily interactions and are also emphasizing to the researcher those aspects that they believe are relevant to be registered in an ethnography. The researched population is also doing, if only on a more practical level, culture, and this operation is equally object of this analysis.

Following the circulation of such representations entailed my own circulation. For traffic is not just the object of the work, but also the means to achieve it: the attempt to follow the circulation of people and goods, and identify the meanings and values that were constructed alongside, required my own circulation in a process that was, itself, very rich in the production of meanings and values as I interacted with the different actors and academic peers. However, due to time constraints and access conditions, as well as the main theoretical concerns, this research does not cover the entire chain, or social life of the cultural representations of the Yawanawa. I do not analyze the singularization promoted by consumers once they have obtained a good or service in the case of the uruku makeup. In the case of public performances of rituals, I limit my analysis to the experiences and discourses of 
visitors to the Yawanawa Cultural Festival.

I have conducted an ethnographic research amongst the Yawanawa, with observation and ethnographical interviews in all Yawanawa villages but one (Escondido) ${ }^{1}$, Cruzeiro do Sul and Tarauacá, where they conduct business and some members reside. Access was negotiated for a long period, starting with a quick trip to Rio Branco in October, 2010, where I first met Joaquim Tashka Yawanawa, a young leader who manages one of the Yawanawa organizations, who then explained me that the population was grouped under two different organizations, developing independent activities. His group, with members of five villages (Matrinchã, Escondido, Tibúcio, Sete Estrelas and Mutum), most of which controlled by his uncles, had formed the Associação Sociocultural Yawanawa (Yawanawa Sociocultural Association ASCY), under his leadership and had taken over the urucum project with Aveda. The larger village, Nova Esperança (New Hope), the area where the urucum project had been developed until 2005, and Amparo, remained under the leadership of Biraci Brasil Yawanawa and the Yawanawa Co-operative (COOPYAWA). Biraci was, until the 2000s, recognized as the sole chief of the entire Yawanawa people. COOPYAWA is deeply involved in economic projects involving the display of Yawanawa spiritual rituals and dances. This internal division created the challenge of obtaining the consent of both leaders and organizations and I soon realized that I would obviously be used in this dispute. The decease of an old chief, Raimundo Luiz (Joaquim's father), in the end of the year, and the mourning period that followed, caused a momentary interruption of all contact, since most of the members went to the burial at the indigenous land and were out of reach. The contact was resumed in early 2011, now with Biraci Brasil Yawanawa. Initially I was regarded as one of the multiple persons interested in visiting the area and seeking to know their spiritual practices. As such, high monetary contributions were asked to me. After efforts of clarification and negotiation, a contribution towards covering the costs of transportation, food and accommodation was set. This is a regular practice for researchers doing fieldwork amongst indigenous populations in the region. I specified that without consent of both organizations and their leaders I could not conduct my research. Joaquim, more careful with the exposure of his culture and fearful of possible repercussions of publications to his partnership with Aveda, was initially more hesitant, but was finally persuaded by Biraci. Later, part of the contribution was given to him.

\footnotetext{
${ }^{1}$ Escondido is inhabited by a single family. The head of the family categorically refused to talk to me, asserting that he was tired of working in his garden and, after hearing the objects of this research, had nothing to contribute. This was the only refusal amongst the Yawanawa. This member is famous in the community for his difficult temper, to the extent that the boatman was reluctant to take me to the village and introduce me to him, but the refusal might as well have been motivated by his involvement with the organization of the labor for the urucum cultivation.
} 
This observation and collection of information was conducted in two periods: the first, along four weeks from early May to early June, 2011, between the end of the Amazonian winter and the beginning of the Amazonian summer, the drier season. The first days were spent in Cruzeiro do Sul, where I could follow Biraci, as he dealt with businesses of the Cooperative and negotiated with the Governor of the State of Acre a position as Special Advisor for Indigenous Health, a position that he accepted for a very short period soon after I left the Gregorio for the first time. I visited the city once more in the period, to talk to some key members of the community, loyal to Biraci. I also visited Tarauacá, where both organizations keep houses. Tarauacá is the municipality (administrative unit) to which the Gregorio River Indigenous Land belongs and, thus, it is the most common destination of members of the community seeking public services, such as health and pension benefits, as well as industrialized goods, which they can purchase in the local shops. Most of the remaining time was spent in Nova Esperança, which concentrates half of the population. I visited Mutum, the second largest village, where most of Joaquim's siblings live, three times, Amparo twice and the remaining villages just once, given the reduced population and the difficulties of transportation. In the smaller villages, I directed my efforts to ethnographic interviews that covered their life experiences from the rubber tapping period to the current times, their involvement in projects and their views about "culture" and its exchange. At Amparo, Mutum and Nova Esperança interviews with most heads of family ${ }^{2}$ were complemented by observation of activities and participation in numerous social gatherings ${ }^{3}$. The second visit, confined to the Nova Esperança village, took place in the second half of October, 2011, and the main aim was to follow the preparations for and the actual $10^{\text {th }}$ Yawanawa Festival, a one week long event that attracts groups of tourists from all over the world to the Gregorio River. During that period, my observation became more participant, since as a trusted member, I was asked to contribute to the organizational efforts, communicating with foreigners and obtaining basic information about them. I used this opportunity to circulate amongst the visitors and talk

\footnotetext{
${ }^{2}$ My formal talks involved much more male than female members of the community. This is not because I avoided talking to women, but because their involvement in the projects was reduced, as actually is the involvement of the majority of the population. They insisted, when asked, that they did not know details and could not provide relevant information. I did have multiple informal talks with women, however, which provided me interesting insights. I also interview the most prominent three key female members of the community: the internal leader of Mutum and the two women initiated in the spiritual rituals, informally considered to be shamans. Moreover, my closest informant was a woman who circulated between the two Yawanawa groups.

${ }^{3}$ At Nova Esperança there was an attempt to guide my conversations. One of the teachers of the local school, publicly recognized as student of the Yawanawa history and culture, was oriented to provide me with a list of members who could help me reconstructing specific aspects of the recent history of the population. In a conversation with him, he did provide me with specific names of old rubber tappers, members initiated in the spiritual rituals, coordinators and workers in specific projects. I went beyond that list, also talking to members that seemed less integrated and with weaker allegiance to Biraci, chief of that village. To my surprise, however, not all the names suggested by him had necessarily positive views about the paths pursued by Biraci and his group.
} 
about their experiences. Due to the particularly hectic nature of the festival it was not possible to talk to all visitors, or to conduct formal interviews, but observation and informal talks allowed me to capture some understandings and motivations for participating.

Given the admittedly short period of fieldwork in the Gregorio River that was negotiated with the Yawanawa chiefs, I complemented my observations, informal talks and interviews in the villages with all other available sources of information on the Yawanawa. The period in the field was focused on obtaining information on their relationship with goods, money and the market projects. In order to obtain further information on the main ethnological features, and notably the inseparable sociological and ideological aspects of it, I used the available ethnographies produced on the Yawanawa and Pano populations. This does not mean that I employed primary and secondary information in an interchangeable fashion. I decided to submit to confirmation all the secondary ethnological and sociological information about the Yawanawa. And for that purpose, keeping in contact with key members of the community after my return from the field proved fundamental. Having developed a trust relationship with them, the challenge was thus to establish a channel of communication in which they would feel sufficiently comfortable. Phone contacts were episodic, limited to some members and periods in which they were in the towns. Yet I realized that the Yawanawa are avid users of the internet. Since 2011, the two main villages are connected to the World Wide Web via satellite connection. Their discomfort with the written language, especially to communicate to someone they knew was a researcher, and a different register of the written Portuguese language prevented the use of emails. The main means of keeping contact after the fieldwork turned to be an often ignored channel for research: Facebook. Facebook is not only, as previously said, the preferred means to make their endeavors public to other members and to the allies around the world, in a quest for respect and reputation, but it was also the platform in which, I realized, they felt more comfortable to share small bits of information. The informal nature of the language, I suppose, eased their reluctance in using any written means to share information. The relationship maintained with the Yawanawa after the fieldwork had a slightly different nature than my initial communications. After developing trust and knowing my research interests, I was transformed in a potential ally and part in their competitive struggles. I became, thus, an actor, and information and opinions were shared sometimes with the aim of making me a vehicle of their publication. They also contacted me looking for my opinion on certain posts on Facebook. The period of contacts covered here starts with the first visit to the Gregorio River, in May, 2011 and ends in August, 2012, with eventual contacts with the single purpose to maintain cordial relations. 
A second stage of the research was conducted in Minneapolis, United States, interviewing executives of the firm that purchases annatto from the Yawanawa - Aveda. Spending a week in the interior of the firm, my goal was to investigate the transformations of the ingredients, the symbolic construction of the product line that uses them and the translations of Yawanawa representations into the product. The firm provided me with most of the marketing and educational visual material produced for the product line, which is object of a specific analysis. As part of my research in Minneapolis, the firm organized a visit to three hair salons, one training institute and one shop where the products are sold and professionals trained, in order to better understand the possible relationship that professionals who sell them and consumers have with the products and their stories. I additionally visited three salons as customer or buyer of products in Manhattan and Chicago. This very short exposure to the realities of the consumption obviously did not allow me to undertake a deep analysis of the processes of singularization that follow or the particular meaningful relations established with the products. However, this material is employed to complete the analysis of the politics of value and construction of the product that begins with the Yawanawa, as well as to clarify the forms of representation that allow for the creation of worth.

The analysis of the collected information was done in a way to illuminate the multiple voices, interests and meanings attributed to the practices that are object of analysis. The intent was not to seek saturation that would yield general conclusions. The processes analyzed here are subject to multiple interpretations, and illuminate them was the fundamental goal. I also followed Fairclough (2001) in that acts of speech and the use of language in general is performative, in the sense that it aims at achieving transformations in the real world. Taking this into consideration, I attempted to situate the discourses of my informants in their personal strategies and according to their loyalties. The analysis of the talks was complemented by the use of my personal observations to reconstruct scenes. I also obtained valuable visual material from the firm. These images were interpreted to recreate the process of construction of the product, which includes not only the material goods, but also the images and representations associated with the sourcing populations.

The reader should expect to find a different treatment of the actors in the two settings that were the object of my analysis. I believe that ethnography has the power of revealing, more than other method, the drama of social interactions. But to do so, the characters are of fundamental importance, as are their positions and trajectories. Therefore, anonymity has no place, unless it is required to prevent any harm, protect the subject or a condition to disclose 
information. I have preferred to include here the real names of the Yawanawa, and cite them, except when I was asked to preserve the anonymity of a member who was talking to me or I considered that naming the author of a certain opinion could be used against them. The reasons are multiple. The social positions, biographies and even personalities influence visions and expectations regarding business and "culture". Their roles in the activities that are the object of analysis here are very specific, reflecting these positions as well. Names matter to situate their acts and speeches in my presence, but also their involvement with economic projects, in the specific social position and trajectories of these subjects. Additionally, the small size of the community and the fact that the management of economic projects is confined to an even smaller group, which incidentally are those whose words are read here, renders any attempt at anonymizing them useless. This does not mean that their words will appear abundantly in the course of the text. Meanings are lost in translation of their form of expression and many discourses, as previously argued, are attempts at constructing a truth that often demands further investigation. At any rate, I have always referred to the sources of information and opinions I discuss over the text, using the real names of the Yawanawa, abbreviated by their initials. In the end of this work (appendix 1), a code showing the names and location of residence of the Yawanawa is presented.

The relationship established with the firm was much different as were the conditions of disclosure of the information obtained in this formal environment. I preferred to maintain the anonymity of all my interviewees, except for two of them with singular positions and that could be easily identified: the president and an advisor for sourcing of raw materials. In the place of their names, the other interviewees were numbered. A code showing the departments in which they work is also presented in the end of the work (appendix 2). It is important to note that this decision reflects more than a simple asymmetry of power. In the case of the firm, the depth of the analysis does not require further information and names, reputations and trajectories do not matter as much as the positions occupied.

Now, a last word on the extensive use of techniques, concepts and even objects of research that are central to anthropology is in order. Even as a sociologist, I am fully aware of the dangers of liminality (Turner 2008) in a stubbornly disciplinary world. Yet economic ethnography should make no disciplinary difference. I share the perplexity that Kroeber (1959: 398) expressed half a century ago with the divisions of the disciplines in face of the fact that "not only do sociology and anthropology then essentially share their basic theory, but this theory is the only holistic one yet evolved for the sociocultural realm". Not least because 
the founding fathers of both disciplines moved between ethnology and sociology (think of Durkheim and Mauss) and the cultural turn in sociology definitely rescued culture and meanings from an epiphenomenal place. I believe, moreover, that these anthropological elements are extremely powerful to illuminate economic action and, more specifically, the analytical dilemmas involving the circulation of cultural representations in the market. Much of economic sociology remains trapped in a representation of market economic action as rational and calculative that prevents it to peruse the cultural meanings of such action and the things it produces. Despite the calls of Zelizer (2010) in the past decades, and good derivative work (e.g. Healy 2006), not much of the discipline approaches the economy as a cultural order. I agree with Graeber (2001) that there has been a return to economizing models and that for most of the discipline, the main formalism tenets apply to the capitalist economies, a point to which I shall return in the conclusion. Economic anthropology, in turn, has analyzed different systems of exchange that exist in societies since the early days of the discipline (Malinowski 2002) and has offered wide theoretical grounds based on rich ethnographies to understand the creation and exchange of value in societies.

\subsection{Structure of the dissertation}

The structure of this work is simple. It is divided in three parts. The first part is devoted to some of the central concepts mobilized in this work. Departing from the very influential contributions of Appadurai (1986) and Kopytoff (1986) to the studies of exchange and material culture, it critically appraises theoretical contributions in theories of exchange that advance conceptions of commodities and the process of commodification. These authors are the departing point to offer working definitions of those terms. Yet, the limitations of these conceptions in light of the research conducted in the last three decades are discussed to come with operational concepts that are put in test in this case. The part concludes with some observations on the broad societal trends underlying the increased interest in "cultures" in the contemporary world, which led to their marketization, and a review of some contributions of the literature to the theme.

Part II of this work is an in-depth analysis of the producers of "culture". Three chapters are devoted to the Yawanawa. They explore the place of alterity, exchange, money and goods 
in their lives, in connection to their own cultural, social and political relations. The transaction is just a fragment of what explains exchange, a culmination of multiple processes full of meaning. Therefore, it is fundamental to examine these underlying processes and relations that animate the circulation of objects and bestow meaning to them. Chapter 3 analyzes some fundamental aspects of the Yawanawa ontology that explain their identity as an aggregate of cooperative members and the role that others occupy in the formation of such aggregate. It also describes the location and patterns of residence of the Yawanawa, indicating a fundamental aspect of their relationship with money, goods and all productive activities intended for external exchange: living near the sources of a river in the Amazon, communications are a challenge still today, even with better boat engines and a new state road. Their patterns of residence also reflect the internal structure of power, the disputes among families and their involvement with the rubber tapping activities. Subsequently, the causes, dynamics and practical consequences of such disputes are explained, and the main characters involved in the negotiations of the circulation of cultural representations of the Yawanawa are presented.

Chapter 4 is devoted to the political and cultural economies of the Yawanawa. The first part discusses the nature of political power and the role performed by the Yawanawa leaders in an attempt to show that manipulating the flow of things and using exchange to animate the society are fundamental traits of political leadership. Consequently, economic projects and alliances in general ought to be understood as part of projects of leadership and reproduction of political relations within the community. The second part analyzes the relationship of the Yawanawa with work, goods and money. The ways they produce individual and social life, reproducing relations and stimulating their rituals, not only show that external objects and work are compatible with their culture, but also inform the different expectations they create involving their engagement in market exchange. They display multiple and ambivalent positions, reflecting their own views of the indigenization of modernity. These views, in turn, are elements of the politics of value in production and exchange. They underlie the negotiations and conflicts arising from market activities involving their cultural representations.

Chapter 5 is a brief historical account, intended to situate the Yawanawa in the broader regional political economy and recreate the development of specific patterns of interaction with outsiders, mediated by the leaders. This history, in the narrative constructed by the Yawanawa and their external allies, becomes part of the value of their representations. Their 
ability to resist the forces of an encroaching capitalism and religious missionaries whilst protecting the forest is an element mobilized to generate compassion and respect. The Part II finally concludes with a brief interlude (chapter 6) to describe another producer: the firm who transforms annatto seeds in makeup using the evocative image of the people of the forest. Aveda was created as a charismatic organization directed to professional consumers enticed through substantive messages about the intersections of beauty, health and nature. Just as the Yawanawa, the firm appropriates images and meanings of external representations it collects from distant populations thought to represent these intersections, according to their own scheme of interpretation and reconfigures the elements to create a message that is meaningful for Western consumers. At the firm, tensions can also be found, but they involve the qualifications of the goods and explain changes over time in the relationship with the Yawanawa and its uses in public communication of the firm. Part II sets the scenario, the actors, the entrenched relations and categories to understand the action. If it corresponds to the bulk of this work, it is because it contains all the elements one need to know to understand the politics of value that animates the circulation of cultural representations of the Yawanawa.

The projects, finally analyzed in Part III, are particular expressions of the cultural and political economies of the Yawanawa and their attempt to navigate the institutions of capitalism whilst securing the acknowledgment of the difference that guarantee their special legal condition. The Chapter 7 is devoted to the partnership with Aveda, the constitution of the product, the politics of value and its effects in their identity politics. Chapter 8 analyzes the second set of activities performed by the Yawanawa, public cultural performances, their meanings to the community and visitors, the political economy of knowledge and their insertion in a complex strategy to resort to the market as an instrumental means to forge enduring alliances that would protect them from the vagaries of the market, generating gifts from commodities. In the conclusion, I summarize the findings and use them to discuss them in the light of certain theoretical questions raised by the investigation of this phenomenon. 


\section{Part I}

\section{Terms of the question: commodities, commodification and "culture"}

Before moving to the analysis of the producers and the determinants of their economic action, some clarification on the central terms of this research is necessary. In this chapter, I discuss some theoretical propositions on these terms in order to better understand these terms and to offer working definitions to organize the empirical investigation. The terms are commodification, commodities, as well as the object of exchange, "culture". Let us start with commodity, from whose concept essential features of the process of commodification are drawn.

\subsection{Commodities: a transient phase in the social life of things}

Albeit subject to some variation in the literature, there is a basic core in the concept of commodity that is widely accepted in the social sciences literature: the concept of commodities normally refers to goods primarily intended for exchange and, thus, containing exchange value, which creates equivalence with other things. Even the narrower sense of the term employed in some streams of economics, to designate a specific class of primary bulk goods with prices defined in international markets, retain this basic idea of commodities as objects intended for exchange. However, the extension of its application to circulating things has been disputed by political economy and economic anthropology. The fundamental question is whether commodities are objects intended for any sort of exchange in multiple social settings or objects exchanged exclusively via market mechanisms, with monetary value as a quantitative equivalent and supported by the specific institutional conditions of capitalist 
societies. As other terms developed primarily to describe the circulation of wealth in Western market societies, its application to different cultural settings is contested. In general, this contention is part of a broader interrogation on the limits of applying Western categories of knowledge to understand another culture. The very notions of production, exchange and consumption were regarded as culture-specific categories, based on studies conducted precisely in the Amazon (Overing 1992), area of this study, as was the conception of the market, considered as a metaphorical cultural model incapable of encompassing alternative models of exchange practices (Dilley 1992).

Exchange theory, it is well known, was divided well up to the 1970s by this debate, opposing formalists and substantivists (Graeber 2001). The former group asserts that the formal models developed by Marginalist economics and its main postulates, including behavioral assumptions, are universally applicable. To formalists, all forms of exchange are oriented towards the rational allocation of scarce resources and are subject to some form of bargain. The latter group disagrees, stating that these postulates are only valid in Western market societies. Departing from the work of Polanyi (1944), substantivists emphasize that the market is but one mechanism of allocation, which gained historical prominence in recent times. Reciprocity and redistribution, linked to centralized political relations, kinship, tournaments of status and external relations of war and peace among groups are other principles guiding the circulation of objects.

In fact, future generations of scholars have moved beyond the debate demonstrating that alternative principles endure even in "market" societies. This point was already present in Mauss' pioneer work on the gift (2005[1925]), even if at some points he indicates the decline of the gift as a producer of sociability, to normatively claim its promotion. Gifting in contemporary societies has been recognized as no "minor appendage to life in capitalist societies" (Cheal 1988: 6) and analyzed by theorists interested in the political and social consequences of reciprocity in modern market societies (Godbout and Caillé 1998). If on the one side Gregory (1982) has defended the notion of gift-societies, on the other he also indicated that alternative principles of exchange such as gifts, barter and political distribution can be also fostered in conditions of expansion of markets, as happened in Papua New Guinea with gift exchange. Even more importantly, research (Bloch/Parry 1989; Thomas 1991) has shown the limits of determining a societal-wide single regime of exchange. There are neither pure gift-societies, nor pure commodity-societies. These principles of exchange might, as well, be fused with market mechanisms in long succession of movements: something acquired 
in the market for money can be distributed by political leaders, given to someone of the kin or exchanged for other objects. Things and persons might circulate in a chain of movements following different regimes of exchange, animated by different social relations, in successive permutations of debt (Thomas 1991). Furthermore, interests and calculation in exchange were also recognized in non-capitalist economies in ethnographic studies (Sahlins 1976; Bourdieu 1977). However, their presence does not indicate patterns of universal behavior, as multiple orientations beyond utility maximization can be found in all economies.

This is a relevant debate for this study, since it deals with intercultural contacts, not just as means, but also as the end of transactions analyzed here. The focus of the investigation sets the boundaries of the dilemmas of applying Western categories, such as commodity, and defining the extension of its application. The object of this research is the social and cultural process of converting cultural devices into commodities, and the underlying social relations. Since the relation takes place in the market, mediated by the culture of the market, as John and Jean Comaroff point out (2009) for similar cases they study, the question on the applicability of Western categories of knowledge is less important than the questions of how these populations developed the basic knowledge about commercial transactions that is essential for commodity exchange, and how categories of the market are interpreted and reconstructed by the community.

Equally important is the problem of the applicability of the concept of commodities. As the end of the process of commodification, the notion of commodity and the limits of its applicability to exchangeable objects are of paramount importance. If any exchangeable object were a commodity, commodification would represent the transition from a nonexchangeable state, in which things do not circulate, towards an exchangeable state, no matter the principles and forms of exchange employed. Yet if commodities are exchangeable objects with peculiar qualities and subject to particular forms of exchange, by means of specific social relations, commodification could as well mean the process whereby objects that could only circulate as gifts, in barter or as politically orders of redistribution, assume commodity qualities and become objects of specific relations. Therefore, before considering the practical meanings of commodification, it is necessary to define what a commodity is.

Following the fading debate between formalists and substantivists, discussions on commodification and the extent of the concept of commodity gained new impetus in the 1980s with the burgeoning number of studies on material culture, theories of exchange and value, many of which endeavored in analyses of cultures in which objects mediate different 
social relationships and intercultural encounters. New methodological and conceptual propositions to understand commodification emerged and the extension of the term commodity to all exchangeable objects was defended by some authors, such as Appadurai (1986). In fact, in his volume on "the social life of goods" two contributions summarize the main positions in the debate: on the one side, Appadurai's (1986: 6) contention that any exchangeable thing, regardless of the form of exchange, should be regarded as a commodity, and on the other side, Kopytoff's (1986) more traditional conception that limits the notion of commodity to objects exchanged in particular circumstances, or a particular situation. This study adopts a concept that is closer to the latter and narrower notion of commodity. It argues that some differences between commodity exchange and other forms of circulation and diffusion of material and ritual objects, especially cultural elements, remain analytically valid. Discussing Appadurai's and Kopytoff's concepts as a departing point, this section attempts at arriving at a valid concept of commodity to understand the specific social underpinnings and outcomes of the process of commodification.

Appadurai organized his seminal volume on "the social life of goods", to which Kopytoff contributed with a chapter. Both advanced a similar methodological proposition: to move further the research on material culture and exchange theory centering on the movement of things in different societies. Tracking the social life of goods, the paths and diversions of things (Appadurai 1986), or writing the social biographies of things (Kropytoff 1986), they aim at understanding commodities as a transient phase in the life of objects and commodification as a process. Moreover, their approach represents a movement from classical accounts of commodification as the irrevocable and irresistible product of economic forces destroying traditional lifestyles and contaminating social relations.

This proved to be in the last quarter of century a fruitful perspective to understand commodification and the complex relations between cultural and economic dynamics that it entails, moving beyond the more simplified "colonization" theories. Considering commodities not as objects, but as a transient phase in the social life of things has many analytical advantages, as discussed below. Yet they differ on the final conception of commodity they advance and their particular visions of the process of commodification.

Kopytoff's (1986) discussion about the extension of concept of commodities is surrounded with ambiguity, since he initially agrees with Appadurai that commodities are a universal phenomenon. Their existence, Kopytoff asserts, "is a concomitant of the existence of transactions that involve the exchange of things" (1986: 68). This reasoning implies that all 
exchangeable goods are commodities and that commodity exchange is the only form of material transaction. However, Kopytoff does recognize other forms of exchange and discussing the cultural specificity that commodity exchange assumes in different societies, he also recognizes that commodification is "a special expression of exchange" (1986: 68). Both assertions invalidate the automatic association between the universality of commodities and the universality of material exchange. As a special expression, it is just one of several others and its universality cannot be deduced from the universality of exchange. In fact, what seems a contradiction, has very limited consequences in his work. Perhaps mobilizing this idea to indicate the centrality of commodities in social life, Kopytoff's work does not rely on claims of universality of the commodity phenomenon, which are, in any case, of very limited potential for anthropological analyses of exchange. This is not a central argument in his work, driven by a different aim: to demonstrate the cultural specificity of classification schemes, which place objects in different spheres and are consequently central to define objects as commodities. He argues that different societies have special places to commodities in their social systems, specific factors to control commodity exchange and particular cultural and ideological premises (ibid. 1986). Yet commodity exchange in general has also particularities when compared to other forms of exchange, among which the form it relates to the social system is probably the most important. Commodity exchange, as substantivists have shown, creates specific forms of social relations.

Kopytoff defines commodities as objects that "can be exchanged in a discrete transaction for a counterpart, the very fact of exchange indicating that the counterpart has, in the immediate contexts, an equivalent value. The counterpart is by the same token also a commodity at the time of exchange", which obviously includes money (Kopytoff 1986: 68-9). And he continues to stress that, given the prominence of the use of money in the exchange of commodities, in contemporary Western societies, the "unmistakable indicator of commodity status" of an object is its "saleability" (ibid. 69). Anything that can be bought for money is, at the moment of exchange, a commodity. A price, in monetary terms, is widely understood as the distinctive feature of a commodity, because money became a symbol of quantitative equivalence, the general denominator of value (Simmel 1978). Yet money is just an observable indicator of a specific form of social relation that commodity exchange creates.

Kopytoff's (1986) is a valuable definition, because it emphasizes some essential - and distinctive - features of commodities: its quantitatively defined equivalence with other objects, more often than not measured by a common metric - money -uttered by a price. 
Social, cultural and technical operations that define commensurability, and notably quantitative comparability between goods, are central to the formation of exchange value, another central feature of commodities. Commensuration is central to the process of commodification, as shall be discussed further below.

Another important feature of commodity exchange mentioned by Kopytoff is the social nature of the relationships created by commodity exchange, a cornerstone of exchange theory. The distinctive social nature of commodity exchange is related to the distinctive purpose of transactions involving commodities. Normally, Kopytoff asserts (1986: 69), these transactions are discrete, intended primarily and immediately to obtain the counterpart value. The economic function of exchange might not be the only purpose, but it is the most immediate goal and is always present in transactions. His statement that "the purpose of the transaction is not, for example, to open the way for some other kind of transaction" (ibid. 69), is too general, categorical and certainly invalidated by evidence. Commodities can be bought to maintain commercial relationships, i.e., aiming at obtaining another counterpart in a future transaction, but goods and money are also presented and commonly employed in intimate relationships (Zelizer 1978). Nonetheless, the main motivation in the specific and discrete act of selling a commodity is to obtain the counterpart value. Kopytoff resumes Mauss' (2005) argument to say that contrary to the exchange of gifts, which mainly aim at developing and keeping relations of reciprocity, commodity exchange is mainly oriented towards the counterpart, the act of exchange itself is discrete and, consequently, it creates an equally discrete social relationship. The existence of a commodity and its exchange in the market clearly presuppose the existence of a dense net of social relations among the producers, the traders and the consumers and may as well produce relationships, phenomena that correspond to the main focus of sociological analyses of the market. However, the primary and most salient purpose of the act of exchange of commodities is not the production or reproduction of social relationships.

But there is still another characteristic of the commodity situation that, albeit overlooked by both authors, it is said to be distinctive in the classical works on exchange by Marx and Engels (1990 [1867]) as well as Mauss (2005 [1925]) and the derivative discussion of Gregory (1982). These authors emphasize that commodities are something detachable and independent from their producers and agents of exchange. In their effort to move the debate on commodification from critical perspectives, they disregard this feature. In order to become a commodity, something has to be an object in itself, with a separate use and exchange value, 
which may bear some relationship with the status of the producer or seller, but cannot be conflated with it. In the first pages of their complex and sometimes ambiguous incursion into the nature of commodities, Marx and Engels (1990 [1867]) assert that commodities are objects outside us. As discussed by Kopytoff (1986) and Appadurai (1986), Western contemporary societies have recently developed a polarity between objects and humans that fosters a conception of objects as physical, often inert and only animated by human words and codes, as opposed to people, deemed individual agents whose words animate these objects. All objects are, thus, considered separate from humans. Even without this particular cultural construction, any exchangeable object has to be a separate entity in order to circulate. Even when some human attribute or service is exchanged, societies operate a symbolic rupture between objects of exchange and humans, no matter the multiple practical problems that some cases pose.

The unique feature of the commodity situation is the possible rupture of any association between producer or seller and object once the object is sold, fostered by a fetishistic act whereby produced or exchanged objects are characterized by their exchange value. This might not be relevant to distinguish commodities from objects that are directly exchanged by barter, but it is a departure from objects that are given in complex systems of reciprocity as the Kula. Mauss (2005 [1925]) suggests that in the gift-exchange, the donor does not simply exchange the object, but also a material and symbolic part of himself. The obligation to reciprocate is partially explained by the drive of the recipient to divest herself of this alien element that exerts power, reminding her of the donor. The object is, thus, tied to this expression of the donor put in the object, which will eventually return to her if reciprocity is achieved. In the commodity exchange, Marx and Engels (1990 [1867]) argue, this expression of the producer or seller of a good tends to be concealed under the qualities of the object and symbolically detached by an act of estrangement and reification of labor. Although some singular and creative commodities retain a strong association with the producer or seller, especially in markets where authorship and origin distinction matter, commodities become something on their own, with a worth that has no necessary relation to the producer and may eventually circulate with no reference to their agents of production and exchange. Commodities, thus, may be fully detached from the agents and circulate autonomously with no remaining bonds to the original producers. In fact, the most interesting cases of commodification involve exactly cases of singular objects, whose value and demand is explained by an association with individuals and groups involved in the production and exchange, such as cultural devices. In these cases, the creative action, negotiations and tensions surrounding commodification are 
heightened.

These central features explain the difference between commodities and other forms of exchange (barter and gift), a distinction that is rejected by Appadurai. He (1986: 13) defends an all-encompassing concept of commodity, as "any thing intended for exchange" (1986: 9. Italicized in original), and mentions at least five practical reasons, related to his agenda of research, which would justify the rejection of such differences. All these valuable insights, however, are not conducive to an invalidation of the difference between commodities and other forms of exchange, nor require an all-encompassing concept of commodity.

The first of such reasons is the fundament of classifications of forms of exchange which, Appadurai (1986: 9) asserts, is the form of production of the good. With Simmel (1978), he states that the creation of value is actually located in the sphere of exchange where no conceptual differences would be found. Without entering here into the monumental debate on value and its creation, a topic that animates economics for two centuries at least and has been equally discussed by sociologists and anthropologists (Graeber 2001), it is sufficient to sustain that this fact is not supported by reality. Different social relations animate exchange through gifting, bartering or selling a commodity. In other words, they suggest different forms of sociability and reciprocity which are not bound to the forms of production of things. One of the differences between these forms of exchange is the density of social relations that underlie and inform it. There is no asocial form exchange. The negation of exchange is the asocial action. Yet forms of exchange generate different forms of reciprocity and, as Sahlins (2008) argues, might be placed in a continuum according to the degree of solidarity they produce, or the importance of generating social relations vis-à-vis the creation of value. Appadurai (1986: 10 ) is right to argue that commodity and barter forms of exchange share a relatively asocial nature, as they both create only limited sociality bonds, whilst equally regulated by social, cultural and political norms. Nonetheless, their difference lies in the use of a monetary equivalent in the case of commodities, an aspect essentially related to the exchange, and not the production.

The second contest to the recognition of different principles of exchange is what Appadurai (ibid.: 9) sees as a classificatory system that suggests an "evolutionary, unidirectional, and historical" (ibid.: 9) movement. He rejects such tones, recalling cases of barter in capitalist societies. Indeed, as affirmed above, alternative principles of exchange endure and might even thrive in capitalist societies. Yet the facts that they are an object of increased scholar interest, defined as different according to practical native categories in 
Western societies and remain linked to distinct social relations are sufficient to reaffirm their analytical worth without evolutionary tones.

In connection to what would be a purely evolutionary classification, Appadurai also believes that the distinctions create a simplistic contrast between societies ruled by solidarity and societies ruled by economic calculation and interest. Following the work of Sahlins (1976) and Bourdieu (1977), among other anthropologists, Appadurai rejects this distinction and contends that any analysis of the circulation of commodities across cultural settings must restore economic interests and the calculative dimension to societies "that are too often simply portrayed as solidarity writ small" and the "cultural dimension of societies that are too often represented simply as economies writ large" (1986: 12). All forms of exchange are related to social, political and cultural norms. Once more, the premise is valid, but does not lead to the conclusion. To assert the difference between gifts and commodities is not the same than claiming that the so-called "traditional" societies are gift-societies, whereas the "modern" societies are commodity-societies. Once more, recent studies that shown the persistence of these alternative forms of exchange in capitalist societies, on the one side, and the existence of money, interestedness and commodity exchange in societies regarded as "traditional" are sufficient to reassert the existence of difference forms of exchanges. As Appadurai himself recognizes, the literature on gift exchange departing from Mauss' work has already stressed the ambiguous character of the gift, a mix of obligation and liberality, altruism and calculated self-interest beneath a veil of disinterestedness. Many anthropologists have also shown that contemporary economies are no less a cultural construction, with the distinctive feature of maintaining the appearance of being fully rational and calculative (Sahlins 1976). Therefore, some interest and calculation may well be found in non-capitalist transactions, just as some kindness and idealistic principles may be recognized in capitalist ones (Graeber 2001).

Yet these studies continue to sustain the particularities of commodity exchange, mainly due to its particular nature of the social relations they entail and also the difference in the form interests and calculation are expressed. These differences are particularly strong when systems of commodity exchange are compared with systems of reciprocity. Whereas commodities are exchanged for a quantitatively equivalent value, notably money, in discrete relations, countergifts are not necessarily equivalent, in monetary value, to the object received. The counter-gift has to "repay" the gift, but not in quantitative terms; the debt is not monetary, but social and, thus, the counter-gift is measured by his symbolic worth, which may or not be related to economic value of the object. The importance is to preserve the reputation and reproduce 
social relations. Precisely because interest and calculation are present in the obligation to reciprocate, depending on the symbolic meaning of the association with others, the recipient may want to impress the original donor by giving an economically or symbolically more valuable object. Bourdieu's work (1977), employed by Appadurai to demonstrate that the exchange of gifts is not exempt of calculation, also reminds us that the public image of a sacrifice of economic interest is as constitutive to the gift exchange, as the obligation. Even if calculated, these aspects are disguised in the gift. In fact, the maintenance of social relations is related to a specific time dimension that recommends a deferral in the counter-gift. This temporary lag between gift and counter-gift disguises the obligatory nature of the latter, as well as the calculations underlying exchange, surprising the original donor.

Another objection to distinguish the commodity from other forms of exchange, central to his agenda of research, is the argument that the circulation of goods is always linked to the fate of persons in society. Again, this was demonstrated by studies about gift exchange. Appadurai himself extensively employs analyses of the Kula in the Western Pacific produced in the 1980s discussing the findings of Malinowski's (2002 [1922]) pioneer work. There, the reputation of men is strongly attached to their accomplishments in promoting and finding channels of circulation of valuables. The same connection between objects and agents of exchange, Appadurai (1986) demonstrates, may be found in the exchange of commodities. This is a fundamental aspect of a processual notion of commodification in which agency is central, as shall be further discussed. Albeit relevant to understand commodification and the politics behind the circulation of objects, this interconnection does not invalidate differences between commodities and other exchange situations. As previously argued, the forms of social relationship established and suggested by forms of exchange are different. This is the fundamental relevance of the distinction. Moreover, commodities may be detached from the agents of exchange, even if they promote their circulation, according to its dispositions and strategies in the social world. The link between biographies of things and persons may be a common trend in all forms of exchange, but that is not the same than the maintenance of an association between producer and product. The exchange of commodities, as other forms of exchange, may be related to the pursuit of social distinction, but this strategic association should not be conflated with an association between agents and the objects they produce or exchange, defined by the symbolic expression of the producer's personality in the object, as it happens with gifts. That the circulation of goods ties the value of objects and the agents that promote their exchange does not prevent the detachment of any expression of the producer or the seller from the object. However, this detachment does not take place in all forms of 
exchange. Discussing the Kula, for example, Appadurai (1986: 19) admits that the valuables are always an expression of the identity of agents of exchange, who present them in different islands. When partnerships that secure the circulation of valuables fail and new agents develop new paths of exchange, the objects assume the identity of the new agents.

Appadurai's last point is that a debate on what kind of thing commodities are and the difference between forms of exchange should be replaced by the more pertinent determination of the commodity situation in the life of an object and the potential of all things to become a commodity. His valuable situational definition, shared by Kopytoff, is not sufficient, however, to invalidate the difference with other forms of exchange. In fact, its adoption only changes the question from what defines a commodity to what defines a commodity situation. In other words, the particularity of commodities, or objects during the commodity phase, may correspond to temporary and not ontological qualities. Attempting to change the focus from social relations underlying exchange to the objects of exchange, Appadurai overlooks the nature of relations that animate the circulation of things, the core of the distinction between commodities and gifts.

Nonetheless, all assertions that would justify an all-encompassing notion of commodity according to Appadurai (1986) are valid and should be considered in a study of the circulation of objects across cultural settings and in different periods of time, as well as in the investigation of processes of commodification. The definitional differences between commodity and other exchange situations sustained here are not as important as understanding commodities as a situation, rather than a kind of thing, and commodification as a complex process, ideas shared by Appadurai (1986) and Kopytoff (1986). Stressing the situational aspect of commodities, in long biographies that reconstruct their total trajectory from production, to exchange, to consumption, provides a richer framework to understand how the circulation of things is related to the life of societies and how commodity exchange is the product of negotiations, tensions and alliances.

Differences in the situation that characterizes commodity and other forms of exchange should also not obscure the fact that in both capitalist and non-capitalist societies, various principles animate exchange and sometimes there are connections between economic and non-economic relations in the flow of objects. Consequently these objects circulate continuously according to different principles and multiple dispositions, from profit making to the reproduction of intimate relations. Commodity situations are often a transitory phase of objects that, once purchased, are distributed in households or given to friends. 
Anthropological and sociological literature is filled with interesting examples of such continuity in the flow of objects under different exchange situations and animated by multiple interests, dispositions and forms of calculation, from Lévi-Strauss' (1981 [1948]) example of how exogamy and the exchange of women among families is useful to obtain the most valuable parts of a cow's meat that are distributed to the new wife's family, to Bourdieu's contention that marriage promotes an economic circulation which includes the access to both a material and a symbolic family patrimony, that is, "its standing in the eyes of other groups" (1977: 181); from Zelizer's studies $(1994 ;$ 2005) on the multiple meanings of money according to the relationship which it mediates and on the interconnection between economic principles and intimate relations, to the examples offered by Appadurai (1986) in which barter is employed as an alternative to international trade when political barriers hinder commodity exchange, in order to obtain objects that will be later be sold in internal markets.

It is a fact that the use of restrictive concepts of commodity, associated to capitalist economies, often follows a normative perspective on commodification processes. This perspective criticizes the colonizing effects of commodity exchange on interpersonal relations and the disruption of other forms of sociability related to alternative forms of circulation of wealth, neglecting the presence of interests and calculation in them. Yet the acceptance of the singularity of the commodity situation among multiple exchange forms, due to the abovementioned features, should not be regarded as an acceptance of these normative assumptions. The interconnection of monetary and non-monetary forms of exchange in the long flow of objects and the complementarity of economic, political and symbolic dispositions that animate exchange is the empirical rule in the contemporary world and, as such, it should be properly understood before any normative claim.

\subsection{Commodification as a tensional and negotiated process: towards an enlarged politics of value}

If commodities are not a specific kind of object, but a phase in the life of some objects, commodification is a process whereby agents promote the inclusion of an object, in a particular society and period, in the realm of things exchangeable in the market. Albeit central to economic transactions in the market, commodification is one of the social and cultural 
processes about which economics has little to say. For economics, commodities simply exist and are produced as such. In many cases the term "commodity" is employed in the lexicon of economists to designate a specific class of primary bulk goods traded internationally (Appadurai 1986: 7). Even when this is not the case, the referent of the term is any object that is produced and exchanged in the market, generally for a monetary correspondent. Orthodox economics do study factors of production, but the drive to organize these factors so as to supply the market with an object is explained by the marginal cost of producing one extra unit of any object sought by consumers. The demand, in turn, is treated as the product of a subjective assessment of the utility of objects. The departing point of economic analysis is the existence of commodities as such, i.e., that objects are already in the commodity situation and, thus, are exchangeable in the market. There is no discussion on the acceptance of market relations involving traded objects. Therefore, the social and cultural processes underpinning the placement of anything in the market for sale for a price (supply) and the acceptance of any object as a commodity (demand) are far beyond the concern of economists.

Commodification must be promoted, which entails a social and cultural process of organization of labor in production and selling of goods. Yet commodities must not only be materially produced; they must as well be culturally labeled as commodities. Before being offered in the market for exchange against money, objects must be "culturally marked as being a certain kind of thing" (Kopytoff 1986: 64), one that society accepts to detach from the producer in immediate exchange for an equivalent, in "a cultural and cognitive process" (ibid.: 64) of classification. Evidence of this can be found in the fact that the same objects may be treated as a commodity by some, but not by others, or at one time, but not at another.

Produced in the very moment of consolidation of institutions and forms of sociability of market societies and interested in investigating the conditions and effects of such societal arrangements, much of the classical social theory engaged in the analysis of commodification as a primary drive fostering the new social organization. Their prolific analyses produced works of great complexity, but also some ambiguity regarding the development of capitalist economic forces and social relations, to which commodification as a process is always related. In any case, most of the authors adopted at some point of their work the already mentioned normative standpoint, offering a critique of the effects of markets in societies. Although not representative of their entire opus, these accounts depict a tension between market institutions and social values, which fatally surrender to destabilizing economic forces of the market. This approach is named "boundless market” by Viviana Zelizer (1988: 620). Within this approach, 
authors recognize social and cultural underpinnings in the historical development of capitalist forces, but once all the necessary institutions for their unconstrained operation are set in place, it is these forces that determine social and cultural values. At least four eminent social theorists revealed this normative approach: Marx and Engels (1990 [1867]), Simmel (1978) and, more recently, Polanyi (1957 [1944]). In most part of their work, Marx and Engels were greatly concerned with the effects of the cash nexus linking humans and the alienation of labor entailed by the capitalist social relations of production. Simmel (1978) considered money as a general denominator of value, homogenizing human values and destroying signs of distinction in objects and humans. The expansion of the cash nexus in his account causes a permanent tension between economic and personal values. The former pressed for the expansion of market transactions, whereas the latter attempted to protect some areas of exchange. With commodification, however, personal values become weaker and lose their ability to resist the forces of economy. The intersection of personal values and money for Simmel is still more deleterious, as Zelizer emphasizes (1988: 621): anytime money penetrates in personal relations, it causes degradation. A more compelling and nuanced account is Polanyi's (1957 [1944]). Polanyi, more than others, recognizes the deep interconnection between economic, political and social processes. Economies are, in his famous formulation, embedded in their societies and polities. Without social and political foundations regulating the forces of the market and restraining their satanic spirits, capitalist economies would not be possible. Nonetheless, once market forces are set in motion, they seek to eliminate constraints and to subordinate social and political processes to its own logic. Full commodification inverts the classical embeddedness of economies in society, subordinating the latter to the former. Writing in the end of World War II, and bearing in mind the successes of Fascism in Europe, Polanyi identifies in the development of free market exchange a force that threatens the very social foundations of modern society and has to be tamed by state regulation. On a later work (1968), Polanyi reasserts, with his substantivist view, the institutionalized nature of market societies. Despite the threats of market forces and the changing place of economy in society, without social and political underpinnings, he states, exchange would not be possible ${ }^{4}$.

These conceptions share the view that economies were subject to cultural and social constraints during the development of capitalist forces and relations, but once fully developed, these forces gain autonomy and subordinate society. It is true, as Steiner (2009) points out, that the Polanyian fears are not fully unsubstantiated, as markets do operate profound changes

${ }^{4}$ For an analysis of the conceptions of embeddedness and disembeddeness across Polanyi's work, see Gemici, 2008. 
in social values and representations and agency is structurally transformed, as agents have to use the rules of the market even to deviate or innovate. Yet these approaches offer a very limited depiction of processes of commodification and fail to grasp its complexity. To consider commodification as the product of inexorable capitalist forces on defenseless societies is to deny any agency, not to mention resistance, in the process, reducing humans to obedient reproducers of structural determinations. These accounts pose, thus, serious limitations to the understanding of commodification as a process. They offer no hints on agency and the connection of humans and the circulation of things. Moreover, their normative standpoint prevents them of seriously investigating the interconnections between economic and non-economic spheres and the persistence of social and cultural values underlying exchange.

This study advocates a different conception of commodification, as a dynamic process promoted by human agency and characterized by permanent tensions and negotiations on the meanings, values and exchangeability of objects, which is directly related to dispositions and strategies of agents and power relations within and across societies. In that sense, commodification should not be regarded as an inexorable force imposed by capitalist forces on defenseless societies. It is not a unilateral irreversible process that necessarily dilutes social relations established around things transformed into commodities. Objects move in and out the commodity state and are differently treated along places and in different historical periods. In the past centuries, many objects were converted into commodities, but some gained sacred status and ritual usages and the idea of putting a price on them became so repulsive that their exchange in the market is no longer tolerated. Even in the same period and in one community, the access and exchange of objects as commodities may be restricted to few members who retain a monopoly and certain circumstances.

This conception retains key features of the processual model developed by biographical studies of objects, advanced by Kopytoff (1986) and Appadurai (1986). As previously said, both regard commodification as a dynamic process in which objects can be placed in or taken out of the market situation ${ }^{5}$. In order to define the relevant analytical elements to empirically investigate processes of commodification, these contributions are critically discussed and complemented by elements that are overlooked by them. Kopytoff develops an ideal model,

\footnotetext{
${ }^{5}$ In fact, Appadurai (1986) and Kopytoff (1986) employ the term "commoditization" to refer to the process of transforming objects into exchangeable commodities. Yet the term "commodification" is preferred here. Both can be found as synonymous in most dictionaries, but in economic literature commoditization denotes a specific process of developing international markets (and price-setting mechanisms) for goods that are fully or partially fungible and, thus, supplied with limited qualitative differentiation, notably minerals and primary goods. Considering that the concern here is with the inclusion in the market of goods and services not normally regarded as commodities, commodification is preferred.
} 
in which the process of commodification is the dynamic and tensional balance resulting from the efforts of agents and culture in general to moderate the clash between two forces: homogenization promoted by economic forces and singularization promoted by culture and the individual. His summary of this model is worth quoting:

"exchange function of every economy appears to have a built-in force that drives the exchange system toward the greatest degree of commoditization that the exchange technology permits. The counterforces are culture and the individual, with their drive to discriminate, classify, compare and sacralize. This means a two-front battle for culture as for the individual - one against commoditization as a homogenizer of exchange values, the other against the utter singularization of things as they are in nature" (Kopytoff 1986: 87).

As a result of specific notions of subjectivity and personhood that emerged in Western modernity, a polarity was established between agents and objects, as previously discussed. This polarity also offers parameters to cultural classifications of objects, which in turn set the limits of what can be exchanged in the market. Societies, suggests Kopytoff (1986: 90), constructs objects as they construct people, employing the same classification scheme. This polarity sets the extremes of a continuum of cultural classifications that is also applied to objects and ranges from homogenous, fully comparable and therefore exchangeable things, to unique, individualized objects with no equivalent, which would make exchange impossible. Commodification, in this model, corresponds to a movement towards the former end: "To be saleable for money or to be exchangeable for a wide array of other things is to have something in common with a large number of exchangeable things that, taken together, partake of a single universe of comparable values", Kopytoff (1986:69) argues.

Underlying this model is the assumption that the environment does not present itself already organized in any ontological way. The world of objects external to the humans is given a meaningful organization by means of cultural operations of classification arrangement and differentiation - which places objects in different spheres of values. Both singularization, that is, the ascription of differences between heterogeneous objects, and homogenization, that is, the establishment of equivalence between similar objects is a cultural operation, resulting in general schemes of classification. Commodification depends on cultural operations, whereby a "natural world of singular things" is "arranged into several manageable value classes - that is, different things must be selected and made cognitively 
similar when put together within each category and dissimilar when put into different categories" (Kopytoff 1986: 70). These operations of classification give birth to several spheres of exchange value, corresponding to a "gradient of singularity" . By situating objects in different spheres of values, culture not only defines what can be exchanged, but also how and to what class of value objects belong.

As Kopytoff's acknowledges, the notion of spheres of exchange is taken from a seminal study of Bohannan (1959) with the Tiv of Central Nigeria ${ }^{7}$. In this case, three spheres were identified: a first sphere encompassing basic food, utensils and tools for farming and food preparation; a second sphere encompassing brass rods, as a kind of special currency, slaves, cattle, medicines and ritual-related objects and offices; and a third sphere encompassing female relatives who could become wives. Within each sphere, all items were exchangeable according to different principles (or moralities).

In his account, there is fundamental drive to promote the exchange of objects, which is limited by the available exchange technology. Commodification is considered the product of technological developments that allow a quantitative assessment of value in goods, establishing homogeneity or at least quantitative comparability. These technologies allow value equivalence and make unlike objects seem "alike with respect to [economic/monetary] value" (Kopytoff 1986: 71). The monetary system is regarded as the cornerstone of this process. "The existence of a sophisticated exchange technology", he argues, "fully opens the economy to swamping by commoditization. In all contemporary industrial societies [...], commoditization and monetization tend to invade almost every aspect of existence [...]" (ibid.: 87-8). In the case of the Tiv, he argues, the absence of a better exchange technology establishing equivalence among things, resulted in different spheres of exchange (ibid.: 72). The introduction of money, as a very sophisticated technology establishing equivalence of value, led to an explosion of commodification and the disappearance of separate spheres.

Nonetheless, contrary to the worst Simmelian (1978) fears, no common standard, not

\footnotetext{
${ }^{6}$ Kopytoff portrays this as an idea already developed in the work of Durkheim and Mauss (1963) on primitive forms of classification. In this pioneer work, they attempt to demonstrate that cultural systems of classification reflect the structure of society, i.e., that society is the source of the categories of human thought. Yet Kopytoff seems to rather concede precedence to culture, as did Lévi-Strauss in his book on totemism (1962a), inverting the logic used by Durkheim and Mauss to explain totemism. All systems of classification, including those organizing social structure, would stem from cultural categories of thought, de-essentializing Kantian imperatives. Culture is, thus, an all-encompassing organization of the known world, including both nature and society. This debate far exceeds the boundaries of this research, but if we allow power structures and practices to penetrate the domain of culture, making it more dynamic and contested than Lévi-Strauss structuralist model, it seems that it is the social practice of culture that both produces contingent organizations of the world and justifies social cleavages.

${ }^{7}$ Bohannan's study (1959) is a widely discussed and often criticized account of the impact of the introduction of money in the Tiv economy during the colonial administration, dissolving separate spheres of exchange. As the only aperture in this rigid classificatory scheme, Bohannan recognized that brass rods were employed as a currency capable of moving objects between spheres. He stresses, however, that in the rigid moral code of the Tiv, only upward moves were respected.
} 
even money, can establish equivalence of all things. Some objects resist to be grouped with others in the same category, because culture emphasizes their differences. Thus, the cultural classification efforts yield different classes of value or spheres of exchange. As strong as the forces of commodification, the forces of culture have an almost instinctive urge to discriminate values. Cultural operations mark some things as exchangeable, but also set aside some objects, ensuring they remain singular and even sacred, for the sake of maintaining diversity. These operations produce prohibitions, taboos, preventing the inclusion of some objects in the sphere of commodity exchange. Sometimes this process involves things that were commodities and are, thus, re-singularized, indicating that commodification is not a unilateral irreversible process. Among examples of objects kept out of the sphere of commodity exchange by cultural rules, he mentions ritual objects and other objects that are held as the "symbolic inventory of a society" (Kopytoff 1986: 73). He briefly recognizes that these movements can be connected to power, expressed in the right to prevent the circulation of objects. This can be an expression of sacred and political power, both in the permission to restrict circulation and in the withholding of some objects in small powerful groups.

In sum, in Kopytoff's model, objects move in a continuum between singular and commodities. A high degree of commodification, homogenizing all things, conflicts with the urges of culture and individuals to find singularities, while a high degree of singularization renders all exchange impossible. He admits that there are no "perfect commodities", or pure commodities, that is to say, a set of completely homogenous objects that only circulate by means of market exchange. Since both forces are simultaneously at work, a full commodification is highly unlikely.

Kopytoff (1986) distinguishes the dynamic of commodification in small-scale and in complex societies. Albeit avoiding the name "primitive" or "simple", this comparison is little more than the sociologically classical distinction between homogenous societies with solid shared cultural values, or mechanical solidarity, in Durkheimian terms, and differentiated societies enabling the expression of individual aims and thoughts, with organic solidarity, again according to Durkheim (1978). The novelty in his approach is the introduction of the problem of commodification in "small-scale" societies. Nonetheless, he reproduces the classical association between these societies and a high degree of culturally cohesion, which is not necessarily the case. In "small-scale" societies, Kopytoff (1986: 76) argues, the status of things is clear in a collective system of exchange spheres and exchange values. Identities are stable and changes conditioned to cultural rules. Culture in these settings provides 
unambiguous classifications and guidance to action, clearly indication objects that can be exchanged as commodities.

In complex societies, however, there is "room for a multitude of classifications by individuals" (Kopytoff 1986: 88). In contrast to "small-scale" societies, persons have numerous and conflicting identities. Commodification promotes a "flattening of values" (ibid.: 88), which produces frustration and, consequently, a drama of identities, struggling to promote singularization and reclassification of objects to which their identity is associated (ibid.: 90). The peculiarity of complex societies is not to be found in its increased degree of commodification, when compared to "small-scale" societies. The difference corresponds to the existence, in the former, of "innumerable schemes of valuation and singularization devised by individuals, social categories, and groups" (ibid.: 79-80).

Therefore, people live in complex societies under "a two-sided valuating system: on the one side is the homogenous area of commodities, on the other, the extremely variegated area of private valuation" (Kopytoff 1986: 88). On the one side the general reliable system of valuation provided by price, on the other multiple and idiosyncratic systems of values (ibid.: 79). In complex societies, cultural rules can be discussed and contested by groups, who can also attach things to different exchange spheres. He argues that since the cultural codes do not provide a firm basis for classifications, promoting or preventing the circulation of certain objects in the realm of the market must be justified, not by associating them to certain spheres of exchange, but by arguments based on religion, morality, aesthetics or professional expertise (ibid.: 82). By this procedure, Kopytoff asserts, commodities absorb all kinds of nonmonetary worth. Yet it is difficult to see any particularity in that practice: non-economic arguments have always been intermingled with systems of exchange, providing elements to determine the meanings and values of objects.

Kopytoff admits that his model deals with ideal-typical economies and admits that better theoretical returns may be gained by studying empirical cases where (1) "forces of commoditization and singularization are intertwined in ways far more subtle" or where (2) “different systems of commoditization of different societies interact" (1986: 88). He also proposes to look into a set of questions that would recognize the role of agency in the process, such as how agents move objects between spheres, what the consequences of this manipulation are for them and the entire society, how a member of a community brakes cultural rules, how it justifies it, whether and how objects are reorganized as a result. This is a far more relevant agenda, which is nonetheless beyond the limits of his model. 
Kopytoff's (1986) model has some qualities and interesting insights to be retained in an analysis of commodification. First and foremost, his biographical approach to commodities implies that these are not things, but a temporary state in the social life of objects. In many cases, commodities are a very ephemeral state in the biography of certain objects and are exchanged only for a limited period, followed by a process of decommodification by its new holder. This is a particularly important insight for this research, since immaterial cultural elements displayed in events, or images of cultures, like objects acquired for rituals and some services, are only commodities for a limited period of time, exiting the domain of the commodities soon after exchange. As a logical consequence, commodification should not be considered as the product of a general and unidirectional process towards the transformation of all things in salable goods, nor the pure effect of economic forces. Commodification should be understood as a culturally mediated process and is the result of classifications, which may result in the inclusion or exclusion of objects from the market.

Cultural operations of classification are at the basis of definitions of the boundaries of what can be sold and under which conditions, besides providing criteria that help to define the value. Finally, an important element to retain from his model is the importance of operations of commensuration to the exchange of commodities. These operations allow for quantitative equivalence among things in the commodity state. If commodity exchange is defined as the transaction of a good or a service for a quantitative equivalent in exchange value, commensuration is fundamental, as a meta-process. In Kopytoff's account, it is deeply associated to technologies that provide guidance to agents about how to compare different objects and determine their equivalence. Commensuration "is the expression or measurement of characteristics normally represented by different units according to a common metric", but it is also responsible for defining "how we value, and how we treat what we value" (Espeland and Stevens 1998: 315). Therefore, it is not just a technological device to establish equivalence, as Kopytoff suggests. The acceptance and legitimacy of technologies to compare values and their specific forms of calculation depend on cultural preconditions and specific dispositions to accept the instruments of comparison and their results. If economics has little to say about commodification, that is mainly because far from being the simple intersection between demand and supply, or the product of subjective functions of utility, the definition of value presupposes operations to establish commensurability that are deeply rooted in culture and society. Rather than being cognitive preconditions for exchange, prices, the ultimate result of operations of commensurability, are the product of cultural representations and social institutions that ensure the efficacy of instruments and technologies of pricing and valuation. 
Notwithstanding these contributions, Kopytoff's (1986) model has many shortcomings. His notion of culture, underlying classifications of objects into spheres of exchange, is too rigid and impervious to reinterpretations, manipulations and creative play by agents. This makes it unsuited to understand intercultural transactions involving commodities, in which agents have different cultural classifications of objects.

The association the model draws between homogeneity and commodities also limits the analysis. Singular and almost sacred objects may as well become commodities, exactly due to these characteristics, and therefore, they should retain some singularity while attaining a minimum degree of equivalence with other objects that would make exchange possible. The more singular is a good, the more precious and closer to the domain of the sacred, the more difficult is to commodify it, but also the more valuable it becomes. The now famous cases of life insurance of adults and children, described with all the tension and drama they entail by Zelizer (1979; 1985), efficiently demonstrate those claims. Even damages to humans or the utilization of human expressions and parts, deemed as sacred in western contemporary world, often generate legal imbroglios over their value, in which a price is put to the sacred. Some of these circumstances are compensations for longstanding intimate relationships (Zelizer 2005), cases of medical malpractice, surrogate motherhood and the market for body parts (Healy 2006).

The more interesting and complex cases of commodification involve singularities. They pose the particular dilemma of how to maintain singularity while establishing equivalence with others objects. Due to this fact, the interest for economies of singularities and markets for unique goods and services has increased in economic sociology. Callon, Méadel and Rabeharisoa (2002), for example, contend that value creation is related to a continuous and conflictive process of qualification, requalification and singularization of goods aiming at circumventing competition. Networks of actors involved in the design, production, distribution and consumption of goods work employing multiple social-technical devices to qualify and position goods in markets, attracting demand. Here, technologies distribute cognitive competences not to homogenize, but to singularize.

A further limitation in Kopytoff's model is the rigidity of cultural classifications and the notion of exchange spheres. Bohannan (1955) saw them as an element that the expansion of capitalist relations would destroy (1955), which was disconfirmed by the survival of different principles of exchange, related to specific social relations. Anthropological literature is populated with interesting examples of the insertion of goods in ritual systems, conferring 
them special meaning and subjecting them to particular - cultural and political - principles of allocation, different from those of the market ${ }^{8}$. The notion of spheres of exchange is also limited because it overlooks the connections among spheres and their principles, in daily practices that set objects in motion, a central agenda of research for economic sociology (Zelizer 2007). Objects are bestowed with different social meanings according to the relations in which they circulate, moving between spheres of exchange. If there is considerable variation of meanings attached to the most objectively equivalent of all things (money) (Zelizer 1994), the same holds true for many other commodities: objects normally traded in the market, even belonging to what would be a homogenous sphere of exchange, can be valued and treated differently, in respect to different social relations that permeate the transaction. In sum, the notion conveys a rigid association of spheres with classes of objects, which cannot account for their movement between spheres.

Thomas (1991: 81) reaffirms the relevance of the notion of sphere of exchange, but with meanings departed from Bohannan's original (1955) and Kopytoff's (1986) derivative conception. In fact, Thomas expands the notion, associating certain logics of exchangeability with classes of social relations (and not just with things) in order to discuss "the permutations of debt", an idea that is highly subversive to the rigidity of the original notion of spheres of exchange. In these "sequences of value substitutions and conversions entailing both persons and objects which might be seen to create 'value' in both" (1991: 75), an object might circulate under "a plurality of transaction types" (ibid.:81). Part of the "promiscuity of objects", discussed in his work (see notably ibid.: 27-30), together with the local meanings, is the change of regimes of value in which objects circulate. All these ideas are useful and might help to illuminate cross-cultural exchange, but reframed in this fashion, they have no reference to the conception of Kopytoff 9 .

At any rate, the model of Kopytoff (1986) has other and more serious limitations. It mutes agency and ignores the power relations behind cultural classifications. When discussing the particular cultural logic of commodification in "complex societies", he does admit that individuals produce classifications, which may mobilize public support, but normally they remain private, among the multitude of individual schemes (ibid.: 88). Interest, power and negotiation in the classification of objects and their qualification have no room in the model. As any other classification in orders of worth, as discussed by Boltanski and Thévenot (2006),

\footnotetext{
${ }^{8}$ Sahlins $(1985 ; 1993)$ describes such processes in Hawaii. Gordon (2006) is even more explicit, in his study of commodities among the Xikrin-Mebêngôkre, about how goods can be introduced in different spheres. Thomas (1991a) equally describes the role of native ideologies in the introduction of European artifacts in Fiji and the Southern Marquesas.

${ }^{9}$ The contributions of Thomas (1991) are relevant and should be employed in this research.
} 
actors advance these assessments and justify them to the public, sometimes persuading them. Since the status of objects is linked with the status of humans as Douglas and Isherwood (1979), classifying things is a powerful mechanism of social classification. In contingent situations, powerful groups or members within groups can advance specific judgments about the spheres (or orders, in Boltanski and Thévenot terminology) in which objects should be placed, according to their own interests.

This is exactly a dimension of the circulation of goods that Kopytoff underestimates. Focusing on the processual dynamics between commodification and singularization of goods, and processes underlying these movements, he says little about the practices that are responsible for them. Kopytoff's biographical approach intends to map the possibilities inherent in the status of an object. Yet these possibilities are realized by real people, who interpret these possibilities and promote departures from normative models of circulation of objects. Cultural classifications are not only created by humans, but also constantly reinterpreted and transformed by humans, especially in contemporary societies. In their daily practice, persons manipulate norms and values, according to their own interpretations and dispositions, seeking themselves to use objects in a socially successful fashion.

These "diversions" are central in Appadurai's (1986) description of the commodification process. Appadurai does not offer a model, but while discussing the circulation of things across cultural settings and periods of time, he offers useful analytical concepts to understand commodification. The processual notion of commodification he advances is more nuanced and less categorical, and there is a renovated attention to the relations between biographies of goods and the biographies of persons involved in their exchange. In fact, there are four elements in his work that are particularly relevant as dimensions to be included in the study of commodification of culture: (1) the concept of regimes of value, linked to the commodity candidacy of any object, (2) a classification of commodities according to the actual paths followed during their social life, (3) the notion of diversions and its socially and politically competitive nature, which links the status of persons and goods and, finally, (4) the importance of knowledge on commodification and exchange of commodities in general.

According to Appadurai (1986: 13), the commodity situation is defined by three features: the commodity phase, the commodity candidacy and the commodity context. The first is a temporal category, corresponding to the moment - reversible, terminal, prescribed or deviant - when objects are placed in the market (ibid.: 13). The commodity candidacy is a 
conceptual feature, defined by cultural criteria that classify objects as exchangeable or not (ibid.: 14). The commodity context links the commodity candidacy to the commodity phase. "It refers to the social arenas, within or between cultural units" (ibid.: 15), regarded as legitimate contexts for commodity exchange. These are specific contexts, defined by cultural categories, in which commodification is the legitimate path.

These three conceptual features, with thin differences, indicate that the process of commodification is the product of cultural, political, social and temporal determinations. Yet these ideas do not add much to the conception advanced by Kopytoff (1986), except for one point. When discussing the commodity candidacy of goods, Appadurai (1986) offers a more fluid classificatory scheme than spheres of exchange: the notion of regimes of value. Spheres of exchange, as discussed before, presuppose a rigid, clear and consensual classification of objects followed by the entire community. This degree of consensus in classifications of objects and attribution of value is hardly found in any society, small or complex. The idea also poses problems to intercultural exchange, for different cultural categorizations of goods would render exchange impossible. In other terms, exchange across cultures would require an agreement on the meanings and values of exchanged objects, and most probably changes in the way they regard the object. Regimes of value, in turn, are a "shallower set of shared standards of value" (Appadurai 1986: 14). It does not presuppose a high degree of cultural coherence between agents of exchange. In fact, the concept of regimes of value convey the idea that the degree of value coherence is highly variable (ibid.: 15), ranging from a simple agreement on price and certain conventions regarding the transaction, to a full sharing of standards and assessment of value of the object, depending on the transaction and the commodity. It is, thus, fully compatible with the existence of divergent assess of values of the object being exchanged. This conception is more adequate to explain transactions across cultures, when objects are placed in the same regime during exchange, due to operations of commensuration, but remain in very different universes of values and practices in the producing and consuming societies. Common grounds of understanding are necessary to allow very basic communication between cultures. However, full agreement on categories is not necessary. The idea of fluid regimes of value suggests the existence of a common ground shared by cultures, where agreement is possible.

Regimes of value seem to refer, in this account, to a minimum set of commonalities to be found across cultures united by the exchange of commodities. But it overlooks the possibility of groups interested in exchange to create new specific regimes of value, out of 
misunderstandings or particular cultural reinterpretations. Relative and reciprocal misunderstandings about the other might still yield, nonetheless, exchange agreements. Traders develop understandings that differ from the original intentions of their counterparts, but they engage in commercial relations. Societies, and especially those producing objects, may also create hybrid languages, out of their relations with "strangers", valid only for their transactions. The notion of a commodified persona, developed by Bunten (2008) to depict the character that performers of traditional customs play in Alaska conveys exactly this process.

Another very useful element of Appadurai's discussion is his classification according to the actual paths followed by objects, which renders four categories, whose description is worth fully quoting:

(1) Commodities by destination, that is, objects intended by their producers principally for exchange; (2) commodities by metamorphosis, things intended for other uses that are placed into the commodity state; (3) a special, sharp case of commodities by metamorphosis are commodities by diversion, objects placed into a commodity state though originally specifically protected from it; (4) ex-commodities, things retrieved, either temporarily or permanently, from the commodity state and placed in some other state” (Appadurai 1986: 16).

Indeed, the most interesting of these categories for the study of commodification is the commodity by diversion. Diversion is a central force behind the movement of objects into and out the commodity phase. The flow of commodities, defines Appadurai (1986: 17) "is a shifting compromise between socially regulated paths and competitively inspired diversions". This approach also renews the Polanyian (1957 [1944]) debate about fictitious commodities, divesting it of its original normative tones: many exchangeable objects are not produced as commodities and have to be placed in new regimes of value in order to be exchanged. The fundamental idea behind diversions is that "actors manipulate the cultural definitions of path and the strategic potential of diversion" (Appadurai 1986: 22). Diversions are creative reinterpretations or applications of cultural rules involving the circulation of objects and, as such, any description is partial when compared to the empirically complexity. Nonetheless, Appadurai discusses some reiterated patterns in the tension between initiatives of diversion and restriction in the flow of commodities.

Diversions, restrictions and enclaves are related to competitive strategies for social preeminence, political leadership and distinction, by means of a contest to produce sign values 
attached to goods and either create new channels of exchange or restrict the existing commodity contexts to secure exclusivity over certain things. In the society that initially holds the object, the diversion of commodities is either a sign of creativity from entrepreneurial members or crisis in the community. Promoting a diversion of an object into the market is always risky and may result in moral censorship. Not least because diversion threatens the social and political system and may face obstruction from political leaders. In any case, diversions of objects into unusual social arenas or cultural milieus normally increase the economic value of such objects, fulfilling the demand for unique and authentic objects. These gains, in turn, can also represent increases in status and legitimacy.

Yet diversions may as well be fostered by demand in consuming markets, guided by tastes and ideologies of larger communities. Among others, this is the case of rituals, tourist art and cultural devices, zones of activity normally protected from commodification. The prescribed path of these objects, Appadurai argues, restricts the circulation in the original communities, but demand for exotic and distant objects would be sufficiently persuasive to promote their exchange, although in controlled contexts. Considering that exchange presuppose the placement of objects in a common regime of value, even if this is limited to an agreement on the price, it seems more plausible to believe that diversions for sale in larger economies depend on creative agency in both producing and consuming markets. Appadurai (1986: 24) recognizes that when the forces of demand are able to promote the commodification of objects with alternative preferred forms of circulation, political leaders in the producing society controls consumption as a sort of compromise. Unrestricted commodification of such singular and precious objects is met with great censure, levied only if traders and consumers abide to the controls imposed on the circulation. Moreover, these objects normally assume the form of terminal commodities, in Kopytoff's terms (1986), entering only once the commodity state.

Commodity, as other forms of exchange, is always linked to political and social strategies. Whereas restricted forms of exchange serves the reproduction of social and political systems, maintaining the relational positions of agents, diversions represent attacks on status and quests for social and political distinction. The promotion of channels of exchange is, thus, an instrument to the pursuit of social preeminence and distinction.

The vast scholarship on the Kula, the particular form of circulation of necklaces and armshells within the Massim islands in New Guinea, since Malinowski (2002 [1922]), verified strong relations between the circulation of objects and the reputation of sailors who 
promote exchange. Communities involved in this form of exchange acknowledge that the successful circulation of valuables between islands depend on skills of men who are able to maintain stable alliances with their peers in different communities or to innovate, creating new alliances and, thus, securing new channels of circulation, when the previous commitments collapse. There is a struggle for preeminence among men, similar to the tournament for honor that Bourdieu (1977) describes in the case of Algeria. The same connection between objects and agents may be found in the exchange of commodities and, especially, in the cultural diversions by which creative members of the community looking for prestige promote the transformation of objects into commodities or find new ways of circulation of wealth for their community.

This sophisticated analysis of the practices behind commodification, as a special movement of objects, demonstrates how the fate and status of persons are connected with the possibilities and status of objects they manipulate. Similar to what happened in the circuits of Kula and tournaments of value, promoting the exchange of commodities and restraining it in certain cases combines the biographies of persons and things (Appadurai 1986: 22). In fact, there is an intimate linkage between ideal paths of goods and ideal social careers of persons. The status of an object often informs society about the status of the holder, trader or user of that object. Acts of consumption are acts of - increasingly individualized - self-expression in societies. But the approach pursued by Appadurai can be seen as an extension of such contention to the whole life and circulation of objects. Things and their circulation are signals and their use conveys a message about the status of the agents involved in the circulation or use of an object.

The notion of diversion highlights the role of entrepreneurial intermediaries, who move between societies and are able to translate signs, promoting minimum agreements on the regime of value of objects. They may also propose requalifications that divert objects from their prescribed paths. In sum, these special agents, controlling relevant information for exchange, are magicians able to offer detachable commodities out of singular objects whose natural path was outside the market or, conversely, transform bulk objects into singularized exclusive commodities.

Their ability to perform these transformations is linked to knowledge they control, which also indicates the importance of the distribution of knowledge for commodification. Kopytoff (1986) stresses the centrality of the diffusion of exchange technologies to the necessary establishment of equivalences for commodity exchange. Yet the role of knowledge 
in the flow of commodities is not limited to exchange technologies. As Appadurai (1986) indicates, the distribution of knowledge about production, exchange and objects in general is a fundamental aspect that guides the circulation of objects. Controlling knowledge is a tool in the competitive struggle of exchange, capable of qualifying objects and promoting commodification. Albeit important to allow production and exchange of commodities, it is not just knowledge that matters, but also its asymmetrical distribution among agents. The particular forms of distribution, related to power relations, create opportunities and constraints in the quests for preeminence in exchange.

Appadurai discusses the role of knowledge and its distribution in different phases of the circulation of a commodity. The first is production knowledge. The practices of production require a technical and standardized knowledge on the processes and materials. Yet even the technical production knowledge is "interpenetrated with cosmological, sociological and ritual assumptions" (Appadurai 1986: 42). An often quoted example of the presence of cosmologies and rituals in the production of commodities under capitalist relations is Taussig's (1980) study with Bolivian tin miners and semi-proletarian peasants. Rituals of production are often a form used by populations introduced to the global circuits of capital to make sense of the new relations in which they take part. In the case of Colombian peasants, working and the belief that capital is productive (fetishism) were interpreted as a necessary pact with the Devil ${ }^{10}$.

That local culture and cosmologies are employed to make sense of new relations of production is good evidence that culture and capitalism are far from being antithetical, as many classical accounts of commodification claim, such as the ones analyzed above. The relationship between cultural and economic dynamics is much more complex and it is always a culture, with its rigid boundaries, that mediates the reception of foreign elements and forces, providing narratives to debate and justify the place and meanings of such elements and forces. External forces and values are always locally reinterpreted according to native cultural standards (Sahlins 1993). This allows the market to be indigenized, the transactions interpreted according to native categories of understanding and action pursued to achieve specific goals.

The role of mythologies and cultural assumptions is not limited to the domain of

\footnotetext{
${ }^{10}$ Another thoughtful, yet purely fictional example of how work and external economic forces in general are interpreted by means of the cultural system (and the mythologies) of the native worker can be found in Werner Herzog's Fitzcarraldo. The Jivaro, an indigenous population of modern-day Peru, decide to help Fitzacarraldo in his obsession to move a boat across the hill from one river to another in the Amazon in order to find a new way to transport rubber. Bewildered, Fitzcarraldo realizes the reason for their voluntary commitment to his project when the boat, already in the other side, is set free by the Jivaro, to sail down the river to the very rapids that Fitzcarraldo was trying to avoid with his alternative path. He is told that they did that to appease the spirits of the rapids and bring good fortune to the Jivaro.
} 
production. This indicates that knowledge and its asymmetries is an important element also in different phases of the circulation of objects. The second important dimension of knowledge discussed by Appadurai (1986: 42) is the knowledge of the market, involving knowledge about circulation and exchange, the consumer and the final destination of the commodity. This is the province of traders and intermediaries, who bridge the gaps between producer and consumer in the long movement of objects through history and across regions. To be sure, gaps in knowledge between producer and consumer do not hinder exchange. These situations create the necessity and opportunity to skillful requalifications of objects in consuming centers. Therefore, these merchants are able, as discussed before, to operate multiple changes in the objects, transforming value and adapting meanings of object to fulfill the expectations of consumers. The larger are the gaps in knowledge, the more open is the object to requalifications, which tend to yield high profits to traders (ibid.: 43).

Another effect of discontinuities in knowledge mentioned by Appadurai (1986) is the quest for authenticity. Indeed, the uncertainty surrounding goods generates the urge to ensure that especially singular, creative and high value objects are authentic. Concerns for authenticity introduce a new agent in the flow of objects: the specialists, which filling in the gap in knowledge, possess a formidable power. His words, supported by an exclusive experience or education, have the power to create and destroy value and his opinion is sufficient to qualify and singularize an object. In the permanent tensions and negotiations of meanings and regime of value that the qualification of objects as commodities entail - an idea owed more to Boltanski and Thévenot (2006) than to the processual approach developed by Appadurai (1986) and Kopytoff (1986) - knowledge and, in special, judgment devices (Karpik 2010) ${ }^{11}$ play a central role. Information is the source of assessments of worth and justifications for qualifications, social processes that partially explain the mystery of value. Therefore, judgment devices and, in special, "experts" have the power to settle disputes on value, as well as confirming the authenticity of objects. Related to the increasing role of specialists in contemporary capitalist, is the fact that "knowledge about commodities is increasingly commoditized" (Appadurai 1986: 54).

A last note on the effects of discontinuities of knowledge between producers and consumers, with special regard to the commodification of cultural elements, can be added. Based on Appadurai's discussion on tourist art, as well as the recent essay by John and Jean Comaroff (2009) on the increasing use of market projects to reinforce ethnic identity and a

\footnotetext{
${ }^{11}$ Karpik (2010) discusses multiple instruments employed to assess the qualities of good. All of these, and not just specialists, are important to bridge the gap between producer and consumer.
} 
sense of "nativeness", it is possible to assert that exchange is possible even amidst misunderstandings. The lack of knowledge about producers of cultural objects may open space for consumers to voice their visions and expectations about the "other" founded in misunderstandings, as well as generic desires for exoticism. In turn, the desire of cultural producers to sell may lead to adaptations of the services and goods offered in the market to fulfill this imagery, without necessarily abandoning other cultural expressions. Producers may concentrate their efforts on the production of highly demanded objects and services, reinforcing the exotic vision that consuming centers cultivate. And often, "the version that is commodified and enacted [...] becomes the 'authentic', the 'original'" (Comaroff/Comaroff 2009). The larger is the journey that a commodity makes from its producing site to its consuming center, Appadurai argues (1986: 48), the more likely some mythologies regarding the product emerge. Central to the biographical approach is the contention that even if "things have no meanings apart from those that human transactions, attributions, and motivations endow them with", analyzing the trajectories of things can "illuminate their human and social context" (ibid.: 5).

The methodological proposal of Appadurai is, still today, rich to unveil a fragment of the process of commodification. Notions such as commodity as a state, the social life of things, which he borrows from Kopytoff (1986), the politics of value that underlies the diversion of objects and his observations about the role of discontinuities of knowledge are good starting points for an analysis. But his proposal has a number of limitations, mostly derived from his extreme focus on the realm of exchange and his adoption of Simmel's (1978) disappointing theory of value. This theory is strangely close to the notion of orthodox economists. Value is defined by how much someone is willing to give up in order to obtain an object. In other words, it is a measure of individual desire. Some economists ${ }^{12}$ might shrug at the idea of studying values beyond that point, that is, to understand how desires are created. But this is the common proposal of sociology and economic anthropology, and central to this case.

The secret of value is not confined to the realm of exchange, but equally lies in the production and the producers. Values must be created, notably attached to material and immaterial objects that require labor. In many cases, the diversion of things to the commodity state entails the purposive production of them for exchange. Consequently, the politics of value must be extended to a politics of production: agents must agree to contribute with

\footnotetext{
${ }^{12}$ Obviously, I refer only to those who reject labor theories of value.
} 
efforts and discuss the meanings of these activities and their results. As Graeber (2001: 31), I contend that the proposal of Appadurai has a narrow focus on exchange and individual objects, and in that sense, another limitation is to miss the structures of meanings, both in production and exchange, which inform the location of objects in classificatory systems. Meanings of objects, as acts of commodification and circulation in general, are encompassed in a broader classificatory system of societies. Not only objects, but the actions necessary to promote the commodification also have meanings according to native schemes of classification. Consequently, a decision on the circulation of an object is not limited to the negotiations on a discrete transaction, but part of broader strategies of societies. This calls for an analysis of commodification that is not restricted to discrete acts of exchange, or specific objects, unveiling the social, cultural, political and historical conditions in which exchange is inserted. Biographies of things are part of biographies of societies and to reveal the former, it is fundamental to indicate how they are connected to the latter.

This explains part of the problem. But whilst reinstating the role of production and producers in the creation and exchange of value, I do not intend to assert that the secret of value is confined to the realm of production or societal systems of classification. And this is specially the case for goods - representations - that connect distant populations. The desire that Appadurai (1986) mentions is equally relevant and must be explained. Given his proposal to analyze the social life of goods and his considerations on the role of discontinuities in knowledge, it is curious that he does not consider that the social biography of goods creates value, a contention already made by Graeber (2001: 33). The story of the life of things, the difficulties to move to the commodity state, the origins and the transactions it entails are all elements that surround the image and esteem an object holds. Recently, Sahlins (2013: 188) proposed looking into the distance and the "qualities derived from the association with a distant place of origins" to understand the value of long distance goods. In a similar, but a broader conception, Beckert (2011) discusses the transcendent quality of goods, which might be spatial, but equally be temporal or social. The distance may, thus, be in time or social spaces. These distances might explain the desirability of goods from distant others and are also important to allow very selective appropriations of the meanings of things and profound reinterpretations according to the point of views of the consumer, potentially leading to the emergence of myths, as Appadurai (1986: 48) mentions.

The analytical concepts discussed here provide a full picture of the process of commodification and offer already some hints about our specific problem. If all that was said 
holds true, under conditions of controlled exchange, things can be commodified while retaining some non-market uses, representations and expressions in specific social relations. In other words, things can circulate in different regimes of value, one of the reasons why the gift/commodities distinction remains relevant. Things can enter the market in certain situations only, retaining dimensions and expressions protected from the market. Certain elements of culture can be produced in order to be exchanged selectively with outsiders, without hindering cultural practices of the group. Thus, a return to nativeness can be coupled with the development of market projects. Moreover, the interconnection of biographies indicates the possibility to use the market to dispute leadership and loyalty of the group with effects in internal politics and external legitimacy. Internally, success makes good reputation; externally, it justifies protected existence to broader national society, indicating participation in productive society.

\subsection{The mystery of value in cultural representations of otherness}

The creation of value is a social process, not only product of social labor, but also a set of processes that are not purely economic, such as the definition of the proper regime of value of an object, its equivalence with others and the acceptance of the particular exchange technology, employed for purposes of commensuration. In conditions of intercultural exchange, it involves combining two perspectives to reach a minimum agreement on the conditions of exchange. One of the most intriguing facts surrounding the commodification of "culture" in general and lifestyles in particular is exactly the current revaluation and requalification of indigenous cultures by Western systems of thought, policies and economic agents. Indigenous cultures were always sources of knowledge and mediators of exchange with western colonial powers. Yet now they increasingly become an object of exchange under new relations established between global economic forces or consumers, and local populations. These processes of revaluation of indigenous cultures are intrinsically related to the mystery of value involving cultural commodities from indigenous populations and are an instantiation of it. If the value depends on both cultural operations of commensuration and its technologies, and cultural and social preconditions for its legitimacy and acceptance, the mystery that surrounds it can only be solved by turning to the historical processes that produced these conditions. 
Throughout the history of cultural encounters, cultural representations have circulated in several ways. There is actually a long history of European consumption of distant cultures and their knowledge through postcards, collections of artifacts, curiosity cabinets, museum displays of artifacts regarded as arts of distant lands, travel writing and anthropological accounts. Anthropology has provided authoritative accounts of other ways of life, based on the contribution of natives who are purported to possess sufficient authority to represent their culture (Clifford 1997). All those instruments of circulation contributed to the constructions of the great divides that structured much of social sciences, between modernity and tradition, history and myth. They promoted a play with mirrors, fed by the nostalgia of a lost past and the myth of a unidirectional pattern of modernity: looking into distant cultures was regarded as means of travelling on time and seeking the origins of modern populations. This circulation always required a great deal of translation, but involved very limited native agency. This study, in turn, analyzes the circulation of such representations in the commodity form, that is, in the market. Since they are not produced for the market, they have to be converted or incorporated into commodities.

Since the Valladolid debates amongst Dominicans on the humanity of Amerindians were closed by a Papal Bull ${ }^{13}$, the interaction between cultures - and their forms of knowledge posed a question on how to handle the cultural discontinuity. Notwithstanding the impact of native cultures in western sciences, thinking and social life, proper to the dynamic of cultural exchange, the overall treatment reserved to native cultures alternated between destruction, assimilation, accommodation between cultures and finally recognition and protection, and always remained a matter of contention within intellectual circles and state policies. Basically, two fundamental views on indigenous cultures were advanced: since Montaigne's (1976 [1580]: chap. 30) work, some political philosophers have cultivated a romantic view of the bon sauvage, innocent humans living in a state of nature, whereas within the discourses of modernity and colonialism native cultures, often named primitive or traditional, were associated to irrational superstitions, often considered closed systems of superstitions beliefs "impervious to ostensibly contrary evidence" (Hobart 1993: 4), a sign of backwardness and a hindrance to the development of the community (Crewe/Harrison 2005; Ratuva 2009). For a long period the limited resources and technical means they disposed to achieve their material needs were considered signs of scarcity, famine and need, not to mention an essential prodigality (Sahlins 2008). If the constitution of modernity involved a rigid separation

${ }^{13}$ The Bull Sublimus Dei, promulgated by Pope Paul III in 1537 forbade the enslavement of native populations from the Americas on the grounds that their human souls should be saved. 
between humans and non-humans - and subjects and objects -, the native forms of knowledge, displaying a different episteme that organizes the universe in such a way that nature is regarded as an extension of communal existence ${ }^{14}$, either as the model for social organization or the result of it, could not be accepted and valued.

In all cases, however, the particular views about the value of cultures and, more specifically, their knowledge and ways of living led to specific forms of intervention, either to have the natives' souls saved through conversion to Christianity, to protect them from famine that derives from the absence of market structures or to preserve their cultural identity. Obviously, these different forms of dealing with cultural difference reflected particular views about the value of their culture and, more specifically, of their knowledge, which have shifted a great deal in the past centuries, but always remained a matter of contention.

Without a necessary transformation in the way their cultures were valued, the role played by indigenous populations changed with the raise of nationalism and the struggle for independence in colonial areas. As the original inhabitants of the lands, they were incorporated into the young nations and their nationalistic imagery. Once incorporated, their almost exclusive occupation of certain portions of land could be employed by states to claim sovereignty over these areas. But in the same period, in the midst of European nationalistic movements, romanticism truly praised traditional lifestyles, both from rural European populations and indigenous populations from distant lands. In the late nineteenth century, in yet another expression of colonial mentality, orientalism cultivated an idealized form of native cultures of Africa and Asia. This valuation did not change the main policies towards indigenous cultures or knowledge. In fact, in the twentieth century native populations were surveyed, demarcated and became the target of developmental policies attempting to create income by inserting them into market structures. As an object of developmental policies, an indigenous question was socially constituted, recognizing the need to intervene to secure the survival of native populations, although the means were diverse (Escobar 1995). The development of a non-evolutionary cultural and social anthropology and the recognition of the right to cultural diversity and the need to protect indigenous cultures fostered by the creation of the United Nations Educational, Scientific and Cultural Organization (UNESCO) were not sufficient to counteract the effects of these policies and their discourses and in some cases provided justifications. Not long ago, a major avenue of international aid was the transfer and introduction of high-yield plant breeds and animal species, together with new techniques, in

\footnotetext{
${ }^{14}$ Although regarded as a contiguous reality, nature is distinguished from culture (Lévi-Strauss 1976).
} 
less-developed areas, which dramatically changed their landscapes. The Green Revolution, as commonly named, spread monoculture farming and livestock and brought roads and power plants to areas rich in biodiversity. By doing so, these aid programmes not only caused genetic erosion, but also an erosion of native social forms by incorporating populations into modernized forms of agriculture (Cunha 1999).

Yet in late modernity the glorification of indigenous "cultures" and their knowledge became more common. On the one side, they are still regarded as recalcitrant traditions hindering development and calling for aid in the form of market development and infrastructure. In fact, in some areas such as South America, their loyalty to their nations is still today challenged by those who perceive their alliances with environmental interests and NGOs devoted to the protection of cultural rights as a threat to national interests. Nationalistic discourses often see any initiative to protect indigenous cultures a move from the developed world to secure economic interests in regions, due to the abundant mineral resources found since the 1970s in indigenous lands (Cunha 2009) ${ }^{15}$. On the other side, however, there has been a different call for protection of "traditional" forms of culture and a renewed respect.

Under what social conditions came "culture" to be valued by Western societies and some of their elements turned into an object of market exchange? What are the social changes that have prompted a new relationship with different cultures and forms of consumption of their knowledge, notably one that is increasingly mediated by the commodity form?

There is a set of very broad social phenomena in the late modernity that provides a first approximation to the question. The specific literature on the commodification of culture repeatedly indicates these as causes to the phenomenon (see Lau 2000; Islam 2010). These are broad social shifts that somehow resulted in new forms of discourse and policy regarding native populations. The indigenous question has been reframed by the anthropological knowledge and activists (Escobar 1995). While the recognition of the need to intervene to protect the populations and secure its survival continues to be almost unanimous ${ }^{16}$, the best approaches and policies are still discussed upon.

The radicalized modernity called into question the faith in the humanly promoted progress and many of the tenets that accompany it. Much beyond the intellectual and aesthetic rage against modernity and its alleged philosophies of history (Giddens 1990), there has been a systematic challenge of the optimistic customary wisdom about material progress and

\footnotetext{
${ }^{15}$ A strongly ideological example of such discourse can be found in Barreto (1995).

${ }^{16}$ Implicit to these discourses is the assumption that there is a question to be solved, either the triumph over primitive and pauper forms of social life or their protection.
} 
development, as well as the employment of instrumental rationality as a means to achieve it. The last century produced compelling accounts exposing the contradictions of instrumental rationality, technology and development, all capable of producing well-being, but also destruction. Moreover, the possibilities of spreading the material conditions experienced by populations of advanced capitalist countries to all humanity were questioned, both due to the asymmetrical structures of capital accumulation and the limitations of exploiting natural resources.

The latter element came to play a significant role in the critique of developmental discourses and in a reassessment of forms of native knowledge. Development, in western sense and as a result of a naturalist conception, "implies the unconditional priority of culture over nature" (Lévi-Strauss 1976: 320). However, the rise of environmental awareness, notably the acknowledgement of value of biodiversity, called for a different social relationship with nature and its resources. "Traditional" forms of socializing and producing in harmony with natural resources become, as a consequence, a possible model to better solutions in western cultures. "Traditional" populations are often considered the holders of valuable knowledge about biodiversity and how to preserve it by means of the establishment of a balanced relationship with the environment, not to mention alternative forms of medicine and rituals. In the western imaginary, the indigenous knowledge of the forest peoples became the romantic symbol of societies embracing traditional lifestyles whose preservation is a proxy for the promotion of biological diversity. Scientific research conducted by ethnobiologists reinforced this conception, demonstrating that indigenous practices of forest cultivation and management were not only responsible for preserving, but also for fostering biological diversity (Balée 1993). The treatment of traditional knowledge as an instrument of biodiversity protection by international documents also reinforced this vision.

A renewed interest in native forms of knowledge and cultural practices is the result of a number of social phenomena: the emergence of social movements defending cultural diversity and the protection of local cultures against alleged homogenizing forces of globalization, as well as a search for new traditions and rituals in a world whose most distinctive cultural feature is its appearance of disenchanted and purely rational (Sahlins 1976). A pervasive argument of classical social theory is that modernity sweeps away all types of traditional social order and promotes a disenchantment of the world. Yet classical social theory also foresaw that as all persons, things and relations become objectified processes over which technical control is to be gained, replacing tradition for reason, there emerges a quest for new 
rituals and beliefs (Weber 1991).

\subsection{The literature on commodification of "cultures": a short review}

Albeit a primary concern for contemporary anthropology, sociology has not yet analyzed the socioeconomic dynamics or meanings that lead to the incorporation of "cultures" into the circuits of capital ${ }^{17}$. In fact, it is important at this moment to briefly map the existent production of social sciences that somehow deals with this phenomenon in order to indicate the contribution of this research. Since "culture" is a fluid concept and encompasses multiple manifestations, it is somehow difficult to define the boundaries such literature, but using the definition of "culture" employed here, as a category of practice that denotes all those practices, relations and artifacts that are held as symbols of the uniqueness of a population, the pertinent literature can be identified.

Closely related to this research are some studies discuss the causes and effects of commercial partnerships with indigenous populations for the provision of environmentallyfriendly and socially responsible goods and services. Two partnerships involving the British cosmetic company Body Shop and indigenous populations from the North of Brazil for the production of Brazil nut oil were analyzed by Turner (1995b) and Ribeiro (2009). Both share similar pessimistic conclusions about the potentials of these agreements to the indigenous populations. The authors situate the phenomenon of commercial partnerships involving indigenous populations, which we could call commodification, in the intersection of processes of liberalization of economies and the diffusion of environmental discourses. These processes alter the development policies and priorities, and increase advocacy of market solutions for indigenous populations, especially linked to environmental services or sustainable production. Turner (1995b) decries the partnership with Body Shop maintained with the Kayapó for being a wage labor relationship in which the real product is not the oil, but the image of indigenous populations and its association with the company. Ribeiro (2009) agrees that these projects neglect cultural patterns of indigenous societies, fail to empower populations and are not alternatives to environmentally harming projects, such as logging, practiced by indigenous populations. He contends that, in fact, these projects reproduce the old forms of Indigenous

${ }^{17}$ Notwithstanding, sociology has produced a vast work on commodification and the constitution of market value for objects, discussed above. 
involvement with the extractive industries in the Amazon. Assessing these projects from an economic perspective, they conclude that these project do not offer financial independence to the natives.

Another, if less common line of research has been to analyze the reconversion of traditional rituals in urban centers of the world. Studies about the development of New Age practices of yoga, ayurveda and cults based on the consumption of ayahuasca were presented by authors like Lau (2000), Sivaramakrishnan (2006) and Islam (2010). Their works focus rather on transformations in the rituals and beliefs associated to these practices, and not the constitution of values or the possibilities of exchange involving these therapeutic or ritualistic products. In general they show how the new practices are harmful to the traditional rituals and practices of healing. In particular, Lau (2000) considers the effects of adoption of traditional systems of healing by Western companies, including Aveda, catering for the new age consumer without listening to the original producers, treating them as mere objects of an external project. In general, this literature silences the producers of "culture", approaching the phenomenon exclusively from the point of view of the analyst and his position.

There is a third stream of research that deals with a particular expression of "culture", the traditional knowledge hold by populations, notably on biological diversity. Besides the normative debate on the best forms to protect indigenous cultures and knowledge, some studies in the subject demonstrate the unsuitability of the regulatory framework to deal with the plurality of regimes of knowledge and property that can be found amongst the so-called traditional populations (Cunha 1999; Cunha 2009). Literature has moved beyond this assertion to recognize also that notwithstanding this apparent unsuitability, recognizing their unique heritage, indigenous groups have unequivocally appropriated the language of intellectual property rights, as defined in the West, in their claims. Following this recognition, a main avenue of anthropological research has been devoted to understand the local uses of the imported categories of culture, intellectual property and traditional knowledge by native communities (Turner 1995a; Cunha 2009). This literature also shows that agreement on the conditions of exchange of traditional knowledge is possible because the indigenous communities have set aside fundamental differences and have pragmatically internalized and essentialized ideas of knowledge, culture and intellectual property.

Connected to the strategic incorporation of instruments, discourses and categories of judgment of modernity is another stream of research that focus on the exhibition by indigenous groups of somehow objectified and rigidified versions of "culture", corresponding 
to the visions of authenticity that non-natives hold, as part of their existential politics. They consciously employ these external categories, including the external representations of the indigenous cultures and their association with the protection of biological diversity as frames for advancing identity claims and protecting their cultural differences. The play of definition of cultures, setting boundaries and associating symbols to certain populations is neither a neutral, nor an objective game. In that sense, it is easily transformed into a tool in the politics of identity. To define something as different or similar and to determine the nature of this difference or similarity can be a political operation of imposed or self-conscious affirmation of identity. Conklin and Graham (2005) discuss the alliances forged between Indigenous groups and environmentalists in Brazil and the use of eco-politics to advance identity claims. Displaying the environmental crisis as a common cause, they show how the incorporation of environmentalist discourses shapes the public image displayed and received by these natives. Conklin (1997) shows how indigenous groups replicate exotic body representations that are associated with authenticity as an effective political strategy and how the self-representations of these populations change in the process. These studies do not discuss the circulation of cultural representations in the commodity state, but they situate a certain reification of these representations and the associated use of institutions of modernity in strategies of identity politics. The appropriation of external and exotic visions of their culture as a political weapon may also explain their willingness to publically perform their culture (Graham 2005), with or without a monetary compensation.

There are other insightful studies examining the circulation of cultural representations and performances in the market. John and Jean Comaroff (2009) authored a volume on the use of ethnicity as a brand, examining many ethnic market ventures and the specificities of producing and consuming "culture" as a commodity. While criticizing some common assumptions of critical theorists on culture and display, they reveal the heightened agency of native populations behind these ventures and their consequences in terms of strengthening of culture and identity. Fred Myers (2002), in turn, analyzes the development of a market for Aboriginal art in Australia, involving the pictorial representation of one of the most sacred manifestations of their culture, the dreamings. Myers shows the dilemmas, tensions of representation and different expectations involving painters. He demonstrates that these art objects circulate in different regimes of value and that even during the period in which they circulate as commodities, the meanings and values of the works are not erased. Bunten (2008) also provides an interesting concept in her analysis of a project of cultural tourism in Alaska. Contrary to popular belief, she contends, the natives have total control over what is shared and 
what is not and, thus, they protect certain aspects of their culture from public display. They consciously develop what she calls a "commodified persona", an actor that performs for visitors, different and separated from the authentic being.

The insights offered by this literature, as well, as its limitations, frame the investigation to be done in the next parts. It is worth pursuing some of the elements advanced by these authors, whilst offering new insights. It seems particularly interesting to investigate in depth how the pragmatic appropriation of cultural representations is being employed by the Yawanawa as a tool for identity struggle. That the market is an arena for political conflict over distribution is widely known. But the phenomenon of commodification of cultures in the way described by the literature indicates that the market can be also a platform for identity claims. The effects that its "pragmatic use" for cultural and identity claims have over these very elements in the long term are still to be identified. The research focused so far either on the causes and consequences of the introduction of western categories and visions of otherness in indigenous communities or in the consequences of the development of commodified forms of rituals. This work, in turn, attempts to analyze the exchange and understand the local meanings and values of "culture" constructed by two different populations brought together by this unique product that is the symbols of difference. 


\section{Part II}

\section{The Producers}

In any encounter, the agents interacting matter greatly. Many have relied on Weber's (1978) short characterization of the market to define it as the realm of depersonalized exchange, or the most impersonal of all communities ${ }^{18}$, and yet the markets are no exception. They might be located in the impersonal end of a continuum of sociability in forms of exchange (Sahlins 2008), and they are still arenas of dense sociability in which characteristics of the agents matter. For the social position of the agents within their communities and of the communities to which they belong in the global society, not just influence the possibilities of engaging in certain interactions, but also how these agents understand and proceed in these encounters. "Market agent" is a general category that says very little and is unable to encompass the social relations that animate and are animated by exchange, the understandings and meanings created and the values exchanged in the transaction. Moreover, it is often the case that these market agents are bestowed with a certain set of dispositions which ignores the creativity through which different agents reinterpret and reinvent market processes and institutions. A "universal bourgeois subject, a self-interested creature of desire acting with an eye singular to the main chance" (Sahlins 1993a: 2) do not exist, nor do they seem a condition for economic action. The same can be said about a universal producer. Although present to a variable extent among market agents, the economizing and calculating disposition that is associated to the economic agent says very little about the reality of such actors or about their own understanding of the undertaken actions. These limitations become visible when agents acting in different contexts or situations are compared: the suq trader and the futures brokers, the art dealer and the clothing retailer are all market agents. Yet they possess different forms

\footnotetext{
${ }^{18}$ It is important to remember, in this regard, that Weber only published in life a characterization of the "market situation" in the Chapter 2, Part I, of Economy and Society (1978: 82), as all the known opportunities of exchanging any object for money. Exchange and competition were the distinct forms of social interaction he defined as belonging to the market situation. The representation of the market as the most impersonal group was added to Part 2 of Economy and Society based solely on unpublished notes. And in any case, it was a theoretical, rather than an empirical market that was depicted as the space of impersonal, anonymous exchange, probably as a result of his adherence to neoclassical economics to understand economies in theory. See Swedberg (1999) for Weber's use of neoclassical economic theory to interpret abstract economic processes and his call for different methods for empirical analysis.
} 
of conducting business and interpretations of such transactions, as rich ethnographies have shown ${ }^{19}$.

This alone calls for an investigation into the agents and their forms of acting and interpreting their action. Yet if the goal is to follow the social life of objects, the movements and consequences of commodification, the values that are produced and exchanged as objects circulate, as well as the means through which market practices and goods are signified differently, understanding the agents, the relations they construct and the circulation of objects within and beyond their communities are still more relevant. These agents are not just part of the process of construction of the objects of exchange (Callon/Méadel/Rabeharisoa $2002)^{20}$, they are also the holders of values that are exchanged and, in this case, the holders of the cultural representations, the "culture" which is circulating as a commodity. Additionally, the political and social locations of the agents are profoundly influential in their capacity to promote diversions of such objects into the commodity state and present valid justifications.

There is yet another and perhaps even more important reason to study native features and conceptions carried by the Yawanawa. One of the central contentions here is that the process of commodification of "culture" is part of active strategies of indigenization of modernity (Sahlins 1999b: ix) in its two possible meanings that I discussed: the reception of forms, processes and institutions from the Western modernity by different cultures, on the one side, and the increased awareness of and interest in cultural difference, on the other. In order to substantiate this contention and replace the trope of global domination and "sentimental pessimism" (Greenblatt 1991) that abound in the narratives of encounters of distant populations with the market and reinstate the agency of natives in their engagements with economic partners, it is relevant to examine aspects of the system of reception of symbols and production of meaning, according to which things and beings incorporated are accorded a specific place in its reproduction (Sahlins 1993a: 16). In the pragmatics of culture that has been proposed and explored by Sahlins, all structures are always subject to empirical shocks. In the Yawanawa case, there were significant changes in the conditions of cultural production that led to some erosion in the system of reproduction of symbols. Yet this did not represent a complete replacement or disappearance. There are native ideological, cultural, social, political

\footnotetext{
${ }^{19}$ The souk was object of Geertz' ethnography (1979), as well as part of Bourdieu's work on Algeria (1977), although the latter understood the $s u q$ as an intermediary transactional mode between the village and the market. Zaloom (2006) offered an interesting analysis of futures traders in her work. Art dealers were the object of Velthuis' research (2005). Albeit more concerned with general aspects of the organization of markets, Aspers' (2010) observation of clothing retailers also show specific understandings amongst those agents. These are just a few examples of a vast universe of ethnographies of the economic life.

${ }^{20}$ Part because the objects, and the attachments of human agents to them, create in turn new social agents, attaching qualities to the bearers of such objects.
} 
and economic - to reproduce a division of life that has little use other than analytical - aspects that, as in any culture (Turner 1993: 64), influence ways the Yawanawa interact with outsiders, appropriate instruments, categories of thought and judgment, seize opportunities and control interferences.

Hence, few words are in order on those aspects of the social life of the Yawanawa which seem to have an impact in the specific ways they engage with other populations and, more specifically, how they understand and proceed in their economic transactions with outsiders to procure resources and goods. All these aspects reflect specific patterns of circulation of objects to, from and inside the community and the social relations that both create and are created by such flow. They indicate native forms of promoting and interpreting exchange and the relations it creates. More than a general ethnology of the Yawanawa, which can be produced assembling elements of the few ethnographies produced on them ${ }^{21}$, this part attempts at discussing the native aspects that mediate the indigenization of modernity and the commodification of "culture".

In other words, the next three chapters are devoted to analyze how economic transactions are understood according to their own system and how they comprise individual and collective strategies. The first chapter (chapter 3) offers a general portrait of the community and its main actors, some ideological representations that guide their action and the geographical location. It equally shows how these representations are used to defuse tensions. The second chapter (chapter 4) attempts at presenting some cultural, social, political and economic aspects that comprise the internal political and cultural economies of the Yawanawa. It provides an analysis of the multiple permutations of debt (Thomas 1991) which produce sociability, power and animate the flow of knowledge, objects and money. After analyzing the tournaments of power, which explain tensions between groups and forms of engagement with market and political partners, it describes the meanings bestowed upon processes of material production and circulation of external goods and money, as well as the ways they are used to reproduce social relations. All these aspects are clearly the result of specific historic developments and, in special, the history of inter-ethnic relations maintained by the Yawanawa. Historical contingency poses challenges to the system and informs the developments of social, cultural and political patterns in response to new conditions. The

\footnotetext{
${ }^{21}$ In fact, despite the increase in number of ethnographies of Pano populations in the 1990s, not much work was done on the Yawanawa. Besides the anthropological reports written to FUNAI's process of delimitation of the Gregorio River Indigenous Land (Brasil/FUNAI 2006), there are two ethnographies: Naveira's (1999) work focuses on the systems of relations of alliance and aggression established within the community and between the community and outsiders. Gil's (1999) work is an investigation of the Yawanawa system of cure, its ritual forms and agents (the shamans).
} 
Yawanawa history, centered in such relations and their connection to the broader political economic developments of the region, is the object of the third chapter (chapter 5).

The last chapter of the part (chapter 6) offers a brief presentation of another producer in these projects. Aveda, the firm that buys annatto seeds and images from the Yawanawa, promotes a transformation of the raw materials (seeds and representations) into a product that is offered in the markets. The chapter offers some notes on is nature, its relations with distant populations and the tensions around the qualification of its products. 


\section{3. "We are like the white-lipped peccaries"}

This chapter presents some characteristics of the Yawanawa. Rather than a general ethnology, it focuses on aspects that bear significance to the forms of relating to outsiders and exchanging goods in the commodity state. All those elements that are related to the political and cultural economies of the Yawanawa are discussed in the next chapter. This chapter sets the basic context for this economy. First, it presents the ontological conceptions about the group and alterity that constitute native ideologies shaping their understanding of themselves and their relations with others. These conceptions are used to make sense of exchange and neutralize conflicts that emerge between groups contesting power. It proceeds to describe the community and its geographical setting, which explains some challenges involving the access to and outflow of goods and the patterns of residence and distribution of the population, relating not only to historical developments in the region, but also to political loyalties, as well as kin and social relations. It offers, then, a brief description of the main characters involved in the economic projects and the controversies of the re-invention and performance of "culture". Economic action relies on social relations and personality. Hence a brief portrait of the main actors and their groups set the stage for the later analysis of the market projects.

\subsection{White-lipped peccaries are good to think: the queixada ritornello}

The Yawanawa, or the people of the white-lipped peccary $($ Yawa $=$ white-lipped peccary, known as queixadas in the region, nawa = people), are part of the Pano linguistic group, native to the basins of the Ucayali and the Jurua Rivers, in the southwestern part of the Amazon. In what seems an instance of totemism, as defined by Lévi-Strauss (1962), the white-lipped peccaries constitute an apt metaphor employed by the natives to describe the strength of their unity and sociability (Keifenheim 1990; Naveira 1999). Many Pano groups are composed of an eponym, followed by the suffix -nawa, meaning in its broadest sense, person. The eponym always indicates with precision, as Keifenheim asserts (1990: 81), the type of people. Other Pano societies display totemic relations with eponymous animals, 
through which they deploy cultural categories of thought to represent rules of conduct with consanguineal kin and affines in terms of their classifications of nature ${ }^{22}$. The Yanawana, however, display no clanic separation or internal dualities that divide consanguineal kin and affines, and thus, the ethnonym does not indicate a system of internal classification of the social structure, but the same cultural categories of thought which are employed to classify nature are employed to represent their social structure. In fact, the Yawanawa often stress that they all belong to the same extended family and are related through a common ancestor of historical times, an old chief who stabilized the contact with non-natives in the region and organized the work of the local natives in the rubber tapping business. Peccaries live in large herds, which occupy a large area and use their unity as a factor of protection. They are, thus, the perfect metaphor to represent their conception of the group. Unlike other Pano groups, among the Yawanawa the eponym is neither considered as given by other groups, nor resented for the pejorative sense the association with certain animals generate (Keifenheim 1990: 81$)^{23}$.

This is, however, a metaphor, and should not be used to infer any confusion between the animals and the Yawanawa themselves. In fact, their cosmology contains a specific myth to explain how the peccaries (the animal) were created, as some humans ate the eggs of a bird that sung yawa yawa, then becoming peccaries and turning into possible prey for the remaining humans. Two young men, who had not joined the group in eating the eggs, were later transformed into a deer and a caititu (a collared peccary). A woman who refused to take part in the meal remained a human, telling the others about the story (Naveira 1999:172-174). This myth not only marks the distinction between species, and between the ensemble and its fragments. It also indicates the intended sociological meaning of the peccaries: it opposes the gregarious, cooperative behavior of the white-lipped peccaries, to the isolation of deers and caititus. In fact, in their cosmology, it is the recalcitrant behaviors that generate tense situations in which both peccary-humans and peccary-animals are on the verge of being confused and hunting becomes potential cannibalism. As a metaphor, the image of peccaries roughly equates with the semantic position of swarms of bees and colonies of ants in the Euro-American cultural system. But peccaries are also invoked for their resilience when part of large groups. Many Amazonian populations, and the Pano are no exception, devise special methods to hunt peccaries that are often compared to their war techniques. In the Amazonian

\footnotetext{
${ }^{22}$ See, for example, the cases of the Marubo (Melatti 1976), the Yaminawa (Saez 1995), the Kaxinawa and the Shipibo (Keifenheim 1990), and finally the Katukina (Lima 1994), with whom the Yawanawa share the indigenous land.

${ }^{23}$ Even the Yawanawa know that other groups do not accept these denominations, often mentioning the example of the Kaxinawa (people of the bat), who call themselves, as many other Pano groups, Huni Kuin (the true people).
} 
perspectivism, a specific ontology that ascribes cognizant powers and personhood to all creatures (Viveiros de Castro 2002c), humans can wear the skin of a peccary as much as peccaries can wear the skin of humans, and thus, what it is said about hunting, can also be said about war: peccaries are fearless enemies (Saez 2001) ${ }^{24}$.

Peccaries are employed in a native sociology because they are good to think about the Yawanawa society, and the expected cooperative social behavior of its parts. The theme is a recurrent one in the cultural and political conduct of the Yawanawa, often invoked in tutti, an instrumental refrain played to project a vision of the community. The Yawanawa proudly describe their community by referring to the peccaries, and the strength achieved through unity is an often invoked symbol to maintain order and the co-operation of members against conflicts and divisive forces. In that specific sense, it is not difficult to see that the sociological metaphor is equally an ideological device, with influences in all social activities, including those oriented towards production. As any ideological discourse, the adherence of individual members to its tenets and prescribed conducts is variable, but there is a political and cultural use of the metaphor in the daily activities, as further explored below.

Peccaries are also a symbol of the endurance of their community amidst the challenges of the inter-ethnic contact in the past century, offered as a symbolic counterpoint to other disaggregated tribes of the region. This is a much valued element by their new allies. As such, this representation is mobilized in present times also with effects in their market transactions. And these, in turn, as generally the new relations and alliances forged by the Yawanawa, have also contributed to transformations in the ritual expression of the motif. The Yawanawa used to perform a ritual game symbolizing the peccaries in which, covered in mud, men would ceremonially maintain sexual relations with women (Saez 2001; See Vinnya/Ochoa/Teixeira 2006). Due to the conflictive effects within the community, notably among the attackers and the husbands of the victims, but also due to possible damages to its external reputation, the Yawanawa seem to have abandoned the practice. This does not mean, however, that the peccaries and their gregarious nature disappeared from the ritual life. On the contrary, the mariris celebration is opened with a dance in which the entire community dances in close association, hand by hand, representing the bands of peccaries. And the model is employed to explain the gestures and steps of other dances. This suggests, however, that the expressions of

\footnotetext{
${ }^{24}$ As pointed out by Saez (2001), the semantic position of the peccaries in the Pano cosmology is the opposite of the position attributed to these animals in other Tenetehara, Mundurucu and Kayapo myths discussed by Lévi-Strauss in the Catitu Rondo, part of the "The 'Good Manners' Sonata”, published in the first volume of his Mythologiques (Lévi-Strauss 1964). In the latter, the white-lipped peccaries are the result of anti-social behavior, most precisely conflicts between affines or the recalcitrance of members in matrimonial alliances, whereas for the Yawanawa populations, they represent the expected social cohesion.
} 
the theme are developing in new directions as a result of their contemporary place in the market for ethnic representations, which only demonstrates the vigor of the motif.

There is yet another expression of the metaphor. The Yawanawa have inhabited the shores of the upper Gregorio River, in the eastern part of the Jurua River Valley at least since the late nineteenth century. They have relocated along this portion of the river, from and to the headwaters, in movements of dispersion, reunion and merger with other local groups following threats, aggressions and alliances. In some measure, this is the result of the particular group dynamic of Pano populations, fittingly described as a compact nebula by Erikson (1993), marked by strong wars with the capture of women and children, and kinship alliances through the exchange of women. But this dynamic was later exacerbated by raids promoted by non-natives, and notably Peruvian caucheros looking for gum trees since the mid-nineteenth century (Erikson 1993; Lima 1994; Naveira 1999). In that period, many groups sought refuge from those raids moving to headwaters, smaller rivers and more isolated areas, meeting other groups in the process. The enlistment of natives into the rubber tapping business also brought together members of different groups and promoted matrimonial alliances with non-indigenous tappers which led to mixed families.

Currently, the Yawanawa community encompasses members identified by other ethnonyms, either because of ancestry or because they were born in different groups, some of which no longer exist. There are at least Iskunawas (currently known as Shanenawa), Ushunawas, Rununawas, Sainawas, Katukinas and Huni Kuins, all from the Pano group, and Shawãdawa (from the Arara group) living among them. They often recognize that there are only few "pure" Yawanawa. Yet this does not indicate internal divisions, but simply the result of alliances through with closer others are incorporated. Currently members associated with different ethnonyms are all integrated into the group and take active part in the communal life ${ }^{25}$. The variety is respected and even praised and there is no attempt to conceal the assemblage of ethnonyms that form the Yawanawa, especially because it operates as a symbol of past victories, skills in celebrating alliances and of their unity under the image of the peccaries.

\footnotetext{
${ }^{25}$ Perhaps the full integration of this assemblage was made possible by the consolidation of the common identity after generations and motivated by state policies of recognition of rights to indigenous populations. In the past, it is possible that members born amongst different groups did not join the same respect in the community. At least one older member mentioned difficulties associated with the fact that he joined the community through marriage.
} 


\subsection{The nawa contrapunctus: alterity as a constitutive principle of Yawanawa identity}

Incorporating selected others, from nearby and afar, to their own community seems a constitutive element of the Yawanawa identity ${ }^{26}$. This particular dynamic is an expression of cosmological and societal aspects that the Yawanawa share with other Amazonian populations. Certain features of their ontology, regimes of subjectification and societal organization drive them into establishing relations of alliance or aggression with others and domesticating difference in the process. These features correspond to the Amazonian Perspectivism (Viveiros de Castro 2002c). Since this cosmology is consequential to understand the role of difference in the subjectification of Amazonian populations, it seems relevant to sketch the main characteristics of such cosmology. As mentioned before, this ontology attributes personhood to all known species. Personhood is a condition associated with cognition: all these different subjects, humans and non-humans are cognizant beings, but they apprehend the world according to different points of view. Albeit sharing personhood as a condition, each being has a different perspective on others, which is related to their bodies, clothing, habits and to the perspective that others have about themselves. Acknowledging that everything around them has a point of view, these populations understand that to engage with the world and relate to others involve apprehending the point of view of what is to be known. This principle pervades exchange as well and, consequently, for Amazonian populations, "exchange is ontological predation: it is immanent constitution and intrinsic subversion, of the interior by the exterior (Viveiros de Castro 2002b). A process of "essential alteration" (Viveiros de Castro 2002a: 263) is, thus, a condition of social life. The historical practice of cannibalism among some Amazonian populations is, in this sense, nothing more than the extreme expression of a general regime subjectification in which the other is constitutive of the self and the social body. This particular cultural dynamic in which the individual and the group is always ready to dissolve and redefine their identity with the domestication of others was equally analyzed by Gow (1991), who attempts to show that the striking appearance of acculturation among Peruvian Amazon natives is not a sign of their weakness but, a result of their own cultural dynamics. This aspect of their cultural dynamic has evidently consequences on the Yawanawa exchanges with non-natives.

\footnotetext{
${ }^{26}$ In fact, the relational identity of Pano groups, or the definitions of alterity, is the most developed trope within the Pano ethnology.
} 
This particular ontology bestows a central role for others in the formation of an everchanging collectivity that domesticates difference and incorporates others. This is not a purely Pan-Amazonian cosmological feature and is, in fact, both expressed in their myths and emphasized in their ethno-history, explored in detail below. There are, moreover societal aspects that foster exchange with external others, becoming a source of this dynamic of incorporation, namely the system of preferential prescriptions for matrimonial alliances. The system of kinship, confirmed by the terminological distinctions, has particular consequences in that regard, which make others a central part of the social substance. The connection of kinship, exchange and sociability is a classical anthropological theme: Mauss (2005 [1923-4]) developed the argument that exchange and reciprocity animate social bonds, which was later employed by Lévi-Strauss (1981[1949]) to contend that negative and positive prescriptions of matrimonial alliance are the basic principle producing continued exchange and solidarity. However, in the Amazon, kinship alliances lead to limited exchange and solidarity beyond the confines of cognation. This is due to a simple reason: positive matrimonial prescriptions, in the Amazonian case, lead to bilateral alliances between crossed cousins ${ }^{27}$.

This system has multiple sociological implications, explored in detail below for the specific case of sociability amongst the Yawanawa. The main consequence, however, is that as affinity - both potential and effective - is contained in cognation, matrimonial alliances produce restricted exchange and are a limited source of dynamism (Viveiros de Castro 2002b). Amongst the Yawanawa, like in other Amazonian populations, the system of kinship terminology expresses this positive preference for the marriage of crossed cousins, distinguished by the parallel cousins, treated as siblings. Crossed cousins are the descendants of parents' opposite-sexed sibling (mother's brother's son and father's sister's son, for the female ego, and mother's brother's daughter and father's sister's daughter for the male ego). By marring the crossed cousins, an ego establishes an alliance with a MB (uncle) or FZ (aunt) and their descent.

The alliance based on the union of crossed cousins was treated by Lévi-Strauss (1981[1949]) as an example of restricted exchange, associated to segmented societies. Since Overing's study of the Piaroa (1975), however, it is known that bilateral alliances do not imply segmented societies or any general principle of distinction between consanguines and

\footnotetext{
${ }^{27}$ The point here is not to discuss the adherence of this or other Amazonian terminologies for kinship and matrimonial strategies to the Dravidian model verified by Dumont in Southern India, with or without differences, but to describe the sociological implications of the bilateral restricted exchange. For a critical review of the application of the Dravidianate to the Amazon, the specificities of the region, as well as reflections on the practical sociological consequences, see the encompassing review of the literature and evidence by Viveiros de Castro (2002b).
} 
affines. The basic feature of such systems, as explored by Dumont for the Dravidian case, is the transmission and reproduction of affinity. The same alliance is reproduced after each union between crossed cousins. Effective affinities also have a political dimension, revealed once more by Overing's ethnography (1975). They create alliances between two groups, but also claims to power based on obligations, as further analyzed below. Yet their main consequence is to generate a flux of goods, services and persons that is intense within the group of effective affines, while restricting the potential exchange promoted by kinship alliances to the close group of cognates. Matrimonial alliances are equally a limited principle of collective organization. Beyond the group of cognates, exchange and socialization require operations of different nature: ceremonies and rituals, aggression (Naveira 1999; Viveiros de Castro 2002b) and, increasingly, economic exchange. Beyond linking two groups of cognates, alliances are employed to produce claims to power.

If society keeps united by reproducing alliances within cognates, reducing difference in its interior, dynamism is projected to the outside. The external other becomes, then, important to animate circuits of exchange beyond the confines of cognates and to generate supralocal structures. In the past, the role of aggression was exactly to establish exchange beyond the village, incorporating new persons and things into the community. Currently, economic exchange has replaced aggression as a mechanism of production of relations beyond the boundaries of cognation and, more generally the boundaries of the village.

In the specific case of the Yawanawa, the role of the external other is highlighted by the fact that they share a common ancestor, the old chief Antonio Luiz. This means that all Yawanawa are remotely consanguine. If one the one side, this animates further relations beyond strict boundaries of the crossed sections of the close cognates, on the other, it minimizes the difference of internal others, increasing the reliance of the external others to animate solidarity and promote exchange with the introduction of difference. The Yawanawa display a Kariera terminology without sections (Naveira 1999: 50 ) confirming the division between parallel and collateral affines. As indicated in the diagram below, the parallel relations are all named with the same terms employed to refer to the relations to the ascendants and siblings. Thus, the father's brother is an Epa like the father, the mother's sister an Ewa like the mother, and the parallel cousins are Utxi, Txipi, Eshtu or Txiku depending on their seniority in relation to the ego and sex, same terms employed to refer to the siblings. In fact, in their daily life, it is common to use equivalents in Portuguese language and only the crossed cousins are called primos (cousins in Portuguese). Avuncular marriages (between 
uncle and niece or aunt and nephew) are in theory rejected and the marriage of a man with his father's sister (atxi) is especially condemned (ibid.: 51). Polygamy was historically practiced, until the wide adherence to Evangelical Protestantism amongst the Yawanawa changed marital practices. In the past, however, chiefs had multiple wives to extend their alliances within the group, transforming obligations to in-laws into respect and loyalty, showing the political dimension of the alliance. In some cases, the positive preference for the crossed cousin is not verified and different strategies are pursued, in specific situations of power, to forge supra-local political alliances, to express power and self-sufficiency in relation to potential affines or even to expand the limits of exchange beyond the narrow cognatic limits.

\section{Diagram 1: kinship terminology}

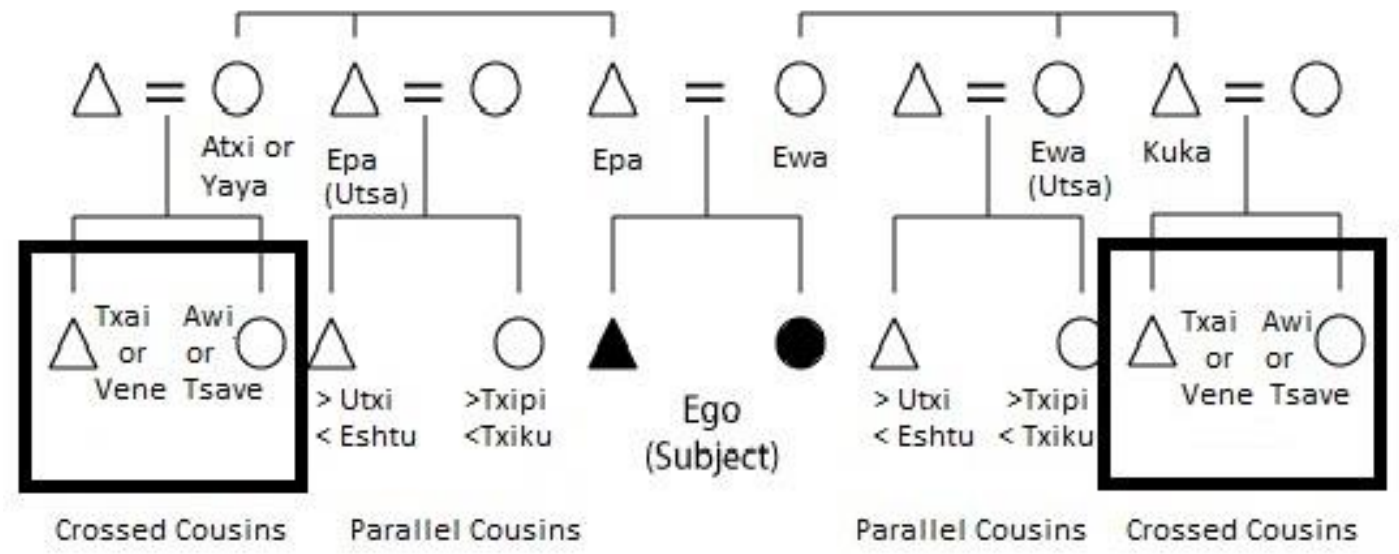

\footnotetext{
Key

Epa $=$ father and father's brother

Ewa $=$ mother and mother's sister

Kuka = mother's brother

Atxi (male ego) or Yawa (female ego) $=$ father's sister

Txai (male ego) or Vene (female ego) = Mother's brother's son or father's sister's son

Awi (male ego) or Tsave (female ego) = mother's brother's daughter of father's sister's daughter

Utxi = younger brother, younger mother's sister's son, younger father's brother's son

Eshtu = older brother, older mother's sister's son, older father's brother's son

Txipi - younger sister, younger mother's sister's daughter, younger father's brother's daughter

Txiku = older sister, older mother's sister's daughter, older father's brother's daughter
}

Together these societal and cosmological aspects make alterity a constitutive element of the Yawanawa identity and cultural dynamic. If the restriction of matrimonial alliances as source of exchange, intensified by the common ancestry in the case of the Yawanawa, reduces difference in the interior and animates relations with the exterior, their cosmology transforms 
this relationship with the other into a permanent incorporation of the other and redefinition of the collective.

In fact, the unity represented by the peccaries and the constitutive alterity are two complementary principles defining the identity of the group and its exchanges. If the peccary metaphor acts as a centripetal force that, just as the preferred matrimonial alliances, discussed below, minimizes and dissolves difference into the social body, a principle of selfdetermination by the other, whose features are incorporated, made theirs, acts as a centrifugal role that opens the community to difference and, thus, new exchange relations. Moreover, the other is not a compact entity, defined by simple opposition from the inside boundaries of the communities. Other is not a single entity, rigidly separated from the inside. Societies, and the Yawanawa are no exception, establish a scale with multiple and non-equidistant grades defining the spectrum of relations of sociability and exchange. This tempered scale not only defines spatial and social distance, but also the intensity of relations, ranging from internal divisions within the group to the most outsider-recognized other (Sahlins 2008). In theory, other can represent any grade from close internal others, normally defined by potential affines, to distant internal others, defined by other relations within the group, to close external others, normally neighboring groups with which relations are pervasive and long-standing, to a distant external other, notably the whites.

Amongst the Yawanawa, Naveira (1999: 55-59) identifies three classificatory categories of social distance: ewe yura, yura utsa and nawa. They are relational and, thus, the concept they convey convertible depending on who is referring and who is being referred. The first, translated as "my body", refers to all the Yawanawa, members that maintain continuous relations, speak the same language and all those who have kinship relations to them (ibid.: 55). The term is employed to differentiate the Yawanawa from other groups, but may also be employed to refer to the other Yawanawa, in relation to the inner circle of relatives. This category of internal other, within which matrimonial alliances are generally established, helps explaining the conceptual unity of the Yawanawa despite the diversity of forming elements. The second occupies an intermediary space between the ewe yura and nawa and can only be defined in relation to these. Translated as "another body", it seems to be a category referring to "others like us", i.e. close external others (ibid.: 56). Utsa ${ }^{28}$ refers to a different group, an-

\footnotetext{
${ }^{28}$ To add some complication, Naveira (1999) mentions, but does not discuss the fact that utsa is also the term employed to refer to the mother's sister and to the father's brother, that is, the aunt and uncle who belong to the parallel line and, thus, whose descendants are outside the group of potential spouses. In that sense, the term also suggests members outside the kinship alliance, internal "others like us". In fact, this seems to be the only usage of the term that remains current among the Yawanawa.
} 
other that is external, but closer than nawa. The relationship established to the yura utsa is weaker than the relationship established within the group, but stronger than the one established with the nawa. This intermediary category is used to refer to groups with whom they have effectively shared territories and pervasive relations have been established, exchanging women and conducting joint rituals. The third and final concept is that of nawa, a term with multiple meanings in Pano languages (Keifenheim 1990), at times used to denote humans in general, but which also were used to refer to the foreigners, the outsiders with whom there are no stable relations.

Naveira (1999) also recognizes that this classificatory scheme seems to have given way to a simpler opposition between yura and nawa, with new practical connotations. As a result of Indigenist movements and policies creating the new collective "Indigenous population" and new inter-ethnic relations with non-natives, the valid opposition becomes índios (in colloquial Portuguese, the term used for indigenous populations) - brancos (white), to which the already existent categories of yura and nawa are respectively applied. My own observations confirm this: nawa was used almost exclusively to refer to the white, including myself, opposed to Indians. This also indicates new relations: if in the past nawa was a distant with whom limited relations were established, an-other that inhabited the periphery of the space of sociability, and frequently seen as an enemy, nowadays nawa is the main allied and partner of exchange, perhaps justifying the relinquishment of the intermediary category of the close other due to the replacement of neighboring native populations as the others with whom privileged relations are established.

The central place for alterity in the formation of the Yawanawa is evident in their historical practices and becomes equally visible from their myths. This is not the place for a systematic analysis of the Yawanawa mythology, which would, in any case, require a careful collection and an examination much beyond the boundaries of my research. However, two myths that were succinctly mentioned and discussed with me provide strong evidences of this relational aspect in the constitution of the Yawanawa identity.

These narratives are not rules of engagement: they do not necessarily shape behaviors towards others. And it is true that they might not be mobilized on a daily basis to understand their experiences as they were in the past. In fact, the uses and performances of myths could themselves be the object of a sociology, as they vary greatly amongst societies. In the Yawanawa case, my experience only confirms what Saez (2002) and Naveira (1999) had noticed: the realm of narration and interpretation of myths seem confined to a group of 
specialists. Only a few of the members, notably the elderly specialists, know them and even amidst the current efforts to educate the new generations into the Yawanawa traditions and cultural practices, these myths are not shared with all. And yet they suggest a constitutive alterity as part of the narratives devised to make sense of their own creation and further developments. Even if not shared by all, myths are always a discourse devised by and about the society, as Clastres (1977) asserts. Furthermore, as seen with the metaphorical association with the peccaries, the Yawanawa cosmology is not absent from politics and daily practices. These myths may still be invoked by some members, those who have central roles in the relations established by the Yawanawa with outsiders, providing a justification that belongs to the core of the Yawanawa culture and, thus, possesses significant legitimacy.

Their myth of creation, or suvini, assigns a central place for alterity in the formation of their identity. In fact, they are the product of an-other and produced together with others. Collected by Naveira (1999: 166-170), it is worth citing some fragments with adaptations according to a version told to me by an Yawanawa going through the initiation process to become a healer, which increases the intelligibility in the English language:

"In the beginning of the generation there was nothing and at the same time people already existed [...]

Right at the start of the history of the Yawanawa people, all animals used to speak. And all the people used to live at the suhuao [big collective house]. One day, a man decided to hunt and found a ripe shekeshi tree [bacuri or platonia]. It was late and, thus, he decided to return home. When he arrived at night, he invited everyone to join him to eat the fruits. So, in the next morning they went to eat the fruit. They climbed the tree and started eating the fruits with joy. Then, an awa (tapir) passed by and saw traces of humans. It started following the traces to see what was it and when it arrived at the tree it finally saw from the bottom the people eating the fruits. When it saw them eating, it asked them what they were doing. They explained they were eating bacuri [platonia]. The man who had found the tree called it awashuma sekes, which means breast of the tapir [awa in Yawanawa]. The tapir stared them with anger and said: 'but you are eating my breast!'. The tapir stepped with strength on the root of the tree, propelling the people all over the place. Some landed on a branch of a big samauma [tree].

On the branch there were many people, and someone said: 'how do we go down now? We will not be able to live here. There is no food, nothing for us. How are we going to descend?' Then another person said: 'let's give hands to each other to go down; otherwise we will be here forever'. Then, they gave each other their hands and circled the tree. They descended very slowly and got back to the ground. They 
were really upset with the tapir and decided 'let's kill the awa for throwing them onto the samauma tree. They did it and celebrated, saying that they had killed nawa. In that place there was an elder, who always remained apart, on his own, doing his own stuff while the others played, worked, very joyfully, but this old man did not like to mingle with the younger, remaining on his own. This little old man had a wife, and the youngsters thought: 'the old man does not mingle, he does not like to be among us, we are taking his wife from him'. They gathered and took his wife, but he did not care about it.

[...] At sunrise, [the old man] woke up, took his small arrows, concealed them [...] and left.

He arrived at a crossroads of trails and looked that Naihutsamuitaita had gone hunting and he was from a different tribe of persons. When he was returning from hunting, the old man hid and whistled [...], the returning hunter listened and replied. Before Naihutsamuitaita arrived [where the old man was hiding], he shot the arrow and killed him. He took his bamboo knife and cut the neck, removed the intestines and inside of the intestines there was the $\mathrm{reku}^{29}$. Then the old man thought: 'well, now that I have this, I will walk with it and with this I will know the things that will happen'.

He took the reku and the head, returned to the village and throwing it in the middle of the people, he said: 'this is what we call nawa. But you killed a tapir and said 'ah, I killed nawa'[person] and then celebrated... you are lying. I am the one who can kill nawa! Look: I brought the head and the reku for you to see'. They were afraid and returned the old man his wife.

[...] The old man who killed Naihu left the reku inside a straw-made bag and hanged it on [the ceiling of] the big maloca [collective house] where they lived in those times. When everybody was sleeping, he listened to a noise inside the bag, without anyone moving or touching it. He listened to a noise just like a winding clock, tsekere, tsekere... he looked inside the bag and there was [nothing but] the reku. He left the bag hanging and once more listened the same sound tsekere, tsekere... checked again and could not see anything.

He heard the sound once more and when checked inside the bag, the first thing that was inside, without anyone having taken the bag or put anything inside, was an Isku [Japu = Psarocolius decumanus bird] feather. It was like a hat made of those feathers. [...] He did not touch the hat.

\footnotetext{
${ }^{29}$ Reku is defined by Naveira (1999: 167) as being the bezoar, a concretion found inside the stomach or intestines of animals often considered an antidote. The procedure of removing the intestines is akin to the one employed by hunters to avoid putrefaction of the killed animals.
} 
When he lied down again, once more he heard that sound. He checked the bag and when he opened it, there was another feather and that feather was of Shawa [macaw], very beautiful, and from that feather another hat appeared.

Once more he lied down, heard the same sound, checked inside the bag and found a snakeskin, used to make another hat, Rumu maiti [snake hat].

The same thing repeated once again and as he checked inside the bag, there was hair of Yawa (white-lipped peccary), from which a hat had been made.

When he looked again, there was a hat made of the skin of kama [jaguar]. This was kamanawa, people of the jaguar.

[...] Once more he checked and there was another hat, this time made of [the feathers] of Shane (a blue budgie). With each new noise, it only changed the objects that came to symbolize each nation.

[...] With a new noise, he checked again and this time was a [beautifully] drawn hat made of paka [taboca, a bamboo]. They were Sainawahu.

Next time it appeared a hat made of the very white feather of Herons, a hat that created the nation of Ushunawahu. After that hat appeared, the noise ceased.

When the noise ceased, the bag that was hanging fell, broke and as it opened, from each hat a nation started to leave the bag. First it was the nation of the feather of Isku. So many persons left the bag, so many, [and] when the Iskunawa nation was all out, the Shawanawa nation left. There were a lot of persons [...] it was like if they were coming from a hole, and everyone left the bag, creating one nation to each symbol.

The old man that had taken the reku remained quiet on his own, standing up and seeing so many persons appearing. He was very scared.

When they stopped leaving the bag, they said: 'it is because of you that we are now here, now tell us what he must do. You are the one who should explain us'. He did not even move and very slowly said: 'all right if you think I did it, if you think you were generated by me and want me to explain you what you have to do, then now we are going to sing, everyone with joy singing'.

[...] They continued making their parties, all very cheerful, all the persons generated, many nations, many people, each with their own songs, playing their songs.

This old man followed them explaining them what they had to do. That little old man always commanded them [...]

When the party was over, they travelled a lot, they travelled so much that they arrived at a precious place that, we believe today, is the sea. [...]" 
Several elements of this narrative highlight the relational aspect of the constitution of the Yawanawa. The initial characters in the myth are general, undifferentiated persons. Moreover, in a clear example of the Amazonian Perspectivism, humans and animals are all personified and interact with a common language, as the incident with the $a w a$, or tapir, demonstrates. In fact, in the variation narrated to me, I was told that in the beginning all creatures were living together. The tapir has a perspective on the situation. Apparently, these general persons misrecognize the awa, believing to have killed a nawa. The elder shows, however, that nawa is, in fact, a different (human) person. A person who is recognized and known as such, but different, carrying within the body the magical power that will create different nations. Thus, the Yawanawa are the result of a process of magical transformation of a magical element of a nawa, the distant other, into multiple human groups with specific symbols. The matrix is the murdered man, who belongs to a different group than those who inhabited the world before and those who are generated by his reku. In other words, they are the result of a murder in which perpetrator and victim are both others, persons of different categories. And it is the power contained in the other that leads to their formation. Furthermore, this operation of differentiation leads to the simultaneous creation of different groups, which reflect the diversity of groups integrated into the Yawanawa in the recent history. Their constitution is simultaneous to the constitution of other groups, but these are special others. The nations that appear are close others, Pano-speaking groups that integrate the Yawanawa composite community (Saez 2002). It should not be difficult to recognize that they correspond to those ethnonyms with recognized members within the Yawanawa. Finally, their constitution leads not only to joy and celebration, but to a quest to explore new and precious places, even if very distant. In that sense, their narratives suggest that curiosity and interest in distant places, this impulsion to explore beyond the confinements of the village and, as a synecdoche, all they could offer - was a foundational element of the new nations, including the Yawanawa.

A second myth that deserves attention is that of the muka veine. Muka veine is also the name given to the sacred spirit contained, according to the Yawanawa, in the shrubs of Psychotria Viridis. The Yawanawa employ the leaves of those shrubs to produce a hallucinogenic brew, named uni, and worldly known as ayahuasca, which is consumed by healers as part of procedures of cure, guiding them to find the causes of illness. The brew is equally consumed during rituals to produce visions in the participants. The sacred spirit of the muka is considered the source of all spiritual and medical knowledge of the Yawanawa. The initiation process, further discussed, involves learning from this spirit by means of the 
ingestion of the brew how to contact all the other spirits. Unfortunately, the myth of the Muka Veine is not documented in any source and I was never able to obtain a full account. Perhaps due to its centrality to their system of knowledge, but also due to difficulties of communicating with experienced and apprentice healers, I was never able to obtain a full account of the myth. In fact, despite the insistent attempts to understand their adoption of and relation to Western industrialized goods and some habits, the myth was never mentioned during my talks whilst I was in the field. This could indicate that the myth is not a current justification for the adoption of goods and practices from the European and later Brazilian societies, which is in fact, not reflected upon in the daily lives of the Yawanawa. Yet the episode in which it emerged shows that it does carry some significance in terms of representing their understanding of the alliances forged with whites, the circulation of their rituals, and the incorporation of new objects in their practical and ritual lives.

The myth was mentioned by a young Yawanawa that was initiated in the spiritual powers and had travelled to Sao Paulo to perform some ceremonies. After returning from the field and knowing of his presence in Sao Paulo, I contacted him, interested in understanding the meanings of sharing these ceremonies with outsiders in big urban spaces. It was during a brief conversation that the myth emerged ${ }^{30}$. He briefly replied to me that it was a very powerful experience to share these ceremonies with the whites, just like described in the myth of the muka veine. Our talk was interrupted before he could tell me the full content of the myth, but I asked him to explain the analogy and he said that the myth narrates how the nawa, here meaning the white men $^{31}$, were a present to the Yawanawa, given by an old and powerful man. This man offered the Yawanawa to fulfill any wish. They then asked for the nawa. The old man warned that they would appear in large numbers. In fact, he cautioned, they would outnumber the Yawanawa. He also advised them not to rage war against the new persons, because they were very powerful. Even with these warnings, they maintained they wish and asked for the whites. When the nawa appeared on the shores of the rivers, they brought new and powerful tools. The young Yawanawa used this as an analogy to signify his own experience, saying that his work in Sao Paulo confirmed what he learned from the Muka Veine. The contacts and alliance with the powerful white, he contended, is a strong experience that creates the realization of powers in the white other. Even fragmented and somehow

\footnotetext{
${ }^{30}$ Later, I electronically contacted another apprentice of healer to verify the content. This person confirmed the content, but did not feel comfortable sharing the myth over the internet, afraid of possible misunderstandings. It is often the case that they are not very confident about their writing skills and are very meticulous about the meanings of their myths.

${ }^{31}$ The multiple (and relational) meanings of the term nawa, to refer to specific or generic others, or to the group of persons (humans in general) are explored and explained by Keifenheim (1990).
} 
attenuated, this narrative concurs to the contention that, amongst the Pano, the stranger is a "sort of reservoir of brute power that needs to be socialized" (Erikson 1996: 79).

Again, this might be not the current devise to make sense of external objects and practices over the past century ${ }^{32}$. However, the myth of the Muka Veine, known to the practitioners of spiritual rituals, can be employed as a justification to the alliances made to different external groups in the politics of value that animates the circulation of cultural representations and, notably, of ritual practices. In fact, allying with the white is never the object of contention, as explored in the next chapters. The objects of controversy are the terms of these alliances and who the best allies are. The role of the other in the formation of the Yawanawa collective identity is not merely an ethnological feature that engenders a relational and centripetal cultural dynamic. This aspect, together with its materialization in terms of mechanisms and agents that mediate between the community and the outside world, create openness and closure, are aspects that have profound consequences in terms of the relations the Yawanawa establish with goods, money and outsiders.

Before moving to the description of the actors and these relations, a last word on these cultural aspects is fundamental. The motif of the peccaries, as a metaphor for societal cohesion and strength, and the central role of alterity in the collective Yawanawa identity, as all the other aspects described below, cannot be interpreted as isolated cultural phenomena. Even if these beliefs and devices are held at the center of their identity as a group and treated as autochthonous, they are constantly moving into new directions as the result of new encounters and exchanges, as shown for the ritual expression of the peccary metaphor. More importantly, it is the specific history of inter-ethnic relations that makes them salient in the daily lives of any community, bestowing these cultural devices with explanatory and justification strength (Urban/Sherzer 1991).

The refrain of the peccary, as a metaphor for societal cohesion and resilience, as well as the place of alterity in their identity, are salient aspects because the Yawanawa are the aggregation of several parts in a tutti that have employed alliances with outsiders to face a state system that attempted to assimilate the natives. They are good to think, inasmuch as they make sense of the place of the community and its challenges in a global society.

\footnotetext{
${ }^{32}$ Yet this myth suggests that the event - the encounter and engagement - was contained in the structure itself, in a way that inscribes history in the system of cultural understanding, as in the theoretical suggestion of Sahlins (1985; 1993b).
} 


\subsection{The community and its location}

The new collective identity, incorporating members of all the mentioned ethnonyms into the community under the symbol of the peccaries started to gain shape as the Yawanawa gathered around the mouth of the small river (igarapé) Caxinaua. As better described in the next chapter, this followed the engagement of their chief and other men in rubber tapping for the estate established in the area. Nonetheless, their identity has only become crystallized after an increasing awareness of special rights associated with their native condition and the delimitation of their land. New rights and the territorial recognition rigidified otherwise fluid Pano identities ${ }^{33}$.

Currently, the Yawanawa speak mostly Portuguese. The adoption of the national vernacular was the result of decades of involvement in the rubber tapping economy, dispersion and the education sporadically provided in the region by women of foremen of the rubber estate or missionaries. They use some words of the Yawanawa language, especially to refer to specific cultural practices, natural species and objects that are employed in rituals. Some situations determine the use of Yawanawa. This is the language employed in the spiritual ceremonies and healing practices by the shamans. Their rituals and their songs are in Yawanawa, albeit some of these songs have been translated into Portuguese in versions only used when they have visitors. Healers and specialists in their cure system speak mostly Yawanawa and share their knowledge only in that language. The spiritual and mythical side is not open, therefore, to those who do not possess the knowledge of the language, which acts as an incentive for the youngsters interested in the healing and spiritual careers. Portuguese, in turn, is the language employed to discuss and negotiate projects and political benefits among themselves and with their allies. The leaders and notable men are good speakers and oratory is praised in the community as a quality of a good man. Uses of languages are also determined by generational differences. Whereas the elderly prefer to speak Yawanawa, and feel uneasy to use Portuguese, the youngest prefer to speak Portuguese. Despite learning Yawanawa at school, they seem to possess limited vocabulary and are normally reluctant to use the language. The middle-aged alternate between both languages, being able to communicate with

\footnotetext{
${ }^{33}$ The problems of identifying members of other Pano groups, which relate to conceptions of identity and alterity and the fluidity it generate are summarized by Keifenheim (1990: 80): "des groupes portent à tort le même nom alors qu'ils sont différents, tandis que d'autres sont distingués alors qu'ils se reconnaissent semblables. Une raison à ces incertitudes: beaucoup de groupes possèdent une classification graduée de l'altérité qui tient compte des différents autres Pano..." For example, Yawanawa is also the ethnonym employed by a group living in the Upper Acre River, currently in Bolivian territories, and by their other half, to whom they establish preferred matrimonial alliances. Both these populations, however, are normally known as Yaminawa.
} 
the elders and the youngsters, but they regularly use Portuguese. The fact that it is the elderly that better speak Yawanawa evinces that, despite the erosion reported by the Brazilian official Indigenist body, FUNAI (Brasil/FUNAI 2006), not even the toil of rubber extraction and the cultural losses associated with it lead to the disappearance of the language.

Since 1983, part of the territory traditionally occupied by the Yawanawa and employed in their subsistence and ritual activities was recognized and later demarcated by the Brazilian State, together with a village inhabited by the Katukina people ${ }^{34}$, comprising the Indigenous Land of the Gregorio River (Terra Indígena do Rio Gregório - TIRG in Portuguese), part of the Municipality of Tarauacá (see Map 1). After a collective campaign to include areas employed for their economic subsistence (fishing and hunting), with special meaning in their legends and myths and old abandoned settlements, the Yawanawa managed to double the size of their land in 2006 to 187,000 hectares, although the new territories have not yet been homologated by the Brazilian Executive $\mathrm{e}^{35}$. The indigenous land is part of the Municipality of Tarauaca, in the central part of the state of Acre, comprising an area that extends from the source of Gregorio River, in the south, to approximately 25 kilometers south of the main road of Acre (BR-364), in the north. An open ombrophile forest covers 95\% of the area. An affluent of the Jurua River, the Gregorio is very sinuous and its water levels are highly variable according to the pluviometric regime. As a result of the constant flooding of its shores, trees fall and the riverbed has a significant deposit of trunks and wood, which makes the navigation more challenging, especially during drier periods. In fact, in the Upper Gregorio navigation is restricted to canoes, boats with small tail engines and, exceptionally, larger flat-bottomed boats.

\footnotetext{
${ }^{34}$ The Katukina referred to here are the Katukina-Pano living on the shores of rivers Campinas and Gregorio, in the state of Acre, and are not to be confused with other indigenous groups also named Katukina. Albeit accepted by its members, the group considers the name an imposition from outsiders, notably due to the regional chronicles of Father Tastevin (1924). According to Lima (2009), they have been recently promoting the use of the denomination Noke Kuin (true people), in addition to the six clan names (Varinawa, Kamanawa, Satanawa, Waninawa, Nainawa and Numanawa). For more information on the Katukina-Pano, see Lima, 1994.

${ }^{35}$ The Brazilian Constitution recognizes in its article 231 the original rights of the indigenous populations to the lands they have traditionally occupied. Since the 1970s, the legislation on indigenous populations has established these territories as Indigenous lands and granted exclusive rights of possession and fruition of them to their traditional populations. These lands constitute property of the Union, are inalienable and ought to be protected by the Government. In practice, indigenous populations depend on a long process through which these rights come to fruition. The federal government, through its Ministry of Justice and the National Indian Foundation (Fundação Nacional do Índio - FUNAI), the federal body responsible for the implementation of Indigenist policies, must recognize these rights through a long process of identification of the territories traditionally used by the claiming group for the development of their social, cultural and economic activities, delimitation of the land, official demarcation by the Minister of Justice and, finally, an homologation by Presidential Decree, which adds the land to the Union's estate. This process, regulated by Decree 1775/1996, can be challenged in court at all times by parts claiming land rights. Even without judicial review, processes depend on the political commitment of federal governments to recognize territories and normally last for decades, often creating tensions with non-indigenous who inhabit or develop activities in the area.
} 
This particular location is an important element to consider in order to understand the dynamics of the Yawanawa relations with the market and external goods. Their territory is remote, but not isolated. In fact, albeit distant from the main market sites in Brazil, the area has been connected to the global markets for a century, as further explored in the next chapter. And yet, the distance influences the access to services, the external pressures against their land, the conditions of transporting products from and to the villages. The distance from the consumer centers and the difficulties of transportation in the forest and through the Gregorio River, which do not allow larger boats with larger cargo capacities to navigate, create additional challenges for their projects of production for the market. Equally costly and difficult is to bring industrialized goods to the villages. Important supplies and notably fuel are overpriced, adding to the costs. Even the nearest towns are far from industrial centers and due to the limited competition, salespersons can practice prices that are higher than mere distance-related costs would justify.

The Yawanawa can walk between villages using forest trails, but the river is the main means for transporting people and goods to and from the villages. Currently most families have canoes and some of them small tail engines. Additionally, there is a small landing strip, constructed by Protestant missionaries in the 1970s, that served for medical evacuations, but is no longer used, since the missionaries were expelled in the late 1990s and currently helicopters can land directly in the clearings of larger villages. The villages are reached by river by small motor boats in a journey that varies between three hours to the nearest, northernmost village with good water levels, and two days to the farthest away, southernmost village in drier periods. With good conditions, the journey to the latter is eight-hour long.

The Gregorio River intersects the road at a small settlement named São Vicente. From that village to the seat of the Municipality of Taruacá, the journey by road of approximately 100 kilometers requires one hour and a half, and to Cruzeiro do Sul, a regional urban center which has increasingly attracted the Yawanawa, the journey of approximately 150 kilometers requires three hours. Connections were improved as the road was paved and finished in 2011, but the rainy season continues to cause damage and pose serious challenges for heavier cars. Some Yawanawa have constituted permanent residence in these towns, as well as in the state capital, Rio Branco. Most of them moved to work for organizations promoting the rights of indigenous populations or as civil servants in government institutions. Some moved seeking economic opportunities as a result of the disarticulation of the rubber enterprise, but these more often than not returned to the indigenous land. The legal organizations of the Yawanawa 
have houses in Tarauaca with offices and accommodations for their members visiting the city. The leaders and their aides in the management of economic projects often visit Cruzeiro do Sul and Rio Branco to manage legal and monetary aspects of the projects and to represent the Yawanawa in political bodies. There are also some members, and notably teachers, undertaking university degrees in Cruzeiro do Sul to complement their training. Yet the more common displacements to the towns are short trips to purchase industrialized goods, reclaim state benefits or seek medical treatment. These stays tend to be as short as possible, due to the difficulties of maintaining themselves in urban settings with limited money. My experience in these towns with Yawanawa visitors revealed the degree of discomfort with an economic system in which access to all resources depend on money. On the other side, however, the Yawanawa appreciate seeing the towns and experiencing their customs and leisure activities. They equally enjoy the experiences of consumption and proudly display objects purchased during their stays, as further discussed below.

\section{Map 1: Location of the Gregorio River Indigenous Land in the State of Acre}

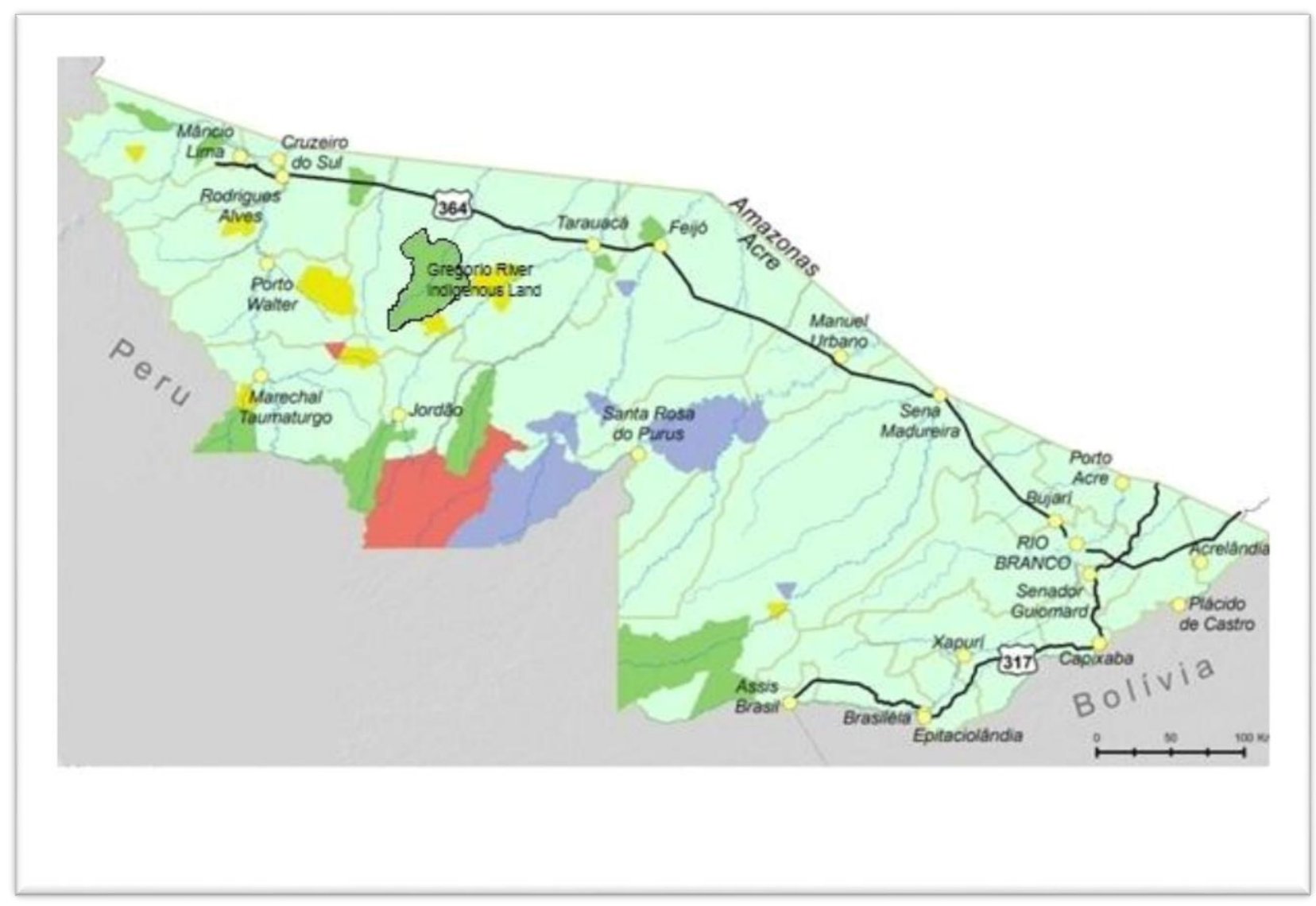

Source: Secretary of Environment, Government of Acre.

Note: colored areas correspond to indigenous lands in different stages of recognition and demarcation. 
The population estimates are very imprecise, ranging from 550 (National Health Foundation, 2004) to 900 (estimate from Biraci Yawanawa, one of the leaders, 2011). Even considering the contingent of Yawanawa living in cities, it is unlikely that the population surpasses 700 members, half of which are children, attesting the demographic boom of the last decade. The population is divided in seven villages located on the river shores, most of which correspond to old rubber tapping settlements. From the North to the South, they are: Matrinchã, Amparo, Sete Estrelas (Seven Stars), Tibúcio, Escondido, Mutum and Nova Esperança (New Hope). The latter is the southernmost and concentrates half of the entire population, followed in density by Mutum and Amparo. The other villages were opened or occupied by the Yawanawa in the last two decades by the sons of the old chief Antonio Luiz Yawanawa. Their decision to move with their extended families was motivated by their desire to retain some independence after the demise of the rubber production and in the new times of economic projects, which these patriarchs voice as being a search for tranquility, and to facilitate the access to forest resources upon which their subsistence depends, notably game and fish. Map 2 below shows the location of four of those villages, which already existed when their territorial limits were revised in 2004 (Amparo was established later and Sete Estrelas was not inhabited by the Yawanawa).

These patterns of occupation of the land and residence are the result of the social, political and economic aspects of their history, including contact with outsiders. Their involvement in the productive activities for the market, namely the production of rubber, led to a series of transformations. The community first gathered around a leader, the intermediary with the buyers of their production, in a village located just across the river from the headquarters of the rubber estate. During the period of rubber tapping, some men would spend periods in scattered settlements, exploring the rubber in trails and returning to the community village for collective events. The new economic activities and occupation of land led to the constitution of houses comprising nuclear families as relatively independent economic units. In other words, they moved from a pattern of a temporary collective house, named in the region malocas, where several families would live while game and fish was easily available and then move to a new collective settlement, to a pattern of permanent housing that accommodates a nuclear family comprising two or three generations with the daughters, sonsin-law and grandchildren of a man. These houses, in a model that is widespread in the region among natives and non-native settlers (Almeida 1992), also constitute a fund of shared resources and obligations, a locus of dense solidarity. An expression of the already discussed matrimonial alliances is that effective affines are equated to the category of co-residents, and 
share a common fund, with their obligations and resources, even when they do not share the same residence. Given the tradition of uxorilocality, sons-in-law lived with the relatives of their wives. Currently, they prefer to build their own houses, but remain close to the relatives of their wives and continue to be members of the house and its fund. They share gardens, take part in joint activities and share obligations, in a flow of things and persons described below. These houses are built after the Amazonian model that was developed by the new inhabitants in the region, over pilotis to protect the residents from animals and overflows of water, using wood for the floor and walls, and palm straw or modern pre-fabricated roof tiles for the ceiling.

This dispersion in villages and domestic units does not indicate significant social partitions. Their cultural practices, kinship bonds and subordination to the representational monopoly of the chief keeps them united. There is a dense network of relationships among the villages within and beyond kinship bonds, further analyzed below, which connects the villages and is not deterred even by the competition between leaders and their organizations. The pre-existing, notably family relations animate an intense flux of people among the villages, with frequent visits and gifts. In fact, the family nucleus of Antonio Luiz, the first chief to stabilize the relations with the white men in the region and to enlist the Yawanawa into the rubber tapping business, is the matrix of the entire community and an essential force that has kept the Yawanawa, as well as outside members incorporated by marriage, united after the contact with rubber patrons. Through several marriages, one of which with a woman from the neighboring Katukina people, Antonio Luiz extended his influence to encompass the Yawanawa and beyond. Currently, all members can trace their ancestry back to Antonio Luiz and are, therefore, relatives. Furthermore, the prevailing system of restricted matrimonial exchange promotes the reproduction of kinship alliances, which keep a flow of exchange of persons and things. Game and some industrialized goods, for example, are given to closer relatives in other villages. This flux is more intense from the smaller villages to Nova Esperança and Mutum, the main sites of the social, cultural and economic life of the community and the sites of schools. 
Map 2: Gregorio River Indigenous Land - borders and villages (as of 2004)

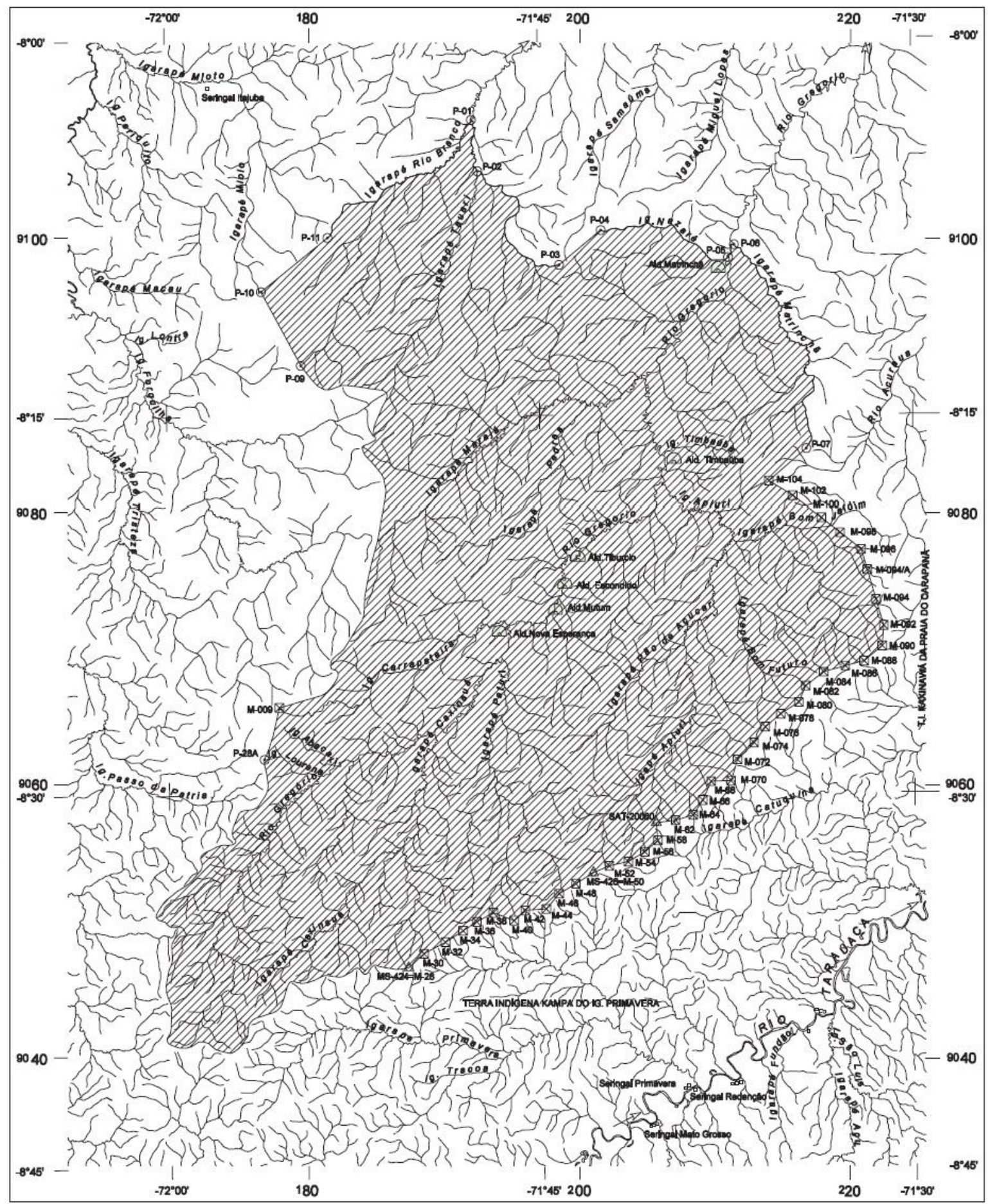

Scale: 1:400.000

Source: Diário Oficial da União, 3rd of April, 2006, Seção 1, p. 38

Nova Esperança (New Hope) is also the largest village, with at least half of the Yawanawa population. It spreads over the two shores of the river, with most of the houses located on the top of an eroded cliff on the west margin. The right margin has scattered houses, some upstream, many of which belong to elders. Arriving at the narrow sand port at 
the west margin, the way to the houses requires climbing the cliff. On the top of it, a row of houses leads to the center of the social life, a yard, surrounded by houses and the school. This yard, or terreiro, is a focal point of community life and used to host the games, dances, rituals and football matches. The houses around it belong mostly to prominent men who are loyal to the village's chief. His house and dining hall, a construction that functions as public section of his house, where meals are served and hosts received, also face the yard. The radial distribution of houses is, in fact, a crude representation of the political and social bonds within Nova Esperança and the degree of participation of the houses in the communal life. In general, those who live around the social center of the village display a stronger loyalty and proximity to the leader and his projects, as well as denser exchange amongst houses, whereas those who prefer to live further away display a weaker allegiance, oppose the ways projects are managed or desire to remain more independent. Those who oppose the rituals and the use of the hallucinogenic uni avoid the yard, as do those who are at odds with Chief Biraci, who is the leader of the village and an organization that represents Nova Esperança and Amparo. Yet this correspondence between the spatial distribution of houses and the power structure is not absolute. The increase of the population and the expansion of the village have led younger men wanting to build their own houses, some of which are very close to the leader, to do it away from the yard. Some people also prefer to live closer to the small tributary to seek more tranquility.

Nova Esperança has a valley that divides the village between the Gregorio and its small tributary, the Igarape Carrapateiro. This valley was used to cultivate bixa trees. The cultivation of urucum was, thus, concentrated in this area. After Biraci decided to abandon the activity, a move explained in detail in chapter 4 , the trees were abandoned and many died. Due to its topography, the area was chosen to build two fish ponds, part of a state project to improve the diet of indigenous populations and to reduce the pressures posed by large villages, such as Nova Esperança, on the surrounding environment. Right across the valley, there were two other constructions associated with the production of urucum: a health clinic, built with funds obtained from Aveda, which was never operational due to the absence of medical professionals, and a facility with machines to extract annatto seeds, an oven and a dry storage area. The first was destroyed and, in a gesture that symbolizes the new times and projects, its wood was employed to build a big shohu, a circular construction with a conic roof, inspired by the ancient communal houses of their myths, where rituals are now performed, in an area separated from the houses. The latter was transformed by a family into a house. Currently, thus, there are no more traces in New Hope of their involvement with the 
production of urucum. And yet this activity was central to the development of the village, which was named Nova Esperança, New Hope, to refer to what was, in their own understanding, a new moment in the 1990s. It was an expression of their expectations surrounding new economic projects in general, and the production of urucum, in particular, after a difficult period of failed attempts to replace the income provided by rubber. The village, half an hour by boat downstream from the old Caxinaua settlement, was opened by Chief Raimundo Luiz Tuinkuru, who was seeking tranquility for him and close relatives. Later, when the old Caxinaua settlement was deemed unsuitable for the new project and the population that it would require, this location was chosen, with the approval of the Chief. The leaders thought that the Caxinaua was too old and its position close to the river sources posed serious challenges for the transportation of heavier goods. After decades of occupation, fish and game were scarce and the area was associated with many health threats, epidemics that resulted from the contact of indigenous and non-indigenous populations in the area. Raimundo Luiz' Jabuti village had a big garden that was considered perfect for the production of bixa trees. The old Caxinaua settlement was recently transformed into the sacred village, totally devoted to the formation of new healers and the performance of rituals by Biraci's group. The area includes the burial grounds of the old leaders, a garden of muka and the vine employed to produce $u n i$, some houses where new initiations take place and a house where rituals with visitors are practiced.

Despite the interruption of the activities with urucum in Nova Esperança, the village still concentrates much of the physical structure of the indigenous land. These facilities were partially constructed during the phase in which the project was fully developed in that village and it was the site of residence of most of the Yawanawa, and are partially the result of federal and state policies. Nova Esperança is the headquarters of one of the two legal organizations that represent the population in external economic transactions and political discussions, the OAEYRG - Organização dos Agricultores e Extrativistas do Rio Gregório (Organization of the Peasants and Extractive Workers of the Gregorio River) - and its co-op (COOPYAWA - Cooperativa Agroextrativista Yawanawa), that was being restructured during 2011/12. The village contains a house, built on the regional style, which is used to store industrialized goods, whenever they are available, and it is employed to host external workers involved in state activities, such as the construction of the fish ponds and a small electrical network providing energy to the houses. It is also the site of the largest and better structured school of the land, with four classrooms, financed by the state as part of a program of differentiated education, recognizing socio-cultural and linguistic diversity and aiming at 
providing education that includes not only the content taught at state schools, but also specific elements of Yawanawa language and culture, researched by local teachers ${ }^{36}$. One of the classrooms contains computers with satellite-based internet access since 2011, as a result of a federal program of digital inclusion. The village has also a health agent, a native trained with basic care skills, since 2012, a diesel-operated generator that provides limited electricity during some hours of the night to the houses and, since 2013, a new facility for the production of crafts by women, as part of state policies to empower women in Acre. The population of Nova Esperança is associated to COOPYAWA and engages, with different degrees of commitment, in the productive activities organized by it. Together with the inhabitants of Amparo, they live under the leadership of Biraci Brasil, as better described in the next session, who intermediates between them and external partners, with the aid of loyal men and two of his sons.

Mutum, the next village downstream from Nova Esperança, has similar services. The settlement, at the mouth of a small river with the same name, was created in 1994 from the same desire of Raimundo Luiz Tuinkuru, old chief, to seek tranquility for him and close relatives, after Jabuti was transformed into Nova Esperança and attracted most of the Yawanawa. Mutum is still the village of his close family, hosting the houses of Raimundo Luiz' offspring, some loyal men and their gardens. It is the headquarters of the second legal association kept by the Yawanawa, ASCY - Associação Sociocultural Yawanawa (Yawanawa Sociocultural Association) - created in the mid-2000s by one of the sons of Raimundo Luiz, Joaquim Tashka Yawanawa and some of his siblings to seek partners and state benefits. Mutum is the main site of cultivation of bixa trees, spread around the houses, and it is also the location of a newly created Yawanawa Ceremonial Center of Healing and Therapy (Centro Ceremonial Yawanawa de Terapias e Cura), a small set of houses built to host visitors during presentations of rituals and cultural practices. ASCY has claimed and received facilities comparable to Nova Esperança. It has a shohu beneath the shores of the Gregorio River, also used during my visit to extract the seeds of the bixa fruits and as dry storage for urucum. Besides this shohu, there is a small house with computers and internet used as an office for ASCY. Other houses surround the shohu, with gardens and fruit trees separating them. A classroom operates for the children of the village and in the end of 2011 the state of Acre also built a fish pond in the location. Some houses of Mutum and in other

\footnotetext{
${ }^{36}$ This is not the place, of course, to discuss the achievements, challenges and shortcomings of these policies. Specific aspects of educational activities will be discussed in relation to the distribution of state positions among the Yawanawa and to the project of recreation of culture.
} 
smaller villages already existing in the mid-1990s have solar powers and batteries, donated within the framework of the partnership with Aveda.

All other villages consist of small clusters of houses with surrounding gardens on the shores of the river and are located normally close to a small tributary with cleaner waters. Most of them correspond to the locations of old colocações, clusters of houses around rubber trails. Amparo is the third largest village. Associated to COOPYAWA, it has strong links with Nova Esperança, and not least because the elders are Alderico and Olívia, foster parents of Chief Biraci. In addition to more than ten houses and their gardens, there is a classroom in the village. The village leader is Inácio and Antonio Carioca, an eminent member of COOPYAWA during the period in which this organization was responsible for the production of annatto, lives on the opposite shore of the river.

Escondido, Tibúcio, Matrinchã and Sete Estrelas are villages inhabited by brothers or brothers-in-law of Raimundo Luiz and their close relatives. They are all associated with ASCY, engaging in their economic projects and, notably, since 2008, they also cultivate bixa trees in smaller quantities. As such, they have stronger links to Mutum, strengthened by the strong family bond between brothers and descendants of Raimundo Luiz. The first two are the oldest settlements. Escondido is a very small village, established by Luiz Brasil da Silva, a brother of Raimundo Luiz and is currently home to a single family, extended according to the uxorilocality custom. Tibúcio was established by João Carneiro, a brother-in-law of Raimundo Luiz who married a daughter of the previous chief, Antonio Luiz, in a location that used to be a Katukina village. It contains approximately ten houses.

Sete Estrelas was equally a Katukina settlement and is, in fact, one of the oldest villages in the area, having seen different residents over time. It used to include an warehouse of a rubber estate (seringal) from which it received its name. After workers and representatives of the estate left the area, religious missionaries used their facilities and built a landing strip, the only one in the territory. Some Katukina, rubber tappers or not, gathered in this area. The missionaries paid for work in their gardens and for game. They also offered religious education and health services in order to attract the population to their masses. The location was, thus, equally visited by some Yawanawa, especially in cases of illnesses. Besides providing basic care and medicines, the missionaries are also remembered in the area for providing emergency medical rescue using small aircrafts. In the 1990s, following the decision of some Yawanawa to expel missionaries from the land due to their disapproval of native spiritual practices, the Katukina living in the area decided to move to another Katukina 
territory (Brasil/FUNAI 2006). The Katukina were more dependent on the missionaries for income and assistance. According to Lima (1994), some long-standing conflicts with the Yawanawa and resentments for past aggressions also contributed to the decision. After both missionaries and Katukina left the area, Luiz Brasil da Silva moved with his family, assuming the aim of keeping the landing strip clear (LBS).

Matrinchã, located close to the northern borders of the indigenous territory, was established in the context of the claims of revision of the territorial limits, in the mid-2000s. The village was established as a vigilance post and received a radio. The Yawanawa leaders suggested to Francisco Luiz Yawanawa (Chicó), another brother of Raimundo Luiz, who was looking for a location to reside with his family, to settle in that strategic position (FL).

As previously said, there is an intense flux of persons among the villages, animated by kinship relations. As a consequence of dues, goods and money also circulate, as described below. In addition to occasional visits, members move seeking opportunities of income. Some go to work, especially in Nova Esperança and Mutum, in periods in which extra hands are necessary, such as harvests and the cultural festivals. Others, however, move permanently with their families. This sort of permanent movement is related to changing allegiances to leaders and the desire to engage in activities that are undertaken by different villages and managed by the other representation organization. They are also an expression of the difficulties that a community united by the symbol of a gregarious and cooperative animal and cognatic links faces as some feuds arose between leadership contestants and their allies amidst their engagement in large projects for market exchange. Yet in order to understand these feuds, their causes and actual significance, it is necessary to briefly describe the main characters that comprise the dramatis personae at one side of the transactions through which cultural representations of the Yawanawa are exchanged.

\subsection{Dramatis Personae}

I have to this point provided a general description of social ontologies and the spatial organization of the Yawanawa. But the characters, their forms of life within their territory and social organization which represent the pragmatics of the described ontologies remain to be presented. Before moving into details of the social organization and the political and cultural 
economies amongst the Yawanawa, which is the topic of the next chapter, a word about the main characters is in order. It would be impossible here to offer a detailed portrait of all the individuals within the community and their interactional dynamics. Sketching the main characters, however, is relevant to understand the concrete ways in which the intentions and personal projects of powerful members of the community inform particular uses of the market and the politics of value that animate the diversions of certain cultural representations to the commodity state. In other words, it sheds light in the ways they conduct business with outsiders. Additionally, this sketch sheds light on how chasms emerge, their relation to the conduct of business, their forms of expression and actual scope, as well as forms of settlement. The nature and practice of political power amongst the Yawanawa and the specific careers of the leaders of the last century are explored as part of the broader political economy in the next chapter. Here, I just offer a sketch of the characters and the games of power.

\subsubsection{Peace in the feud}

As previously indicated, all Yawanawa families can trace their ancestry back to a common founding ancestor, christened by the owner of the rubber estate as Antonio Luiz. This man was recognized as a leader due to his abilities to intermediate with the white, having stabilized the contact and organized the Yawanawa to perform activities of rubber tapping and support to the tappers and foremen in the region, such as hunting and cultivating food crops. During the first decades of the involvement in the rubber extraction, Antonio Luiz had a strong influence in the Yawanawa and neighboring populations. Men from other ethnic groups came to work for him, knowing about his ability to negotiate and the respect from the rubber patron. Marrying several wives, he extended his influence in the community and beyond. Antonio Luiz took a Katukina woman, Angelica, as his second wife. She was the most prestigious of them, but the fact that she was already married with children heightened the skirmishes with the Katukina (Lima 1994; Naveira 1999). In fact, the Yawanawa relations with the Katukina in the past century oscillated between respect and subordination and distrust and animosity.

Antonio Luiz is currently remembered also a wise man, with a vast knowledge about the healing system and spiritual practices in general. According to Naveira (1999), he is cited as a source of such knowledge to the still living full healers, the xinayas. In this sense his is widely regarded by the community as someone who kept the population united and preserved its 
traditions. His family nucleus, comprising his direct descendants, notably his sons and grandsons, became a prominent lineage claiming special benefits and rights. He was replaced upon decease by his older son, Raimundo Luiz, who ruled the Yawanawa during a particularly difficult period in the area, amidst national initiatives to turn the area into more productive land and increased control by the rubber estate over the use of forest resources. According to older generations, his leadership was not unchallenged. Many confided to me, confirming the account of Naveira (1999) that he neither commanded the same power than his father, nor was always respected by his brothers, some of whom remained independent. There are a number of reasons raised for this, from contentious allegations involving his spiritual abilities, to the difficulties to maintain good relations with the rubber estate that acquired the land, which in turn led to a loss of his representational monopoly. These weaknesses indicate fundamental elements of power that are discussed in the next chapter. In any case, this succession of leaders of the same lineage created expectations of a dynastic power, which is still invoked by Raimundo Luiz' offspring. This dynastic group has claims to material and symbolic resources. In her account of the challenges she encountered as a firm representative sent to the Gregorio River to oversee the urucum project, May Waddington (Ribeiro 2005) emphasizes that the nuclear family of Raimundo Luiz always demanded privileged access to resources simply due to their position and Mutum was a necessary stop of shipments of provisions. These claims, justified in dynastic terms, partially explain disputes existing amongst the Yawanawa.

However, it is the fact that the power escaped from this family nucleus in the 1990s, which turned this family alignment into a chasm. In the 1980s, Raimundo Luiz' first-born, Raimundo Sales Luiz Yawanawa, and one of his cousins, Biraci Brasil Yawanawa, went to Rio Branco in order to obtain formal education, which would enable them to better negotiate with land holders and to claim rights (RSL, BB). Biraci Brasil was more successful in his involvement with non-governmental and governmental Indigenist politics and later with market partners, and was acclaimed the new leader, with the assent of Raimundo Luiz. As Sales failed to show a prowess in intermediating worlds and procuring resources, Biraci became a prominent representative of the Indigenous populations in Brazil and the Americas, articulating movements with other famous Indigenous leaders and trying a political career. Upon his electoral failure, the fracture of the popular movements of the 1980s that sought to block the federal state policies of rural development that threatened the forest and its population, Biraci decided to return to his community, in what he presented as a call to solve the stagnation, dispersion and lack of perspectives that followed the recognition of land rights 
and the expulsion of land holders (BB). The end of subsidies to rubber represented the loss of a source of goods that were, at that point, regarded as absolute necessities and prompted many members to look for employment in farms or towns of the region.

Biraci crystallized his preeminent position by securing resources associated with a new economic partnership for his people. Returning from his participation at the United Nations Conference on the Environment and Development (UNCED), held in 1992 in Rio de Janeiro, with the idea of engaging the Yawanawa in the production of annatto, together with other two native species, andiroba (Carapa Guianensis) and pupunha (Bactris Gasipaes), he managed to reunite a disperse community. Offering the village a fresh economic start after the stagnation of the rubber economy, and an opportunity for many Yawanawa who had gone to the towns or farms to return and still have access to essential goods, he was acclaimed leader, a position confirmed by the old Raimundo Luiz, who then retired to his private life.

The new position of Biraci was also challenged. The lineage of Raimundo Luiz reclaimed access to special resources and challenged decisions taken by Biraci Brasil (Ribeiro 2005). Raimundo Sales, in especial, claimed to be the chosen leader, betrayed by his close friend, Biraci. However, he failed to prove his abilities to bridge the worlds of the village and its traditions, on the one side, and the world of the monetary market economy, on the other. His abilities were allegedly questioned by his own father and he equally recognizes his failures, justifying them in terms of his lack of formal training to deal with the complexities of the market and politics. Sales remained close to his dynastic group, while living in Rio Branco and later Tarauacá, where he built a career at the National Indigenist Body, FUNAI (Fundação Nacional do Índio) (RSL). Another source of contention came from many of the brothers of Raimundo Luiz, who having converted to Evangelical Protestantism, did not agree with the decision of Biraci and his loyal men to expel the missionaries, arguing that they also provided important health services to the community (FY, JCJ, JCF, ALC and LBS). The paths followed in terms of recovery and reinvention of cultural practices have also been challenged, consisting in the main tension involving the commodification of cultural representations and explored below.

Biraci attempted to strengthen his links with Raimundo Luiz marrying his daughters, all of which were $a w i$, i.e., preferential partners ${ }^{37}$. Some of these unions did not endure, but his marriage with Putanny Yawanawa did. Nonetheless, the new economic project of the Yawanawa, the large influx of resources and different expectations regarding the distribution

\footnotetext{
${ }^{37}$ Raimundo Luiz was Biraci's mother brother.
} 
of benefits divided the community and heightened the opposition between the family group of Raimundo Luiz and the group of Biraci Brasil. The details of these tensions are analyzed further below, but at this point it is important to note at this point that the challenges and tensions that emerged in the community in connection to the production of annatto provided an avenue of expression of leadership contests associated to attempts of controlling the circulation of objects and resources from and to the community. At this time, Raimundo's family had a new representative challenging Biraci's control of the flow of resources: Joaquim Yawanawa, a young son or Raimundo Luiz. Joaquim had left the village at a very early stage, to seek health treatment and remained in Rio Branco, where he was educated by missionaries. Joaquim had an intense contact with non-governmental organizations promoting Indigenous rights, like his cousin Biraci, and a better formal education than any other member. At the dawn of the personal computer era in Brazil, Joaquim learnt computing and basic video editing skills, which he later used to promote the image of his community. As part of the new project of production of annatto, Biraci negotiated with the firm the award of two scholarships to provide training in English to community members that would facilitate the negotiation. Joaquim was one of the members awarded. He used this opportunity not only to learn English, but also to become involved in groups promoting Indigenous rights in the United States and International organizations. Joaquim was exposed to institutions and groups that had undertaken projects to revive cultural expressions and were dexterous managers of economic and cultural projects. Returning to Brazil, Joaquim naturally became involved in the intermediation between the Yawanawa and the firm, helping Biraci to manage the project outside the village.

At this point, however, there were a number of reasons for tension creating a crisis in the community. Fundamentally, the interest of the Yawanawa in the production started to fade as expectations of benefits were frustrated amidst decreasing return of resources. May Waddington, hired by Aveda to represent the firm and act as an intermediary, equally became a target of criticisms and suspicion (MSF, JY and ALC). In face of the difficulties to siphon the efforts of the community, repeated questioning about the resources and conflicts with Joaquim, Biraci decided to abandon the project. The production declined and many trees were attacked by ants and weed (Lyons 2011). Engaged in the initiation to become a healer, once more presented as a call (BBY), Biraci withdrew and managed to persuade loyal families to abandon the project. Realizing the increased interest in cultural performances associated with their spiritual and healing system, Biraci embarked in a new project to re-invent traditional practices and invited the community to make cultural revival their main focus (JY, MLY and 
BBY). Joaquim, in turn, was committed to continue the partnership, supported by those who considered it advantageous.

This feud led, in 2008, to a division of the population between those who decided to follow Joaquim and continue the production of annatto and those who remained loyal to Biraci and abandoned the project. The production halted in Nova Esperança. Joaquim, close family members and allies created a new association with legal personality. The new association, named Associação Sociocultural Yawanawa (Sociocultural Yawanawa Association - ASCY) took over the partnership and signed a new contract for the provision of annatto and images to Aveda. Biraci Brasil and his allies continued part of the organization created at the beginning of the project, COOPYAWA. The Yawanawa who opted for allegiance to Joaquim and ASCY left Nova Esperança and settled in any of the five villages associated to the new organization (Matrinchã, Sete Estrelas, Tibúcio, Escondido and Mutum). Amparo, the village of Biraci's foster parents, and Nova Esperança remained part of COOPYAWA and engaged in its activities. The fields of annatto trees were abandoned and new trees were cultivated by ASCY initially only at Mutum and later in the other associated villages (BB, JY, Lyons 2011).

Considering the social ontology that emphasizes the importance of union and cooperation, the formation of two organizations was particularly troublesome for many Yawanawa. These conflicts could have led to an actual fracture and call into question the unity and the sociological metaphor that describes it. However, I did not verify any expressive partition affecting the daily sociability of the community. There is a competition between leaders and loyal men for resources and exchange partners. And the population is be mostly divided in their engagement and the fruition of the resources that come with these activities, but some also circulate between groups to obtain these resources or due to kinship and social relations.

These associations are the legal and institutional expression, in a saturated form, of a conflict that has developed over a decade and which, in turn, indicates a long-term competition for power. Despite their existence and the resentment between leaders and notable members, it does not seem adequate to say that the Yawanawa are divided in two. Previous bonds, notably based on kinship, unite the Yawanawa despite the continuing opposition between the two groups. There are overarching social relations that maintain members of villages associated to different organizations in constant contact and exchange. They are, after all, relatives and the conflicts did not seem to weaken the obligations 
associated to kinship. During my stay, I observed situation in which game, fruits from their gardens, industrialized food, fuel, medicines and other goods circulated between members and villages that are associated to different organizations. There are members of Raimundo Luiz' close family who live in Nova Esperança and keep strong links with the population of Mutum. Since most of the population has limited information and control over the directions of the large economic projects undertaken by the organizations, they also remain more or less indifferent to the quarrels, mostly confined to the leaders and loyal people. Some Yawanawa also circulate between villages seeking income opportunities, changing temporary allegiances.

Far from replacing the native ideology that depicts the Yawanawa as a cohesive and cooperative group, the conflicts and ensuing competitive setting are interpreted and judged according to the queixada ritornello. The conflicts and existence of a structure of dual representation are not current or easy topics for the Yawanawa. Mainly a chasm of family origins, they are reluctant to discuss these issues and display sadness when they do. The Yawanawa do not like to present themselves as a fractured society and only discuss the quarrels amongst members after insistence, preferably in small settings and not without some discomfort. In order to preserve the image of unity and harmony amongst the white-lipped peccaries, many of the members have chosen the external intermediary of the annatto project, May Waddington, to blame for the conflicts. The metaphor and its ideological consequences are frequently invoked to call for cooperation.

In practical terms, it seems more adequate to say that the Yawanawa have now two organizations to dispute resources offered by private partners and political entities. The feud eventually led to a competitive peaceful setting. They claim similar benefits from the state and are often trying to replicate activities to generate income undertaken by the other. Both speak for the Yawanawa and are forced to cooperate in some instances and tolerate initiatives of the other organization. Both sides are aware of this. Joaquim, for example, told me they had overcome internal disputes and now each organization follows its own path. The website created to promote and inform prospective visitors about the Yawa Festival 2013, included in the text describing the Yawanawa a brief note, reassuring readers that there is no division: "Currently there is another organization, the Sociocultural Yawanawa Association, managed by Joaquim Tashka. However, this does not represent a division of the families. Both organizations, despite the different foci of their actions, work for the harmony and material, cultural and spiritual harmony of our People" 38 . Biraci Junior goes farther. According to him,

\footnotetext{
${ }^{38}$ Available on: http://xiifestivalyawa.blogspot.de/ Retrieved on 15.06.2013.
} 
"this only strengthens the Indigenous community. Since we have two organizations, we can work with different projects" (BBJ).

The situation here is somehow evocative of the classical interpretations of Gluckman (1955) based on Evans-Pritchard observations of the feuds amongst the Nuer and invites us to ponder on how the presentation of a group in the market and the promotion of external alliances lead to allegiances between conflicting groups, or at least compromises. Gluckman asserts that "men [sic] quarrel in terms of certain of their customary allegiances, but are restrained from violence through other conflicting allegiances [...]. The result is that conflicts in one set of relationships [...] lead to the re-establishment of social cohesion" (1955: 2). Some loyalties enforced by custom force conflicting parties to restrain. It is often the case that genealogical descent from distant common ancestors, he continues, justifies settlements achieved through rituals. Kinship acts as pressure to ritually settle conflicts. Amongst the Yawanawa, this is exactly the case. If on the one side, family factions are a cause of conflict, their common descent from Antonio Luiz and the resulting kinship bonds animate solidarity that bridges the division.

There are other customs that lead them to compromise. The notion of unity is enacted through ritual and invoked in face of external challenges. Politics and the market, the main sources of symbolic and material resources of the Yawanawa, also have their customs, which require them to act as a single entity. If on the one side the contest for resources in the market and politics gave rise to conflicts, on the other it is also a factor requiring the Yawanawa to present themselves as a singular body or, at least, to reach agreements. After all the object of attraction of external allies and resources is "culture", an expression of ethnicity. The element granting them special rights and policies, on the one side, and economic resources, on the other, their special legal condition and their brand, is this constructed notion of ethnicity with its common customs and knowledge. As previously said, otherwise a relational and fluid concept, collective identity is rigidified and sanctioned by law and policies (Urban/Sherzer 1991; Costa 2012). Mirrored in our own and defined in response to their recognition by official institutions as a different collective body sharing a common identity, the notion of ethnicity underlying what is put to display and exchange is by no means different than the one that underlies national identities. And as such, the representation of this collectivity, the very object of exchange, must project, just like nations do, a single totality, a community which does not tolerate the expression of fissures (Anderson 1991: 7). There are, of course, singularities, first to the display of communities considered "traditional", unexpected 
survivors of a project of single modernity (Sahlins 1999b), and then to the display of the Yawanawa ethnicity in particular. In general, the display of indigenous cultures must emphasize their difference from modernity-at-large, normally coupled with romantic views of a past lost in time or history. They must publically present themselves in agreement with an image as a traditional and harmonic community that has preserved their environment and customs. And, as Comaroff and Comaroff (2009: 12) assert, they must abandon all divisions and become one people, with one set of customs "withdrawn from time or history", which the Yawanawa have certainly realized, appending the expression "from time immemorial" to all their cultural practices. The Yawanawa narrative depicts a gregarious and cooperative group that has endured a century of occupation of their territory.

Again, just as the nationalism ideologies, this ideology has great efficacy within the community as well. Conflicts and divisions, in their own understanding, would harm their image. The Yawanawa believe that their respect by outsiders lies in their ability to maintain their unity and harmony as a community. As they compete for these allies, they are forced to reach agreements and reinforce this ideology. In fact, the activities performed by each organization are presented simply as activities of the Yawanawa, without reservations. They often mention the names of the involved villages and have recently included a brief note about the existence of another group promoting activities in written communication about their events, like the one quoted above. However, outsiders do not seem to pay attention. The visitors I met did not know that there were two organizations promoting activities.

The recurring theme of their mythical and historical unity, especially under external threats and opportunities, is also invoked by the leaders and their groups inwards to defuse different opinions on the paths of the community and frustrated claims of individual benefits. The plasticity allows employing the queixada ritornello as an ideological representation that emphasizes that the necessity to prioritize the needs of the collectivity and the relevance of unity over the pursuit of individual interests, represented by different and non-gregarious animals that resulted from the mythical creation. It works as an ideological justification for the importance of centralizing the resources and flow, as well as controlling what comes to the community. This discourse has a dimension of warning against the perils of individualism and uncontrolled flow of money inside the community. The strong shared representation of the Yawanawa community is, thus, equally useful to ensure cooperation with the leaders and promote collective efforts that are thought to strengthen the community. 
Despite these effects of their collective representation as a single, homogeneous community, it is important to resist functionalist tendencies to subsume their production of culture and the projection of their identity to a simple requirement of the market or special policies devised for Indigenous populations. For the production of culture and its reenactment is never purely an action of self-interest. As the means of making sense of the world, not least of the collective self, culture is more than simply ideological domination or hegemony, as in the World System Analysis Gramscian formulation (Wallerstein 1990), it is a symbolic scheme that effectively organizes and signifies all objects, interests, persons and the material processes that produce them (Sahlins 1976). Even interests, calculation and gains are subject to cultural interpretations.

Before moving to a description of the main characters behind the politics of value that animates the circulation of cultural representations, a last word on this dynamics of conflict and cooperation and its relationship with the competition for material resources is in order. This quest of leadership contestants for resources and its effects on the societal organization, explained in detail in the following chapter, seems to evoke multiple moral views of the market, and to be located in between moral assessments that are often thought to be contradictory, complicating normative conclusions on the commodification process: there is a suggestion of doux-commerce interpretations, as the customs of markets organize the conflict and help preventing open feuds (Hirschman 1986; Fourcade/Healy 2007), but also indications of the promotion of envy (Fourcade/Healy 2007: 14.7) and the erosion of social bonds (Hirschman 1986). This should serve as a first indication that the process of commodification analyzed here cannot fall under simplistic normative interpretations in any direction. Further evidence of the surprising drives and consequences of circulating cultural representations in the commodity state should occupy much of Part III. Now we return to the presentation of the characters in this process.

\subsubsection{The main characters and their organizations}

Despite not deterring a broad solidarity that maintains the Yawanawa united, the dual representation implies that there are two groups of actors competing for resources. These groups, comprising one of the leaders and their loyal followers, also correspond to the stakeholders in projects that involve the circulation of cultural representations of the Yawanawa intending monetary gain. They are the agents with voice in the controversies about 
meanings and values that underlie the circulation of images, rituals, practices and objects of the Yawanawa. They also concentrate the managerial agency, the control of activities and resources: they organize the production, direct rituals, deal with bureaucratic and legal requirements, and decide how the resources are employed. Both chiefs concentrate greatly the powers of negotiation, but they are aided in the internal management of activities by these loyal members. These Yawanawa are also those who hold public jobs in the villages, financed by the state but nominated by the leaders: teachers, health agents and forest agents. These positions grant their holders influence in important areas of the community life. The distribution of these positions is clearly a mechanism of creation of loyalty. Affiliated to the organizations are also the healers, from beginners to experts, fundamental in the performance of spiritual rituals which are an important source of allies and resources. The Yawanawa shamanism has branches that allows for specialization, as further discussed in relation to the careers (Gil 2001). There are also members who study traditions, legends, plants and rituals without becoming healers. In any case, only two members of the community are recognized as possessing the full power of cure, being able to manipulate the spirits through prayers. They are also the sources of all spiritual knowledge, as well as many myths and legends. Due to the power and respect they command, these elders do not limit their relations and actions to a single organization. A detailed list of these notable members is provided in the box 1 , below.

\section{Box 1: dramatis personae}

COOPYAWA, Biraci's organization, represents Nova Esperança and Amparo. The families that remained in Nova Esperança after the formation of ASCY retained some degree of loyalty to Biraci. Amparo, as previously said, is home to the extended family of the foster parents of Biraci, Alderico Pequeno and Olívia. His close aides, however, who share the administration of COOPYAWA are ${ }^{39}$ :

- Juraci Brasil (Juca), brother of Biraci, who recently returned to Nova Esperança, after decades living in the state of Amazonas, to become a village leader. He represents the organization in legal and bureaucratic procedures in the town and internally manages collective economic activities, organizing the work and transportation of production. The community sought state support to several activities, but as of 2012, the production of manioc flower was the main collective activity, together with the Yawa Festival.

- Putanny, Biraci's wife, one of the youngest daughters of Raimundo Luiz. Putanny undertook the diet and completed the initiation steps to become a healer under the guidance of Tatá. Together

\footnotetext{
${ }^{39}$ The list is not ordered by any particular criteria.
} 
with her sister Hushahu, she is one of the first female spiritual experts of the population. She is also a prolific producer of crafts, which she sells in venues where she is invited to perform. Putanny is particularly creative in the re-invention of rituals and crafts, incorporating new elements and performative elements inspired by her contact with new age groups.

- Aldaíso Vinnya, one of village teachers, researcher of the traditional knowledge of the Yawanawa. Asking the elders, Aldaíso was able to gather and register natural knowledge, as well as the history, traditions, myths and games practiced by the Yawanawa. He introduced this content at the local school, which is employed to reproduce such knowledge and induct the new generations into the Yawanawa folkways. He is considered a talented craftsman and one of the main champions of the project of the re-invention of culture.

- Valdemar Yawanawa Acrino, also a teacher at the school. Valdemar is a loyal jack to Biraci, which secured his job at the school. He undertook the initiation to become a healer and takes part in the performances of rituals within the village and in external tours.

- Manuel da Silva Filho (Tika), another teacher at the school and researcher of the Yawanawa myths and traditions. Manuel is very loyal to Biraci, but revealed some disagreements on the ways their spiritual system is being shared and performed with outsiders and the role that uni has taken in the community.

- Fernando Luis (Nani), Biraci's closest man, acted as a local leader and a foreman, organizing the work with annatto, the distribution of incoming goods and bridging demands between workers and the group who managed the project when in Nova Esperança. He still retains great respect, not least for being a son of Antonio Luiz. He undertook the initiation steps into the healing system together with Biraci and is now a healer. He is a school teacher and during the research was obtaining university training in Cruzeiro do Sul.

- Kuni, a healer that was able to forge his own alliances with outsiders interested in the spiritual practices. After initial contact during one of the Yawanawa Festival, Kuni associated with new age groups from the southern part of Brazil and is invited to perform at their venues.

- Manuel Pequeno (Kapakuru), also a teacher at the school, enthusiast of the culture, refined craftsman and producer of rapé. He is a very active participant in the rituals and is entirely devoted to the project of re-invention of culture, aligned to the hegemonic discourse about the past and the present. He rejects all other economic activities as foreign to the Yawanawa and considers that cultural performances and rituals their true essence.

- Manuel de Jesus Brasil (Naynawa), is the village's health agent. He has basic training to provide health care and perform tests. In addition, Naynawa applies the secretion of the phylomedusa frog known as kapum, which is employed to improve the stamina and alertness of hunters. He also applies it to visitors.

- João Inácio, leader of Amparo. He is involved in the management of economic projects. Like other members of Amparo, he has a particular view on the paths of the community. He shares the 
frustration of some members with the absence of income opportunities and the concentration of efforts on the re-invention of culture which, as further discussed, is a path that offers income opportunities only to a few.

- Antônio Carioca is loosely associated with Biraci and OAYERG. As João Inácio, he is involved in projects that generate income for the community, but remains critical of the public performances of rituals and the excessive focus on the re-invention of culture.

- Biraci Jr., one of Biraci's sons born in Rio Branco to a previous marriage of Biraci to a non-native, has moved to Nova Esperança and helps his father and Juraci in the management of collective economic endeavors. Trained to develop projects with public funds, he is helping to develop the village's crafts and an incipient production of wood furniture. He also deals with administrative tasks of the organization in towns. Biraci Jr. is an enthusiast of the life in the village and the Yawanawa culture. He is part of the group that was recently initiated into the formation to become healers, together with Valdemar. He also participates in the tours to perform spiritual performance outside the village.

- Shaneihu, the other of Biraci's sons born in Rio Branco, remains in the city. He is a singer, but participates actively in the external organization of the Yawa Festival, coordinating with a travel agency to arrange the fluvial transportation of tourists. He uses some of the Yawanawa chants to compose songs.

- Yawarani, one of the full-fledged healers and specialists in the cure and spiritual system, is vaguely associated with Biraci and is responsible for new initiations of members that are loyal to Biraci. An elder, he is widely respected and has also travelled to perform rituals and cures in new age urban venues and other partners of the organization.

ASCY, in turn, represents the other five villages (Mutum, Escondido, Tibúcio, Sete Estrelas and Matrinchã) and is identified with the family nucleus of Raimundo Luiz and most of his brothers, who are the heads of the smaller villages. Despite respected and sometimes consulted, these elders do not have a strong voice in the direction of economic projects and are critical of some developments. The main aides of Joaquim are almost all his siblings:

- Mariazinha Luiza Yawanawa (Naywany), Joaquim's older sister, a health agent and the village leader at Mutum. Mariazinha has a strong dynastic position and has been one of the main challengers of Biraci's power. Mariazinha is a loyal follower of Joaquim and, Christian as her father, mildly supports initiatives to re-create the cultural practices. She is a strong supporter of the partner with Aveda for the production of urucum.

- José Martim organizes the works for the production of annatto in Mutum. He has criticisms on the ways the resources are managed and distributed. 
- Katia Luiza (Hushahu), another of Joaquim's sisters is a healer, having been one of the first women to undertake the initiation. In fact, she was the first to seek the elders to obtain the knowledge, in which she was followed by Putanny. She is also an artist and uses her visions to produce new patterns used for body paintings (kene) and crafts. Recently, she started to paint on canvas. She attracts some visitors interested in the rituals and is active at the Yawanawa Ceremonial Center of Healing and Therapy, the form through which ASCY intends to display and share spiritual practices.

- Paulo (Matsini), Joaquim's brother, is also a healer. He has toured to cities and received visitors.

- Luzia (Waxy), Joaquim's sister, is divided in her allegiance between organizations. She used to help her sister Putanny in Nova Esperança and, simultaneously, is a legal member of ASCY, showing how kinship binds both groups. Upon the failed attempts of her son to undertake the initiation into the spiritual and healing system with Biraci's group, she moved with him to Mutum, where they both integrated the group of young apprentices.

- Raimundo Sales, the oldest brother of Joaquim, failed to secure the leadership position. A resident of Tarauacá and an ex-civil servant at FUNAI, Sales is now an external advisor to the organization. Christian, he is critical of the spiritual practices, especially involving allies from urban cults. Defending his position as the natural candidate to leadership, Sales also questions some attitudes and decisions of Joaquim and ASCY, although related to them.

- Tatá is, together with Yawarani, one of the full-fledged healers. He teaches the new generation of apprentices in Mutum and also performs rituals for visitors.

The fact that these main characters, more than the community as a whole, are pivotal to understand the circulation of cultural representations and, more generally, the political and cultural economies of the Yawanawa, is significant. Leaders and their loyal followers, together with the healers command significant respect and are those who truly control the directions of economic projects with outside partners. The involvement of the general population with the management of these projects is much reduced. Negotiations take place outside the village, involving leaders and close aides, and the management of resources is centered around the same characters. An expression of this exclusiveness in the direction of economic activities and their resources is an exclusiveness of the speech about them. It is not trivial that when I revealed the focus of my research at many houses, I would hear from the heads that they could not help me and did not possess any information about the conduction of business, contracts and the generation of income. They would normally refer me to the leaders and these members who help them to conduct business in the villages and in the towns. Their experience these economic activities merely as producers and performers of 
"culture". In the latter case, their actions are understood rather as a reenactment and representation of the collective self.

A very different situation involves the main object of economic exchange with outsiders, "culture". Traditions, rituals, songs, games and cultural practices in general are a popular topic subject to heated debate. Everyone has something to say about the initiatives to recreate traditions and to perform them to outsiders. The main point of contention amongst the Yawanawa and the circulation of their cultural representations involves the paths of "culture", the importance it gained, the forms of promoting it and sharing it with outsiders.

The views on the initiatives to revive and recreate cultural practices may roughly be divided in three. There is a group that has recently transformed the reinvention of cultural practices and traditions, the recovery of legends, stories, crafts and artifacts employed by the old generations into the main focus of their existence. Some of them say the most important challenge for the Yawanawa currently is to learn how to live like authentic Yawanawa, as they used to do in the past. They show a heightened concern that with the bereavement of the elders, repository of traditions they cannot afford losing. They endorse the efforts of what they see as cultural recovery and strengthening, a position defended by most of Biraci's aides, as well as by Joaquim and the healers Katia and Paulo. They realize the worth of culture and are prone to perform rituals to outsiders, even if revealing different views on how this should be done. These members, actively involved in the activities of cultural research, reproduction and performance, comprise a group that can be called the romantics, for their similarity to the group of European artists and intellectuals that, in the nineteenth century, embarked in a project of production of symbols of their national collective identity. They often display a limited interest in productive activities for external exchange. Most youngsters can be found in this group, as the performance of rituals became a socially valuable and profitable career. This group is not homogenous, since their members espouse different views of how to share spiritual practices with others and the extent to which this should be the focus of their lives. Their positions within the community obviously matter: they are teachers at the schools, initiated healers and health agents, besides youngsters aiming at the shamanic career. These positions are understood as relevant for the undertaking, but their salaries and income opportunities, in the case of healers, also create the possibility, for those members, to refute other activities that would bring them income. In fact, since this project corresponds to the vision of Biraci and, to a minor extent, Joaquim, the groups of each village - they are concentrated in Nova Esperança and Mutum - also correspond to the close aides, the loyal followers. In these positions they are expected not only to show loyalty, but also to use them 
to the benefit of the project. As explained in the next chapter, the school is an important space to promote culture to the new generations and the very idea of the centrality of their traditions to their survival.

A second position, held by mainly the older brothers and sons of Raimundo Luiz, reflect Christian beliefs they acquired through missionaries. They assert that the spiritual rituals are dangerous, should not be practiced or displayed to outsiders. A third and final position can be found amongst those members, notably residents of Amparo, José Martim and some marginalized families of Nova Esperança, which criticize the excessive focus on cultural practices that bring income only to a few who have access and interest in the associated knowledge. These members would prefer the development of other income opportunities. More distant to the centres of power, these members have little voice. They do voice their disagreement or, more precisely, different views about meanings and roles of cultural practices, but do not interfere in the actions of the core group devoted to the cultural reinvention.

In general, however, the characters have all strong opinions on the new moment of the re-invention of culture and revival of rituals. These different views are all represented in the tensions underlying the diversion of cultural rituals and symbols to the commodity state, even in attenuated forms and with native forms of justification, as further explored below. They represent the parties in the politics of value involving cultural representations, but also indicate different expectations about their engagement in economic projects and the different resources they bring.

This chapter provided a general portrait of the Yawanawa and their native views on their collective identity and the other. It also described the location of the community, which creates difficulties for the outflow and inflow of goods and persons, and presented the main members, their chasms and organizations. The effects of such difficulties, the general patterns of social and political relations that animate that circulation and the relation of such conflicts with the contests of leadership, remain to be explored. I have equally not discussed how the community interprets the labor that is necessary to produce things that go out, nor the objects that come in. These aspects of the cultural and political economy of the Yawanawa are the object of the next chapter. 


\section{Permutations of debt: the political and cultural economies of the Yawanawa}

This chapter continues the presentation of the Yawanawa, focusing on aspects of their collective life that symbolically and materially carry some significance to the activities that are necessary to produce and circulate values. In order to better understand the relationship of the Yawanawa with the forms, processes and objects they have appropriated, but also to understand the forces underlying and the consequences of their engagements with the market, it analyzes some of the political, social, economic and cultural aspects that comprise the internal political and cultural economies of the Yawanawa. It follows some of the multiple permutations of debt, the "sequences of value substitutions and conversions entailing both persons and objects which might be seen to create 'value' in both" (Thomas 1991: 75) to understand the internal dynamics, the social relations and the native scheme of reception of external objects.

In the past chapter, ontological aspects were presented, together with a sketch of the main characters and their conflicts. I contended that big economic projects of the 1990s, and notably the production of annatto, were a heightened avenue of expression of conflicts between contestants of leadership and that the conduction of business in general is related to projects of political power amongst the Yawanawa. To better substantiate this claim and to indicate the central role of leaders in the politics of value underlying the commodification of "culture" - in exchange, in general - I first discuss the nature of political power and the role of a Yawanawa leader. Subsequently, I discuss the units and vectors of solidarity responsible for material processes and internal circulation of goods and persons, their productive activities and the incorporation of objects and money in their social relations and according to a particular scheme of interpretation. I show that the economic projects involving the circulation of cultural representations are not the only sources of income and that several monies circulate within their Indigenous land. I also present the main products of the Yawanawa for external circulation.

In the absence of deep symbolic or moral categories to interpret or judge external things, the main issue becomes the fractured and ambivalent expectations that community and leaders have involving external exchange and those things we designate as modern. In his rich 
ethnography of the Copper Belt, Ferguson (1999) shows that, even in a setting of economic decline and exploitation, there is a range of reactions and strategies available to cope with changes brought about by modernity. When traditions and difference are the means to engage with modernity, strategies become certainly more ambivalent, for it is not just a matter of domesticating modernity, but also doing it in ways that are consistent with the display of tradition. I attempt to describe the opposing views that emerge between leaders and some notable men of "culture", on the one side, and the rest of the population, on the other.

\subsection{Political leadership: the power in the debt and the intermediation between worlds}

Much has been written and discussed regarding the nature of political power in South American Lowland societies. For a long period, there was a consensus among scholars about the absence of authority or capacity to resort to physical force as the most distinctive feature of chiefdom in the area, even if different attributes were recognized. The pioneer work of Lowie (apud Granero 1993) asserted that chiefs enjoyed power only temporarily as required for collective endeavors and manipulated their mystical capacities to impart words and interact with deities in order to create power. In his memoires of his travel through Central Brazil, Lévi-Strauss (1955) also contended that chiefs have no coercive power, referring specifically to the Nambikwaras. The highly influential work of Clastres (1974), in turn, characterized the relationship between leaders and followers as an asymmetrical exchange in which the former would always be a debtor, and thus, a powerless prisoner of the group ${ }^{40}$. The chief would never be able to compensate with goods and words the women he receives from the group. Additionally, chiefs would retain no control over economic activities. Granero $(1986 ; 1993)$ challenged this consensus and the narrow association of authority with physical force in the terms, he argues, authors borrow from Radcliffe-Brown's definition of the political system. Granero contends that there are ways of obedience other than physical force, namely, the knowledge on "mystical means of reproduction" (1986: 658), criticizing his predecessors for not considering "all magico-religious knowledge or ceremonial expertise among the generalized attributes of the Amerindian leaders" (1993: 215). He explores the

\footnotetext{
${ }^{40}$ And, thus, Clastres (1974) concluded that these were not stateless societies, as the typology devised by Evans-Pritchard and Fortes for Africa would contend, but societies "against the states".
} 
politico-religious leaders of the Amuesha as characters who stand above internal conflicts and divisions and whose knowledge is considered capable of ritually producing life, i.e., the means that are necessary for it.

Albeit contending that these sources of power are not limited to shamans, but are also shared by priestly leaders and other chiefs, Granero places a strong emphasis on the religious factor of construction of political power or, at least, the ritual mediation between political power and the provision of material needs. Showing that the political and the economic are deeply intertwined is his main quality. However, his characterization, and notably the mediation of this relation by rituals and ideologies of production, does not seem to aptly describe the reality of the Yawanawa leadership and, at best, it only partially explains its power. Since leaders are agents normally at the forefront of relations with outsiders, it is highly likely that the nature and sources of political power changed over a century of ongoing relations with non-natives. Nonetheless, even the scarce information about past leaders provides a different characterization. Naveira (1999) argues that past chiefs have exerted power and influence through knowledge and control of spiritual processes, not necessarily related to rituals of production, but through which they could effect alliances and aggressions of internal and external members. Moreover, albeit a relevant source of political power amongst the Yawanawa, the spiritual factor does not seem to be central in the past decades. The most respected healers currently are not considered political leaders, whereas the political leaders are not considered the most powerful healers. Finally, albeit recognizing other elements that create leadership, such as the distribution of goods and oratorical skills (1993: 221), Granero's conception misses fundamental traits and the dynamic of power amongst the Yawanawa.

In fact, an empirical examination of the main features, bases and limitations to power exerted by the Yawanawa in historical times yields a portrait of a much different character. Amongst the Yawanawa claimants to power, reputation must be constructed and the position asserted in connection to the fortunes in the establishment of relations with outsiders and the steerage of values that promote the circulation of goods and resources, from, to and within the community. In fact, the position must be reasserted at all times and is often challenged by contestants (Naveira 1999: 70). Chiefdom is neither reached by election, nor strictly by inheritance. Leaders are consecrated as a result of their actions. Even the heirs of an old chief must demonstrate their capacity to rule in order to be recognized as leaders. In this sense, 
authority is fragile, as in Clastres (1974), but leaders do have power, have eventually exerted violence and retain economic control.

Unlike other Amazonian societies, where the absence of native words to designate political leaders is taken as evidence of the introduction of such institutions by colonizers, the Yawanawa have a set of native words to designate characters that have exerted some political authority. The first of those words is shanaihu, meaning owner of the place and referring to men who controlled settlements. This is the word they told me when I asked then how they call the leader in their own language. Other words associated to political leadership collected by Naveira (1999: 67-68) are niaihu, translated as "to stand up", denoting a firm position, and rua, "different than others", which only feature in myths. No historical leader, i.e., leaders remembered by the native chronicle, was called by the latter title, but its mythological description might be considered an indication of the presence of some relevant traits of political leaders before the contact with non-indigenous institutions. As the main character of the myth that describes the origins of the multiple types of uni, the sacred concoction, pepper (yutxi), tobacco (nawë) and datura (хира), essential ingredients employed in healing procedures, the rua is connected to the bequest of these sacred and therapeutic substances. They were created out of parts of the deceased rua, the first person to perish when death was not yet known (ibid.: 68). Knowing how to manipulate these ingredients and dispense health and strength is a possible element of power used by leaders, but even more importantly, the myth describes the rua as someone who offers the society powerful resources.

The new relations established with non-natives and the constitution of new rights and state institutions to deal with the rights of indigenous peoples introduced new instruments of power. These are new forms to stand out from the others, common men, and create asymmetries that generate debt, and thus, elements upon which reputation and leadership claims may be built. Yet, even if new mechanisms of power are added and other relativized, the roles they create and the effects they operate remain to some extent the same, at least in the short historical period covered by the Yawanawa memory. In other words, the practice of political leadership under historical contingencies has preserved its main roles, only changing emphases on each of these. Considering that information is only available for leaders who interacted with non-natives, it is difficult to determine the exact changes, but the way the functions continue to be framed in similar terms indicate that the new instruments, notably the market and state institutions, were signified and incorporated through native practices in ways that did not totally subvert the internal structure, as it should become clearer when the 
Yawanawa history is analyzed ${ }^{41}$. In fact, leaders were active engaging with colonizers and later by government institutions as intermediaries.

The Yawanawa chiefs have increasingly become similar to the character of the Melanesian Big-Man, in the original description of Sahlins $(1963)^{42}$, in a process that is likely to be linked with the introduction of new institutions, objects and relations in the past century. However, before simply adopting this conceptual character to define the roles and sources of leadership amongst the Yawanawa, it seems more fruitful to analyze the role performed by concrete leaders and how their authority is constructed, i.e., what the elements from which some power is drawn are, and how their claims are justified. The construction of reputation and the legitimacy of claims for power, responding to changing dynamics and conditions of interaction with outsiders, will become clearer with an analysis of the Yawanawa history and some biographical notes about the epic trajectories of the leaders. Here it should suffice to indicate how the effective and aspirant leaders about which there are memories relate to these valued practices and roles. The evidence I provide here comes from two past leaders (Antonio and Raimundo Luiz), an aspirant that was not consecrated (Raimundo Sales) and the two current leaders that divide the power (Biraci Brasil and Joaquim).

There are four elements that are associated to the construction of reputation and allow the formulation of leadership claims: (1) the ability to forge alliances opening the community to the external other and their resources, (2) the knowledge of the forest resources and related hunting and fishing skills, (3) knowledge about the spiritual and healing system, myths and legends and, finally, (4) membership to a hereditary lineage of leaders. Leaders and contestants will manifest these abilities and qualities in different degrees and will build their claims referring to those who are most developed in their cases. As said, if the importance of each of these elements is variable in face of historical circumstances and personal qualities of

\footnotetext{
${ }^{41}$ The limited information available about leaders of the past does not allow to conclude whether these changes were entirely determined, à la Sahlins $(1985 ; 1993)$ by the local system or if, à la Thomas (1991), they were the product of the entanglement of the local order with global processes in a way that changed the local system. In the Yawanawa mythology, some of the roles, notably the one of distributor and the promoter of relations with outsiders are present (see Naveira 1999), and the native discourses of legitimation of power emphasize traditional roles, but this could be a strategy to create more stability to the position, as discussed below.

${ }^{42}$ I emphasize that this is a resemblance with the Big-Man as described by Sahlins (1963), because other works, and notably Godelier's (1986) place the Big-Man in system-wide typologies that do not apply to the Amazon. In the conceptualization that the figure received from Godelier (1986), big men, rising from the manipulation of competitive exchange systems, are thought as expressions of a societal-wide system of exchange, notably, gift-economies (where persons and things substitute each other), an idea subject to many criticisms, for assuming that there is a single form of exchange in such societies and that the classification of systems of exchange, as well as the particular meaning of the gift, constructed by analysts as an antithesis to market exchange, are valid practical categories, accepted and mobilized among the analyzed populations (Bloch/Parry 1989; Strathern 1990; Lederman 1991). Godelier's comparative typology between big men and great men is useful, however, to underline the differences between the Yawanawa chief and Granero's life-giving ritual chief (1993): the conceptualization of Granero is evocative of Godelier's description of the great men, notably because of the ritual complexity. The control of rituals is an aspect of Yawanawa leadership, as described below, but it is the manipulation of such rituals in a competitive exchange system, a feature of systems of big men in Godelier's (1986) typology, that seems relevant.
} 
the contestants, being at the disposition of men seeking to stand out from the rest of community, the roles or functions they represent are relatively similar. These skills must be sufficient for leaders to animate the community forging relations, to intermediate between the internal and external worlds, representing the population, and to procure and distribute valuable resources as result of alliances, generating a debt to be paid in form of political allegiance. The brief analysis of the matrimonial rules and the role of alterity in the Yanawana ontology already emphasized the importance given to exchange with outsiders. The role of managing these relations between interior and exterior and incorporating the other clearly brings respect and power.

In the past, there were fewer mechanisms to fulfill these roles and leaders would resort to marriages, hunting, rituals and feasts, as well as shamanic powers. Through marriages and past leaders were polygamous - they established relations with different families and offered their services to the head of such groups. Good hunters generated debts that equally bind them to different members of the society and create respect. Feasts and rituals, performed by those who commanded knowledge on the spiritual system, would open the community to outsiders, invited to join such rituals. Through other aspects of the shamanic knowledge, they could impart health and harm others.

Currently, these roles may be performed through different instruments and institutions. Forging alliances, negotiating benefits and manipulating the flow of resources and their internal distribution, more than any other role, seem currently associated with political power. Even without open competition until recently, leaders built their honor in attempts to forge alliances that promote exchange, in a way that is similar to the tournaments of value described by Appadurai (1986) and inspired by entrepreneurship of men involved in the Polynesian and Melanesian circuits of exchange (moka and kula). Those who succeed in representing the community outside and making resources flow are considered honorable men, whereas those who fail do not command respect or authority. The role of leaders as intermediaries in projects and steering the commodification of objects is fundamental. Thus, the politics of value that animate exchange with outsiders and the contests for leadership are indissociable.

It is not just the capacity to intermediate, represent and procure resources, but also the distribution of these resources that create power. The size of a man is measured by the size of his gifts and the capacity to distribute. A prowess in procuring resources is only meaningful if coupled with generosity in distributing them, as Pimenta (2006) noticed for another regional population, the Ashaninka. Generosity in the administration of the flow of goods and the 
resources amassed through alliances not only creates respect and social cohesion, but also generates a debt, to be paid in the form of allegiance. Thus, the distribution of resources, state benefits, jobs and opportunities is a form of creating power and leaders who are reluctant to share the benefits face challenges from the community. A good leader is measured not by what he amasses, but by what he distributes. The generosity of a leader, or more precisely the debt it generates, is the link between the prowess in procuring and distributing resources, resulting from exchange with outsiders, and the construction of political power. This relationship highlights the political aspect of the gift, discussed by Godelier (1996): the gift is not just a constant play between freedom and obligation, but also between solidarity and superiority. It is, thus, also a political act, in the sense that it subjects the receiver. All this suggests some interestedness and calculability to the acts of a leader. Nonetheless, the temptations to conflate this character to that of a rational calculative maximizer should be avoided. For if exchange is not only economic, but also bestowed very specific ontological, social and political places - and the goal of this part is exactly to reveal these places utilitarianisms of any sort are the wrong code to interpret the actions under analysis.

Since the contact with white settlers in the early twentieth century, the Yawanawa leaders occupy an intermediary position between the community and external institutions, notably land occupiers and patrons, missionaries, state officers and representatives of the companies doing business with them. More than an authority exerting control inside the community, the leader is a good emissary of the communal interests, capable of navigating institutions. The leaders have sought the monopoly over the intermediation with external institutions, negotiating on behalf of the group, controlling the alliances and the resources that flow. In such way, they create an asymmetry on which their power rests: the power to procure resources and distribute them. Given the introduction of new goods into their daily lives as a result of the relations established with non-natives and the distance to the towns where these necessities may be procured, distributing them in the villages is an expected role of the leaders. Historically, leaders sought these goods mediating the relationship between the population and rubber patrons. This mediation entailed and organization of the productive work of the community, siphoning collective efforts. Thus, in order to procure and distribute resources, leaders also needed to mobilize the community to collective productive endeavors. This pattern was kept in future economic exchange involving outside partners even after their land rights were recognized and their territory demarcated. In fact, leaders became also the bosses of the Yawanawa, although the relationship is rarely framed as such in the native 
discourse. If this were to happen, the resources brought as a result of the exchange of the internal produce could not be framed as a political distribution of gifts.

Over time, leaders took an active position to establish alliances that would promote exchange and bring goods to the community. All the four leaders remembered by the Yawanawa were able to secure such exchanges and bring resources to the community, two of them through the sale of rubber, game and food produced in their gardens and the two current leaders through the sale of annatto and the trade of cultural representations. As further discussed in the next chapter, two already deceased leaders, Antonio Luiz and Raimundo Luiz, organized the work of men, designating rubber trails and later collecting the production of rubber, crops from gardens and game, exchanged with the rubber patrons who owned the areas. In fact, replacing a previous leader who was considered unfair, Antonio Luiz is remembered as the intrepid leader who first established stable and very positive relations with the owner of the land and rubber patron (Vinnya/Ochoa/Teixeira 2006: 23-28). He is also evoked as a generous leader, whose good relations with the patron allowed him to procure goods by himself, sometimes travelling to large Amazonian towns, and always furnishing the community with plenty. Raimundo Luiz is considered weaker than his father Antonio Luiz for his apparent difficulties negotiating with new owners of the area, especially the use of forest resources, which led some of his brothers to establish independent settlements and exchange directly their production. Nonetheless, he did organize the work of many men, established new rubber trails and was considered an important intermediary by the land owners and government officials, securing goods for the Yawanawa. He was very generous, as well, sharing his food and work tools, as remembered by his son Sales, in a way that, even if somehow exaggerated, emphasizes the qualities of a great donor expected from leaders:

"[He] Did not have any pleasure in having, only in giving. He gave away many clothes, machetes. He exchange things when he wanted to see others content, happy. Daddy did not know how to eat by himself. He always shared his food. He thought who he could invite to share or called someone who was passing by. When someone in need appeared, he could not close his eyes. People were always at daddy's home to ask for help" (RSLY).

The reputation and legitimacy of Biraci Brasil and Joaquim, current leaders, rely on their abilities to procure resources in the current "market for projects" with private and state actors (Pimenta 2006). Biraci was responsible for the initial agreement and development of the partnership with Aveda, later taken over by Joaquim. The loss of control over the 
resources related to this partnership caused a crisis of authority and legitimacy to Biraci's position and provoked the defection of many members to different villages and their new organization. Yet Biraci retained respect and power in Nova Esperança through several actions, including becoming an efficient entrepreneur of performances of culture, and notably spiritual rituals, forging alliances with urban groups interested in such practices and organizing the annual festival. Joaquim has also realized the potential of these performances and, with a different model, is also procuring resources by these means. Raimundo Sales, however, was not a good intermediary, failing to forge new alliances and to act in the best interest of the community whilst manipulating resources, being rejected as a leader.

The development of new rights and institutions for the protection of indigenous populations in Brazil reinforced this position of the leader as an intermediary capable of representing the community and negotiating benefits. Leaders also became politicians outside the community, claiming the recognition of rights and the implementation of policies in state and federal bodies. These policies, further analyzed in the next section, became an important source of resources, complementary or sometimes more significant than those obtained through market transactions, used for the members or the community as a whole. They brought electricity, education, trained health agents and forest agents recruited from the community and increased food security. They equally represent job opportunities for the population, as teachers and agents, appointed always upon the suggestion of the leader. A particular form of enlisting loyalty is, thence, the distribution of such opportunities to villagers.

Raimundo Luiz, the first leader to have contact with governmental institutions, soon realized the importance of dialogue. He was the first to participate in official meetings in Rio Branco and at FUNAI's headquarters in Brasília, which would lead to the first demarcation of an Indigenous land in the state of Acre, in 1984. With the same spirit, he sent his first-born son, Raimundo Sales, and Biraci Brasil to the capital of the state of Acre, Rio Branco, to obtain formal education that would enable them to better negotiate with the then owners of the land on the shores of the Gregorio River, obtain fairer conditions of exchange of their produce and claim rights and benefits from the government. Raimundo Sales would later join FUNAI as a civil servant (RSLY), but this did not enable him to intermediate benefits or secured any preeminence amongst the Yawanawa. Furthermore, this happened in a moment in which much of the organized actors in Acre directed their struggles against the government agencies and its developmental policies 
Biraci Brasil was much more successful in politics. He was a prominent member of the indigenous movement in Acre and then at the national and Pan-American levels, where he met and worked with the most notable leaders in the Brazilian non-governmental Indigenist movement of the 1980s, an exposure that introduced him to a new vocabulary of rights connected to cultural difference and environmental protection and, consequently, enabled him to seek better relations with political and economic partners. He was part of the group of Indigenous populations and rubber tappers who forged the Alliance of the Peoples of the Forest (Aliança dos Povos da Floresta) to fight against the transformation of the forest in cattle ranches. Albeit short lived, the organization had long-lasting consequences to the state politics of Acre. He later joined FUNAI as part of a strategy employed by the government to co-opt important leaders, but unpleased with the organization, returned to non-governmental organizations and run for a seat at the Federal Chamber of Deputies, losing the elections (BBY. Also see Ribeiro 2005). After returning to the village for a period that he defines as a moment of full "dedication to his own people", he recently held, for a short period, a position at the Government of Acre as a special assistant for health policies to Indigenous populations.

Once more he considered the experience frustrating and decided to retreat to the village's life and concentrate on spiritual activities (BBY). Nonetheless, his influence in interethnic politics and the respect he commands amongst state politicians remain unaffected. He is still contacted by state authorities on matters pertaining Indigenous populations and is still considered the main reference and speaker of the Yawanawa by state and federal bodies. As a result of his political skills, but also its larger population, Nova Esperança has the largest school, a health agent, a forest agent and was the first to receive a power generator, fish ponds and a building to develop crafts. After the loss of control over the production and sale of annatto, and the interruption of the activities in Nova Esperança, Biraci has increasingly used his political connections in a favorable context of repeated state governments committed to the advancement of indigenous rights. He is able to negotiate positions for loyal villagers as health and forest agents and as teachers at the Nova Esperança school and due to his good relations with state politicians, he is also sought by people from different Indigenous groups who expect to obtain state jobs.

His rival, Joaquim, raised in Rio Branco, had also a vast exposure to politics and was a member of non-governmental organizations devoted to the promotion of the rights of indigenous peoples, namely the CPI-AC (Comissão Pró-Índio do Acre - Pro-Indian Commision of Acre). Later, as he was awarded a scholarship by Aveda to study English in the United States, he became acquainted with movements of Native Americans and was exposed 
to their strategies to gather and mobilize resources, as well as to vocabularies of rights and the value of cultural difference. Due to his better understanding of international programs and policies like REDD (Reduced Emissions from Deforestation and Forest Degradation) and protection of traditional knowledge through proprietary forms, he became an informal representative of the indigenous populations of the Amazon in international forums and organizations (JY). He equally negotiates benefits on behalf of the Yawanawa villages under his leadership and is able to secure similar benefits to those offered to Biraci's organization.

The possibility of mediating relations that make resources flow and of distributing them generating debt, depends not just on entrepreneurial abilities, but also on knowledge and oratorical skills. These are essential to frame the distribution in terms of a political gift. A good leader must know how to move in the external world and dialogue with potential allies, but must also be able to report, preferably in a solemn way, his achievements. In the first decades of relationship with non-natives, the mere knowledge of Portuguese was sufficient for a man to stand out. Some basic calculation skills to deal with the exchange of rubber with industrialized goods equally created notoriety. With the increase in the complexity of relations established by the Yawanawa with external institutions, the new national and international rights, as well as the opportunities brought by environmentalism, more knowledge is required from leaders. Before becoming a leader, a man must be a notable man within the community and an enormous value is conferred upon the knowledge on how to act and understand the urban world and institutions, the market and the official citizenship, with its language of services, rights and obligations. All those who lived in towns and especially those who participated in non-governmental or governmental organizations of promotion of Indigenous Peoples' rights, enjoy respect amongst the Yawanawa, even if their understanding is partial. People like Luzia (Waxy), who lived in Rio Branco for a long period, whilst married to an employee of FUNAI, are much respected and sometimes sought by other members facing problems with outside institutions, from health treatments to family law issues. For these community counselors, knowledge also becomes an element that animates sociability and generates a debt, reciprocated in several forms by their fellow Yawanawa. For leaders, the perception of a good command of knowledge bestows legitimacy to their actions. In both cases, the distribution of knowledge is an important element in this political economy.

In fact, a good leader is a bridge between worlds and must offer clear signs that he is able to move in both. A strong leader is neither purely a market man, nor purely a village man to employ Bourdieu's (1977) dichotomy applied to the Kabyle. Besides representing the community, promoting new alliances and the associated exchange, activities performed in the 
exterior, the leader must show capacity and take part in the activities of production and reproduction that villagers normally perform inside the villages. Taking part in the daily life of the community, sharing customs and traditions is very important. A good leader will also be able to mediate conflicts, to which customs are fundamental, and animate the community through rituals and feasts.

Before being a notable man outside the village, a leader should be a respected man within the community. Men stand out through their abilities in hunting, fishing, cultivating productive gardens and displaying a throughout knowledge of their territory and its species. Any men aspiring notoriety in the community will seek these skills. Good farmers, hunters and fishers are always mentioned by the community and their adventures are a common conversation topic. Obviously, this requires dexterity in dealing with the risks of the forest and translates a vast knowledge: for hunting and fishing, they must know where and how to capture the animals; to maintain gardens in the forest, they must know how to domesticate crops. This knowledge is not separated from traditions and their particular ecology, a special relationship with the environment that dictates multiple prescriptions in the ways of procuring forest resources. In part, the respect commanded by productive hunters and fishers is related to the debt that they produce when distributing game and fish outside his house. Yet the honor related to these activities is also related to the praise of a traditional lifestyle and the identification it creates with fellow Yawanawa. Knowing the history of their people, the legends and customs is relevant for the same reason. Realizing the value of such features of the "traditional" Yawanawa, leadership contestants attempt to be known as respectable village men and resort to their knowledge of the forest, its species and the customs that guide the village life. Referring to the qualities of a good village man allows more solid claims to leadership, since these skills are less subject to the uncertainties of the market and the vagaries of government politics.

At the same time, as performing "culture" became an important source of revenues for the Yawanawa and visitors are attracted by their stories, myths and legends, displaying the features of a traditional leader fits better the romantic character that visitors expect to find at an Indigenous community. The economic gains are not, however, the only reason to cultivate these abilities and knowledge, since there is a strong internal respect for these abilities, not least in the current moment of re-invention of traditions and renaissance of cultural production. 
Antonio Luiz is remembered as a man who always honored the traditions, besides being a good farmer and hunter. Many elders, as well as Biraci and Sales, told me with pride about the regionally famous feasts he organized in their old settlement, which were joined by nonnative tappers and neighboring populations. These were opportunities to establish good relations, but also to bring the community together. He was also remembered as a good farmer and hunter. Raimundo Luiz is often mentioned as a prolific farmer and many accounts about Nova Esperança emphasize the variety of fruits that could be found when the village was Raimundo's settlement and garden (BBY, MLY, VVBY). Raimundo is also remembered by many (ALV, JY, MLY, LY) as a depository of knowledge on traditions, rituals, games and the historical and mythical chronicle of the Yawanawa. He was a good storyteller and was one of the main sources used in the 1990s by members to rediscover and re-enact cultural practices. And he seems to have used this opportunity to try to steer this process of recreation of traditions (Naveira 1999: 161).

The new inter-ethnic relations and representational tasks entailed in forging alliances and negotiating benefits require leaders to spend long periods away from the village, which increases the challenge of being a good village man. The current generation of leaders and contestants spent long periods of their lives away and only Biraci returned to reside in their territory. Failing to command the respect needed to become a leader, Sales never returned to the land and, deeply influenced by the Protestant missionaries, he never participates in the rituals. Joaquim lives in Rio Branco and visits the territory to discuss issues with the community. Joaquim tries to join rituals when visiting Mutum, but he is not recognized as someone with the skills that would be required of a good village man. Currently, it is Biraci who employs good abilities as a village man, a thorough knowledge of the forest and the traditions as an exclusive trait. His group of loyal men emphasizes the importance of these traits and often challenges the capacity of Joaquim to rule arguing that, far from the community and its life, he cannot make the best decisions for the people. Biraci takes part in the daily life of Nova Esperança, organizes hunting and fishing parties and likes to narrate stories of the mythical and historical encounters of current or past Yawanawa with different populations and animals. He is particularly proud of his knowledge over the territory, telling me that he has wandered over most of the vast land, and his abilities as a hunter, which he supposedly inherited from his foster father, known as the best hunter in all community (BBY). Underscoring his greater involvement in the life of the village is part of his strategies to compensate the loss of resources associated to the production of annatto and forge the image of a traditional chief, playing with the expectations of visitors. Amidst the project of revival of 
culture, traditional features create empathy internally and externally. Emphasizing that those aspects of communal material and spiritual life held as traditional are the most valuable, that income is only secondary and its divisive effects should be controlled, Biraci attempts to maintain his leadership while animating a communitarian ideal of society in which cultural and subsistence activities are central. The importance of being a good village man was also realized by one of Biraci's sons with a non-native, born and raised in Rio Branco, who moved to the village. Perhaps a future candidate to leadership or at least a prominent position, Biraci Junior sought to compensate for his urban socialization and be considered as part of the community marrying a Yawanawa, establishing himself in Nova Esperança and undertaking the initiation into the spiritual practices. This decision is framed as a desire to live in the forest amongst his people and is clearly not purely a strategy, showing in reality the efficacy of this project of re-invention of tradition. Yet the possibility of building a reputation within the village and the associated symbolic and material resources probably fosters such decision.

A third element that generates respect and power is the knowledge and practice of spiritual healing rituals. Shamanism is a complex element in the political and cultural economy of the Yawanawa and its relation to power was particularly variable in nature and intensity according to the relations and history of the region in the past century. In a way, this knowledge may be inscribed in the same logic which relates other elements to political power. Shamanic powers allow to act as an intermediary between worlds, to animate the society, incorporate others, and generates a debt: the shaman has the power of words to communicate with the spirits (yuxin) and knows the language of the myths, being able to act as an intermediary between the natural and the supernatural worlds; through rituals and games the spiritual specialist animates the society and promotes openness to outsiders who are integrated through participation; and by imparting health and stamina to make good hunters, they generate debt.

In the past, shamanic powers were fundamental ways of establishing relations with outsiders, either of alliance or hostility. Healers could also impart health and protection from bad spirits, and some famous healers would offer these services to members of other groups and even non-natives. Their practices are essential to cure the bad hunters, taken by bad luck, or panema, which follows the non-compliance with prescriptions and interdicts involving the killing of animals and preparation of game. Besides healing, their knowledge included the capacity to inflict aggression within the community or against enemies, which conferred them significant power (Naveira 1999; Gil 1999). Additionally, older healers, full xinayas, 
confessed that seeking this knowledge was a form to free themselves from the dependence of others (Naveira 1999: 71). Among Pano populations, some notable leaders were at once political and spiritual leaders (ibid.: 76) and the same holds true for Antonio Luiz, a much respected xinaya, i.e., a full-fledged specialist with vast knowledge on rituals, prayers and medicinal plants. His power rested especially on his shamanic abilities, to a point that an elder that knows medicinal plants, when asked about spiritual practices in the past, presented Antonio as a powerful healer, and not as the political leader: "There was a very strong paje $e^{43}$ called Antonio Luiz. He cured blowing air, he prayed over caiçuma ${ }^{44}$ [...]. He knew the sacred chants and he knew many medicines from the woods, he had many witchcrafts [...] We had a lot of fear, because if we did not, we would not be alive today" (APSY).

Nonetheless, the healing and spiritual system of the Yawanawa has particularities that make the concentration of spiritual and political powers in the same person less likely. The system of cure contains branches of specialty that can be independently pursued and practiced by individuals. The Yawanawa have adopted the terms shaman and its Brazilian vernacular equivalent, pajé, to refer to healers they consider have completed all initiation steps, acquired a vast knowledge on different techniques and can cure. These correspond in practice to the xinaya (those who can use prayers to cure). There are, however, at least four other terms employed to refer to specialists that possess knowledge on specific techniques (Gil 2001: 336). Some members, even without completing all the formation and observing the interdicts required to obtain the powers to cure, possess knowledge, notably on medicinal plants. Details of the career are provided below, but the essential aspect in relation to leadership is that, first, the powers of shamanism are distributed amongst a number of specialists. And in fact, seeking spiritual powers, or some knowledge onto the healing system, is often mentioned as an alternative source of power to that commanded by the political leader, since it equally allows persons to outdo others and help others, creating debt ${ }^{45}$.

Historical reasons also made this association less likely in the past decades. Spiritual powers decreased as a mechanism of establishing relations of alliance and aggression for most of the past century and the practices associated with the spiritual healing system were

\footnotetext{
${ }^{43}$ Although using the Tupi-Guarani originated word "pajé", adopted in Brazilian vernacular, which roughly translates as a shaman, as further explored below, the Yawanawa do not have any structural equivalent to a shaman.

${ }^{44}$ Caiçuma is a fermented drink with manioc, maze, sweet potatoes or a combination thereof, produced through the contact with saliva of women that chew the cooked vegetables.

${ }^{45}$ Among the current members with some spiritual knowledge, the case of Augusto Pereira, whose fear and respect for Antonio Luiz was cited, is particularly expressive of the will that animates some members and the controlled access to the knowledge: an outsider that joined the community through marriage, his kinship relations to specialists were too weak and no one wanted to teach him. He decided to self-taught and took some initiation steps, including the interdicts. As a result he obtained knowledge on the medicinal plants (Gil 1999: 30).
} 
repressed by Protestant missionaries and some land owners. This is the context under which Raimundo Luiz undertook his initiation and which helps explaining his ambiguous relationship with shamanic knowledge and his powers. Prepared to succeed as leader, he obtained knowledge from his father Antonio Luiz and went through all the initiation steps to become a xinaya. However, he broke the prescribed interdicts that follow the last step, failing to obtain the power to cure and falling ill as a consequence (RSLY). Raimundo also converted to Christianity and distanced himself from the Yawanawa spiritual practices, only returning to them at a late stage of his life, under a different context of increased interest from outsiders, in a timid way and not without objections from his frightened wives. Coupled with his difficulties to maintain the monopoly over the intermediation with rubber patrons, this weakened Raimundo's leadership and questions about his powers led to challenges, especially from his brothers, with whom he maintained a conflictive relationship (Naveira 1999: 25). Albeit not a xinaya, Raimundo is regarded as a leader with a vast knowledge on the myths, legends and even many cure procedures, just lacking the power needed to guide the spirits of the yuxin. He was equally acknowledged as a source of knowledge on Yawanawa traditions by many members involved in the project of recovery of cultural practices, and not least by his firstborn, Sales, who remembers Raimundo's knowledge: "he did not complete [the initiation] and felt sick. But daddy had a total command. He knew 142 traditional stories, myths. I counted. He had an answer for everything in the Yawanawa science” (RSLY).

Additionally, becoming a full-fledged healer is a full-time task, which is a challenge for men that must represent their community outside and procure resources. In fact, until recently, pursuing a spiritual formation and knowledge on the forest, on the one side, and pursuing good alliances with economic and political institutions, on the other, were exclusive, since the latter required long periods of absence, as already noted. The two men considered xinaya, who command significant power and control the knowledge of spiritual practices, are not the political leaders. In recent years, with the increased interest in the practices and knowledge controlled by specialists of the healing and spiritual system by outsiders, being a healer became a way to distribute not just health and produce good hunters, but also to amass material resources that are obtained through performances of rituals. Once more, the knowledge on the healing system is associated with opportunities to forge, changing the nature of the debt produced. At the same time, given the centrality of the project of recovery and re-invention of traditions to the community, stimulated by the income opportunities, but not only, this knowledge bestows great respect on the beholder. 
Consequently, spiritual powers and control over rituals and the healing system might not produce leaders, but political leaders seek knowledge to better rule and to increase their power over the population. Besides the power that it brings, knowledge about the spiritual world and its healing system adds legitimacy to the leader. Some knowledge is also fundamental to control the restrictive access to the system that enable alliances and the circulation of resources, promoting or restricting initiations of new members and managing presentations and performances of rituals within and outside the village. Only a true expert can decide which members are able to access this knowledge and then, share it with others, performing rituals to an external audience. It is equally only those perceived as experts that can argue over how these performances should be and which practices can be displayed, taking a central role in the politics of value that animate the circulation of such practices. Therefore, if not possessing the knowledge and power to cure, leaders seek at least to control the formation of new healers and intermediate performances and treatments to outsiders. And even if not initiated, leaders should demonstrate some knowledge of myths and legends, and more importantly, take active part in the rituals, drinking uni and inhaling rapé.

The current leaders pursued different strategies to exert some influence in the economy of spiritual knowledge, whereas Sales rejected it altogether. Sales asserts he never had "the vocation" and, as his father, "embraced the true God that the Gospel preaches" (RSLY). Biraci, in turn, decided to undertake the initiation, in his own words, following a call (BBY). This followed an apparent decision to focus on cultural activities as a means to strengthen his respect and authority amidst the conflicts involving the production of annatto. He completed the formation, learning with one of the xinayas, Tata, and observed the interdicts. Joaquim is not initiated, but supported the formation of two siblings. In common, Biraci and Joaquim became intermediaries between healers and outsiders who have interest in participating of rituals or obtaining spiritual knowledge, creating a new space in this economy of knowledge. And to strengthen the legitimacy of such activities they attracted a xinaya to their close circles, whom they represent. Each organization has his full-fledged healer, who is employed as a depository of knowledge, as the instructor of newer generations undertaking the steps into the spiritual formation and considered the biggest authorities on cultural matters, whose highly respected opinions on the forms of display of rituals is used to legitimize or criticize the activities these organizations promote in the territory and outside. They possess the authority to bestow the character of tradition to the practices developed by the community. Their opinions are quoted by the leaders and their acquiescence considered fundamental. As previously explained, Biraci and his group are closer to Yawarani, whereas Joaquim and his 
group are closer to Tatá. Given the position occupied by these elders in the society and respect commanded by them, the only to be recognized full experts in all surviving healing techniques ${ }^{46}$, they are free to circulate between groups and I noticed that apprentices, even if taught by one, seek guidance from both.

The last element employed to build leadership claims to be analyzed is the belonging to an alleged dynasty of leaders. This belonging is obviously invoked by members of the family nucleus of the previous leaders, but it is equally claimed by other contestants, as means of justifying and maintaining their power. There are no absolute rights to dynastic succession and no clear hereditary rule, but leaders of historical times are connected by kin and have resorted to the belonging to the lineage of previous leaders to claim their position. As previously asserted, even members of the dynasty must be consecrated. Apart from the dynastic claim itself, being part of the family nucleus of a leader places the descendants in a privileged position to acquire the knowledge and develop the skills that produce eminence and prestige. Sharing the experience of the leader and the private resources, they are more likely to stand out from others. It seems that more important than being in the direct succession line, is to be related to the previous leader, integrate his family nucleus and share his knowledge. Given the marriage prescriptions and attenuated matrilocality, the relation between a leader and his sons-in-law, who owes respect and must provide for his wife's father, creates a strong bond that can strengthen the claims of sons-in-laws. This gives to the claimants some space to justify this belonging and the sharing of the legacy left by previous leaders in different ways.

The leadership claims formulated on the basis of this dynastic belonging are obviously stronger among the family nucleus of direct descendants of the Antonio Luiz-Raimundo Luiz lineage. Sales and Joaquim are sons of Raimundo Luiz, but it is the former who espouses the strongest dynastic posture amongst all the claimants, not least because his claims of respect and authority are built entirely on his privileged position in the lineage. Referring to the respect he commanded from the previous leader, he attempts to build a preeminent position in the community. As the oldest son, he stresses the conviviality and the intimacy with his late father, using the informal form "papai" (daddy) to refer to Raimundo Luiz:

"Being the oldest, having lived during the apex of the strength and knowledge of my dad, I learnt much. My younger brothers were raised without his teachings, because daddy was then old and had no more strength. Joaquim left the village at very early age. He felt sick and remained in Rio

\footnotetext{
${ }^{46}$ Gil (2001) indicates that the Yawanawa report and reserve a specific term to some healers who were able to incorporate the yuxin (spirit), but no one is able to do so anymore.
} 
Branco with missionaries. Joaquim would only live with daddy when he was sick, when he was already old. I never left my dad! When he was already old, he used to say to my brothers to talk to me. He did not do anything without consulting me. He always required them to seek my advice. And he used to say 'whatever he does, I approve'. I really had his trust. I learnt a lot with him” (RSLY).

In this way, he differentiates himself not only from those outside the lineage, but also from other sons of Raimundo: referring to Joaquim, one of the youngest sons of Raimundo, Sales asserts that he was the one who, living side-by-side with Raimundo during the peak of his vigor, could learn the most. He was not able to prove or use any of these teachings, however, in a way that would enlist allegiance from his fellow Yawanawa. Moreover, it is clear that these teachings did not include anything related to the sacred and ritual aspects of the Yawanawa culture. After all, his childhood corresponded to the period in which, under the new owners of the land and condemnations of Protestant Missionaries, the expression of Yawanawa culture was most restrained. Maintaining his Christian faith, Sales continues to talk with disdain and distrust of spiritual practices, especially when they include outside allies. Raimundo Luiz tried to create a successor among his offspring and he sent Sales to Rio Branco with the purpose of producing a leader with better urban skills to deal with the land owners and government institutions. Yet members of different villages confided that Raimundo did not trust the abilities of Sales to lead the Yawanawa and he did not back his claim to power, accepting and supporting Biraci's ascension after his return to the land.

The fact that the family nucleus of Raimundo Luiz has stronger claims based on this element does not prevent Biraci to use this argument as well. He also resorts to his relation and conviviality with the previous leaders to justify his leadership. Raimundo Luiz was Biraci's maternal uncle and, thus, Biraci was both a grandson of Antonio Luiz and a txai, a preferential potential affine, to Raimundo's daughters. Biraci emphasizes the fact that, having been born after three losses of male children by his mother, he was raised by an aunt ${ }^{47}$ in the house of Antonio Luiz, with whom he lived in the later years. He equally mentions that upon the decease of his biological father - his mother passed away much earlier - Raimundo invited him to move to his house, which he denied, preferring to work in rubber trails. To strengthen his relation with Raimundo's family, Biraci attempted to marry several of his daughters without success until settling with one of Raimundo's youngest, Putanny. Given his

\footnotetext{
${ }^{47}$ It seems that it is customary for Yawanawa mothers to give children to sisters to raise them when there are grounds to believe that they cannot safely nurture them.
} 
successes in external politics and as an intermediary in economic projects, this was a mutually beneficial alliance. His ancestry via maternal line and conviviality with Antonio Luiz, as well as his bond with Raimundo Luiz are all invoked by Biraci to claim his belonging to this hereditary line of leaders. He equally supports the attempts of his own sons, and notably Biraci Jr., to rise to prominence in the community (see box 2). At the same time, Biraci reminds that "leadership must be consecrated by the people" and that "to be the heir does not mean to be the leader" (BBY). In fact, his precedence over Sales and the lack of authority of Raimundo Luiz amongst his brothers suggests that, indeed, leadership is not an office and every claim must be constructed and legitimized. Nonetheless, Biraci's resort to the lessons from Antonio Luiz and connections with Raimundo's kin are part of an attempt, which also includes his emphasis on skills that are associated with the traditional lifestyle of the Yawanawa, to secure more stability to the position of leader and reduce the harm of potential failures in the competitive plays for resources, protecting it from the vagaries of politics and the market.

\section{Box 2: Managing "culture": Biraci's sons and the future of leadership}

Biraci has two sons born in Rio Branco to a previous marriage of Biraci to a non-native. Socialized in the town, they achieved higher formal educational attainment, through which they developed a very particular managerial language. Both of them have been involved in special training to handle projects and, as they become involved in the affairs of the community, they bring with them this language, still absent within the villages even after multiple significant projects. In different ways they are promoting both the resumption of cultural practices and the generation of income for Nova Esperança. Shaneihu, aptly named after the ancient word for leader, lives with his family in Rio Branco, where he studies management and deals with administrative matters of the Yawanawa. In particular, he is responsible for dealing with a travel agency and organizing the transport of visitors to the Festival from São Vicente to Nova Esperança. He is also a singer of songs inspired by Yawanawa chants but, in his own words, his work is a fusion of styles. At the same time, he is devoted to transforming the festival in a viable and permanent ethno-tourism project, centralizing the sales of participation.

His brother Biraci Junior has taken a somehow different path. He abandoned his university course to move to the village. He has since then learnt the skills of a good village man, married and, very interested in the spiritual practices, undertook the initiation to become a healer. At the same time, he is involved in the internal management of economic projects and state programs in the village. He 
has sought better formation to manage these projects and to claim external benefits. As a result of training received at $\mathrm{COIAB}$, he obtained funds to finance the production of high quality manioc flour and, in 2011, was discussing resources to promote traditional crafts. Junior is, thus, seeking the mix of village and market skills that create a notable man. Approximately a year after starting his formation, he already performs spiritual rituals outside the village, taking part in the recent tours of Yawanawa healers in Italy in 2012 (BBJ).

In common, the brothers employ a particular language when talking about economic activities or even the cultural performances. They seem more comfortable to discuss them as instruments of generation of income and to call for new forms of management that will increase the gains associated with these activities. Joaquim has no embarrassment to discuss money and his active instance in seeking economic partners, but he did not reveal this managerial language. At the same time that the village attempts to introduce a co-op with a strict control over the distribution of goods, this might indicate a moment in which the circulation will subsume to a logic separated from political and kin ties.

At this point, I can summarize how these four leaders and a failed contestant have mobilized elements at their disposal to create honor, enlist loyalty and command power amongst their fellow Yawanawa. I have briefly exposed how the practical meanings of elements that bestow reputation and superiority have changed as result of shifting contexts and relations with outsiders, to which leaders, acting as intermediaries, are essential. I have similarly sketched the varied ways they were creatively mobilized by these claimants of political leadership in connection to their personal biographies, in ways that will eventually become clearer once the history of the Yawanawa is examined. In common, they all attempted to represent and bridge the internal and external worlds, animating the society and distributing resources. In order to do so, they mobilized all or some of four elements, as displayed in Table 1.

Table 1: Leaders and their elements of power

\begin{tabular}{lllll}
\hline \multicolumn{1}{c}{$\begin{array}{c}\text { Chiefs (and } \\
\text { claimants) }\end{array}$} & \multicolumn{1}{c}{$\begin{array}{c}\text { Ability to forge } \\
\text { alliances }\end{array}$} & $\begin{array}{c}\text { Spiritual } \\
\text { knowledge/power }\end{array}$ & $\begin{array}{c}\text { Knowledge of the } \\
\text { land/good } \\
\text { hunter }\end{array}$ & $\begin{array}{c}\text { Dynastic claim } \\
\text { constructed }\end{array}$ \\
\hline $\begin{array}{l}\text { Antonio Luiz } \\
\text { Yawanawa }\end{array}$ & $\begin{array}{l}\text { Contact with } \\
\text { rubber patron, } \\
\text { representational } \\
\text { monopoly }\end{array}$ & Wide and respected & Yes & $\begin{array}{l}\text { Initiated the } \\
\text { dynasty }\end{array}$ \\
\hline $\begin{array}{l}\text { Raimundo Luiz } \\
\text { Yawanawa }\end{array}$ & $\begin{array}{l}\text { Weakened } \\
\text { intermediary role, }\end{array}$ & $\begin{array}{l}\text { Formation was } \\
\text { interrupted }\end{array}$ & Yes & Son of Antonio \\
\hline
\end{tabular}




\begin{tabular}{|c|c|c|c|c|}
\hline & $\begin{array}{l}\text { some brothers } \\
\text { remain } \\
\text { independent }\end{array}$ & & & \\
\hline Sales Yawanawa & No & No & No & $\begin{array}{l}\text { Son of Raimundo, } \\
\text { grandson of } \\
\text { Antonio }\end{array}$ \\
\hline $\begin{array}{l}\text { Biraci Brasil } \\
\text { Nixiwaka } \\
\text { Yawanawa }\end{array}$ & $\begin{array}{l}\text { Contact with } \\
\text { Indigenist } \\
\text { movement, with } \\
\text { Federal and State } \\
\text { Governments, } \\
\text { ayahuasca cults } \\
\text { and business } \\
\text { partners }\end{array}$ & $\begin{array}{l}\text { Yes and manages } \\
\text { performances } \\
\text { outside the village }\end{array}$ & $\begin{array}{l}\text { Yes, he was raised } \\
\text { by greatest hunter, } \\
\text { known as a good } \\
\text { hunter himself. }\end{array}$ & $\begin{array}{l}\text { Raised at the } \\
\text { house of Antonio } \\
\text { Luiz. Married to } \\
\text { Raimundo's } \\
\text { daughter, making } \\
\text { him son-in-law } \\
\text { and subordinated } \\
\text { to Raimundo's kin. }\end{array}$ \\
\hline $\begin{array}{l}\text { Joaquim Tashka } \\
\text { Yawanawa }\end{array}$ & $\begin{array}{l}\text { Contact with } \\
\text { Indigenist } \\
\text { movement, } \\
\text { International } \\
\text { Organizations and } \\
\text { business partners }\end{array}$ & $\begin{array}{l}\text { No, but manages } \\
\text { performances and } \\
\text { organized } \\
\text { "Ceremonial Center } \\
\text { of Cure and } \\
\text { Therapies" }\end{array}$ & No & $\begin{array}{l}\text { Son of Raimundo, } \\
\text { supported by the } \\
\text { dynasty }\end{array}$ \\
\hline
\end{tabular}

The intrepid Antonio Luiz, the native who offered Yawanawa labor to the new land owner, as described in the next chapter, is widely regarded a great leader who knew how to move between worlds: a powerful healer imparting health and capable of harming enemies, on the one side, and an able intermediary with the rubber patron, capable of organizing the work of men and bringing a plethora of goods to the community. In addition, through marriages and the organization of feasts, he animated the community and promoted alliances. Sole intermediary of the Yawanawa with patrons and foremen, procurer of valuable goods and generous giver, he was capable to produce debt.

Raimundo Luiz, his firstborn son, also combined a good command of spiritual knowledge, traditions and stories with the role of intermediary with landowners, if only in a weaker manner. Raimundo did not possess the power of cure and had more challenges negotiating with the landowners and bringing resources to the community. His authority was challenged by his brothers, some of which preferred to remain independent in their own settlements. In a move that much later turned to be controversial, Raimundo accepted the presence of missionaries in the land. Most of the old members of the community remember this with gratitude for the health care that was provided by the mission. Later in his life, he took active steps to promote the recognition of land rights.

Sales, in turn, raised to be the leader, sent to Rio Branco to obtain formal education that would enable him to better represent the community in face of land owners and state authorities, enjoyed only a short period of respect, during which Biraci was involved in external politics: first working with his father for the recognition of land rights and the 
expulsion of outsiders of the land, and later securing resources to enable the Yawanawa to produce rubber and other forest products without external intermediation. Despite growing with Raimundo, Sales rejected the Yawanawa spiritual knowledge, never accumulated substantial knowledge on the stories, legends and myths and is not known for his hunting and fishing prowess. His reputation was finally besmirched by malpractices in the sale of rubber and some accounts of conspicuous consumption in towns, which he confirms with regret, justifying his attitude as a lack of knowledge on how to deal with significant amounts of resources and the mesmerizing power of money (RSY).

During the same period, Biraci demonstrated better skills to forge alliances, both in politics and with market agents. Biraci was raised in the house of Antonio Luiz, trained by the best hunters and chosen by Raimundo to go with Sales to Rio Branco. Biraci mastered the grammar of special rights and benefits, but also the language of business partnerships. After a relatively successful career in multiple movements promoting rights of indigenous peoples in Brazil and the Americas in the 1980s, he used his skills to reunite his community, deprived of sources of income, with a partnership with a foreign firm. An able politician, but also an enthusiast expert on his territory and its creatures, Biraci gained enormous respect and was consecrated the new leader when he introduced the project to produce urucum. Awakened to the value of their cultural practices, he mobilized a group around efforts of recreating traditional cultural practices. He has brought multiple resources obtained from market and state partners. Additionally, he is initiated in the spiritual healing system and an intermediary between healers and external groups interested in their practices, which visit the village or invite practitioners to perform their rituals. He has, thus, control over performances and new initiations. Through good allies, which mobilize both the traditional and the modern skills he acquired, Biraci has created a loyal sect of families that remained in Nova Esperança.

After a decade of unity, however, conflicts involving the production of urucum and the resulting resources led to a challenge by another member of the lineage of leaders. Joaquim, also educated in Rio Branco among movements of Indigenous populations, chosen to travel to the United States to learn the language, returned to Acre to become the new hope of Raimundo's family. Committed to keep the urucum project, he enlisted the loyalty of those interested in the activity and inaugurated a period of a competitive leadership. Joaquim lives in Rio Branco and commands no spiritual or traditional knowledge. He is not recognized as a good village man, either. Yet he is supported by a strong family and is capable of forging alliances that bring resources to the community. Managing these relations and creating debt, Joaquim manages to enlist loyalty among his family and four other villages, headed by 
brothers of Antonio Luiz. Far from neglecting the worth of their spiritual practices, Joaquim has associated with a xinaya and two healers who are his siblings. Creating a center to receive visitors and perform spiritual practices, he controls the access to this knowledge which is currently very valuable.

\subsubsection{The Yawanawa leader: a Big-Man?}

Now that a description of actual leaders of the Yawanawa allowed us to empirically define the roles they have exerted and which elements they have mobilized, it is possible to return to and validate the assertion that leadership amongst the Yawanawa bears a significant resemblance to the Big-Man described by Sahlins (1963). Sahlins compared the Melanesian Big-Men with the Polynesian Great-Men and his portrait of the former can be clearly applied to the Yawanawa leaders, notably the current ones: the Big-Man, just as the Yawanawa leader, combines an interest in the general welfare with his own self interests. "His every public action is designed to make a competitive and invidious comparison with others, to show a standing above the masses that is product of his own personal manufacture." (Sahlins 1963: 289). As for the access to power, "Big-men do not come to office, they do not succeed to, nor are they installed in existing positions of leadership over political groups. The attainment of big-man status is, rather, the outcome of a series of acts which elevate a person above the common herd and attract about him a coterie of loyal, lesser men" (ibid.: 289). Leadership is a creation of "followership", which requires the demonstration of skills "that command respect - magical powers, gardening prowess, mastery of oratorical style, perhaps bravery in war and feud" (ibid.: 290-1).

There are reasons why this image, subject to a recent inflation (Wagner 1991) should be employed with reserve. The Big-Man is not just part of a comparative typology of political power devised for a different geographical and ethnological setting, but equally an expression of a system of competitive exchange to be found in segmented societies. The conception was also criticized by Wagner (1991) for its underlying notions of society and individual which were foreign to Melanesians. Additionally, there is an unnecessary evolutionary tone underlying the conception, expressed in the fact that Big-Man societies are depicted, in the original work of Sahlins (1963), as loosely structured, unstable and, thus, less capable of producing the achievements of societies where chiefdom is an office. Some particularities of the system in which the Big-Man is inserted cannot be verified in the Yawanawa setting. They 
display no ontological social divisions and exchange has not a deep competitive logic as in Melanesia $^{48}$. Nonetheless, even if the internal competition is not as intense as amongst Melanesian Big-Men, the fate of Yawanawa contestants to power is linked to their prowess in procuring symbolic and material resources and, in recent years, two leaders have competed for them. Even before this competitive setting, which by no means indicates segmentations, there were always contests of power: Antonio Luiz accession followed the replacement of another leader, regarded as deceitful; Raimundo's brothers did not seek to replace him, but remained independent; and Biraci was able to displace Sales.

That leadership has increasingly assumed the features found in the Big-Man should cause no surprise. First suggested in some papers in Godelier's and Strathern's volume on Big and Great men (Lemmonier 1991; Liep 1991; Schwimmer 1991) and further discussed by Liep (1996), there is a tendency of intensification of practices associated with big-manship that results from the entanglement of local political systems with colonialism and capitalism. In this sense, there is a bigmanization of power, not as an imposition of colonial authorities, but as an appropriation by native leaders of new instruments and principles of social differentiation brought about by colonial processes to generate or reproduce power and, in particular, the management of exchange systems to produce asymmetries, debt and power. War and alliances, as means of securing external resources, give way to competitive quests in the market and state politics. It is worth considering that this process stands in between the two rival and schematic views on the advent of the market, as described by Hirschman (1986): these new forms of exchange bring peace and organize external relations, as the douxcommerce view indicates, but they provide new conditions for internal competition, undesirable in case of wars against outsiders, which increases the risk of divisions.

More than simply pointing out the similarities with caricatures, invoking the image of Big-manship to describe the Yawanawa political power aims at sheding light at the role of leaders in the broader circulation of things, persons and values that comprise the political and cultural economy of the Yawanawa. And this holds true even for the "inflated anthropological cliché" of the Big-Man (Wagner 1991). Based on an opposition between the individual and society that does not seem departed from conceptions revealed by the Yawanawa mythology, in which certain individuals stand out from the group - the mythical rua and shaneihu -, the conception of Big-Man indicates a person that promotes solidarity and animates the group

\footnotetext{
${ }^{48}$ This point is used by Pimenta (2006) on his description of political leadership amongst the Ashaninka, a population living in the westernmost parts of the Jurua River valley, to justify his refusal on adopting the qualification to the Pinkatsari, the leader, which nonetheless displays some features of the Big Man and many similarities with the Yawanawa leaders.
} 
beyond certain confines, whilst promoting his own personal aspirations. He makes society, so that he can stand out as an individual. He integrates and transforms the scales of production, enlisting collective efforts of the community. Moreover, his status, both the cause and effect of such efforts, is constructed through the accumulation of debts from the community: a man must give to be, and not have to be. The Big-Man distributes the surpluses produced by the collective efforts that he animated increasing his status.

At least since the establishment of the relations with non-natives and the dissolution of the pattern of common residence, the Yawanawa leaders have exactly been this force of unity, capable of mobilizing efforts to produce levels of cooperation that are higher than the houses and even the boundaries of the Yawanawa. The surpluses produced are, in turn, transformed into external objects that are distributed to the community. The suspicion on the accumulation or excessive consumption of leaders only confirms that status is based on the debt. From organizing collective hunting, to contributing to feasts, to allotting rubber trails, to gathering the population around the production of annatto, leaders in the past were animating the society and accumulating a credit. This role of transformer of scales and creator of the community finds its fullest expression in the efforts of the current leaders to creatively reinvent the cultural practices of the Yawanawa. Re-presenting the traditions, they create the Yawanawa community and its collective identity.

The Yawanawa leadership shares with the Big-manship the connection of manipulation of competitive exchange, animation of the community and production of political power. This discussion of the role and nature of leadership amongst the Yawanawa was intended exactly to emphasize the relevance of projects of political leadership to explicate economic projects that entail the movement of objects in the commodity state and chasms they produce. The production and maintenance of leadership amongst the Yawanawa integrate a complex set of permutations of debt, corresponding to the political and cultural economy of the Yawanawa. Values obtained through different regimes of exchange, i.e., political redistribution, commodity exchange and gifts, framed as the product of the skills, intrepidity and knowledge concentrated by the leader, are transformed into political loyalty.

Paraphrasing Sahlins (2008: 186), if leaders make projects, projects make leaders, for if the political relation produces economic exchange, the economic exchange also generates political relations. In fact, the relations between the workers in the projects and their managers are considered a relationship between the community and its leader/intermediary, one of generalized reciprocity, in Sahlins' terms (2008: 193-4), in which transactions are "putatively 
altruistic" and "reckoning of the debts outstanding cannot be overt and is typically left out of account". The counter-obligation "is not stipulated by time, quantity or quality: the expectation of reciprocity is indefinite" (ibid.). If on the one side, leaders can only expect loyalty in exchange for their distribution, on the other, members of the community can only expect compensation for their loyalty and, in the case of those involved in economic projects for external exchange, for their efforts. Leaders have the option of excluding non-loyal members from the delivery of goods, but they need to maintain good relations to an ample base of support to remain in power and be able to mobilize the community for collective productive tasks. Since reciprocity can only be expected, but not explicitly demanded, this source of power is fragile and generates relations that are open to permanent tensions.

The other side of this intimate relationship between political power and economic activities is that distribution of resources is eminently political, and even if part of permutations of debt that involve multiple regimes of exchange, framed in a language of gift and favor. This means, as further explored below, that the distribution of resources is in no way a strict compensation for activities actually performed in relation to collective economic projects, as confirmed by both leaders and many other members (see BBY, JY, RSY, JBY, and JMY). In fact, maintaining the native ideology that these resources are political gifts and collective efforts oriented to the community and not individual gain, is part of the skills required from leaders to maintain the legitimacy of their power. Reproducing this ideology of the gift is crucial to keep power, legitimacy and to elicit collective efforts for producing. A good leader must animate the society appealing to notions of common good and collective interest, for big projects which, in turn, make them leaders. This point needs not to be fully developed here, since it is at the crux of conflicts of expectations involving the urucum project.

Yet this aspect sheds light in skills that are required of leaders in connection to their ability to forge relations, promote exchange, procure and distribute resources. They must use opportunities of social gathering to emphasize their efforts to forge exchange and bring resources in a way that the nature of gift is reinforced and loyalty is covertly demanded. These gatherings should also serve the purpose of reaffirming an ideological notion of community to siphon collective productive efforts and the fundamental role of such efforts to strengthen the community as a whole and not benefit its individuals. Consequently, as already asserted, oratorical skills to communicate the abilities are a complementary trait of leaders, both inside and outside the community. In fact, not only leaders, but notable men attempt to be good 
orators, and are very fond of good speeches. This is a condition to report their successes in a way to justify their position, but also helps them to forge alliances and negotiate benefits, notably through state and federal politics. In fact, a glimpse into these gatherings and assemblies, which I try to offer in box 3, provides rich insights into the workings of leaders and their different styles.

\section{Box 3: Two leaders, their interactions and what this says about leadership}

I argued that different elements are available to construct claims to leadership and particular contestants will mobilize them not just according to the relative worth of each of them in particular contexts, but also according to their personal capacities and strategies of mobilization. In fact, contexts for power are expressions of different personalities. The role of their personalities and situational definitions seems to be far more relevant than I can substantiate or explicate here. Trying to understand it raises the problem of how to understand the individual or personality in social sciences, and not least because these leaders, and especially Biraci, could be said to be fractal persons, individual and collectivity in one (Wagner 1991).

Since the foundational methodological statement of Durkheim (1983 [1895]), confining the object of sociology to the external expressions of modes of being, thinking and doing, in opposition to psychological streams, the role of individual traits, even if only to understand how actors creatively reinterpret external - objective - conditions of action, have been one of the major debates of the discipline and caused great trouble for those who recognized such role. The introduction of the notion of self by H.G. Mead (1934) and following works of interactionists were far from consensual and just added fuel to the dispute. These attempts were often chastised for introducing unnecessary psychologisms, or in the words of Bourdieu, trapping the analysis into a limited subjectivism that could not fully account for human agency (1980).

There are, in more recent times, a number of attempts to solve the agency-structure divide, to bridge objectivism and subjectivism, many of which simply accept both without actually solving the problem (Martin 2003). Bourdieu (1977; 1980), for example, proposed the concepts of habitus, capital and field ${ }^{49}$. These notions seem to do little to illuminate the importance of individual traits here, because these leaders had very similar socialization, came from similar social milieu and pursued the same strategies of accumulation of capital, albeit in different spaces. Following Biraci and Joaquim in the town and in the village reveals complex personalities which are situationally defined and individual variations of general dispositions, in ways particularly akin to Lahire's (1998) conception of

${ }^{49}$ The latter which, interestingly, given the strong rejection of psychology by Bourdieu, was first developed by theories of Gestalt (Martin 2003) 
plural actors. Nonetheless, this theoretical digression has little purpose other than asserting that an analyst might have troubles, as I do, to single out a social theory to make sense of the role of personalities to define leadership styles and actions of Biraci and Joaquim. General categorizations of authority, such as the famous Weberian typology $(1978$, ch. 3), might help, but to say that Biraci is a charismatic leader, whereas Joaquim is more of a rationalized patrimonial type, might be too farfetched or a hastier caricature rather than the ethnographical description.

True, the discourses, interactions, presentations in public of these leaders are good to think about these theories. Yet and risking at some contamination by pyschologisms, I believe that far more than validating theories, describing some scenes of interaction of these leaders in the town and the village helps to understand how leadership claims are actually constructed and move from a fairly abstract and conceptual discussion above, seeing how these elements actually work.

Living in a larger town - Rio Branco - Joaquim is fairly anonymous. Fairly, because during the access phase of my research, I found Joaquim at the central square of Rio Branco, suggestively named Peoples of the Forest (Povos da Foresta) talking to two men of another indigenous group. Joaquim is certainly known to the local movements of advocacy of indigenous Peoples' rights and to some politicians. In future encounters, and during the local elections, he often made comments about close politicians. Joaquim shows less interest in state politics and is fairly critical of some politicians. He also scourges public policies of social assistance and the individual dependence they would create. $\mathrm{He}$ makes no attempt to disguise that his actions in political forums are purely interested and intended to obtain benefits. His world is not confined to Rio Branco or Acre. Since his period living in the United States and with support from Aveda, he has maintained contacts with international organizations, discussing topics of heritage, intellectual property and, more importantly, the market for environmental services and the REDD program. During the United Nations Conference on Sustainable Development (UNCSD, Rio+20), in July 2012, he attended one of the several parallel sections as a guest speaker. He confided to me, before travelling to Rio, that he had no intention to discuss environmental regulation. His participation was a way of looking for new partners. Joaquim also allows less time for meetings and conversations. My interactions with him where always relatively short and normally interrupted by him, who excused himself alleging that he had other appointments. Joaquim is very enthusiastic about new media and technologies and uses them to promote his people. It seems that every of his actions is calculated to obtain immediate results in terms of collective and individual gain. His position as a leader is framed as a personal sacrifice motivated by a call. Married with one child, Joaquim asserts that he returned from the United States after repeated dreams in which he was asked to return and help his community. At that time, he says, the community was adrift and the good partnership with Aveda in peril. He had no alternative, goes his reasoning, other than curtail his life abroad. And without any material gain, he emphasizes. In other words, he saved the project. Biographical illusion (Bourdieu 1986) excused, this account reasserts the historical - and heroic agency of the Yawanawa elite in their narratives, a topic further analyzed in the next chapter. 
If the comparison is allowed, Joaquim sounds like a member who was called to assume the family business. And as further discussed below, he has a model of business that attempts to maintain the exclusivity of the access to the Yawanawa and their culture. In so doing, the value paid for it, he asserts, could be higher. He rules by result and concentrates his efforts in seeking new projects to bring income and improve the conditions of the community. Perhaps a better businessman, Joaquim does not seem to have realized the full extent to which gifting is a political act. According to him, he distributes resources to communities - not individuals. Distant from the village lifestyle, he does not pretend to be a good hunter. He praises and promotes the "traditional" style and its associated practices, such as fishing, hunting and organizing their rituals and even frames it in terms of their heritage and their value. Yet he does not partake in such activities, except for rituals, when he visits Mutum with or without visitors. He goes to Mutum frequently to discuss collective activities.

I had the opportunity to visit the village during one of such meetings, but was kept outside the house where the discussion was taking place. It was a very long meeting at close doors, involving only a small number of members: his siblings Katia, Paulo and Mariazinha, village leader, and few men who coordinate the work with annatto. Neither Joaquim, nor any other of the attendees shared any information. At that time, the village received representatives of a French NGO that intermediates deals of carbon credit and I supposed that this was the subject of discussion. In any case, Joaquim displays an appearance of professional management, although complaining that he makes no money with the projects. His main compensation is political loyalty. Despite his position as an heir, he knows that loyalty depends on his capacity to seek new partners, maintain good relations with Aveda and bring resources. This was the reason why many of his followers abandoned Nova Esperança. Joaquim equally frames projects and economic opportunities in general as means of collectively helping the community and criticizes individual claims. At the same time, Joaquim reveals some ideas that would be sufficient to classify him as a liberal: he defends the personal and autonomous initiative of indigenous Peoples and, more importantly, is critical of state transfers, although not being politically able to prevent them (JY).

Biraci, in turn, suggests a character that is more of a politician, a diplomat, than a business executive. His actions in town suggest his reputation. I had the opportunity to accompany him through the streets of Cruzeiro do Sul days before my trip to the Indigenous Land. His stay in the town does not go unnoticed to local shop owners and other notable members of the local community. He was stopped by several of them in the street. Biraci, in turn, is not indifferent to this respect and, as explored below, knows this is associated with the successes of the Yawanawa in promoting their image, attracting outsiders and generating income. Since this stay was right after he was invited to join the state government as a special advisor for Indigenous Peoples' Health, I witnessed as many men would suggest that they or close relatives were available to help in health districts, the local centers of attention to health of indigenous populations. Biraci always confirmed that he would have the power 
to designate people to work in these districts and maintained their hopes of getting these positions. Biraci has a local network of allies, result of continuous exchange over years. His conduct of business is a mobilization of this network. At a supermarket, after being denied a discount, he left the goods he had selected and expressed his frustration: if the supermarket manager does not offer a discount, he is not a friend, because friends make discounts, he said. And "I rather buy from a friend", he continued. He always invites people he meets in the streets to visit Nova Esperança and see its tranquility.

It is his life in the village, however, that is more revealing of the ways he claims leadership and reasserts loyalty. Biraci strictly espouses a vision according to which the world of the village and the world of the town are two separate, guided by specific codes. At the sunset, sitting with his loyal men on the tip of the cliff, Biraci turned to me, as the only outsider in the group, and said that, in their territory, everything is inspired by the spirits of nature. It is nature, he insisted, that guides him to do the best for his own people. When I met him in Cruzeiro, he also revealed that the spiritual world and the material world must be separated and said that spiritual practices belong to the sacred village, despite the fact that he promotes performances in urban centers. Upon the loss of control of the production of annatto, Biraci espoused a sort of native "hostile worlds" (Zelizer 2005) vision, dividing material and cultural processes and interests, a vision that is endorsed by all his loyal aides fully committed to the project of cultural reinvention and further discussed in the next section. During these meetings, the conversations are all about mythical creatures, anthological hunting and fishing parties of the past, distant forest spots, all suggesting the command of traditional skills. Biraci clearly seeks to be perceived as a man of tradition, a good village man, which in turn corresponds to the expectations of outsiders, always looking for pristine communities. He is a warm host and a good entertainer, sharing legends and stories about the Yawanawa over meals with visitors.

His meetings with groups of loyal men at the dining hall of his house or his community assemblies are true political events, in which loyalties are asserted. These are two different occasions. Every morning, when food is ready, a group of loyal men (Aldaíso, Juraci, Manuel Pequeno, Valdemar, Kuni, Manuel Pequeno, Nani, Manuel Nainawa and some elders, notably Jorge) and some youngsters gather around a table. This is public display of loyalty. Albeit open to any, only close aides and those seeking an audience with Biraci join. Wives of these men bring contributions to the common meal, but did not stay. Absences of some members are mentioned during these meetings. Biraci utters long speeches, alternating between reminders of his generosity, advises and warnings. In these long exercises of clientelism, the leader shows how the population is dependent of his prowess intermediating jobs at the state administration or resources. He is sometimes interrupted by men who confirm or agree with his words. In a meeting I attended, Biraci warned the youngsters about the importance of remaining loyal and being grateful to the leader, who could, in turn, offer them opportunities. In his own words, "those who have never been with me, I do not remember, I do not think about them". More than Joaquim, Biraci seems to know well the pivotal role of displaying generosity to his followers. He reminded them that they had the largest number of government jobs of 
all Indigenous villages in Acre, thanks to his political influence. He went on enumerating his achievements since his epic journey to Rio Branco, at fourteen, with his cousin Sales, escaping with rubber that they could not sell outside of the estate. In a speech that was intended for the community as much as for me as a visitor, he recalled the story of their fight for their land rights, the expulsion of foremen and representatives of the rubber estate, followed by the expulsion of missionaries and other feats, such as the construction of the school and the training of a health agent. Biraci added that during his absence he had negotiated a health clinic with a permanent doctor and medicines, as well, as the construction of fish ponds. He rhetorically asked who was responsible for all that, to later reply that it is thanks to his political bonds that the community obtains all these benefits. The age of projects, he said, is over. Implicitly denying the possibility of developing a market activity, he argued that the private sector only helps populations in severe need, and they were not in such a bad situation. Politics, he shared, is the way of obtaining a better life, justifying the absence of projects other than the festival bringing significant economic resources to the population. He also praised the village life, discussing the challenges of the urban life, with unemployment, poverty and talking about the "blessings" of having a recognized land and the spiritual connection with the forest that attracts so many visitors, interested in obtaining some of their knowledge.

Days later, Biraci, who was about to leave the village to assume the position of State Special Advisor on Health of Indigenous Populations, would call a public assembly, and repeat the same exercise of display of his achievements and praise of the village life over a three-hour long meeting. Attended massively by the community, and in this case also women and children, the assembly also served for Biraci to remind his fellow Yawanawa about the value of their culture and the importance of protecting their forest. He mentioned that keeping the forest had become a form of obtaining resources and asked them not to create new gardens. He justified his future absence, which was in fact short, reminding them that he would continue to act on behalf of the Yawanawa. These general assemblies, in which sacrifices are asked, benefits offered and collective interests reasserted, are an instrument to create and project community, a union of a centennial assemblage of families.

Biraci appeals more to the traditional qualities of a Yawanawa, not least the spiritual knowledge that would be necessary to guide the people, including its activities to procure material resources. Biraci equally insists that preserving their "culture" is the most important task of the community. Knowing that these abilities represent symbolic and economic capital, he is not refusing access to those things that are associated with modernity. And at the same time, despite publically saying that the "age of projects" is over, he confided that his organization must create income opportunities and bring industrialized goods to fulfill the expectations of the population. I believe that more than a plain rejection of the material aspects related to leadership, his traditionalist attitude is an attempt to transform his position in an office, protecting it from the vagaries of the market and the need to procure resources. As any Big-Man, he wishes to become a great man (Wagner 1991). 
This section dealt with the role of leaders bridging interior and exterior, promoting the circulation of things and persons and, thus, animating relations and the very community. This should serve the purpose of demonstrating that divisions that emerged in recent times are related to the contests for leadership and those, in turn, are expressed through the capacities of leaders to promote the circulation of objects. Additionally, it indicates the central role of leaders in the politics of value that underlies the diversion of things into the commodity state. This long debate on the elements and nature of political power amongst the Yawanawa is justified exactly because leaders are the central characters in the efforts to control and promote the circulation of things. Not least because they must mobilize the community and advance arguments to justify the requirement of efforts and the movements of their objects or performances. Yet, this is only a fragment of the political and cultural economies of the Yawanawa. The controls that leaders command over the circulation of objects, persons and symbols is significant, but they do not account for the full circulation or its interpretation by the community. In order to understand their engagements with the exterior, the meanings and expectations regarding the commodification of some of their belongings, it is equally important to analyze how the material production and external objects are inserted into the existing social relations and interpreted according to native cultural schemes.

\subsection{The production of life amongst the Yawanawa: work, goods and money}

The last section outlined that the production and exchange of value is political. It also revealed the relations between the leader and community. This section will attempt to show that production and exchange of value is also rooted in social relations and their cultural scheme. Showing how the Yawanawa produce individual and social life and how objects circulate to, from and within the community, I continue to explore the political and cultural economy of the Yawanawa. In analyzing objects that come in and out, and the relations in which they are inserted, the aim is to reveal this cultural economy, whereby not just culture mediates the flow of objects, but also objects mediate between cultures. This is analytically relevant to show that the relations forged by the Yawanawa with the market and external 
institutions, entailing the circulation of local and foreign objects, does not represent the destruction of their culture or social relations. Understanding the particular meanings they bestow on productive activities and objects they obtain through exchange is also significant to understand how and why producers are willing to invest their labor in producing and promote the circulation of their objects, or in other terms, the politics of production.

Research has shown in the past decades that all things, and even the most impersonal of all, money, are subject to earmarking by particular social relations (Zelizer 1994), cultural reconfigurations according to local systems of classification (Sahlins 1976; Sahlins 1988; Sahlins 1999b; Thomas 1991; Taussig 1980) and particular moral judgments, related both to social relations in which they are employed and cultural classifications (Parry/Bloch 1989; Taussig 1980; Wilkis 2013). Every cultural system has a native scheme of classification that allows interpreting and acting upon new elements, incorporating them with local accents in existing social relations. Even disruptive forces are signified locally and prompt particular emotions (Sahlins 1985). Taussig's (1980) study with the peasants of the Cauca Valley (Colombia) is a good example of how even Western symbolic interpretations of material processes - in the case, alienation of labor and commodity fetishism - are subject to reinterpretations. For the peasants, this is a pact with the devil, which renders money good for consumption only, never to be employed for productive ends. Wilkis (2013) studied how money prompts different judgments according to the origins and uses amongst the Argentine poor, in a context in which money is scarce, subject to rapid changes of value and seizure.

Sahlins (2013: 179) demonstrates with a plethora of examples the widespread, or indeed general, practice of embodying foreign goods with otherwordly powers according to local schemes of interpretation. For the South American lowlands, besides general observations on the ontological predation, which manifests itself in the constant incorporation of the other and its possessions (Gow 1991; Viveiros de Castro 2002c; Cunha 2009), ethnographies show transformational powers attributed to external objects. Hugh-Jones (1992) writes about the desire of the Barasana of Colombia for European objects. Far from being an external imposition upon them, these are desired for the powers they contain. These objects are considered a creation of shamanic powers of the father of the White people and now come from the world of the dead, represented as the towns of the Whites. The possession of these objects leads them to contact the world of the dead and allows them to act against their better judgment. Gordon (2006) is the author of a comprehensive analysis of the domestication of money and goods amongst the Xikrin Mebengokre, which shows not only how money and 
external goods are used to reproduce social relations, notably kinship, but also how it animates the internal exchange of symbolic and political economy of onomastic. Money is an operator of transformation, a magical object that allows incredible productive capacity (ibid.: 278), is employed to produce persons and more specifically, "beautiful persons" (ibid.: 339).

A rapid recollection of the discussion on the role of alterity (chapter 2) should suffice to evince that, for the Yawanawa, there are also "vital powers that inhere in otherness" (Sahlins 2013: 180). The Yawanawa were created with others (close ones), and asked for the Whites (the Nawa), even when warned about the incredible powers of this new people. Besides the account of the Muka Veine (again, chapter 2), many accounts of the challenges of relating with the Whites are framed in terms of how to appropriate their powers. Manuel Nascimento Pequeno, Kapakuru, is particularly clear about this in a testimony to which I shall return again in this section:

"If we only know our side, we will not be able to relate with the White, we will not be able to know the things that are very big for us to hear. We, indigenous peoples, do not have this gift that the White has. Currently, among our people, we call the White by the name 'Erunawa'. Why do we name the White 'Erunawa'? Eru is iron. Then, they [we] compare [say] that they are the sons of iron, the sons of technology. We did not create that technology. That technology is something of the White people. Thus, to relate we need to learn, we need to study" (MNP).

Objects of the Whites are considered the result of a gift (in the sense of talent) they do not possess and, thus, they want to master how to use them. However, this statement should not be exaggerated: he talks about these objects with wonder, but does not reveal any particular symbolic device or ritual through which these objects are signified by the Yawanawa. Moreover, Kapakuru, a teacher at the school in Nova Esperança, is a researcher of the Yawanawa legends and traditions and deeply involved in the project of reinvention of "culture". Thus, he has an increased concern about the place of such things and tries to find and justify a balance between traditions and modernity. And even being in that position, he reveals no negative moral judgment on external objects. The challenge revealed numerous times by the Yawanawa who take active part in this cultural project is how to regulate and control new elements, perhaps how to domesticate its powers.

Outside this group, there is not much reflection upon the role of external goods or money, incorporated in their social lives. In fact, external objects are never treated with 
estrangement and no particular symbolic devices or rituals natively employed to justify their use. They seem to be an integral part of their lives - including ritual life - and justifications or explanations only emerge when the researcher questions them. The absence of a strongly symbolical mechanism to interpret and incorporate such objects does not mean that they are devoid of particular social and cultural meanings. Even without a shared and active cosmological meaning to these objects, they do seem to possess a great power, as Kapakuru asserts, to the point that they justify efforts to obtain them ${ }^{50}$. Moreover, the local system of social and cultural reproduction bestows specific meanings, roles and uses to such objects. Work, goods and money are instrumental to the Yawanawa and put at the service of the production of individual, social and ritual life.

The society described here is not traditional. The Yawanawa are not a pristine community, uncontaminated by the contact with outsiders, from natives to Europeans and, later, what came to be Brazilians. However, the local dynamics are particular, not a simple reproduction of national or international forms and processes. The multiple institutions and objects that were inserted into the Yawanawa forms of producing individual and social life were reinterpreted according to their social structure. This is not to say that there were not significant changes in their ways of living. The continuous relations with non-natives also led to the incorporation of new instruments of social and cultural reproduction that became an essential part of their lives and, over time, led to a relative erosion of relations and the scheme to interpret foreign elements. Yet neither culture, nor the relations it entails disappeared. And most new elements and institutions have been introduced into ongoing relations and cultural practices.

Much of the traditionalist discourses of some members may be reputed to an existential strategy that is symbolic and material. In general, it reflects specific views about the future of the community, expectations and attempts of the leaders to control the circulation of objects. That "foreign goods are turned into the service of domestic ideas and notions of good life", as Sahlins (1993a: 17) asserts, is the crux of the question here, for there is no single notion of good life. The engagements of a community with the global circuits of capitalism come with different expectations, especially amidst an identity project and in a moment in which its livelihood increasingly depends on this project. As a result, they face the challenge of

\footnotetext{
${ }^{50}$ This power is not essentially different than the power goods command in Capitalist societies, except for the fact that they are recognized as objects of the external other and it is reasonable, as Sahlins (2013) states, that the value and power originate, at least partially, from the distance.
} 
balancing the forces of modernity and the desires to preserve their distinctive habits they held as traditions.

Identity is forged through the assertion of a difference that also reflects expectations that outsiders, the Whites, project on indigenous populations. Moving in this play of mirrors, incorporating instruments of the so-called modernity, whilst exchanging the representations of difference, translated in particular practices and habits, are actions surrounded by ambivalence and a multiplicity of expectations in the community. These are the most fundamental traits of the social and cultural circulation of objects in and out the Yawanawa community. Both the more traditionalist discourses involving work, goods and money, and the unproblematic way with which they approach external things in instrumental ways are part of the ambivalence and the different expectations involving their entanglements with the global economy. There are, in fact, different views for the future of the community, which emerge in the controversies involving the production of life. As Gordon (2006) states for the Xikrin, these views speak in terms of tradition and change to advance a narrative of cultural survival. Their differences lie in defining where each of these terms are located. Multiple expectations may be placed into a continuum from the most traditionalist and collectivistic position, to the most productivist and materialistic. And even this representation does not bring out a reality in which the former position might yield more material gains than the latter. In any case, it should be evident that these expectations are at the center of the politics of value underlying the production and circulation of their cultural representations in the commodity state.

In order to capture the ambivalence and the different expectations, we must understand the cultural economy of the Yawanawa: how money and objects circulate and the values they carry. But before, in an attempt to demonstrate the nature of their entanglements with external institutions, and show how they are put at the service of social relations and ritual, I turn to the units and vectors of solidarity and the productive activities performed by the Yawanawa.

\subsubsection{Units and vectors of solidarity}

The units and vectors of solidarity amongst the Yawanawa matter because they guide the flows of goods and monies within the community, determining the permutations in the forms of circulation. Solidarity is kin-structured at its basic level and may be depicted as concentric spheres, from co-residents, to close and potential affines, to distant cognates, which correspond to the entire community, since they share a common ancestor. The 
existence of two leaders only affects activities of their organizations. The basic unit of solidarity is a house group ${ }^{51}$, organized around a male elder. Currently, most houses are inhabited by a man, his wife and their single children. Yet these houses are linked by matrilocality rules: all the daughters of a male elder, her husbands and their single children share a group with a common fund. This unit creates intense flows of solidarity and economic cooperation expressed in a common fund of rights and obligations. The basic subsistence activities, such as working in the gardens, hunting, fishing and collecting forest resources are shared by this fund. The bulk of labor is performed and the main means of subsistence of these units are obtained in gardens maintained by each group. They also constitute basic units of circulation of monetary income as gift. Wages, compensations and state benefits also integrate the common fund.

Close relatives, in the same or in different villages, are the next unit of solidarity, less intense than the house group. They exchange food, game, money and industrialized goods in case of necessity. Kinship also animates solidarity between villages. In some of my trips, I participated in the gifting of game to relatives living in different villages. In case of need, money or industrialized goods are also given to relatives outside the house group. This kinbased flow across villages, sometimes affiliated with different organizations, and notably between Nova Esperança and Mutum, is a good evidence that the dual representation of the Yawanawa and the associated conflicts did not represent an actual division of the population. These relations confirm the impression of many Yawanawa, that the competition is now restricted to the leaders. In addition to regular relations animated by kinship and eventual gifting of game, fish or even some goods in case of necessity, some members also move from one village to another to stay closer of the families or to take part in economic activities. Valdemar and Luzia (Waxy) are two examples involving the main villages of each of the organizations: Valdemar moved to Nova Esperança to take up a position as a teacher. Luzia, divided in her allegiances, alternated between Mutum and Nova Esperança, finally settling down in Mutum to undertake the initiation to become a healer.

Larger groups, normally within a village, also join collective hunting and fishing parties, clean the village, work in collective gardens and for economic projects held by the community. Game and fish are shared amongst the participants, but as discussed below, they expect an individual reward for their involvement in productive activities that are not for

\footnotetext{
${ }^{51}$ House here is employed here in the sense of dwelling, and not in the sense employed by Lévi-Strauss (1984) to describe House Societies. The groups are just a number of physical houses grouped around an elder and a common fund of obligations and rights, and not a moral person that perpetuates its name, titles and fortune, in a principle of societal organization that is alternative to kinship, as in the formulation of Lévi-Strauss.
} 
subsistence. Each house has a representative who attends meetings summoned by the village leaders Joaquim and Biraci. These gatherings were already described in the context of leadership claims. They constitute an arena for reasserting loyalties and discussing undertakings of the village or their legal organizations. Larger assemblies in Nova Esperança also serve to inform the community about benefits and projects negotiated with their allies. In general, they are moments in which a village-wide or organization-wide solidarity is experienced, even if masking frustrations and differences. Less than loyal members or those at odds with Biraci do not attend these meetings. Dealing with a much smaller group, the meetings organized by Joaquim do not reveal the same dynamic.

In general, the community life in the larger villages is sparse in the absence of the leaders. Social life tends to be limited to house groups and close relatives and friends during the periods of their absence. This holds especially true for Nova Esperança, demonstrating the role of the chief in animating the community. During most of the period corresponding to my first visit to the village, Biraci was absent dealing with his nomination as Special Health Advisor. There were not many occasions in which more than close relatives and friends assembled or organized joint activities. Exceptions were uni ceremonies and the gatherings of men during the sunset on the top of the cliff facing the river to share their adventures in the woods, their encounters with snakes, jaguars, stingrays and enormous fish, or remember legendary battles. But the village life was transformed upon Biraci's arrival. Besides meeting his loyal men every morning for joint meals, and discussing collective works for the village, he also organized a number of village-wide activities, such as a football tournament. The role of the leader to animate the community besides the limits of the close kin is essential.

Other instances that generate solidarity at the community level are the rituals, the annual festival and the school activities. Both Mutum and Nova Esperança hold all these activities, but I only experienced them in the latter. The re-invention of traditions amongst the Yawanawa led them to stage their ritual games and dances (mariris) as a practice to disseminate the knowledge about them and prepare the community for their annual celebration, turned into an occasion in which they receive a large influx of visitors. These rituals are part of the broader socialization and strategies of coupling. Therefore, they are joined by large numbers in Nova Esperança, but not by all of them. This fact reveals different views on the intensification of the practices that, according to the elders, was only interrupted during the period in which Protestant missionaries were present. Some are simply disinterested, but others, faithful to Christian beliefs, refuse taking part in these rituals. 
Additionally, there are regular night uni ceremonies, in which a healer and a small group of people engaged in regular cultural practices, notably youngsters, gather around a bonfire. The ritual they carry out consist on the consumption of the hallucinogenic brew uni and the singing of chants in order to activate the transforming operator of the yuxin, the spirits, contained in the sacred vine employed in the concoction. The spirits guide the participants through visions that are considered a means of spiritual healing and guidance ${ }^{52}$. These ceremonies congregate members of the group of romantics and, notably, youngsters interested in learning more about the shamanic system. Attracted by the hallucinogenic experience, these ceremonies lure them into the universe of cultural practices. Some of the romantics recognized that uni is as a major factor enlisting new generations to their ranks (ALV). Since the chants are sung in Yawanawa, participants in the ceremonies become interested in learning the language, and often also develop an interest in obtaining more knowledge about cultural practices in general, if not in the currently very attractive shamanic career, as further discussed in the next part. It does not seem trivial that these ceremonies became the main cultural expression of the Yawanawa and other Pano groups that consume similar brews, within the community and with outsiders, displaying the selectivity with which "culture" is reinvented and performed. This is far from a consensual phenomenon amongst the Yawanawa. More than the dances and games, these practices are object of disapproval on several grounds. This is part of the tensions in the politics of value of the circulation of such practices and will be analyzed in the next part. Nonetheless, once more reflecting different views on tradition, the censure ranges from the fears of those who remain Protestant, to criticisms on the transgressions of meanings and forms of these rituals as a result of the contact with different cultural traditions.

Albeit a matter of contention, the mariris and the ceremonies form the basis of the Yawanawa Festival, originally an internal annual weeklong celebration of the community and its ideals, ritually represented in the games, dances and ceremonies. These feasts, which now attract dozens of tourists, require collective preparatory works and produce collective and individual resources. Object of the last chapter, these feasts are interruptions in their daily labor activities to celebrate the community and are joined by the majority of the population. In preparation for the celebrations they would organize collective hunting and fishing parties and share the prey during the feast. Currently, both organizations organize festivals open to

\footnotetext{
52 Without discussing in depth the particular symbolic significance of the experience as part of the Shamanic and Ethnomedical system of the Yawanawa, it is nonetheless possible to invoke the famous comparison made by Lévi-Strauss (1973: Ch. X) between shamans and psychoanalysts in his analysis of the Winnebago myths: the shaman provides a language, through which the patient makes sense of her condition as the spirit that causes the disease is guided out of the body of the patient. This language, a myth, is shared by shaman and patient.
} 
tourists. The state government provides support and offers benefits, as part of their commitment with the indigenous populations and knowing that these events attract visitors. Those, in turn, represent one of the main sources of income for the community and some families, which sell crafts and obtain some donations from new friends.

Finally, the schools are an important instance of socialization and production of life amongst the Yawanawa. Materially, they are responsible for employing 15 teachers only in Nova Esperança and others in Amparo, Mutum and Tibúcio, in addition to providing food for children, which is normally distributed to the houses. More important than income and food, is the space the school provides for a socialization of the new generations and the development of the project of cultural reinvention. These schools are inserted into a project maintained by the state government of Acre to provide differentiated and bilingual education for indigenous populations, result of the articulation of representatives of these peoples claiming special rights and the State Council of Education (ALV). Their classes include Yawanawa language, the sacred chants (saites) and the practice of the traditional dances and rituals (mariris). Children are also taught how to prepare the attire for these dances, a skirt made of palm leaves, and the patterns of body painting that represent different animals and symbols of the Yawanawa mythology (kenes). The schools are not only the institution in which the project of cultural reinvention was initiated in the late 1980s (ALV, VLA), but also often associated with the creation of the Yawanawa Festival, discussed in the next part (VLA).

Perhaps, in no other social space the ambivalence about adopting the new external forms whilst preserving their distinctive ways is as evident as in the school. The differentiated education lies at the crossroads of the attempts of the indigenous populations of Acre to learn necessary instruments to dialogue and move in the world of the Whites, whilst acknowledging the need to use this space to reproduce the markers of their difference, the traditions, before their total demise. It is also at the schools that this challenge to define a middle ground between embracing modernity and preserving tradition appears to be more a reflection on existential dilemmas and less permeated of strategic considerations on power and external reputation. This is not to say that the school is protected from the conflicts between leaders and different views on the paths of the community. In fact, they are reflected in the tensions to define the role of the school in the socialization of children. However, the romantics, who dominate the teaching positions, albeit nominated by the leaders, seem to espouse a genuine interest in rescuing cultural practices and traditions and protect what they recognize as a 
"culture", a unique set of artifacts, practices and knowledge about the world ${ }^{53}$. Teachers are amongst the most purists of the romantics. This does not translate into a rejection of novel objects and forms, but on a focus on research and practice of things they regard distinctive, to which the school is pivotal. Aldaíso tells that:

"when I returned to the community to work [...], the question was to work in the school to really strengthen our culture in relation to our ceremonies, our history, myth, dance, chants, rituals and the strengthening of the language. [The project was] to look, research a bit on the origins to work this as a material for the Yawanawa education" (ALV)

They want to live as "real Yawanawa", as Aldaíso told me, and find themselves dealing with different expectations of implementation of a state policy. They know they need, and the parents want, to teach children how to move in the world of the Whites. At the same time, they see the school as an instance to learn and recreate their traditions and to decolonize their minds. The latter attitude finds a telling example in their complaint against school books that represent a nature much different than theirs and, thus, to which they vaguely relate: "[children] must take the book by the Secretary [of Education of Acre]. Nobody knows what is written. It has nothing to do with our life. Instead of studying the tapir, which is from the forest, children study elephants, from Africa" (FL). This is a sort of imported knowledge that clearly does not help them to move in any world and, thus, can be easily repelled. Yet not all questions are so easy to solve in the attempt by the community to find a balance in socializing their kids in both worlds. They want them to learn the traditions, the signs of difference with which they are acknowledged and respected by allies, and which entitles them to special rights and benefits. They also want them to learn about the national society, its particular institutions, forms of exchange and the economy. They want the school to preserve and spread their language and traditional knowledge, but the new high school has the declared intention to promote the admission of youngsters to university. The renewed interest by outsiders on their knowledge and cultural practices and increased support from the state government seem to shift the balance towards more emphasis on the traditional side of their education, partially bridging the two main goals of schooling. As the worth in their difference is acknowledged by outsiders and the state, knowing the "culture" becomes, more than a romantic interest, a way to forge relations with non-natives and bring resources to the community. Tensions, however,

${ }^{53}$ As previously argued, their position also allows them to do so: their wages allow them to reject income opportunities related to productive activities. 
remain: to define the content that defines this difference, the conditions of access to the knowledge that is praised by outsiders and to preserve spaces of social life for those who do not embrace traditions.

\subsubsection{Work}

The production of individual and social life can hardly be separated. If on the one side, the productive efforts of the Yawanawa are structured by their solidarity bonds, on the other these are produced by the exchange of the results of these efforts. Thus, productive activities, for subsistence and for external exchange, are inserted in social relations. Other important features about labor amongst the Yawanawa are its relation to ritual and its essential instrumentality in terms of securing means they consider adequate for their subsistence. Interrogating the Yawanawa about their working activities in the past, as rubber tappers, and currently in the projects, the aim was to trace the formation of a rational disposition to produce surplus for exchange. The interrogation of their patterns of work, which are necessary to explain the production of objects for circulation in the market, initially followed the analysis of Bourdieu (1977; 1979) about the formation of wage workers in Algeria and the disenchantment of the world, replacing customs of allegiance and honor by dispositions of rational calculation. In order to survive in an economic system imported by colonization, Bourdieu (1979: 3) argues, workers must learn the rules of this system, with its "techniques of payment or marketing, methods of accountancy, calculation, and organization". In effect, the reception of these demands, he contends, is mediated by creative transformations by local agents using customary dispositions. Yet this is but a transitional phase: "economic organization tends to impose itself as a quasi-autonomous system which expects and demands of the individual a certain type of economic practice and dispositions [...]. The spirit of calculation and forecasting, insensibly acquired and assimilated through implicit and explicit education" (ibid.: 4). The acquisition of such dispositions, he added, is differential and based on the social position of the agents. Thus, some would have more conditions to adapt, whereas others - and his analysis of the unemployed confirms his contention - would be remnants of a past.

The next chapter puts to empirical test the applicability of this argument in the Yawanawa history, but describing the ways their productive activities are organized in their lives, both for subsistence and for external exchange, should suffice to conclude that the 
Gregorio River is not Algeria and the Yawanawa world is far from disenchanted ${ }^{54}$. Neither decades of rubber tapping, nor their involvement in large economic projects analyzed here led to a replacement of their instrumental, autonomous and ritualized approach to labor. Moreover, all those aspects that would be expected from market actor seem absent. Long term planning, forecasting, calculations on maximization of profits are generally absent and even amongst the notable men responsible for large economic projects, not many display these abilities. In fact, they associate the lack of such dispositions with an unpreparedness to manage large projects and the intake of resources, as better explored in the next part.

As said before, they are not traditionalists, do not reject working and do not hold strict moral views on labor or the objects they obtain in exchange for it. In general, the first observation yields a portrait that conforms to European prejudices about the natives in the Americas: they have "moderate standards of sufficient work", to use the apt expression of Sahlins (2008: 52). Far from confirming the anxious chronicles by Jesuits on the difficulties to convert and discipline the savage souls (Viveiros de Castro 2002a), this fact may be interpreted according to a different vantage point: the Yawanawa are constantly occupied in their productive activities, but they have no urge to accumulate objects or money and believe work is strictly a means to obtain necessities, both forest resources and industrialized goods they incorporated in their social lives. This reality runs against theories that predict that the insertion of local populations in the global circuits of capital necessarily represent their submission to relations of forced or wage labor, such as World-System Analysis (Wallerstein 1974).

As further explored in the next chapter, their involvement with activities aiming at obtaining external objects did not imply shifting the focus of their lives, abandoning their subsistence activities or the social and symbolic relations in which they are inserted. Working conditions have not been imposed from the outside, as the difficulties to meet productivity goals set by their contracts with partners in the last decades prove. Collective activities are requested and organized by their own leaders as part of an exchange of material benefits and political loyalties. And even the chiefs do not command any coercive powers. They all stated that engaging in any activity, especially the collective works and those for outside exchange, is a decision of each individual. The Yawanawa work according to their own schedules, rhythms and to produce amounts that they find sufficient to meet their needs. Some activities

\footnotetext{
${ }^{54}$ In fact, when Bourdieu (1977; 1979) equates these set of dispositions to a 'cosmos', just as Sahlins (1976) demonstrated that rationality itself is inserted in the Western cultural system, he betrays his argument on disenchantment of the world. The world of rational calculations, this cosmos of capitalist economic action is no less enchanted than any other economic system.
} 
are even equated to leisure, especially when they unite large number of relatives. The compulsion is imposed by the need to procure means of subsistence and fulfill the net of social obligations on which solidarity depends.

The forest and their land provide the basic resources they need. Fishing, hunting, collecting forest resources and farming are the basic working activities ${ }^{55}$. However, consumption is not limited to these natural elements. Over the years, they incorporated an ever increasing number of industrialized goods that they consider indispensable for their survival. In order to obtain those, they need to obtain money or to perform additional labor. In fact, when asked why they first engaged in productive activities for exchange, the answers were all small variations of a same theme:

\footnotetext{
"to buy salt, soap, kerosene, some sugar, ammunition to hunt" (MSF).

"We bought salt, soap, kerosene with the work, with the rubber" (FY).

"they started working for the patron to buy some necessities, on which they depended, such as: kerosene, to light up during the night, salt, [since] they began to like eating with salt, and they needed some clothes to wear" (ALV). "without that work, no one could buy salt" (PCY)
}

Still today, productive activities intended for outside exchange are mainly motivated by their desire to obtain necessities they cannot obtain directly from the forest. These have changed over the years and vary across families, but there are goods that are generally desirable, such as industrialized food, medicines, fuel, boats, engines, cell phones, fishing gear, flashlights, machetes, shotguns and ammunition - the latter to aid them moving in the forest, hunting and fishing. Despite the attempts of leaders and their organizations to frame large economic projects as initiatives to benefit the collectivity and to use a system of generalized reciprocity to distribute some of the gains, these activities are associated with expectations of individual income. When discussing productive activities that are done collectively for market exchange, most of them often say they happily engage in them to obtain goods or income. The romantics, those engaged more directly in the project of reinvention of traditions, are obviously more critical of material activities that, in their view, require them to become workers like the Whites. These, they believe, are detrimental to their

\footnotetext{
55 Thus, retaining their land and access to their resources were effectively fundamental to preserve the conditions of reproduction of their cultural and social systems
} 
culture, their language, their lifestyle and their unity. Coordinating collective works has always been a challenge, especially due to the different expectations involving such activities.

But the works I saw involving annatto were far from intense or abusive. At the time I was in the indigenous land only Mutum was harvesting the fruits and extracting the seeds. If much, half a dozen members ${ }^{56}$, men and women, under the coordination of José Martim, spent some hours of their days under the shohu extracting the seeds from fruits they had harvested. The seeds were then left to dry and stored. While working, they talk and listen to music. They did complain that the work was not fairly rewarded, but did not about the activity itself. The memories of the production in Nova Esperança are not very different, as described in the next part. The work was moderate and people spontaneously remarked that working with urucum represented an opportunity for social gathering as much as a productive activity. Productive work for market exchange was never the focus of Yawanawa social life, nor became the sole productive activity.

Currently, the opportunities for collective work involve, in the case of those associated with COOPYAWA, the production of manioc flour, entailing the work in a collective garden and in the warehouse where they prepare the flour. Collective labor also involves cleaning the village and preparing it to receive visitors during the Festival. All activities surrounding the festival are not framed as work, but as preparations for their own celebration. Nonetheless, some people complain about the lack of compensation and receive daily wages. Those who actively participate in the performance of rituals during the festival do not understand these activities as work, but as ritual, showing how blurred the categories become in the situation. Villagers associated with ASCY have the option to engage in the cultivation of bixa trees and the extraction of the annatto seeds. The productive activities entailed in these two last projects, the expectations and conflicts will be the object of part III. Individuals or houses may also obtain money producing crafts or offering services, notably in the gardens, to other houses.

Albeit not full-time workers, the population shares a great pride on those activities that are considered traditional forms of obtaining their means of subsistence. Agriculture, fishing and hunting are also activities that produce and reproduce social relations and cultural symbols. Their long involvement in the production of rubber did little to alter their status as forest peasants, a mode of life joined by the tappers who were transplanted to the region since the late nineteenth century. The forest, with which they establish a relation that is as much

\footnotetext{
${ }^{56}$ Obviously, more people are involved during harvesting times.
} 
symbolic as material, with a particular ecology that is a reflection of their particular way of constructing the environment, is the basic giver of life. It is the forest that provides means of subsistence, and it is also the forest that materially and symbolically provides the objects they trade with outsiders to obtain money or industrialized goods.

The basic productive activity of the Yawanawa involves working in gardens that provides their basic nutrition. Most of their working time is used in these gardens, located in several locations along their territory, normally close to the shores of the river. These gardens necessarily produce manioc, maize and bananas, which constitute their staple food. They might also produce papaya, ananas, sweet potato, sugar cane and pumpkin. Their gardens, plots of land rarely used for more than five years due to the natural growth of the surrounding forest, are used in a rotation mode and the cultivated areas have mixed crops, the only constant being manioc (Brasil/FUNAI 2006: 80-82).

Working in the gardens unites family members, animating family bonds, especially amongst close cognates. Most gardens are kept by a single house, but there are gardens of extended families, notably in the smallest villages. All members of the house contribute to agricultural works. Men do the clearings and clean the land, which are the heaviest activities. Women work cultivating and harvesting the crops. The help of sons-in-law, brothers and brothers-in-law is expected, especially during the phase of clearing. Even when affines do not share the same house, their work is expected and, thus, their obligations are equated to those of the co-residents.

The obligation to work in the gardens of the father-in-law or the senior member of his house, determined by the norm of matrilocality, is part of the permutations of debt between persons and things that animate social life amongst the Yawanawa. Integrating a house group through an alliance with a female member of such group, the son-in-law also becomes part of its fund. His work for the gardens, as well as hunting and fishing is justified in terms of contributing to the collective efforts of the house, which will provide means of subsistence for his wife and children. This participation in a common fund entails obligations, since a good son-in-law must provide for his family, but also represents rights. All the sources of income are shared by the house. Since the introduction of state facilities run by the locals, public employment also became a possibility of contributing. A wage earned as a school teacher, a forest or health agent is a much welcomed contribution to the fund. In turn, monies obtained through state transfers, notably pensions to the elders, are additions to the fund that younger members can use. Some Yawanawa confided that sons-in-law are more willing to contribute 
with work, knowing that they may share the pensions obtained by the elders. In sum, these different sources of things and money that circulate within the house group strengthen the bonds between the elders of the house and younger men.

Hunting and fishing are other habitual activities to obtain basic needs. They are also part of rights and obligations within a house group, mostly done by the male members of a nuclear family. Fishing takes place especially during the Amazonian summer (May to October), when the river is drier and fish are spotted and caught easily. Fishing may mobilize solidarity among families: during a specific form of fishing called "lake fishing", for example, performed in lakes that are formed as the water levels decrease, entire families, including women and children, join to catch fish. This gives occasion, according to Biraci, to "many marriages. Because the youngsters stay close. And they have an opportunity to meet. And there is no competition, since everyone catches" (Brasil/FUNAI 2006: 73).

Hunting is preferably done during the winter, when there is more rain and animals seek refuge in drier places and is easier to spot them (Brasil/FUNAI 2006: 84). Capturing game is a male task, but women are responsible for treating and preparing the meat and for keeping campsites that provide support in larger hunting parties. Hunting may gather any number of men. They might be individual, done in a small house group or congregate brothers-in-law and friends from different houses of brothers-in-law (close cognates). There are also collective parties with the entire village, organized by the chief. Hunting is not a purely material activity to secure immediate nutritive needs: it is very social in the relations it mobilizes and promotes, it is surrounded by cultural norms and it might be a ritual. Even when done by a single man, it creates reputation for the hunter within and amongst houses, making him a preferred potential affine. Besides showing the capacity to feed others, it demonstrates the knowledge, endurance and bravery that is necessary to move in the forest and find animals. As meat is gifted within and amongst houses, it also animates bonds beyond the house group. Larger hunting parties, in turn, are true ceremonies, a word used by Biraci to describe then (Brasil/FUNAI 2006: 86). During those occasions, which mobilize entire villages, women prepare the campsite, clean it and prepare manioc and other food to the hunters as they start bringing their animals. The party takes place over days and hunters return to the camp with the captured animals, to rest and eat. The game is divided by the leader to the entire community. These are also tournaments of reputation amongst the men. The news spread about highly productive hunters and their ability to bring a praised game. Good hunters are renowned men among the community. Oderico, foster-father of Biraci, is probably the 
most famous of all living hunters and commands enormous respect. Every time he was mentioned or introduced to me, his name was followed by the epithet "this is our greatest hunter". Naveira (1999) argues that the debt created by good hunters, which distribute game beyond the house group, cannot be ever paid by non-hunters, creating long-lasting bonds.

No other productive activity is so regulated by norms that derive from the native symbolic construction of their environment and its species. Their relationship with their environment is not a response to material needs, but oriented by their symbolic construct of nature. Their specific perspectivist ontology of nature, as discussed in Chapter 2, inspires a particular ecology that is as material, as symbolic. Hunted animals are seen as an expression of a personified entity and possess a spirit, which needs to be subjugated and respected. To hunt a white-lipped peccary, for example, a hunter must demonstrate the superiority of the man-peccary over the animal-peccary, translated into a very good knowledge on the forest (Brasil/FUNAI 2006: 91). Hunting is a true total social fact, in Maussian sense (Mauss 2005 [1923-4]): it is a material activity to procure nutrition, but it is also a social phenomenon, since it creates reputation and forges relations based on the cooperation between hunters and the distribution of game, an exercise of political power, represented in the act of organizing a collective hunting, and an expression of a cultural system, since this exchange also involves the spirits of nature. Game is regarded as a gift from the forest, which must be respected and treated accordingly.

Hunting is also rooted in social and cultural norms due to the extensive regulation that surrounds the activities of hunting and treatment of the game. There is a set of prescriptions and interdicts on which the success of the hunter and the health of the woman who prepares the meat depend. Killing an animal is only justified if its meat is consumed. Wasting parts or disposing the remains improperly might offend the spirit of the killed animal that offered the gift of the game. Hunters cannot have sexual relations and should not eat any sweet in preparation to hunt. Additionally, there are dietary restrictions: some animals cannot be killed, whereas others should not be eaten under certain circumstances, such as pregnancy and illnesses, or by children and hunters. There are also rules involving the preparation of the meat by women (Vinnya/Ochoa/Teixeira 2006).

Ignoring these rules leads to a condition that in Yawanawa is called yupa, but widely known in the Amazon as panema. This is an existential state that translates in bad luck, lazyness and lack of vigor. The upset spirits prevent hunters of finding and killing game. The main treatment against the condition, the use of kapum, is also employed to prepare new 
hunters and is currently also consumed by outsiders interested in increasing their stamina. Kapum is a secretion obtained from the skin of a frog (Phyllomedusa bicolor) when submitted to stress. The substance is rubbed onto small burned spots of skin and thus reaches the blood system. Its immediate effects are "nausea, swelling, tachycardia, and diarrhea" (Cunha 2009: 49-50). This is how it is applied, always in the first hours of the day:

"Three o'clock in the morning, the hunter wakes up and asks his wife (yushan), to prepare a caiçuma made of manioc or maize in a good amount of water. If possible, very thin. Caiçuma is known in our mother tongue as manman sheik or atsa manman. ... It is necessary to drink a good amount, until your belly cannot hold it anymore. Afterwards, another older hunter, killer of loads of game must apply ten, twenty, thirty or more injections [stings] of kapum in the arms, legs or, if he prefers, it can also be in the chest or stomach. The injection is a small burn in the preferred areas of the person with a stick of a vine known as sheu. At each burn, the hunter imitates the sound of a dear, a wild boar and other animals. This way, when you hunt, the animals find you and run. .... Once burned with the vine, the small area of burned skin is removed and the kapum milk is applied. In thirty seconds the hunter starts feeling the pressure of kapum and all the manman is vomited"(Vinnya/Ochoa/Teixeira 2006: 93)

The discharge of caiçuma symbolizes the cure from all the bad luck, the sleepiness, the sweets or sexual intercourse the bad hunter might have had. Kapum became one of elements of the regional culture - the recipe is shared among many natives of the region - that circulated over the world and generated great interest in their spiritual and healing practices. Moreover, it became a cause célèbre when populations of the region and the Brazilian government attempted to revert a patent given to the synthesized substance (Cunha 2009). Many visitors from the region or outside are interested in trying what became known as the frog vaccine, seeking to increase their stamina. This service is offered during the Yawanawa Festival and its counterpart organized by ASCY.

This code of interdicts, prescriptions and cures involving hunting and fishing demonstrate how their productive activities are not devoid of cultural orientations, albeit these do not seem to effectively affect their production for exchange and the relations with partners. It also indicates that, despite the challenges of the rubber tapping years and the presence of Christian missionaries, fundamental aspects of their native ontology, essential part of their culture, remained active. In fact, this particular symbolic ecology of the Upper Jurua natives is 
now shared by many non-native tappers. If many habits were developed in the continuous interaction between these two groups of forest peasants, the particular ecology developed in the region over the past century seems more indebted to the natives. The transplanted workers came to understand their new environment - the forest - through the eyes of the established population.

\subsubsection{Things that come in, things that go out ${ }^{57}$}

If the basic relation of the Yawanawa with work, despite different visions regarding their involvement in economic projects, is one of instrumentality, their relationship with goods and money is equally pragmatic. Over the course of years, the Yawanawa have been exposed to an ever-increasing number of industrial goods. The frequent visits to the neighboring towns increased the number of objects they consider useful. They are avidly interested in innovations, always asking visitors, including the researcher, for objects difficult to obtain, from flashlights to GPS navigators. As previously said, they are not traditionalists and these goods are creatively incorporated into their social relations and even cultural practices, but there are ambivalences. Biraci emphasized multiple times that he does not understand why the indigenous populations should not adopt new tools, remaining attached to rudimentary tools and methods of production (BBY). They are willing to incorporate new objects that help them to perform their daily activities and develop their way of life. Many industrialized goods have been incorporated to enrich cultural artifacts and practices. The Yawanawa use industrial beads and machines to produce crafts and typical objects used in connection to their rituals. Beads are the most appreciated present from outsiders. They are equally eager to use film and picture to share these rituals with outsiders and, during the current wave of initiations, they have introduced the use of digital voice recorders to register the lessons of the older xinayas, the healers. In what seems to me a "culture" cult, in the sense of Wagner (1981), just as the one practiced by anthropologists, they hope that these media will document the invaluable lessons of the elders for the next generations.

The Yawanawa have been involved in the production of a number of video documentaries and are avid users of Internet and social networks, on which they constantly post about their whereabouts and public performances. After the production of an initial

${ }^{57}$ This analysis is clearly inspired by the work of Gordon (2006) on the indigenization of money and goods amongst the Xikin. Tere are also many similarities in the findings. 
documentary financed by Aveda, Biraci started to work with a professional photographer from Sao Paulo, who produced an exhibition about the Yawanawa for the Rio+20 Conference and is editing a book about the Yawanawa. Technologies are, thus, incorporated as means of increasing the visibility about the population and its practices, a matter of great pride. The use of Facebook to inform and comment on the performance of rituals in different places has also apparently become an instrument in the competition of the two groups. It is often the case that members of Tashka's group criticize members of Biraci's group for what they regard as a banalization and desecration of their rituals.

Most objects are employed in their daily lives without any unfamiliarity or reservation. And they are incorporated without much debate on their effects. But amidst the tensions of securing their difference and its reproduction whilst amassing the benefits from participating in the market, leaders and some members, notably the romantics, have debated and sometimes prohibited some objects. I asked many Yawanawa if they regarded the adoption of new objects and how these affect the protection of their cultural customs and the traditional lifestyle they are so willing to recreate. One of such conversations was particularly interesting, because it took place in Tarauacá, and involved Valdemar, the elder Jorge and Kuni, all enthusiasts of the Yawanawa culture and engaged in the process of cultural reinvention. Jorge is regarded as an expert in medicinal plants, Kuni is initiated and frequently performs rituals in the south of Brazil and Valdemar was about to start his initiation diet. They all insisted that living without goods brought by the interaction with non-natives is unthinkable. These things, they asserted, make their lives better and easier. In general, they do not represent a destruction of their culture. But the words of Jorge show the tensions and the respect to the leader:

"I believe that today our things, this question of cell phone, radio... because there are many people with radio in our village, it is good to inform about the news of what is happening in the world. The question of the cell phone also works... people want to take a picture, also in the towns, because cell phone in the towns is nice to contact a friend, to get the news, these things. I believe these small things do not harm our culture. But the television is a big thing, it disrupts so quickly that if we are holding a cultural event, few children will be willing to take part. If there is a television, wow, the community finds it beautiful to see other places, a soap opera, and then it replaces culture” (JLY).

There was a strong campaign of Biraci and his loyal men against television, regarded as an alienating element that hindered their efforts to unite the community and promote cultural 
practices. As a consequence, some people moved to different villages, where television is accepted. This ban was once more object of debate when Nova Esperança received a new power generator. Interestingly, culture became an argument to determine the reception of objects. This is not exempt of contradictions and selections about those elements that are truly the core of their identity. The acceptance of industrialized food, for example, in detriment of their own dishes, attests the boundaries of what "culture", in its recreated form, is.

More than customs, norms or heavy moral interpretations, it is the distance to towns and the difficulties to move in the forest that influence their relationship with money and industrialized goods. The distance has an inflationary effect on prices. The costs of transportation and, notably fuel, that is produced in the southern parts of Brazil, is added to already high prices that can be charged due to the limited competition. Even Cruzeiro do Sul and Tarauacá, the closest cities visited by the Yawanawa, are distant from the main industrial sites of Brazil and objects are much more expensive. The need to go to towns and the price of transportation by boat explains the limited desire for money and the general preference for industrialized goods. However, the relative desire for money vis-à-vis industrialized goods has changed in recent times. The latter continue to be preferred, but money is becoming more desirable. With new state benefits, money has also become more present. But even these new sources of monetary income depend on trips to banks in the town and, thus, the capacity of their beneficiaries to travel. The communications have improved in the last years with the paving of the main state road and new and cheaper engines. For these reasons, engines and boats are amongst the most desired goods. Families that do not have conditions to buy them depend on relatives or neighbors to lend them or give rides to the city. It is common in the villages to ask a member who is going to a town to purchase goods or bring the money they receive as state benefits from the bank.

Money has very limited use in the villages, since there are no objects to be bought, and only exceptionally circulates between houses. It is rare and mostly concentrated in the towns, where it is obtained and spent. During the rubber tapping years, as explored in the next chapter, the Yawanawa were able to purchase a number of basic industrialized goods that became necessities to their lives from warehouses that were kept by the rubber estates. These goods were obtained against the obligation to deliver an equivalent amount of rubber, game, food or the performance of services required by the patron and his foremen. This equivalence was determined by monetary units, but physical money was rarely employed. Consequently, money was for most of the twentieth century a unit of value but not a means of exchange. 
During this period, transportation was difficult, boats very rare and the towns much smaller and difficult to reach. At the same time, it was during that period that the Yawanawa incorporated industrialized goods, creating dependence towards intermediaries who bring goods.

After the demarcation of the land and the expulsion of the foremen of the rubber estate, the Yawanawa had to organize a scheme to obtain goods and distribute them. This task felt under the responsibility of the leaders, which had acted as intermediaries before. Many Indigenous populations of Acre developed co-ops to replace the warehouse (Pimenta 2006) and the Yawanawa were no exception. With the income they obtained initially selling rubber and later with the production of urucum analyzed in the next part, they bought industrialized goods to furnish the co-op, which were offered in exchange for the involvement in the productive activities. The distribution has never followed a logic of balanced reciprocity logic as the cantineiros, the dispensers of these goods, informed (RLSY, ALC, BBY, FLY). When asked about the forms of distributing material resources received collectively, the Yawanawa always emphasize that, as a community united by family bonds, they could not adopt the cold hearted ways of the town. They feel obliged to help their relatives in need and, thus, these goods were always distributed according to family ties. The other side to the system is that they do not require any contribution, in the form of labor, in order to impart goods. Therefore, they were never able to keep the flow of goods. If the Yawanawa do not accumulate capital, they do accumulate debts. The forms of distribution of resources, without counterpart and to feed political loyalties, often leave their organizations with limited resources. They also have trouble keeping up with bureaucratic requirements to keep their organizations running and often must pay fines for non-complying with such demands.

This was an important discussion topic during my fieldwork. Realizing the success of some co-ops amongst other indigenous populations, the Government of Acre was introducing in 2011 a program to implement co-ops, with the donation of an initial amount of goods, in all Indigenous lands of the state. The fact that strict controls and a system of balanced reciprocity would be introduced, requiring some work or produce from the Yawanawa, was a matter of heated debate. This reveals that their discussions are not so much about the morality of goods, money or exchange, but about the forms of engagement with the work for external exchange and the expected results. Those who engage in activities expect to receive some individual compensation. Many are frustrated with the political forms of distribution or the preference for investments in collective needs, a preference of Joaquim and ASCY. These distributive 
conflicts explain recent positions against the circulation of money within the villages, explored below.

At stake here is also the political logic of distribution of resources obtained from partners. Loyal members, recognized as those who contribute most to collective endeavors, i.e., those activities planned by the leader, are also considered entitled to receive more (BBJ). In effect, the members of the two legal organizations occupy positions that allow them to control the intake of resources. The state positions are also distributed to close allies. And paid cultural performances are limited to members who are invited through alliances with urban groups that are mostly controlled by Biraci's group. This generates a concentration of resources, leading to a situation of differential consumption, to use the apt expression by Gordon (2006: 275). Albeit mostly used to reproduce social relations and ritual practices, money has become a principle of social differentiation as well. These members have more and more expensive goods. But I noticed that much of this excess of consumption take place in towns, far from the judgmental eyes of the community. This might be due to the larger availability of goods or because displaying material differences would undermine the ideology of community and the idea that projects strengthen the collectivity. At the same time, in this system of political distribution, which attempts to subsume the relation between leaders and the community under a logic of generalized reciprocity, leaders are supposed to have more, so that they can give. As previously discussed, it is the volume of imparted goods that makes a leader.

The Yawanawa economy is centered on things, not money. There is no disposition to accumulate money, at any rate received in very small amounts and exchanged as fast as possible with necessary goods. There is also no display of monetary wealth within their land. Money is, in fact, often interpreted as a scarce and necessary means to obtain goods that the forest does not offer. It is only logical that hunting gear, flashlights, machetes, shotguns and ammunition, used to obtain resources from the forest, together with food, clothes and medicines, which cannot be produced, are the main objects of consumption. Their short stays in towns attest their discomfort with a monetized economy (see box 4). But their desire to obtain goods justify having money. The presence of money in the villages is less consensual, however, being criticized by leaders and some notable men.

Box 4: Nobody gives you anything in the town 
Visiting Tarauacá and Cruzeiro do Sul with some Yawanawa, I experienced their uneasiness in an environment in which all relations are monetized. They often turned to me for small contributions so that they can face the smallest expenses. In one of these occasions, during a talk in Cruzeiro do Sul with Nani, he said: “....if you need to solve something [...] you need money here. If you do not have this here, you do not solve anything, because nobody gives you anything here in the city. You see that even a popsicle if you do not have money, you do not buy, nobody gives you. Then, money is mandatory for you to solve your problems" (FLY). In another trip, my guide in Tarauacá spent the three days anxious to return to the village, despite the fact that I paid all meals and he benefited from the exclusive pleasures of the town.

In recent times, money became more present amongst the Yawanawa. Using the classification devised by Zelizer (1996), most of the money comes from entitlements, some from gifts and some from compensation. Money is obtained as an eventual compensation for the contribution of members to economic projects. They also sell crafts during the Yawanawa Festival or their visits to towns. The Federal and the State governments are the most regular sources of monetary income. Compensation in the form of state salaries earned by school teachers, health and forest agents, together with entitlements, are the permanent sources of monetary income in the village. I have discussed before how the state positions are politically distributed and, thus, how they reproduce political loyalties. Yet it is worth adding that through this mechanism the leaders still command significant control over the monetary income of their people.

The role of Federal and State governments is not limited to the creation of jobs. There are a number of programs, focused or not on indigenous populations, which also bring benefits to the Yawanawa. Governments are also part of the network of allies established by the leaders, as some of these programs require political bargaining for their implementation. In recent times, Nova Esperança and Mutum were benefited by the construction of fish ponds as part of a state program to improve their diet whilst reducing environmental impacts and the installation of electric generators, as part of a federal program, providing limited amounts of energy to the houses. Satellite Internet was also installed in the villages. The state is an important supporter and no minor force behind the introduction of new objects and institutions in their lives.

In addition to these salaries and other benefits resulting from state programs, the Yawanawa receive three different benefits according to their status. The elders are entitled to a special rural retirement pension that does not depend on previous contribution 
(FUNRURAL) $^{58}$. Poor families are entitled to the national conditional cash-transfer benefit, Bolsa Família (Family Allowance) ${ }^{59}$. The basic criterion for inclusion into the program is an income below half of the legally determined minimum wage per person or fewer than three minimum wages per (nuclear) family. Parents are entitled to additional benefits for their children. Since most of the nuclear families do not make beyond the income threshold, they are all entitled to the benefit. Inclusion into the program was secured by the local government of Tarauacá, responsible by law for making the register of the "poor population" to provide them with better policies of social assistance ${ }^{60}$. Family allowance regulation determines that the benefit should be paid under the name of the mother (or the wife) and, thus, that benefit is gendered. The gendered logic also applies to the use of the income, since it is mostly men that travel to receive the cash deposited in banks and purchase goods. Without a systematic survey of all houses, I may say that it seems that almost all - if not all - Yawanawa families are recipients of the Family Allowance benefit. Finally, under certain conditions, pregnant women qualify, as special rural workers, to a maternity allowance (Salário Maternidade or Maternity Wage $)^{61}$, if they decide to have their children in a health facility.

Albeit relatively reduced in their monetary value, these social benefits were cited by many as their main source of monetary income and a fundamental one to meet their needs in terms of industrialized goods and medical care. As with the very acquisition of such goods, distance is an important element to be considered. Due to the limited amount of some of these benefits, it is sometimes more expensive to go to a town to withdraw the cash. For this reason, there are special arrangements in that regard: some wait the money to accumulate over some months and others organize a rotation of persons in charge for going to the town, withdrawing the cash benefits for many and buying them a list of goods. Most of the families consolidate these monetary incomes that originate from the state and share the use of resources. Within the house groups, the money obtained through state benefits and salaries flows as gifts. Since these benefits are given to women and elders, solidarity is reinforced within the matrilocal group. In special, they foster the contribution of the son-in-law in the form of food and care to the house fund, in the expectation of being able to use the money. Some Yawanawa told me, with irony, that the new flow of state benefits made sons-in-law once more "obedient" and

\footnotetext{
${ }^{58}$ I refer to the Fundo de Assistência ao Trabalhador Rural (Support Fund for the Rural Worker) created by Lei Complementar 11/1971.

${ }^{59}$ The regulation of the program is mostly done at the policy level by the Ministry of Social Development, but the program was enacted by the Federal Law n. 10.836/2004.

${ }^{60}$ The benefit is paid by the local government with federal funds and, thus, most mayors conduct a wide campaign of registration to enhance political support with very little cost. Tarauacá was no exception and since part of the population with electoral rights is indigenous, those were also included.

${ }^{61}$ See Law n. 8213/1991, art. 71 ff.
} 
"respectful" to their fathers-in-law, but the fact that both women and elders receive benefits mean that the strengthening of the bond is bidirectional. Together with food and care, money is integrated into the common fund shared by the house and, thus, reinforces kin obligations and produces sentiments, in ways similar to the analysis of Zelizer (1994). Money is also used to demonstrate or reciprocate care, in the form of small gifts or help in case of need.

These new sources of money have recently generated an incipient circulation within the villages, as compensation. Families that have limited benefits help families that have limited hands, offering their labor in the gardens of the latter. The house groups with no state employee and no elder are those normally more inclined to accept any work for compensation in cash or goods. Many of those who are critical of the excessive focus on the recreation of cultural practices are in such situation.

Money does not generate strong moral judgments, as previously said, but these much appreciated benefits are scorned by both Joaquim and Biraci. These flows are not controlled by their organizations and they introduce money within the village, reducing the need for intermediaries. They also believe, just as liberals, that these programs create dependency and are alms to secure political support to the government. Joaquim also believes that these new sources of monetary income introduce bad habits, such as drinking alcoholic beverages. There is a similar aversion against the effects of money, which inform their preference for distribute goods as compensation for collective work.

Up to this point, I attempted to demonstrate that the Yawanawa are not traditionalists and money is not condemned. There are ambivalences and different positions regarding specific forms of obtaining money, notably in the case of public performances of spiritual practices. But they accept money as a means, covet it in moderate amounts and expect that productive activities performed for exchange would result in money or their equivalent in necessary goods. Therefore, some recent positions regarding the evils of the presence of money should be examined, as an acute expression of such ambivalences and differences of expectations regarding the market. I believe that these positions were adopted in response to conflicts involving the distribution of resources of large economic projects. Leaders recognize the dignities that emanate from having money, a crucial point linking economic projects and their politics of identity and examined in the next part. They also accept the fact that money is instrumental and goods do not harm their culture. Nonetheless, leaders and some close aides started to espouse a hostile worlds (Zelizer 2005) vision that is similar to that of several classical analysts on the effect of money on society. They believe that money tends to 
dissolve the sense of community and fraternity, creating jealousy and conflicts. Now, this attitude can be a general one, aiming at limiting the circulation of money or related to the money obtained through certain activities, such as ritual performances. The latter is at the center of the tensions that comprise the politics of value of such rituals and will be analyzed in Part III, when the commodification of cultural practices is discussed.

The former corresponds to a more traditionalist position to be found amongst the internal elite. They believe that money introduces a new principle of differentiation that is harmful to the ideal of community. Two notable members with an intense involvement in the projects, each representing one organization, showed concern involving the use of money as compensation in ways that are worth quoting. The first is Antônio Carioca, who controlled the distribution of goods during the period in which Nova Esperança was involved with the production of annatto.

"if I have money I buy, but if my uncle does not, he does not buy. Then if I have conditions to buy I am going to humiliate him, because I have money and he has not. With this money I will buy the things I want and condemn those who cannot to the worst possible humiliation. Because I will not divide with him, I will not give the money: 'take this money'. I have my money, my purse might be full, but I will not say I have money to him. This is not from our culture and because it is not, it is like a bomb amidst us [...]

So much confusion we had because of money" (ALC).

Mariazinha, older sister of Joaquim and the leader of Mutum, reveals a similar position:

"I do not see wealth: when we talk about money, we talk about power. The world of the White outside is full of power. [...] In a community, it has to be different. [...] To me, if we had gotten money in the community, I think it would have been worst. Instead of helping, it would have divided. Instead of unite and strengthen as we always imagine, it would divide the people" (MLY)

There are a number of reasons for these visions, which are necessarily related to economic projects and alliances maintained by the Yawanawa. They might be situated in the attempts of the organizations to control the flow of money and to frame collective activities that bring material resources as benefits for the community and not individuals. When leaders deride state benefits, this is clearly related to the diminished role as intermediaries in these 
sources of income. The same rhetoric, stressing the unity under the symbol of the peccary, might be employed to defend a political distribution of resources maintaining the existing power relations. It is likely that the distributive conflicts that large sources of resources set in motion amongst the Yawanawa demonstrated the bitter side of the market for their own personal projects.

Nonetheless, attempts to control the flow of money do not fully explain these positions. The debates on the role of money are related to the forms of existence and public display of the Yawanawa. They concern the ways they want to be perceived and exist. Not surprisingly, restrictive positions are found amongst people who are not beneficiaries of a restricted system of distribution. They are also part of their existential strategy of reaffirmation of their Indigeneity, translating a true concern about the future of community life and its bonds. The fact that they came to reproduce the idea that economy and culture are antithetical is related to the representations that the non-natives maintain. If they want to reassert their difference, a right to exist in a different way, as well as the benefits that come with difference, they need to be perceived as different. Since these traditions became central for their external worth and their new strategy to obtain material and symbolic resources, they need to abide to expectations of the consumers of their images.

The assimilationist paradigm is still the most common form to understand indigenous populations in Brazil, reinforced by decades of state policies that were oriented by the same tenets (Lima 1991). Acculturation is often seen as inevitable and those who do not preserve a very traditional image are often accused of no longer being indigenous or losing their identity. This poses the dilemma of embracing the good things that modernity can offer them, whilst reasserting their difference at all times and not displaying themselves in public in ways that could be perceived as non-traditional. Arguments about their "acculturation", the waste of productive lands "given" (not returned) to natives and associations with bad primitive habits are still common in Brazil. Their attempts to forge stable alliances, more than simply seeking business partners, is partially explained by their need to revert these images and constantly defend their existence amidst the forces of development. In that sense, their image is considered important for their existential claims: the difference they want to see respected against the attacks from national society must be one that is accepted, even praised.

Their image, their name and their culture have become the main elements that circulate. The Yawanawa produce annatto, manioc flour and some crafts that are sold outside the indigenous land. However, "culture", in its immaterial manifestations and associated 
material artifacts, is the main object exported by the Yawanawa. The Yawanawa are very conscious about their own image and know that their identity have become a sort of brand with which they attract new alliances, if not business partners. May Waddington, a former intermediary in the annatto project, asserts that the Yawanawa are "an editorial success" (Ribeiro 2005: 30), very able to employ media to promote their image. The website Youtube counts no less than 2,660 videos of the Yawanawa ${ }^{62}$. Their reputation is the way into acquiring resources, and thus they want to display an image of a harmonic community with a simple life in communion with a rich forest. I have already said that conflicts are not a matter of public discussion and when the topic is raised, many will promptly explain that disputes were solved and that once more peace and harmony reign. Alternatively, they would try to explain with sorrow that the conflicts, limited to the leaders and their close loyal members, do not reflect what the Yawanawa indeed are and that they true essence is not conflictive. Sometimes, they invoke the peccary metaphor and state that "we are all peccaries. We are always together".

Even more than diverting attentions from the recent conflicts, the Yawanawa want to steer their public image. This is especially true for those who relate with outsiders. This well shows their attempts to steer the image of their community so that it abides to our expectations. This might be an interested attitude, but not only seeking material gains associated with it. Any person attempts to preserve their faces in their public presentations and this involves assuming roles that are expected by others, as Goffman (1959) and Strauss (1997) indicate. As a representative of a group, one also aims at preserving the honor and image of the collectivity to which one is associated. Knowing that alliances depend on this image, as they do, is another reason to this common social management of impressions, in which I was certainly involved (see box 5). And alliances matter not just for their material resources. Allies that can spread good words and the name of the Yawanawa are important to help them to protect their existence and special rights in a society that still carries the ordinary prejudices and criticisms against indigenous populations. They also want to avoid associations with phenomena that often maculate the images of other indigenous communities, such as alcoholism, prostitution or begging, for the indigenous, seen as separate from the rest or society, are not allowed the vices of the rest of the population: alcohol, prostitution, begging are common symbols of disgrace. In public speeches the Yawanawa often compare themselves with other populations of Acre that, in their view, do not share the same fortune and lost their essence. Their lifestyles were disrupted, the populations impoverished and

${ }^{62}$ www.youtube.com. Search term "Yawanawa". Retrieved 25.06.2013. 
ended in a cycle of vices. Uttering these comparisons, they also want to reassert the internal commitment to maintain the traditions and avoid these foreign perils, such as alcohol or drugs.

\section{Box 5: "Write beautiful things about us"}

Kuni, a healer that has won a number of followers in New Age groups in the Southern Brazilian towns of Curitiba and Porto Alegre, in which he performed uni rituals, was the most concerned community member during my presence, initially following me during my talks. At some point, I asked him what was the reason for such concerns and he replied that he was worried about what I was writing and would publish about the Yawanawa. He told me that past researchers wrote lies and bad things about the Yawanawa. He was referring to Miguel Naveira, who according to him lied about the dangers of uni and rare. After explaining to him the principles and ends of my research and saying that every family, group or organization has good and bad things, Kuni replied to me: "write xarakapá (beautiful) things about us".

To a great extent, the interest of outsiders in the Yawanawa cultural practices derives from their use of ayahuasca, or uni, in their language. Basing their image to a considerable extent in their ritual uses of ayahuasca could be seen as a challenging task in societies that retain prohibitionist instances to many psychotropic substances. However, not just the regional population is respectful and praiseful of ayahuasca. The rituals and the substance itself are the main factors connecting the Yawanawa with large urban centers of Brazil and, recently, Europe. The success of this strategy and the role of the state of Acre in fostering these associations are the object of the chapter on the public performances of rituals.

In this long chapter, I attempted to reconstruct the political and cultural economies of the Yawanawa. I contend that the social, political and cultural relations established amidst the flow of things, among themselves and with outsiders, are relevant to understand their engagements with the market and, notably, the politics of value that underlie the commodification of their cultural representations. I argued that the construction of leadership is related to the ability of notable men of manipulate exchange and forge alliances that 
animate the otherwise closed society. Economic projects and the politics of alliances pursued by the Yawanawa are closely related, thus, to the personal strategies of prominence of contestants to leadership. In addition, I described the relationship of the Yawanawa with work, goods and money, revealing particular motives and meanings of economic action. I indicated that the Yawanawa incorporated instruments of modernity that generally served to reproduce their social relations and rituals, but also introduced new principles of differentiation mediated by their structure of power. The Yawanawa reveal a great deal of ambivalence and different expectations regarding the involvement in market activities that not only explain the politics of production underlying the commodification of "culture", but also translate multiple visions of how the community should interact with their allies. All these elements would play a pivotal role in the dynamics of the projects examined in Part III. Now, it is necessary to understand the historical development of these specific patterns of interaction with outsiders, always with the mediation of the leader, the challenges of maintaining their culture and their awakening to the worth of their difference. 


\section{From Caboclo Seringueiro to Guardian of the Forest}

In this chapter, the history of the region and the engagements of the Yawanawa with new populations in the twentieth century are considered in order to situate the development of the political and cultural economies of the Yawanawa in the broader political economy of the Amazon. The importance of history cannot be overstated, given the intent of this research to understand the entanglements between local and global forces and the role of local schemes and entrenched social and political relations in mediating the relationship. In the first place and on a more general level, local history reveals the roles of the institutional internal dynamics in the peripheral policy and of local agency in global processes. These institutions may be employed by processes started at the center of capitalist dynamics and, in turn, use these processes in name of their own oligarchic goals (Sahlins 1993a; Mahoney 2010). In that sense, tensions, contradictions, but also the domination and violence cannot be explained without examining the passions and interests of the local and regional elites, as well as the actions of national and local governments. States in peripheral areas like Acre are not minor actors, as World-System Analysis (Wallerstein 1974) prescribes. On a more specific level, the history of the Yawanawa and the Upper Jurua Basin is approached to delineate the cultural dynamics over history and the development of certain patterns of material activities and of interaction with outsiders mediated by the leader that were reproduced by the projects analyzed in the next part.

This history, especially as experienced and narrated by the Yawanawa, matters on a practical level as well. The regional dynamics to which they have been exposed in the last century reveal a permanent tension between local agency and forces threatening their cultural and social reproduction. Notwithstanding their agency and endurance, this history is not absent of facts that substantiate pessimistic views about the integration of this population in the circuits of capital. It is exactly because of these challenges that their history becomes a tale of endurance and, as such, of native agency. On this level, history, as appropriated by its own agents, constitutes their identity. Not just because culture is historical, but also because the narrative it prompts establishes a tale about identity formation, endurance and development. These narratives, a self-referenced account of history, are part of the object of exchange analyzed here: their "culture" encompasses the legends about their historical 
experience. History is also story, giving perspective and worth to the culture and its population. In other words, history bestows value to the product and explains the attractiveness of these populations. This is the most important level of analysis. Even if history, as retold by the agents, creates the danger of the biographical illusion (Bourdieu 1986), it is exactly that illusion that should be analyzed, for it constitutes the history that permeates the exchange with partners. For this reason, there is no intention here to provide a detailed account of the political economy of the Southern Amazon over the last century. Some specific traits and processes should suffice, on the one side, to reveal the importance of the Yawanawa agency and the local institutions in the historical dynamics and, on the other side, to present the elements that would be later deployed to construct particular narratives about endurance and worth of the Yawanawa culture ${ }^{63}$.

In the late nineteenth century, galvanization and the invention of the automobile turned rubber in a much sought after commodity. Rubber is extracted from the trunk of trees that are native to the Amazon. Given the high quality of specimens of Hevea found in Acre, the area was soon occupied by Peruvian and then Brazilians establishing estates to extract rubber (Dean 1989). This was a period of violent raids against indigenous groups of the region to secure possession of the land and prevent threats to the rubber estates. The rubber boom also attracted poor dispossessed men from drought-struck areas in the Northeast of Brazil. Since the early twentieth century, according to the available sources (Brasil/FUNAI 2006; Vinnya/Ochoa/Teixeira 2006), the Yawanawa maintained stable contact with land tenants in the area producing rubber and became involved with the activity in ways described below.

Until the 1990s, the historiography on the rubber economy focused on its economic inefficiencies, political violence and social destitution. Furtado (1963: 148) sums this general understanding in his work on the economic history of Brazil asserting: "Despite [...] the fortuitous enrichment of a small group of persons, the great population shift of nordestinos toward the Amazon was nothing more than an enormous waste of human beings". The accepted interpretation then was that the system consisted in a short boom that produced enormous profits for a regional elite, until the Amazon faced the competition of rubber plantations in Southeast Asia. In the early 1900s, the British had been capable of introducing the most productive varieties of Hevea, via Kew Gardens, in Southeastern Asian colonies. The plantation system introduced in Asian colonies was much more productive than the

\footnotetext{
${ }^{63}$ The reader must not expect to find new findings here about this history, since I simply use the limited amounts of sources available, complemented by my own interviews, to situate the reader in a reality that might be unknown and yet is relevant. I was particularly interested, during my interviews with the older Yawanawa, to understand their relationship with the rubber tapping. And some of their perceptions are inserted here.
} 
extraction from native trees in the forest, which required opening tracks and keeping foremen in isolated points, requiring a week or even more to transport the rubber balls.

The rubber production did not disappear completely, financed by state credit and subsidies. Some forest peasants continued in the area tapping rubber (Almeida 1992) and some land tenants continued to occupy the area since, even if not very competitive, there was continuing interest for their production, as an alternative to the price-setting trust formed by the British. During World War II, Acre had a second boom, when the producing areas in Asia were controlled by Japan. Finally, after the war, the activity continued to prosper under Federal subsidies (Dean 1989).

What is more, this "waste of human beings", natives and non-natives, produced a particular socioeconomic arrangement with enduring legacies and a creative relation with nature. Thanks to efforts of authors writing about the rubber tappers in Acre (Almeida 1992; Franco 2008), we have a more nuanced version of the historical developments in Acre in the twentieth century. They revealed a great deal of local agency, but also certain features of the system that deconstruct the vision of a totally irrational and violent system. Since there is not much to add, instead of retelling a well written history, I present some of the basic features of the rubber tapping economy that had lasting legacies amongst the Yawanawa, situating their political and cultural economies within the broader regional political economy.

The most important of such features is the unique relationship established amongst the actors of the system, united by a chain of debt (see diagram 2 below). Debt, Almeida (1992) pertinently reminds, also represents credit, but more importantly, it maintains the social relations among involved actors. During the peak of the rubber prices, the business was controlled from the big Amazonian towns of Manaus and Belém, exporting centers. Foreign companies never managed to replace these intermediaries or take direct control of the producing areas. The price of rubber was defined at these exporting centers, taking into consideration the international demand. In order to obtain the wild harvested rubber, the exporting firms would lend capital to patrons holding lands in the Amazon. These patrons, in turn, or their foremen, would enlist a number of men willing to engage in the activity and send them to a rubber estate. These tappers lived in small settlements around a number of rubber trails in the forest, paths with specimens of Hevea that the tappers would follow to tap and later collect the rubber. Rubber estates would equally possess a number of warehouses, furnished with industrialized goods, from foodstuff to guns. At the beginning of each rubber season, tappers would obtain the basic instruments for their work and goods at these 
warehouses as a credit, promising to deliver the equivalent amount in rubber at the end of the season. In order to gain the right to extract the rubber, these tappers had to pay a rent for the trails they controlled.

The relationship they established with the land tenants and their foremen was, thus, not one of wage labor, but of clientage. And due to scattered nature of the activity and the long time-span, despite some attempts, patrons and foremen were never able to control the rhythm, instruments or forms of labor. For the tappers, and the same holds true for indigenous populations involved in the activity, the face of the rubber estate was the warehouse with its goods. Committed to pay their debts, these tappers would then spend the season collecting rubber, which would be brought to the warehouses, weighted and priced. If the tapper produced more than the monetary equivalent of his loan, he was allowed to use this surplus to buy new goods or, exceptionally, obtain cash. Nonetheless, since the estates depended on their labor to obtain the rubber, even if at the end the tapper accumulated debts, he would still have credit up to a reasonable level (Almeida 1992).

The fundamental terms of this arrangement were the monopsony of the warehouse regarding the rubber produced in the estate and the monopoly of industrialized goods in the region. Coupled with the distance and the absence of means of information, this also represented that the prices for the rubber and the goods could be fixed at any rate by the warehouses. Without money circulating, tappers could only buy, in theory, from the warehouse. Nonetheless, the region was visited by boat peddlers who offered better prices for the rubber and lower prices for goods. Albeit considered illegal and repressed by authorities, they were always present, as recalled by the Yawanawa (FY). Moreover, highly indebted tappers that could not obtain credit would normally escape the estates and seek other activities, while other less productive tappers could always choose to remain in the forest as peasants. In fact, the access to forest resources, Almeida (1992) reminds, created a complex economy that was not limited to the extraction of rubber and, after the boom, became increasingly diversified, with more time allocated to farming, hunting, fishing and collecting other forest resources. Therefore, the patron relied on credit to maintain the tappers producing. 


\section{Diagram 2: Rubber tapping economy in the Twentieth Century Amazonas}

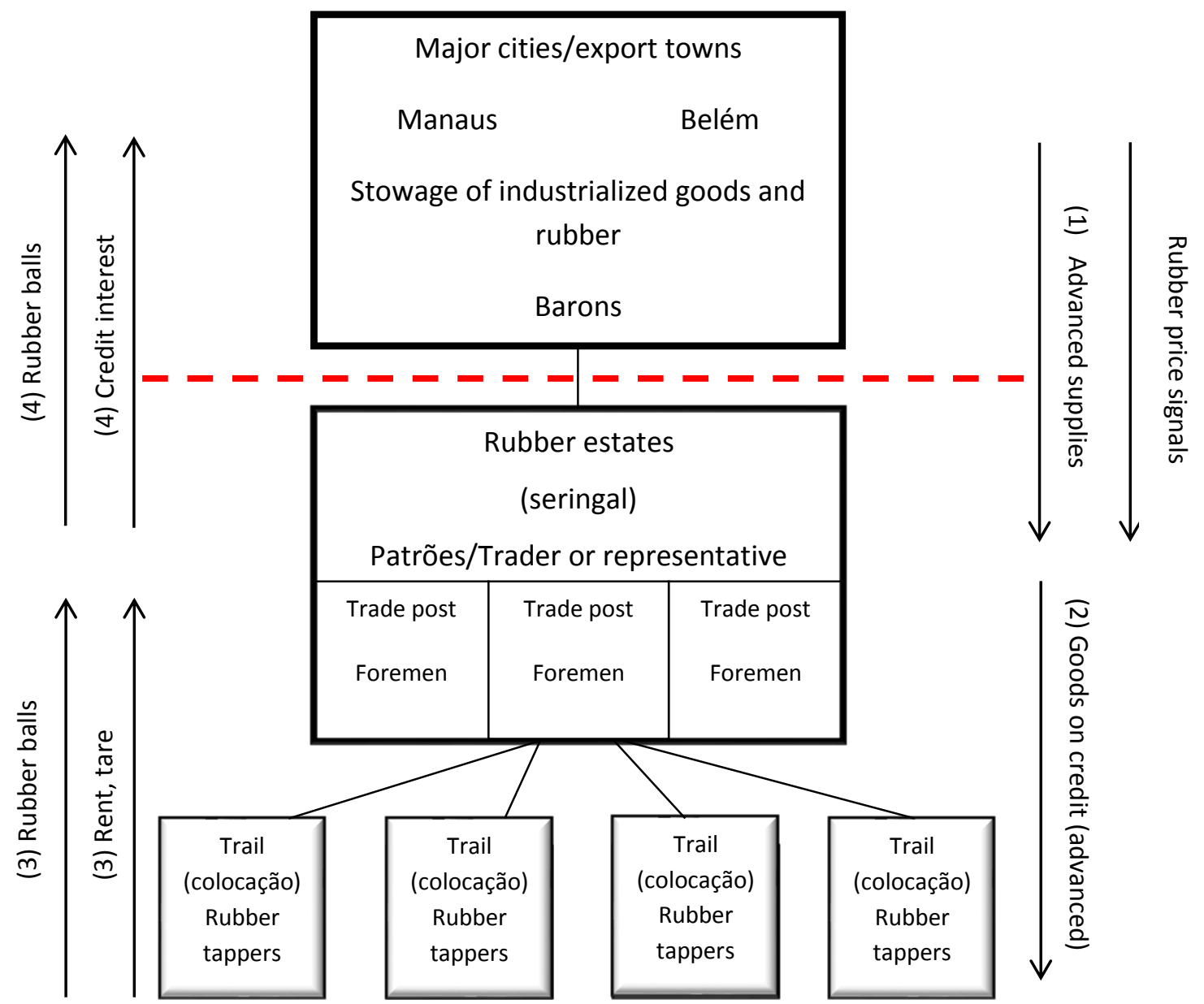

A fundamental tension was at the center of the system. Peasant houses were free to establish their own economic strategies to obtain necessities and income: either producing more rubber in exchange of commodities or undertaking other forest activities that provided subsistence. As long as access to land and forest resources was granted, this was possible. For most of the period, they were allowed to develop small gardens, to hunt and fish as means of subsistence, and never allocated all their time of labor to tapping. This, in turn, conflicted with the aim of patrons to maximize accumulation by increasing production of rubber and reduction of consumption. This tension was deemed one of the causes of the inefficiency of the system, but it indicates that treating the relationship as debt slavery is simplistic. Hypothetically, forest peasants in general, and the Yawanawa in particular, were not obliged to enter into rubber tapping activity, i.e., to regularly produce rubber for the trade posts, but they would in order to obtain industrialized goods. Since the beginning, it was the decision of 
some members to engage in the activity, attracted by the opportunity to obtain goods they could not produce and did not know before.

Another element mentioned by Almeida (1992) that is important to consider and was particularly relevant in the experience of the Yawanawa with the rubber is the existence of mutual moral obligations linked to the patron-tapper relationship. Rubber tappers, including the Yawanawa, established a close, very personalized and long-standing relationship with the representatives of the estate in the area. This generated certain expectations and mutual respect that went far beyond the commercial relation. In case of need or disease, tappers expected to obtain favors from the warehouse.

These features remained relatively stable until the 1970s, but there were transformations that reflected the changing position of the region in the global economy. In the work of Almeida (1992) it is possible to distinguish four phases:

1) Prior to 1870 , when the sovereignty over the area was still unsettled between Brazil and Peru. There were episodic incursions of rubber traders in the area to obtain latex. Peddlers would buy rubber and other forest resources in exchange for goods.

2) 1870-1912 - the rubber boom, inserting the Upper Jurua Basin into global circuits of capital. To meet higher demand, labor force is brought from poor areas of the Brazilian Northeast in a system of almost indentured labor. This was the period in which control over labor was more intense. Additionally, the feverish occupation of lands in the region led to violent conflicts among armed groups claiming tenure, some of which involved the natives.

3) 1912-1943 - after the boom, with a decreased and constant population and less pressure over land, conflicts cease, tenure stabilizes and there is the development of a regional economy including products other than rubber. More time is dedicated to subsistence activities.

4) 1943-1985 - After the new boom during the Second World War, in which rubber tapping became a military operation in support for the allied efforts, land holders become clients of the state, through multiple programs of subsidies and incentives, mainly the PROBOR (Programa de Incentivo à Borracha Natural - Program of Incentive of Natural Rubber). At the same time, however, Federal agencies promote a number of developmental policies for the Amazon based on land regularization and tax incentives for productive activities, fostering the purchase of land for cattle ranches. 
The history of the Yawanawa, their relations with rubber and the conditions of development of their cultural practices run parallel to the above-mentioned history. Living not far from the sources of the Gregorio River, it is likely that this area was one of the last in the Jurua Valley to be permanently occupied by Brazilians. In fact, the Yawanawa narrate that other populations met them in the Upper Gregorio escaping from the violent raids against the natives by fearful foremen and tappers who were paid to establish estates and initiate rubber settlements ("colocações") on behalf of patrons (Vinnya/Ochoa/Teixeira 2006: 15). They were also victims of such raids, led especially by Peruvians searching for gum trees (Castilloa Elastica), which were removed and transported for gum extraction in Peru (ibid.: 17). The assemblage of populations living around the Tarauacá, Liberdade and Gregorio rivers that encompass the Yawanawa indicates that the Upper Gregorio was a meeting point for these populations and that the Yawanawa were extremely successful forging alliances and incorporating neighboring populations, in a historical pattern that reproduces the ontological features described in chapter 3.

Considering the available information (Tastevin 1924; Vinnya/Ochoa/Teixeira 2006; Brasil/FUNAI 2006), it is possible to assert that the Yawanawa already maintained stable relations with land holders or their foremen in the area in the first decade of twentieth century and decided to contribute to rubber tapping, being involved mostly in support activities, such as providing cultivated food, game and cleaning rubber trails. Their involvement persisted for most of the century, until their land rights were recognized and their land demarcated in the 1980s. This system in which labor was exchanged for goods was extremely influential for the community, and the distance to consumer markets made the arrangement very attractive. It also introduced the Yawanawa to the consumption of industrialized goods. There was, however, a fundamental difference in the way rubber tapping was organized by the Yawanawa. Since the beginning of their involvement with the activity, and so the Yawanawa ethno-history highlights (Vinnya/Ochoa/Teixeira 2006: 22-29), there was always a native chief who organized the work of men, negotiated tracks in the jungle and attempted to monopolize the exchange of all rubber collected by members of the community. In fact, after a conflict for the land, it was the young Antonio Luiz who contacted the new land holders, the Cariocas, in a true act of bravery that led him to the leadership of his people. Before doing so, he had already contested the intermediation powers of a young Yawanawa raised by the previous land holder, accused of tricking the people while organizing their services. After the 
conflict and arrival of the Cariocas and their personal army claiming rights over the area ${ }^{64}$, Antonio Luiz decided to hunt and give the game to the new patron, leaving it on the porch of his warehouse. He was using their traditional form of establishing an alliance, offering food. Carioca left some salt on the same porch and Antonio Luiz, realizing that he could obtain new objects that were envied by others, returned to visit Carioca with more game. He, then, received a knife. After a number of such transactions, the Yawanawa realized that by moving around the new landholder they could obtain all those new objects (Vinnya/Ochoa/Teixeira 2006: 22-26). The intrepid Antonio Luiz united some of the essential roles that produce a leader: he animated his community, forged an alliance and consequently generated exchange with an outsider. Using the regional term normally employed to denote the operations through which natives were incorporated into peaceful, stable economic relations with outsiders, it is possible to assert that the Yawanawa "pacified" the outsiders. The Cariocas accepted their contribution towards the work in order to prevent violence and promote cordial relations between natives and non-native rubber tappers (Brasil/FUNAI 2006).

Antonio Luiz and Carioca established a friendly relationship, which included baptizing the former and allowing him to make trips to larger towns in the region to purchase goods. Invited by Carioca, the Yawanawa settled across the river from the main trade post of the seringal (rubber estate) Caxinaua, where they remained until 1992, when they moved to Nova Esperança to develop the new urucum project. They were especially involved in activities that were complementary to the rubber tapping itself, like opening and keeping tracks in the forest and providing game for foremen.

Whereas most rubber tappers had direct relations with foremen and individually conducted the exchange at the trade posts, the Yawanawa leader was, for most of the time, the only intermediary and responsible for the relation with all white occupants. In practice, then, native men were working for their own chief and much of his power relied on the abilities to conduct external businesses and understand foreign institutions. It was the chief who would take all the rubber to the trade post and bring essential goods back to the community, which would then be distributed to the families. Members of the older generations tend to describe positively this activity and the relationship that the old Chief Antonio Luiz developed with the then owners of the area. The concentration of intermediation and representation powers, which also translate in powers to distribute resources, had a double meaning for the Yawanawa. The chief possessed a great deal of agency, but the negotiations he held were

\footnotetext{
${ }^{64}$ Until the Federal programs of land regularization, land ownership in the Amazon fundamentally meant continuing occupation backed up by the use of force, if necessary, and a contract with a previous occupant, if any.
} 
surrounded by mystery and opacity and, thus, the goods they received were considered as much a gift of the chief as a reward for their work. The terms of the negotiation were not known by the community. During decades, they did not speak Portuguese, nor dominated basic calculation skills. At the same time, foremen and owners trusted the leaders and granted them some autonomy. In sum, internal structures of power, fed by external resources, mediated the relationship between a global market of rubber and the local effects in the community.

This model has enduring legacies for the Yawanawa. It fostered qualities already discussed in the chapter 4: a strong association between leadership and capacities to procure and distribute resources in a logic of generalized reciprocity in which objects are translated into political power. Additionally, it created dependence towards a local trade post for the supply of industrialized goods. More importantly, however, was their insertion into a market activity, a demanding labor remembered with ambivalence. Many elders who worked under Antonio Luiz and the Cariocas actually miss the old activity, asserting that it used to secure all the objects they needed and that they always had plenty. In general, they compare them with the highly productive non-native tappers, declaring that they produced only a fraction of their non-native colleagues and, thus, never had surpluses. Some use this to express that the activity was not suited for them: "[We] did not achieved the goals like the White tapper. The White tapper tapped 500, 600, 1000 kilos of rubber, 2000 kilos and the indigenous never got more than 200, 300 kilos in a year." (MNP). Nonetheless, this equally indicates that the Yawanawa never turned rubber tapping into their main activity, remaining forest peasants:

\footnotetext{
"They [the indigenous rubber tappers] also did not produce as much as the White tapper because they did not only collect rubber, they also had their farming activities, the garden, the banana, planting things for subsistence. Most of the indigenous preferred to eat and drink than engaging in a big economic production that is not worth for those who live and depend on the forest." (MSF)
}

The attitudes of those who worked under the new holders that bought the land from the Cariocas are much different. Until the 1970s, when this transfer took place, they had never faced any restriction on the use of forest resources or land, freely developing their traditional forest activities. The monopsony of the purchase of rubber was not totally enforced and they could eventually sell rubber to peddler boats. They also report the celebration of their parties during the Carioca years, inviting neighboring populations and rubber tappers in their 
particular way of cultivating friends. These parties, one gathers from the accounts of the elders, were a mix of traditions developed out of the contact with non-indigenous tappers, including musical instruments and dances (sanfona and forró) and their own practices, including the consumption of uni and their dances (mariris).

Just as reported by Almeida regarding non-native forest peasants (1992), the Yawanawa accounts emphasize a general deterioration of their condition in the 1970s. Those were times of rapid expansion of the agricultural frontier in Brazil. In the name of development and national security, the Bureaucratic Authoritarian state offered tax incentives and major land regularization to foster the occupation and development of any productive activity in the Amazon, attracting notably cattle ranchers. A consortium from the South of Brazil, PARANACRE, purchased four thousand square kilometers around the Gregorio River, including the Yawanawa territories, and developed rubber extraction. A bigger firm, PARANACRE implemented more strict credit systems, requiring more work from the Yawanawa to obtain their necessities. The firm also restricted the practice of subsistence economic activities, such as agriculture, hunting and fishing, increasing their dependence on the trade post (Brasil/FUNAI 2006: 33). They also took actions against the peddlers to enforce more strictly the monopsony of rubber.

More importantly, PARANACRE broke the moral bonds they maintained with the Cariocas and the new Yawanawa leader, Raimundo Luiz, was not always in good terms with them. As previously mentioned, he did not hold the monopoly over the exchange at this point, with his brothers and other Yawanawa negotiating their particular rubber trails and selling their production directly with the representative of PARANACRE. The intensification of activities and the greater independence of the members led to a relative dispersion of the population. Gatherings only took place for joint celebrations and rituals. Intense inter-cultural contact and the general attitudes of mockery towards the indigenous populations produced embarrassment involving the old cultural practices. Simultaneously, an American Protestant mission settled in the area. The Brazilian governmental body for the protection of indigenous populations, FUNAI, and Raimundo Luiz allowed missionaries to settle in indigenous areas to provide the locals with services that the state did not. The New Tribes of Brazil had a very ambiguous role in the area ${ }^{65}$. They offered much needed health care for a population already exposed to new diseases and victim of numerous epidemics (Brasil/FUNAI 2006: 115). They

\footnotetext{
65 The same religious organization continues to operate in the Brazilian territory, albeit object of numerous scandals involving their activities. The New Tribes Mission and the official Indigenist body, FUNAI, are raging a true war, with the latter accusing the former of murder.
} 
also taught the Yawanawa language, to which they translated religious texts. On the other side, however, their aid was subordinated to the mission of converting the Yawanawa. Local rituals and the system of cure, the consumption of $u n i$, their dances and songs were repressed, considered demoniacal. Soon these practices were abandoned or conducted in private spaces, leading to the erosion of associated cultural forms. Most of the Yawanawa adopted Christian beliefs and even some of those who are now reinventing traditions pay tribute to elements of Christian theology - especially those which are not contradictory to their own. The native assessment of the presence of the New Tribes mission, such as its actions, is also very ambiguous. Members who adopted and keep the Christian faith highlight the availability of medicines and health treatment and ponder that their interference in the internal affairs of the community was minimal. Others, related to the cultural enterprise, argue that nothing else was more harmful for their traditions than the mission.

The official Yawanawa ethno-history leans towards the latter. The 1970s and early 1980s, with its mix of Protestant mission, PARANACRE and the omission of state authorities in recognizing indigenous rights, are considered the most difficult period in the history of the group. This is the background employed in their ethno-history, and aptly by their economic partners, against which the movement of "rediscovery of culture" is presented and the benefits of partnerships are assessed and presented. Terms like "rediscovery", "recovery" or "reaffirmation" of culture, mobilized by them to refer to the current times make sense when opposed to a past of alleged loss and erosion of cultural practices. Their accounts emphasize the difficulties to maintain their culture alive and prevent the relinquishment of their traditional practices (ALV). The Yawanawa mention that they were "disappearing" during this period, that their culture was an object of mockery and their language considered slang. And this is not a false account of the facts. Back then, they were considered "caboclos"- a local term, with pejorative connotations, used to designate populations of mixed origins. More than a prejudice, the power of assigning those populations to the generic category of "caboclos" represented displacing them to a different collective identity with a clear political goal: in so doing, official authorities could deny the very existence of native populations in Acre and, thus, defect claims to special rights recognized by the legislation to the autochthone populations in the midst of modernization projects set in motion in the Amazon in the 1970s (Aquino 1983).

A particular episode illustrates with particular strength this process of denial and categorical displacement. When Biraci and Sales Yawanawa moved to Rio Branco in the 
early 1980s to obtain formal education to better defend the community, they first headed to the local FUNAI's office. They asked if they could stay in the House of the Indian, a hostel kept by FUNAI to host natives temporarily living in the city. The head of the office rejected Biraci, arguing that he was "too white" and did not look like an Indian.

The situation would start to change in the early 1980s, when the land was first visited by a group of FUNAI workers in an almost private campaign of identification of indigenous groups and information about land rights. The official agenda of FUNAI at that period, subordinated to the project of development of productive activities in the Amazon, was to prevent any indigenous resistance to the development of these activities: in areas with strategic projects, they were attracted and displaced to free the way to those projects. In other areas of the Amazon, the project was to define indigenous territories they would be confined, preventing threats to cattle raisers and farm owners occupying the region. Despite the efforts of idealistic members of FUNAI, this process of land recognition and demarcation had obviously very limited indigenous agency. The Yawanawa conquered the first indigenous land of the State of Acre, but without intervening actively in the process. As a result, the area originally granted excluded relevant cultural and economic parts of the territory traditionally occupied by the group (Brasil/FUNAI 2006). In any case, the recognition of the indigenous territory allowed them to manage their land, within some legal limits. PARANACRE was removed from the area. In order to continue to obtain essential industrialized goods, they continued to collect and sell rubber, now without the need to pay rent for the tracks and selling their own rubber without intermediaries at Eirunepé, a town located downstream the river Juruá, in the State of Amazonas.

Simultaneously, selected members of the community were exposed to new movements of indigenous populations and rubber tappers, which amidst the national transition to democracy, were articulating to fight for land rights and the preservation of the forest. Soon after the first visit of FUNAI to the area in the early 1980s (Brasil/FUNAI 2006), the Chief Raimundo Luiz decided to send his oldest son, Sales, and Biraci to Rio Branco. There they were exposed to a new constellation of actors and the language of rights of recognition. In 1982, Biraci took part in the first meeting of the Indigenous Leaders of Acre, organized by the Pro-Indian Commission of Acre (CPI-Acre) and the Indigenist Missionary Council (CIMI). Later, he coordinated with one of the most notable leaders of the Brazilian indigenous movement, Ailton Krenak, the Acrean branch of the Union of Indigenous Nations (UNI-AC). In the years that followed, Biraci attended numerous international events for the promotion of 
indigenous rights and helped to organize the Coordination of the Indigenous Organizations of the Brazilian Amazon (COIAB) (BBY). The rubber tappers were also organizing to secure their rights to forest resources against the expansion of agriculture and cattle raising in the region. Together, indigenous groups and forest peasants formed the ephemeral Alliance of the Forest Peoples. This process would culminate in Biraci's candidacy to a seat at the Chamber of Deputies in 1986's election, for the Workers Party. Losing the election, he was then invited to work at the FUNAI office in Rio Branco. Sales would also be incorporated into the state apparatus, as part of a general campaign of FUNAI to co-opt vocal indigenous leaders.

The incorporation of some members of the constellation into official politics just worsened already existent fractures of the movement. Whereas rubber tappers were moving within the idiom of distributive justice, organizing in unions and directing their struggles to land reform and forest protection through the creation of extractive reserves, indigenous groups turned to identity claims aiming at the recognition of exclusive rights over traditionally occupied land. The decline of the rubber economy prompted by the demise of state subsidies required from the Yawanawa an alternative to income generation. Currently seen by them as an act of desperation, a poor mimicry of firms from southern areas of Brazil acting in the area, the Yawanawa developed with the support of FUNAI a short-lived and failed project of logging, which would cost them harsh criticism from allies (BBY, FLY).

New opportunities for the Yawanawa would emerge in the exact opposite realm: that of the preservation of the forest. The association of indigenous populations with the preservation and even promotion of biological diversity advanced both by sciences (see e.g. Balée 1993) and international documents (see e.g. UN 1987), created new opportunities for indigenous populations. Invited by Krenak to represent him in the side events held in Rio de Janeiro during the United Nations Conference on Environment and Development (UNCED), Biraci decided to look for an alternative for his community. The trip provided the first contacts with environmentalists and was a critical moment in the awakening to a renewed collective identity for the Yawanawa. Discussing his experience, Biraci mentions that it was the first time he realized that the attitudes of the population of Acre towards the forest and the indigenous populations were not universal. In Rio he found persons who regarded him as a native and told him that he had to preserve the forest, his culture and his language. He acknowledges that a reflexive turn followed suit. He started to see himself differently and this "brought a hope, a self-esteem" (BBY). 
After his electoral failure and the fractures of the indigenous movement of Acre, Biraci decided to dedicate himself to his own people. His self-biographical account of this period is particularly epic. For him, the return was a call by the community, a desperate plea to bring together a population scattered by rubber tapping and divided by conflicts amongst Raimundo Luiz and his brothers. Beyond personal rhetoric, these conflicts were real, proved by their division in different villages and the income was very limited, as was the access to basic services, offered only by the missionaries. Biraci was convinced that the solution involved an economic project that could bring income. His experience with the indigenous movement, the urban education, and the regional and national politics taught him how to negotiate, but also instilled a sense of how dignity is built in the market. In his own words,

"I realized that in the world of white men, in order to be respected, you must learn to speak their language. You need a certain financial autonomy to be respected. [...] If you have a firm, a car, goods, if you have money [...]. If you have money everybody calls you: come here to buy at my shop'. They give you discounts. When you do not have money, [they do not give you things] not even upon trust [...]. I learned that. Thus, in order to be respected, we also need that [money]" (BBY).

He found that opportunity in Rio in 1992. Biraci attended a workshop organized by the ethnobiologist and anthropologist Darell Posey at the Parliament of Earth, an event organized aside of the UNCED summit, to discuss market-based projects with indigenous populations to generate income whilst protecting biological diversity. He listened to Aveda's founder Horst Rechelbacher introducing the concept of making hair and make-up products with purely natural ingredients and declaring that he was looking for natural colorants to replace synthetic and petroleum-based dyes. Biraci immediately thought about natural pigments that were employed by the Yawanawa in traditional body paintings. After meetings with Aveda's president and technicians, and visits to the community to assess the feasibility of producing the available dyes, they agreed on the cultivation of 30 hectares of urucum (Ribeiro 2005). This project was followed by others and, together with the recognition of new rights to indigenous populations under democratic rule, would increase the standards of living, facilitate identity claims and foster their expression, as analyzed below. As a consequence of this new moment, selected leaders of the community decided to expel the missionaries, so that they would be once more free to practice their rituals and cultural expressions. 
The details of the development of this and other projects reveal the politics of value, or how agents play with rules and mobilize different categories of understanding and judgment to steer market exchange bearing in mind individual and collective projects. That is what we analyze in the next part. But now, for an Upper Mississippi interlude. 


\section{An Upper Mississippi Interlude: Beauty is as beauty does}

Hitherto I have presented in details the actors whose culture, in represented forms, circulates in the commodity exchange. The goal so far has been to investigate the meanings these actors bestow to their economic undertakings and, more specifically, to commodification, the objects and processes it entails and brings. I also attempted to situate these actions of promoting ethnicity in broader strategies of indigenization. I finally showed that the local accents, which they imprint to the external things, processes and institutions and the local mediations of their social structures are not consensual or homogeneous and that the community displays different expectations regarding these strategies. But before moving to the projects themselves, it is necessary to present, even if in a broad-brush fashion, another actor involved in these processes.

This research deals with two sets of products, resulting from specific projects or alliances maintained by the Yanawawa. One is the set of cultural practices, notably those that are part of their ethnomedical and shamanic systems, which circulate through their agents and visitors. This exchange requires the attendance of producers and consumers in a common space. The other product, I will attempt to argue in Part III, is not properly the annatto seeds, that the Yawanawa produce and employ in their body paintings, but uruku, a trademarked line of makeup produced and sold by Aveda Corporation. These products entail the transformation of seeds and the represented image and location of the Yawanawa into a new entity, which creates and is created by a network of actors. The encounters that originated this network and its dynamics need not to be explained here, as it is the topic of the first chapter (chapter 7) of Part III. Yet a few words on Aveda are in order, since despite using material and symbolic outputs of the Yawanawa, the firm is also a producer, involved in the cultural economy underlying this exchange. Part of the methodological proposal of this work is that economic transactions are better understood if the actors, their positions and specific interpretations are taken into account. And there is no ontological reason why this cannot be done with a firm. Even amidst agents fully integrated into market institutions, different orientations and creative forms of action might be found. Not least, because creative patterns of economic action might be a form of deflecting competition. 
Given the limited access to the firm, I provide here a general portrait, focusing on the ways they represent and legitimize their actions. I attempt to demonstrate that despite all the differences with the Yawanawa, Aveda has also been extremely dependent on the workings of his chief and his visionary leadership, and that its success in enlisting loyal customers, mainly professionals of the hair and skin care industry, is related to its appropriation of foreign values through the mediation of the Western categories of thought. I finally show some fundamental tensions around the defining qualities of its products and the vision the firm wants to project. These tensions are significant to the politics of value underlying the commodification of cultural images of the Yawanawa and annatto seeds, which in the case of Aveda, affects the process of qualification of the product.

\subsection{Towards green: a tribalization of beauty}

The history of the development of the green and natural segment in the beauty industry is well described by Jones (2010: Ch. 8) and is relevant to situate the emergence of Aveda. Since the 1960s, the beauty industry faced attacks from a series of organized actors. It was not only accused of projecting ethnocentric and unattainable images of beauty that were oppressive to women and dismissive of culturally-specific patterns of beauty, but it also became increasingly clear that its products also represented a major threat to human health. Unreal promises to make all women alike, despite their differences, were criticized by feminists and colonized peoples calling for diverse forms of bodily expression. Environmentalists and consumer movements, in turn, started to raise concerns about industry practices and the risks of beauty products. Until that moment, scientific methods of synthesizing ingredients and concocting them were considered the safest and most effective way to create skin and hair products. But a series of scandals in both sides of the Atlantic involving chemical ingredients in cosmetics shook this consensus. The next decade produced a plethora of scientific evidence of the carcinogenic potential of regular hair dyes, increasing health concerns. Animal testing equally came under criticism. By the 1980s, the Ozone Layer crisis exposed the environmental damages of aerosols.

The industry response was varied. It would eventually adapt to the new times, more in terms of marketing than in terms of alternative ingredients, but the first reactions of large 
companies was to deny what they normally saw as exaggerated claims aimed at scandalizing the public opinion ${ }^{66}$.

These events gave impetus to the incipient niche of green and natural cosmetics. The concept always existed, in fact, as herbalists, traditional pharmacists and perfumists predate the mass cosmetic industry. Nonetheless, natural products were discredited by the technological progress of the industry, at least until the scandals led to the recognition that beauty was not a synonym of health and science did not imply safety. And thus "natural", "botanical", "organic" and "green" became new categories and labels to the products of the beauty industry. Obviously the definitions and scope of these terms and their adoption by the industry always remained debatable. In fact, most of the firms continue still today to add "plant extracts to the same chemical formulas used in their existing products" (Jones 2010: 282).

Simultaneously, in different fronts, there were calls for decolonizing the image of beauty that was pervasive in the industry and liberating it from the patterns of beauty that enslaved women. Some firms also began to respond to these calls, albeit with different results. In the intersection of these challenges, multiple new firms selling all-natural products were created in the late 1970s, founded by influential leaders with new ideas for the sector, amongst which The Body Shop and Aveda became the most famous (Jones 2010: 283). Central to the development of their businesses were the presence of a rich discursive element, an institutionalized ideology calling for alternative practices, and their exposure to distant populations and their practices, which inspired them to return to natural ingredients and holistic practices, to recover the harmony of beauty, nature and health.

In the case of Aveda, as the name of the firm already indicates, the inspiration came from an encounter with Ayurveda, the ancient holistic system of healing from India. Combining the Sanskrit words ayur (life) and veda (science or knowledge), ayurveda means "the science of life". One of the oldest healing systems of the world, its cures are based on the use of five basic elements, sensory diagnoses and the uses of mostly botanicals and oils. The system "aims to integrate and balance the body, mind and spirit" (USA/NCCAM 2011) and, thus, it provides a platform for reintegrating beauty and health. This encounter happened in the 1970s, when Aveda's founder, Horst Rechelbacher, met Swami Rama, an Indian Guru in Minneapolis. Rechelbacher was so impressed that he spent six months in India learning about the uses of plants and oils. A hair stylist and salon owner, he developed products based on

\footnotetext{
${ }^{66}$ See in this regard, the reaction of the top research scientist at L'Oreal, quoted in Jones (2010: 279).
} 
essential oils and introduced aromatherapy in his salons upon his return (Jones 2010: 285). The Ayurvedic practices seemed to him a solution to replace the heavily-chemical based, dangerous hair products that had made him sick.

The history of Aveda is inseparable from the history of its founder, the Austrian-born Horst Rechelbacher. Even after selling the firm to the giant Estée-Lauder and opening a new competing firm, Rechelbacher continues to be strongly associated with his first business creation and Aveda, in turn, at least internally and discursively, continues to uphold his rich narratives that give sense to the services and products it provides. The firm and, indeed, his experience, is founded on a myth of origin which shares elements of a Classic Greek Epic and the Schumpeterian conception of entrepreneurship (Schumpeter 1968[1934]). The narrated version of the development of Aveda, repeated in every interview he offers (Cf. Young 2011; Gordon 2011) and in his book (Rechelbacher 2008), emphasizes the ways in which he transformed challenges and hardships into opportunities to change his and others lives. One of the chapters of his book Minding your business bears the suggestive title "Crisis = opportunity". Rechelbacher's trajectory is narrated in a trope of endurance and intrepidity analogous to that of the workings of the Yawanawa chiefs. It all started in Klagenfurt, Austria, where Horst was born to an herbalist mother and a shoemaker father deeply affected by his experiences of war. At fourteen, he decided to take an apprenticeship as hairdresser at the salon across the street. He turned to be very talented and his scissors were the ticket to travel around Europe, practicing his vocation (Gordon 2011). Invited to the United States in 1963 to tour the country with the American Beauty Association, Rechelbacher found himself in a life-changing experience: a drunk driver crashed into his new car, bought with his earnings of the tour. In his own words, he

"ended up in a hospital with several broken vertebrae. [...] I was flat broke and owed a great deal of money in medical bills. The hospital confiscated my passport, leaving me with no choice but to stay in Minneapolis and take a job at a salon to pay off my debt.

So there I was, a young, internationally acclaimed hair stylist at the top of his game, fresh from the most prestigious salons in Europe, suddenly injured, broke, and stranded in a then unfashionable city in the Midwest" (Rechelbacher 2008: 57).

Within months working at a local salon he managed to obtain credit to open his own. "Horst from Austria" was an immense success, followed by a cosmetology school, but other 
crises followed. He realized that the chemicals contained in the products he employed in his services were harming him and his clients. Luckily, his herbalist mother had the cure for his illness: a homemade brew (Young 2011). This was a trigger to rediscover the world of plants: "Through my mother, I discovered my passion for the plant world, and we began to develop shampoos, balsams, and massage oils from a plant base with lavender, rosemary, and eucalyptus. My customers were thrilled." (Gordon 2011). But a third crisis came with a burnout and a failed marriage, prompting him into his journey to India. Ayurveda provided him a solution for all the problems he saw in the industry and upon his return, in 1978, he decided to start a business producing flower and plant-based hair and skin products. He named the new company Aveda, after the Sanskrit Veda, meaning knowledge. Rechelbacher later found all that $A$ means all, making it the perfect name (all knowledge) (ibid.). The firm began to sell hair and skin care products to local salons and to develop service rituals associated with beauty.

Ayurveda was, in fact, more an inspiration and a philosophy than an actual guideline for the products and services provided by the firm. In fact, his first product, a clove shampoo, was the result of his mother's work, not of any Indian wisdom. Except for the spas later developed by Aveda, where some adapted Ayurvedic practices are offered, the sensorial system of diagnosis and cure of traditional Ayurveda was transformed into new products and ritualized services using turmeric, aromatherapy, the notion of dosha, or humors, and the notion of chakras, or body energy centers. The three doshas that, according to Ayurvedic lessons, are humors that combine in unique ways to comprise a person or ideal-typical bodies are presented to customers as a system of classification of their own mental and physical states that would enable them to select specific products for each dosha. Each of the seven chakras, in turn, related to sentiments and expressions of human life, is associated with a specific fragrance or, in their words, a "body mist". A full range of service rituals to be offered to clients seeking for beauty services was developed and its institute was used to train professionals on how to perform them. In 1999, Rechelbacher published a book on some of these natural health and beauty rituals (Rechelbacher 1999).

Aveda integrated environmental concerns, health and beauty in a way that catered for the Western contemporary client. Beauty would be healthy again, in a holistic way. Aveda introduced much of the Western world to a sort of Ayurvedic philosophy and aromatherapy which is, obviously, a creative reinvention of Eastern practices. The development of these ideas and this cargo cult of Eastern and distant practices are mediated by cultural patterns and 
values that are essentially Western ${ }^{67}$. This cultural exchange is no less dependent on the local schemes than the appropriation of modern artifacts by indigenous populations is on their native schemes. This quest for alternative strategies for holistic well-being and health, in which beauty is inserted, aims at operating bodily transformations at the individual level with results that are valued in the West, even if the search for personal well-being is framed as means to remedy the social and environmental malaises of modernity. It is through the individual and its practices that these illnesses could be cured (Lau 2000: 4). The practices of consumption of Aveda products, including the uruku line, and the discourses created by Rechelbacher, can be understood as expressions of "individualism and self-reliance" (ibid.: 4) that displace Eastern philosophies from their original semantic fields, reframing them according to Western categories. Thus, he writes about "ayurveda individual incentives" (1999: 37) to describe a number of individual behavioral prescriptions derived from Ayurveda. There is nothing more central to the cosmology of Western capitalism than utilitarianism and its naturalization as a principle of action.

The appropriation of Ayurvedic practices through the lenses of Western radical modernity makes possible to transform the millennial practices of aromatherapy, a central component of the Indian healing system, into a solution for the commonest of individual problems of the modern subject, as the firm suggested in the 1998 issue of its magazine: “... your boss chewed you out. Your partner isn't affectionate lately-nor washing the dishes. Your voicemail box is empty. Even the parking attendant ignored you this morning. We've got a solution: plant Aromaology/therapy" (Aveda 1998: 11). "Scents", the text continues, "can even help you work harder and smarter" (ibid.: 13). "Because Aveda's heart's connection is to Earth" says Rechelbacher in another firm's publication, and because we are displayed as part of a "web of all things" in the same publication, "the art and science of pure flower and plant essences" (the firm's registered motto), may be used to transform "nature's bio-energy into personal health and vitality". And vitality, or potency, seems to be central to the New Age quest for alternative therapies and rituals, as further discussed below, in regard to the consumers of Yawanawa rituals. This complex cosmology linking beauty, environment and well-being can only be interpreted - and sold - from a Western perspective.

Aveda was founded at the intersection of the challenges to the beauty industry with a discourse against petroleum-based ingredients that, according to Rechelbacher, should "carry a warning label", a new environmental paradigm and a critique to the artificial beauty of

\footnotetext{
${ }^{67}$ I reproduce the geographical metaphor for modern Capitalist areas of the world, but not without reservations. In the case of Aveda, Japan is one of its main markets, which blurs these geographical representations of cultural systems.
} 
supermodels (Koelln 1995). The firm often uses non-European-like models and appeals to visual cues that are invocative of Eastern lands, without actively challenging the gendered, heteronormative patterns of Western beauty. At the reception of their headquarters in Blaine, a small board has the saying "Beauty is as beauty does", an idea equally mobilized in the communication of the firm. The firm was organized around a mission signed by Rechelbacher and still present in all Aveda retail shops: "Our mission at Aveda is to care for the world we live in, from the products we make to the ways in which we give back to society. At Aveda, we strive to set an example for environmental leadership and responsibility, not just in the world of beauty, but around the world". It was the first to sign the Ceres Principles, a tenpoint corporate environmental governance agreement created in 1989 following the Exxon Valdez oil spill in Alaska.

It was also, together, with the Body Shop, one of the first companies to associate with distant communities to source ingredients. Aveda does not espouse, however, a "trade-notaid" policy and, in fact, frequently mobilizes its network of professionals, clients and supporters for philanthropic campaigns to help communities and environmental causes. Given the difficulties to find usable botanicals for hair and skin care after decades of heavy use of chemicals, Aveda understood these partnerships as a sourcing technique, framed as a search for the ancient knowledge on natural beauty still retained by these populations. In the words of David Hircock, the hunter of natural resources for the firm, "it all goes back to the philosophy of the brand": looking for plants capable of generating good products proves "the power of plants" (DH). Nonetheless, once they have found an ingredient with the potential of yielding a high performance product, they can extend on the wisdom they obtain. At least in its original conception, this knowledge extends far beyond the ethnobiological: whether Australian Aborigines or Moroccan Berbers, these "traditional" communities are all repositories of a valuable knowledge on beauty, environmental concern and lifestyle. In his book, for example, Rechelbacher (2008: 74 ff.) discusses the lessons he drew from his experience amongst a tribe deep in the Brazilian Amazon, a certain Yabba tribe of the Gregorio River, obviously referring to the Yawanawa. I shall return to this point later when discussing the annatto project, but the cultural economy underlying exchange works for both parts of the agreement and as much as the Yawanawa receive values, they also send them. But again, the lessons are framed in essential categories of thought and in the general symbolic scheme of the Capitalist cosmology:

"My time with these indigenous Amazon people taught me some of the most important business lessons of my life, especially as regards team 
management. I also learned much from the about community - about living, working, and worshipping together in harmony with nature's rythms. [...] Since then, my business systems have been built around cooperative teams that reflect the influence of these indigenous tribal systems" [...]

Indigenous cultures are the members of our human tribe who live at the point of impact in our biosphere. Their ways of knowing allow them to perceive and understand many things that elude the more 'sophisticated' intelligence of our experts in white coats and business suits. Their fine -tune sensitivity to the natural world is an invaluable resource that humanity cannot afford to lose." (Rechelbacher 2008: 75-77).

The romantic description continues with its bon sauvage trope, describing a pristine, harmonious and democratic community for a couple of pages. Despite discussing the lessons from a distant population, there is no need for the introduction of incomprehensible or unknown ideas. The lessons are, indeed, all much known or at least understandable for us. The first is about how cooperation makes for a better management system. The second is about harmony with nature. The third is a challenge to our modern notions of the superiority of expert knowledge and the "white coats" of sciences. This displays how business agreements are possible amongst misconceptions or very limited understanding, because objects and ideas transplanted to new cultural settings defy their material and ontological original properties and are open to reinterpretation. In this case, if we compare his lessons with Biraci's lessons in Rio, it is easy to conclude that the commonality that would make cooperation possible was a lifestyle in harmony with nature.

The specific ways these partnerships, the ingredients and the lessons taken from the populations with which they interact are communicated by Aveda, as well as the efficacy of such messages and their target groups, are questions further analyzed in reference to the uruku line, which incorporates annatto from the Yawanawa. It should suffice here to show that these stories help validating the firm's discourses, act as a symbolic resource and a mechanism of enticement within the firm and amongst its main and most loyal customers, hair and skin care professionals. Clearly, these partnerships demonstrate the commitment of the firm to help communities and the congruence between environmental concerns and corporate development and profit. More importantly, they aim at promoting, at least amongst the professionals that constitute the core target of their substantive message, the connection with the ideals and magical properties of a distant location. According to the current President, Dominique Conseil: "there was an early vision, since the inception of the company, to connect consumers 
of the modern world to traditional and Indigenous wisdom and diversity" (DC). When effective, stories about these partnerships produced by the company offer, in the words of Beckert (2011: 116), a "transcendence of place". Through the ingredients contained in the products, its consumers have the opportunity to symbolically connect to the ideals and legacy of a distant population. More than the association with a distant place, however, they build a biography for the products.

The firm developed around this complex set of discursive and symbolic practices, showing concern for the environment and well-being in connection to beauty. On the one side, Aveda became a strong name among hair professionals who attested the performance of its products. On the other side, these discursive and symbolic practices surrounding the products created a true followership. The firm concentrated on selling its hair and skin care, makeup and fragrances in hair salons, creating a successful distribution mechanism, first in the United States, and later expanding to Europe and Asia. Later, the company opened a number of retail shops, spas and expanded its training facilities, named institutes.

Their main channel of sales has always been hair salons affiliated with Aveda. The affiliation is a very particular form of franchising. Aveda does not necessarily determine the design, the protocols of service or forms of aesthetic expression. Nonetheless, the affiliation at its minimum means that the salon carries Aveda products, using them in their services and selling them. It operates as a qualification or judgment device (Karpik 2010), signaling the clients of certain predictable patterns of quality and style, which are associated with the brand. The affiliate salons might adhere to the brand in different degrees, offering additional services and rituals associated with Aveda or selling and using exclusively their products. To signal this degree of association to the clients, Aveda devised a number of different categories and labels. Any client looking for a salon on the Aveda website has the option to check if the affiliated salons offer exclusively Aveda hair color, participate in the Pure Privilege loyalty program, perform complimentary sensory rituals, spa services or meet goals set for their Earth month (Aveda 2012a). Salons performing complimentary sensory rituals abide to a protocol of "guest service experience" devised by Aveda, which involves "comforting tea, stress relieving rituals, aroma sensory journey and product recommendations" (Aveda 2012b). These rituals are further described below. The Earth month, an annual campaign to raise funds for designated environmental causes, is an important aspect of their brand. The campaign acts as a network of fundraiser teams in salons, institutes and spas for projects selected by the firm, normally run by non-governmental organizations. 
The company also owns some flagship salons and spas, in which they demonstrate to the rest of the industry their conceptions and put to test their services. In order to develop and spread these conceptions, techniques and rituals, Aveda developed training facilities for hair stylists, cosmetologists and estheticians, called institutes. These facilities are either owned by the firm or by others, but the idea is to train a particular type of professional. Many Aveda salons prefer to employ professionals trained in these institutes, avoiding the need to induce them into specific procedures, techniques, language and rituals. As any educational institution, institutes are a fundamental space of sharing values. More than any other space, these allow the firm to instill its ideology, as well as aesthetic and ethical values in the future professionals. They form, thus, a community. In addition to training facilities, Aveda has a number of spaces that comprise a network in which images, concepts, styles, fads and fashions are shared with professionals and loyal clients. Thus, the average client may expect to obtain a similar result in an Aveda-affiliated salon.

Aveda is mainly a professional brand, marketing its products through a network of fiercely loyal professionals that work in thousands of hair salons, spas and training centers. This network is built around a regular magazine, a loyalty program, called Pure Privilege, conferences for professionals, the participation of their hair and makeup designers in large fashion events and an Inner Circle formed by loyal clients. The latter is a group created for panel survey and product testing. The participants are selected from programs such as Pure Privilege or specific purchases and rewarded with the opportunity to attend special events with professionals, inspiring personalities and representatives of the sourcing communities. The company strives to maintain this network, which operates as a niche insulated from competition, just as the model described by White (2002).

Forging professionals strongly identified with the tenets, the myths, the techniques and faithful followers of the developments of the brand can be an effective way of guaranteeing the long run success of any firm. Albeit not being a direct selling organization or sold by door-to-door representatives, the role of its founding prophet and devoted professionals in selling the products creates a model not far from the Charismatic Capitalism of organizations analyzed by Biggart (1990). These organizations are built on the belief of moral values of entrepreneurialism, an institutionalized ideology that creates a following. In the case of Aveda, commitment and loyalty are secured through the moral value of integrating beauty, health and well-being, not just for the client, but for the world as a whole. The employees of the firm and professionals associated with the brand that I met seemed to believe genuinely in 
the transformative capacity of their partnerships and environmental practices, and reveal their true enthusiasm with the project. This is an instance of deep acting (Hoschchild 1983), in which the workers own identities become intermingled with goals and values of the employers. As a consequence, similarly to the representatives of direct selling organizations, they reveal "a pleasure in being associated with what they perceive as an important moral enterprise" (Biggart 1990: 141). Just as other charismatic business organizations, the firm also created a community with multiple spaces - conferences and the Inner Circle - to celebrate membership and loyalty. Finally, the reliance of an eccentric but inspiring leader on an effective bureaucracy to turn whimsical ideas into profitable reality, another characteristic described by Biggart (1990), is clearly present in the history of Aveda. When Hircock talks about the beginnings of the partnership with the Yawanawa, this becomes evident: "you would understand that, in some ways, this is a project that one should not have done" (DH) was uttered at the beginning of our conversation. It worked, he adds, against many odds. And it worked because he and other professionals managed to overcome the challenges of transporting annatto seeds from Acre to Sao Paulo without being destroyed by fungi and bacteria to later transform bixina dye in an ingredient of usable cosmetics.

Despite these tensions and challenges analyzed in the next section, the ideological construct which Aveda employs to elicit a loyal group of professionals and close clients is not a deception. If the message created as result of this cargo cult of Eastern artifacts appears to be less than coherent, a pastiche of holism and individualism, and somehow an opportunistic appropriation of alternative philosophies and environmental concerns for profit, this is because modernization - equivalent to indigenization - entails putting foreign ideas to local uses, according to local accents. Furthermore, there are no reasons to believe that the involved actors do not sincerely believe in the transformative powers of beauty. On the contrary, it does elicit commitment from professionals because in the first place they believe they need to adopt new practices of beauty, health and towards the environment. Without this homology (Bourdieu 2005), the meanings of this construct would not find true carriers in these deeply motivated professionals. For them, this provides a language to make sense of their world and occupation. Beauty is as beauty does legitimizes services that many judge as superficial, showing that it is not just about skin care, but about harmony and preservation of nature. Nonetheless, just as we find different expectations surrounding modernity in the Yawanawa case, we also find different discourses and aspirations of incorporation of practices and principles in the case of Aveda, to which I now turn. 


\subsection{Beauty is as beauty does: for whom?}

In 1997, Aveda's products were sold in about 30,000 professional salons worldwide, 2,000 of which were exclusive carriers of Aveda products, as well as in a number of its “experience centers" retail shops, generating annual revenues of USD 120 million. The beauty industry giant Estée-Lauder then offered USD 300 million for its acquisition. The fifth largest beauty company in the world with almost USD 8 billion in revenues in 2008 (Jones 2010: 372), the family-controlled Estee-Lauder had a number of reasons to purchase the venture. The firm was interested in expanding its participation in the hair care segment, which represented only six percent of its revenues (ThomsonFinancial 2010) and in using Aveda's distribution channels for its makeup and skin care products (Canedy 1997). As part of a broader movement of the industry to incorporate alternative medicine practices, Estée-Lauder was also interested in the Ayurvedic-inspired products and services offered by Aveda (Jones 2010: 316). Rechelbacher remained in the firm during a transition period, after which he was replaced by Dominique Conseil, holder of a degree in Pacific Anthropology and Polynesian Languages, as well as a Masters in management.

Due to priorities and existing products of Estée-Lauder, the focus on hair products was strengthened, and makeup lines reorganized. This move affected the annatto project, since the ingredient is mainly employed in the makeup line uruku. Yet this was not the only change. My short visit to the firm, in early 2012, and the conversations I held with some employees, revealed that despite a high turnover since the acquisition, there is a lasting tension about the image of the firm and its future, mainly regarding the use of non-plant based products and, to a minor extent, the risks involving sourcing ingredients from distant communities.

More than producing hair and skin care products, the firm has built a reputation around a philosophy of producing beauty whilst doing beauty. Their products are considered to be highly effective and perceived as safe and environmentally friendly. Obviously, the mission of producing purely natural, organic, non-petroleum based, responsibly sourced plant-based products, on the one side, and the goal of achieving the highest possible efficacy do not always go hand-in-hand. Aveda under Rechelbacher seemed unequivocally committed to challenge the notion that science made for better beauty products, but this does not mean that the beauty being offered in its products was not scientific. My conversations with the Research and Development Team at the firm revealed the challenges entailed in using natural, plant-based ingredients to generate high-quality colorants, fragrances and, above all, to 
preserve them. Transforming them into effective products compliant to the patterns of beauty and standards set by industry requires technological transformations in a network of actors, raw materials and processes.

The very introduction of Eastern ideas of well-being into the hair and skin care industry was already marked by a tension between nature and its legitimation in terms of quality of the product. Thus, when presenting aromatherapy in an issue of its magazine, Aveda reasserts consumers stressing its scientific acceptance: "aromatherapy", they inform, "is now taught at medical institutions in Germany and England. And in the U.S., the first postgraduate course is offered at Purdue University. But then, it becomes "aromaology", the medicalized version of the practices under the scrutiny of Western sciences. In fact, this tension has only increased with the orientations of the new parent company, despite its commitment to remain loyal to the original mission of the firm.

The main effort behind the development of the firm was to prove, and Rechelbacher seem obsessed with this, that beauty and individual and environmental health are one and only. Yet the company always strived to sell top products as well, creating a relative tension that does not surface in their basic ideology. The research and development team at Aveda insisted they have to work with a fairly limited range of essences, colorants and preservatives provided by nature (5) and still depend, in their words, "on all those firms from New Jersey". Firms from New Jersey, I learnt, stand for the main representatives of the chemistry industry in North America, providing synthetic and mostly petroleum-derived ingredients. They proudly produce their own fragrances, considered one of the villains of the beauty industry, from organic-certified oils, but they define as naturally derived ingredients those in which "more than $50 \%$ of the molecules comes from a plant, non-petroleum mineral, or other natural source" (Aveda 2013).

On a tour through their factory in Blaine, Minneapolis, I was taken to a separated area where barrels containing these chemicals, with tags showing their origins from large industries in New Jersey are stored. This area is segregated due to security reasons, but the attitude of the tour guide and the idealist chemists who I saw on our way, showing it with some frustration and shame, especially when compared with their enthusiasm with the plants lab, could suggest that for them this is a tainted area they want to isolate from their otherwise clean production, even if these substances are later added to their products. Their employees uphold this almost religious commitment to produce clean and good products. 
This shows how the institutionalized ideology cultivated by Rechelbacher continues to guide the employees at the firm. On the other side, the new administration seems more convinced that the role of the firm is to offer high performance hair and skin care products, which are additionally green and make a difference. An analysis of the communication of the firm over the years shows the introduction of the term "high-performance" to describe its products after the purchase by Estée-Lauder. "Some people say you cannot pursue naturalness and deliver cutting-edge results" declared the new president, Dominique Conseil, in an interview to the Fast Company (Sacks 2006), but talking to me, he confided that their clients, professionals and end consumers alike, are very demanding on the performance of the product and they do not want to be perceived as a "granola" company:

"The brand has to be desired for the efficacy of its products. It's a fine line that we try to walk. There is a feel good factor that some people see [...] but it is not the core of the value proposition. And we need to be very careful about this. We have a director of creation that is very sensitive about this. She always says when she looks some pictures 'that is a bit granola. It is too rural'. We sell high added value product, so we cannot be too raw material." (DC).

Conseil tries to find a balance between the purely natural and the high performance. He reasserted Rechelbacher's mission of bringing healthy, safe, environmentally sound products that are as beauty as they do good. Yet, there are indications that the firm moved from aiming at producing high performance green products, to intending to produce as green as possible high performance products. Clearly, this generates different reactions within the firm and amongst followers who remain loyal to the original vision of the business.

A similar tension involves the degree of reliance of the firm in sources of raw materials from indigenous and traditional communities. The introduction of new regulatory instruments to access their knowledge on biological diversity, and notably the Nagoya Protocol on Access to Genetic Resources and the Fair and Equitable Sharing of Benefits Arising from their Utilization, added to the Convention on Biological Diversity, created new challenges to deal with these populations that were highlighted during my talks. These new regulations aiming at protecting populations create new demands and necessary procedures, besides increasing the legal liabilities of establishing partnerships with traditional populations. These instruments, together with scandals, criticisms and skepticism surrounding initiatives like Fair Trade have created a sensation within the firm that these partnerships are under increased public scrutiny and led to a more strategic approach to sourcing raw materials in distant communities (DH). I 
was told that agreements such as the one that was done with the Yawanawa, despite the fair compensation for the seeds and all symbols and images employed, would hardly be possible now (DH, 5).

In addition, these partnerships have presented them with multiple challenges. Learning how to deal and negotiate with different populations, finding intermediaries capable of translating and bridging two worlds, respecting different codes, securing both the goals set by the firm and their partners, as well as fulfilling expectations are difficulties they face in every partnership. Albeit passionate about them, David Hircock reveals that every new contact involves dealing with unique difficulties (DH). These challenges expose the firm to public questioning and criticism that, according to some, are not well received by the new owners of Aveda. The Lauders, I was told, strongly associate their names and reputation with that of their firm and, thus, they are personally affected by any criticism or accusation directed against the firm.

The specific challenges and internal tensions in the firm involving the annatto project will be further analyzed below, as part of its politics of value, but a critical article on the partnership published in 2011 (Lyons 2011) apparently called into question the maintenance of their relationship with the Yawanawa. At the same time, as discussed above, these partnerships are an important part of the image of the firm and strongly defended by all the employees to whom I talked. It is exactly because they are so challenging, that their business is transformative and rewarding. And this adventurous nature was at the center of Rechelbacher's original vision of the business. The partnerships are a symbolic resource possessed by the firm to show that they are doing more than just selling beauty products, a discourse that motivates and elicits loyalties from employees and professionals. Amidst these tensions, Conseil must prove that, despite no longer run by Rechelbacher, the firm remains the tribe envisaged by its founder, a community of values loyal to its original substantive mission, and capable of maintaining the charisma that moves its professionals.

The long inquiry into the actors that are producing cultural representations served the purpose of understanding the specific meanings bestowed upon economic action and its results. This is necessary to the aim of approaching exchange as a social, political and cultural, as much as an economic phenomenon. And it is equally important to determine the reasons for circulating things, the passions and interests that animate the politics of value. The first three chapters (chapters 3 to 5) provided a portrait of the Yawanawa, setting the context 
to understand their engagement with projects that entail the circulation of their cultural representations. Agents move in these relations and categories of meanings, sometimes creatively. The first of such chapters dealt with a self-image of community that can be invoked to steer exchange, the place of outsiders and their location and patterns of residence, a factor that increases the challenge to incorporate the other and their things. It continued explaining the relationship of conflicts with dynastic claims to power and presenting the main characters of the two legal organizations that represent the Yawanawa, as well as the main visions about culture. Chapter four also revealed the importance of distance to explain their relations with good, money and work, after discussing the relationship between projects of leadership and the promotion of alliances that result in material and symbolic resources in the community. The chapter offers a sketch of the political and cultural economies of the Yawanawa that explain why they engage in productive activities for exchange and how external objects reproduce political power, social relations and rituals. It also revealed the different expectations that come with the indigenization of modernity and different discourses related to existential visions. Chapter five offered a brief history of the Yawanawa in the past century to reveal the development of certain patterns of political action and relations with outsiders. History is also important to explain the valure of their product or brand. Chapter 6 offered a short presentation of the firm, Aveda, its charismatic nature, the commitment to reconcile beauty, health and environment indigenizing foreign discourses and wisdoms and the tensions it generates in the qualification of their products.

Now I finally turn to analyze the projects. 


\section{Part III}

\section{The Products}

This part analyzes two economic projects, not always framed as such by the Yawanawa, developed over the last two decades and still existing. The previous part set all the conditions that explain the dynamics of production, exchange and distribution of resources. Here I offer a description of the projects and these products, the politics of value underlying the circulation of their products and the consequences for the community. In the conclusion, I will attempt at reconnect the conditions described in the last part with the events described here. 


\section{Of Seeds and Culture}

This study looks at two still-running economic activities and specific partnerships developed since the 1990s by the Yawanawa, their development, challenges and meanings to the involved actors. The first is the production of annatto seeds for Aveda. Those seeds are found in the fruits of Bixa Orellana, a small tree that is native to Tropical America. They seeds contain Bixin, an orange-red pigment that has been widely employed for centuries as a natural colorant (FAO 1995). The actual project involves the cultivation of trees and extraction of the seeds, for further processing to obtain Bixin at an industrial facility in São Paulo, Brazil. The dye is then sent to Aveda's manufacturing plants in North America. The Yawanawa had traditionally employed the pigment, manually extracted from wild harvested seeds and mixed with natural oils, to produce body paintings that are considered symbols of protection and beauty.

\subsection{The Product: urucum-uruku}

The annatto project started in 1993 with the cultivation of 30 hectares of Bixa, known in the Amazon as urucum $^{68}$, in a village renamed to celebrate the new age of the Yawanawa: Nova Esperança, or New Hope, and to which most of the Yawanawa moved as a result of it. As already mentioned (chapter 5), the inception of this project took place in Rio de Janeiro, in 1992. Yet some details of the meeting and following development of the project, as described by May Waddington, the translator and intermediary employed by Aveda, are worth recollecting to understand the formation of the network of agents and devices that constructed the product, as well as the role of politics and expert knowledge. Callon/Méadel/Rabeharisoa (2002) emphasize that experts are fundamental to create products in technology-intensive industries. But here we find a similar situation, in which an expert bridged the parts. The workshop in which Biraci and Horst Rechelbacher met was organized by the ethnobiologist

\footnotetext{
${ }^{68}$ Although the word in the Yawanawa language for the fruit is nane, most of the local population uses the regional term urucum, which was adopted in Portuguese. The firm also employed this name in its line of product, albeit writing it urukum. I prefer to use the Portuguese term here in its original form.
} 
and anthropologist Darell Posey. Posey was one of the main advocates of the role of indigenous populations in the promotion of biological diversity in the Amazon and seeking partnerships through which they could protect their lands and their traditional knowledge associated to biodiversity. This discourse provided an opportunity to indigenous populations and attracted Rechelbacher in his quest for natural, environmentally friendly and healthy ingredients to produce beauty. Rechelbacher came to Rio announcing his interest to finance the production of natural ingredients by indigenous and rubber tapping populations of Acre (Ribeiro 2005: 222).

The event also reveals the network of allies forged and mobilized by Biraci over time. The attendance of Biraci was dependent on his prominent position in the Indigenist movement of Acre. Biraci went to Rio as a representative of the MPIVJ (Movimento dos Povos Indígenas do Vale do Juruá - Movement of the Indigenous Populations of the Jurua Valley), invited by Ailton Krenak, who due to clashes withi the indigenous movement decided not to attend the event (Ribeiro 2005: 221). This small organization was formed with the support of the allied CNS (Conselho Nacional dos Seringueiros - National Council of Rubber Tappers) and Krenak, who had negotiated a grant from the British charity OXFAM. Funds from this organization were used by the Yawanawa to develop economic activities, notably sell rubber, after the expulsion of the landholders. After a brief period away from the movement, due to the involvement of the Yawanawa in logging, Biraci was invited to return by Krenak and sent to Rio to represent the organization at the UNCED. In Rio de Janeiro, he met Perfeito Fortuna, an influent performing artist and member of the Santo Daime church, who would become one the main allies in the times of cultural performances.

Soon after the Rio summit, Horst Rechelbacher travelled to Acre with a representative of the CNS. He visited several indigenous populations and was invited to the recently created extractive reserves, through which the rubber tappers secured common access to forest resources in the early 1990s. Amidst this competition between forest populations for the resources promised by Aveda, Biraci used his position in the movement to captivate Horst, who in turn decided to start his project, initially intended to include other populations, with the Yawanawa (Ribeiro 2005).

After a meeting with Biraci, Rechelbacher committed to send a team to investigate the potential use of natural dyes regularly used by the Yawanawa. Technicians visited the Indigenous land and realized that the red pigment employed by the Yawanawa was extracted from Bixa Orellana. They proposed, as a result, a consortiated cultivation of annatto bushes, 
pupunha (Bactris Gasipaes) and andiroba (Carapa Guianensis). Pupunha is a palm fruit commonly consumed as food in the area and andiroba is employed to extract an oil with antiinflammatory action amongst multiple uses, from insect repellent to use in cosmetics. Hoping that the Yawanawa would find suitable buyers for the other crops and the project would, thus, secure their financial autonomy, Aveda committed to the purchase of the bixa seeds, paying 2,5 times the market price of the product (Ribeiro 2005: 242). The Yawanawa could also employ the seeds to produce a common food colorant in Brazil (colorau). The firm provided an initial loan of USD 50,000 for the cultivation of the trees, which some indicate was later converted into a donation (ibid.: 242).

Seedlings $(13,000)$ with high amounts of Bixin were brought from Embrapa, the Brazilian, state-sponsored company of agricultural research. Therefore, although traditionally employed by the Yawanawa, the project did not incorporate any accumulated knowledge on the species. Both Aveda and the Yawanawa stressed the initial technical challenges of the first harvests and mentioned that after receiving the seedlings from Embrapa, there was a learning and maturation period, initially planned to last two years (Ribeiro 2005), but that lasted much longer (DH). Technicians explained how to protect the new bushes from common threats (fungi and others) and how to extract the seeds so that they could yield a high amount of usable Bixin, with the least oxidation - the main problem they face, since it changes the color of the pigment (3). The first usable harvest was only after five years (DH). They also received machinery to remove the seeds from the fruit, dry them and treat them prior to their transportation to Sao Paulo, where the Bixin was extracted at an industrial facility. At its peak, the Yawanawa produced 4 tons per year of Bixa seeds (Ribeiro 2005: 242).

As a result of conflicts analyzed below, the population of Nova Esperança ceased its participation in the project after fifteen years and the plantations in the village were abandoned. Some trees still grow the fruit, but the main area once used for the cultivation is now a fishpond. Since 2008, the project is maintained by the Yawanawa in the five villages associated to ASCY, under the leadership of Joaquim Yawanawa. A new contract with Aveda, signed in 2003, stipulates the provision of 2.5 tons/year with preferential rights for the purchase of surpluses (JY).

Since the inception of the project, Aveda has negotiated and paid for the rights to employ Yawanawa images and symbols. In the older version of the contract, besides royalties, the firm committed itself to pay a negotiated amount for each image employed in its merchandising. According to Biraci, the values paid for those images varied between US\$ 1 
and 5 thousand (BBY). Currently, there is a three-part contract, which includes non-disclosed values for the production of annatto, the rights of image and social projects.

Those images build upon the advertised effects of the partnership for the community, namely the preservation of their culture and, as a consequence, the protection of the forest. Thus, they display the community in their traditional vests, amidst their ceremonial games or, at least, painted with urucum, demonstrating the beauty of the ingredient, as used by the sourcing community. The firm says it draws inspiration from the original uses of urucum to produce a different form of beauty. The packaging of the products also incorporate Yawanawa designs, stylized symbols of sacred animals (see images 3 to 5 below).

It can be safely argued that together with the seeds, the object of exchange is the cultural representations of the Yawanawa, which travel across cultures to be translated and incorporated into makeup products sold by Aveda in the United States, Europa and Asia. Urucum is, then, presented as a natural ingredient, but one that incorporates the wise recipes of a distant community in the distant Amazon for beauty. It is also a product that helps preserving a culture and its harmonious lifestyle. All these reasons, the firm expects, would justify the premium that consumers pay to have make-up products made of Yawanawa urucum.

Bixin has been known in European soils for many centuries and widely employed as a food colorant. It is native of tropical areas in the South and Central Americas, but after transplantation is now widely available in other areas, where it is cultivated in farms and is fairly inexpensive (FAO 1995). On the other side, the producing areas of urucum trees in the shores of the river Gregorio are many hours away, using motorized boats, from the nearest road and, then, at least three days away of Sao Paulo, where it is processed and exported to the manufacturing plant of the makeup products. According to Joaquim Yawanawa, Aveda currently pays approximately three times the market price for urucum, but the revenues the Yawanawa obtain selling their image rights have always been much higher than the price paid for the actual production (BBY, JY). Clearly, the image of "otherness", the pristine beauty of their community and their body painting, is the essential object of exchange. The product is a specific line of makeup, traded mark with the Anglicized name $u r u k u$, which incorporates the seeds, images and symbols of the Yawanawa to suggest a distant location (the forest) and the natural beauty achieved through the pigment. The most recent material related to the makeup line (Image 1 below) displays stylized symbols made by American designers who visited the community and saw the kene, patterns of body paintings of the Yawanawa symbolizing spirits 
of nature. The image also brings the message "out of the forest", informing the reader about its origins (the Yawanawa People of Brazil) and reminds her that the partnership helps the community.

\section{Image 1: Uruku}

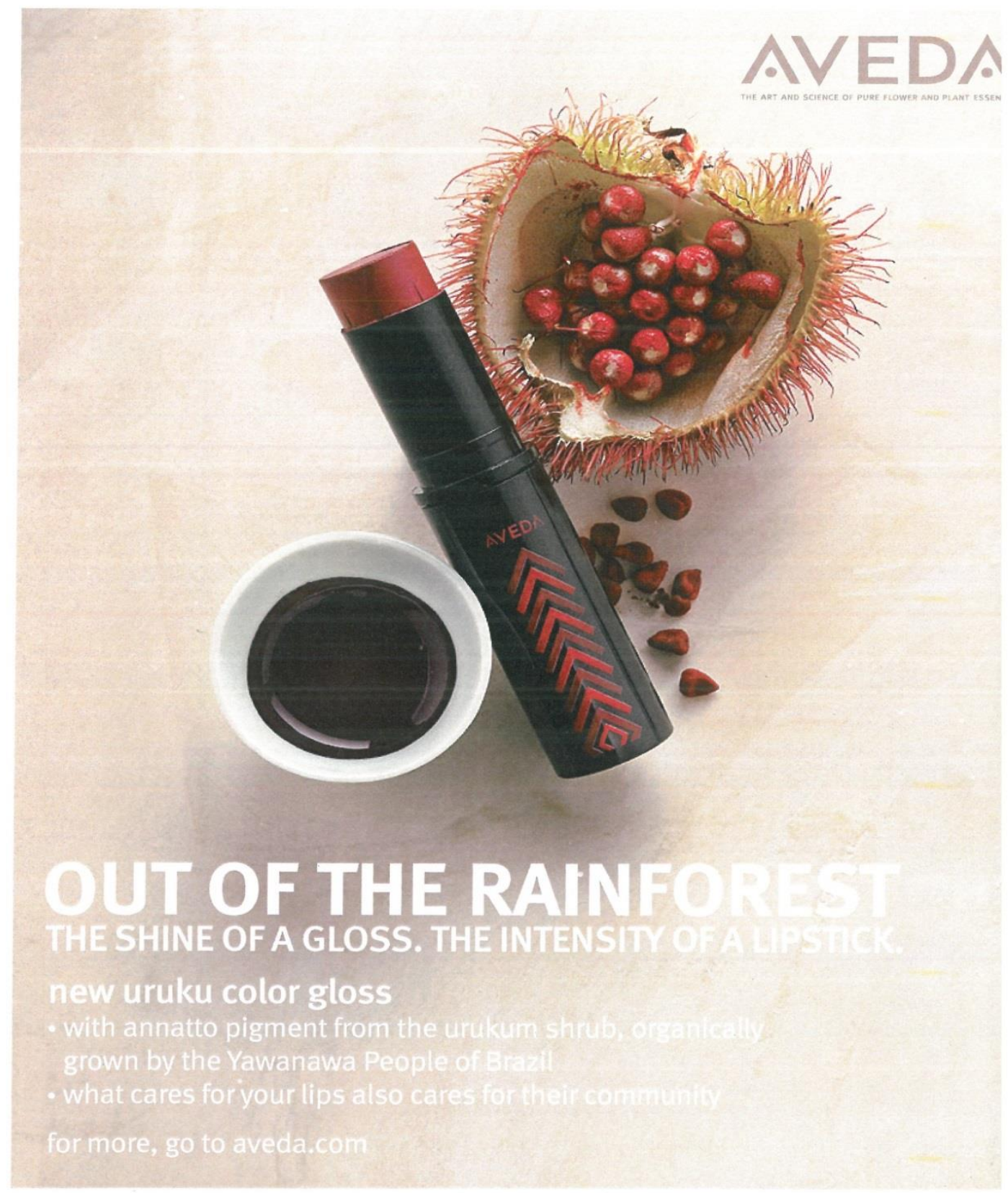




\subsection{The politics of value of urucum}

Biraci's success with the Aveda project granted him respect and loyalty, which led him to the leadership of the community, consecrated by Raimundo Luiz. His position was, thus, linked to the new alliance and the capacity to siphon efforts of the community for the production of urucum. Persuading the population was not very difficult because the project was seductive. The Yawanawa, I realized during my fieldwork, are particularly proud of their agricultural skills, notably applied to small gardens they keep to the production of food crops. The village then occupied by Raimundo Luiz and his family, Jabuti, was transformed in the center of the project and renamed Nova Esperança (New Hope). Moving to a new village was a motive of joy for a number of reasons. The old Caxinaua settlement was prone to epidemic surges of diseases and, after decades of occupation, finding game and fish around it had become extremely challenging. The funds for the development of the project and the payment for image rights brought resources to the village, complemented by donations for improvements such as solar panels to the houses and a health clinic, both of which unfortunately no longer exist. Their cultural attachment to the urucum and the perspective of having it once more at convenient distance was another factor of attraction. There was sufficient production for them to be able to use it in their body paintings once again. Their image of painted natives attracted Aveda and the partnership provided them both the ingredient and the reasons to paint their bodies once more. This element is particularly important to understand how that project contributed to the assertion of their collective identity. Moreover, selling uruсum in the market was not regarded as problematic, since for them the product sold is just a seed and no negotiation of meaning was necessary.

The work with the urucum trees required only seasonal work and, except for the harvest, little work was needed to maintain the bushes. These were planted in an area around the houses and, thus, working was an opportunity for people to gather. Some Yawanawa equated the experience of working in the plantation with a community event, in which entire families would go to the fields. The project attracted the population, which was scattered in old rubber tracks and the towns of the region, also offering a limited amount of essential goods in exchange for their involvement. Work was organized in similar ways to that of the rubber tapping period, but instead of a trade post owned by outsiders, the Yawanawa formed a co-operative to distribute industrialized goods purchased with the project revenues. The distribution was far from impersonal. Affinity bonds and allegiance to the group that managed the project - Biraci and followers - certainly secured better shares. At the same time, as 
members of an extended family, they felt it was hard for those working for the co-operative warehouse to deny someone an essential good, even if that person had not contributed much to the project.

Therefore, at the same time that the project served the purpose of Biraci's individual project of leadership, it did build upon known forms of organizing and rewarding work. It did not reorganize power relations or forms of internal distribution of resources. Once more, just selected members of the community took part in the negotiations with the firm and knew the terms of the agreement. Additionally, the distribution of resources continued to operate in the form of the distribution of goods by trade posts, with the difference that the co-operative did not operate for profits. Nonetheless, the project eventually led to increasing expectations within the community, which were not met by the leaders.

In the mid-2000s, a conflict between two factions led to a temporary suspension and a reorganization of the urucum project. The causes of such conflict are complex and there are multiple accounts within the community. Given the positive assessments of the work entailed by the project by almost all the participants, it first causes surprise to realize that half of the Yawanawa, those living in Nova Esperança, are no longer involved in the production of urucum. The decision, however, was taken by Biraci Yawanawa, after a communal assembly in which Joaquim was elected to run the project. Amongst the causes for such conflict there was a struggle for controlling its material and symbolic resources, involving Biraci and Joaquim, the lack of transparency in the management of resources by the co-operative created by the Yawanawa, the failure of such organization to meet material expectations of those working in the project and difficulties to negotiate increasing demands presented to Aveda, currently attributed within the community to the reliance on an external intermediary, an anthropologist who acted as a translator in the first meeting between Aveda's founder and Biraci Yawanawa. Personal intrigues and accusations of misappropriation of resources by both parties increasingly directed to the external intermediary, populate the local imaginary about the fact. Many members, including those who managed the project, recognize that there was limited control of the use of resources. They also mobilize an external vision about indigenous groups to justify this as a lack of proper training to handle a company. Indeed, the management of the project was not very professional. Much of the income was spent in the cities, both to maintain legal organizations and the members of the community while solving bureaucratic problems or purchasing goods. There was no allowance or salary for the manager 
of the project. Most of these questions remain a problem for those who are still involved in the project.

Yet the conflict and posterior reorganization of the project must also be understood against a latent and ongoing conflict between the descendants of Raimundo Luiz in their quests for inherit his power, and Biraci Yawanawa, whom thanks to its ability to navigate the official state institutions and to establish partnerships that bring resources to the community, was acclaimed leader of the Yawanawa upon his return with the idea to produce urucum. Raimundo's older son, Sales, and older daughter, Mariazinha, confessed they have not always accepted Biraci's rule and continued to claim that the power remained within the family (MLY). Waddington, the intermediary in the project, also informs that the family demanded resources to legitimize Biraci's rule (Ribeiro 2005).

For the Yawanawa, there were also trust issues involving the use of an external intermediary and the difficulties of communicating with an American firm. As part of the negotiations with Aveda, they obtained two stipends for community members to go to the United States and study English. One of them was Joaquim Yawanawa, one of the youngest sons of Raimundo Luiz, educated in Rio Branco and a member of an indigenist organization. Returning from his experience in the United States, where besides learning the language, Joaquim also made contacts with the local and more entrepreneurial indigenous movement in New Mexico, he increased his participation in the project. The conflicts became more acute then, with demands for more control of investments from the new owner of Aveda, Estée Lauder, difficulties to negotiate with a much larger firm, and claims of more resources by members of the community. Amidst this situation, Biraci decided to start a diet, which marks the initiation into the spiritual life and requires relative isolation. Joaquim increased, thus, his control of the project and, during an assembly meeting, was chosen to replace Biraci as its manager.

Since the loss of control, Biraci Yawanawa decided to curtail his involvement in the production of urucum and persuaded many families in the village to follow his decision. Following a spiritual path that could bring him power and resources, he adopted traditionalist arguments to justify his position. He mentions the cold attitudes of the new owner of Aveda towards the community, which before was the beneficiary of multiple philanthropic projects. The conflicts involving the workers in the project are reputed to the divisive effects of big economic projects and money in the community, which would divert them from traditional feelings of brotherhood and communitarianism represented by the queixada and instill an 
individualism that is foreign to an indigenous population. There was an initial moment of strong divide in the community, with some members leaving Nova Esperança to continue with the project. Realizing that peace was fundamental to resume their own projects, both leaders and their organizations came to terms with the division. In order to preserve order, the conflict is increasingly reputed to the workings of the intermediary and there is mutual public display of respect for activities developed by each group, even if privately or within the community both leaders contest the rival's initiatives.

In the light of, against and beyond some observations of Appadurai (1986), this case reveals some interesting aspects of the politics of value underlying the commodification of goods. It confirms the pivotal role of traders, as intermediaries with good knowledge of the market, to promote the circulation of the object. In this case the intermediary is also the leader, whose position depends, as explored in chapter 4, on commanding a good knowledge on how to operate in the market. Biraci, Joaquim and some aides had a long experience in urban areas with multiple institutions in which they learnt the languages of politics, rights and the market. It was during the period when he lived in Rio Branco that Biraci realized the dignities of the market. These intermediaries, as indicated by Appadurai, bridge the village and the external world through the alliances they forge. In doing so, they assert their leadership. Contrary to the prediction of Appadurai (1986), however, this project of diversion of an object - their images, and images of their body paintings - into the commodity state is not an attack against restrictions in the flows of objects maintained by the elite. Albeit relying on entrepreneurial action, in this case it is performed by members of the elite, not against it. This case also confirms the importance of including the realm of production and the negotiations involving expectations of producers into the analysis, since the tensions were mostly located in that sphere. Even if work was appreciated, conflicts surround expectations of income and goods created by the work for the projet.

\subsection{Producing and selling Uruku}

The engagement of the Yawanawa with the activity does not explain the entire project. The negotiations of the value of the product also involved the firm who purchases it and transformes it into makeup. There is not much to say about the singularization of objects - 
makeup - that follows their purchase, since this would require a survey into the consumers. But some observations on the politics of value involving the firm and their main target, professionals, can be shared. The long distance separating the parts and the limited knowledge each side possesses about the other do not hinder exchange. Commensurability is established through some categories that both actors appropriate and mobilize, even if retaining semantic differences. The fundamental element of commensurability here is beauty, for the Yawanawa also regard that painted bodies are a sign of beauty. The beauty of urucum is inserted, in the Yawanawa case, in the belief that these painted bodies are protected against spirits and the diseases they may provoke. Thus, beauty is connected to health and nature, corresponding to the ideal that Aveda attempts to promote from its inception. Nature is an important category behind the encounter of Horst Rechelbacher and Biraci Brasil, in Rio de Janeiro in 1992. The challenges to protect their land, located in the forest, allows the firm to establish a connection between the partnership and the protection of the forest.

This very basic level of commonality leaves great room for a requalification of the objects by the firm. I argued that the product is the magical transformation of the seeds, images and symbols of the Yawanawa together with associations that this combination allows to construct with the place of origin of the ingredient, into a high performance makeup. The Yawanawa are conscious about the value and uses of their image, since the firm sent representatives to their land to produce these images. Moreover, as the communications department of the firm informed (6), the stories about sourcing are written after interviewing members of the communities. Aveda produced a video, in which some of these interviews are displayed. Some informative material on the partnership published by Aveda brings factual information about past and present challenges of the Yawanawa (see images 3 to 5).

Nonetheless, there is a large room for recreation. Neither the Yawanawa control the content of the message produced by Aveda, nor does Aveda seem to possess a thorough knowledge about the Yawanawa. It does not seem accidental that the firm was eager to obtain any possible information obtained during my stay in the community. Yet the fragments they do obtain from the Yawanawa are elements employed to qualify the good, in the sense employed by Callon, Méadel and Rabeharisoa (2002). These fragments of information are assembled together with the extracted pigment and chemical processes to stabilize its color and protect it from biological threats. Particularly important are indications of its location of origin. 
The politics of value inside the firm entails the negotiation around the qualification of product. The firm, I attempted to demonstrate in chapter 6 , develops its activities amidst a permanent tension to define its fundamental value. Known among demanding consumers looking for the highest possible performance and enticing emotional professionals with their stories of partnerships that connect them with nature, the firm must negotiate to define the meanings and values of its products. The new parent company seems more inclined towards the former, but the availability of different channels of communication with the public attenuates this tension.

The construction of the story sharing representations of the Yawanawa takes place in these various channels and is received differently by specific audiences. Aveda representatives emphasized that there are hardly specific strategies for ingredients or lines of product. Their goal is to produce a general message about the brand. In recent times they have increasingly relied on new social media and internet, reducing printed materials (7). They also informed that the main target of their communication is a group of professionals and a number of close customers that comprise a loyal network. Dominique Conseil shared the results of a recent survey showing that around 40 percent of final consumers are aware of the mission of the firm, but 91 percent of their professionals are aware and identify with the mission (DC). Another survey from 2011, conducted with customers from the United States and the United Kingdom, reveals that only 58 percent are aware the pigment comes from the forest and less than a third was aware of the story ${ }^{69}$.

The circulation of these images in the broadest sense takes place through the participation of hair and makeup artists who represent Aveda in large fashion events (fashion weeks), partnering with famous designers to display new hair styles and techniques. In these spaces, the message is fundamentally about high performance. There is no space or time to discuss environmental and social actions and the focus is the beauty and fashion trends. Any message about what beauty does is lost in the essential statement of what beauty should be according to the codes that haute couture attempts to define for the next season. In these circles, the firm is known for the quality of its products. In connection or not to these trendsetting events, their products also figure regularly in magazines, but with limited or not attention to the sources of ingredients.

In the points of sales, salons and Aveda shops, small pieces of information are shared. The salons I visited all had an area, around the entrance, where the products are displayed and

${ }^{69}$ Only selective results of this survey were shared with me and unfortunately I did not manage to obtain methodological information. 
sold. Product placement images, signs and the organization of products are fairly similar. In fact, they act as a good identification that the salons, catering for different social spaces and with multiple designs, are part of the Aveda community. The following image (image 2) should help situating the form and extent of transmission of the message. Here, the focus is on the support Aveda gave to revise the territorial limits of the Gregorio River Indigenous Land. The image brings a young girl, painted with annato.

\section{Image 2: Retail area, Aveda Institute, Minneapolis.}

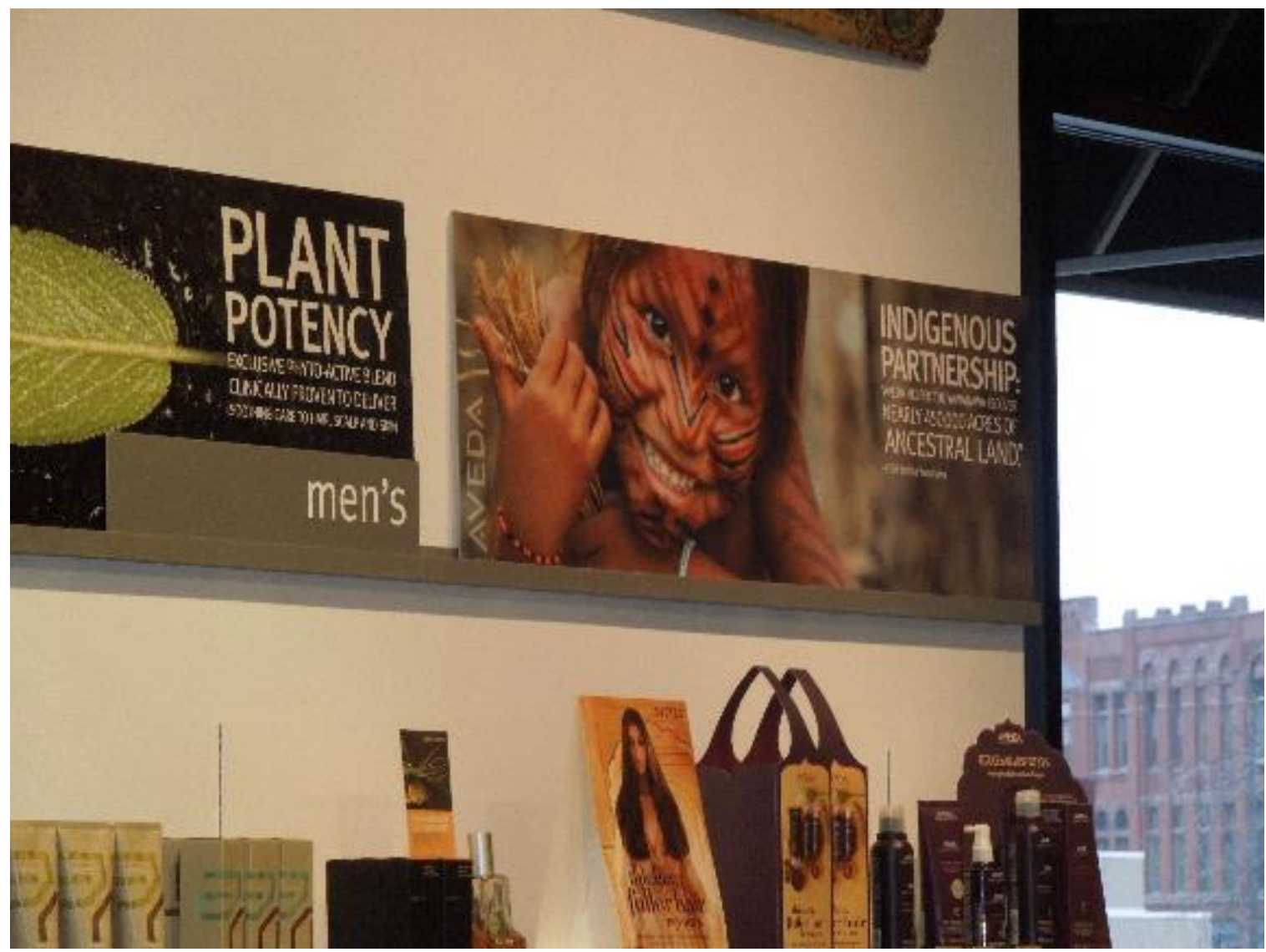

Customers have the opportunity to try the makeup after their salon treatment, when they are offered a "makeup finishing touch". The consumption is ritualized, but the ritual of beauty provided has no intention to mimic the Yawanawa rituals. Indeed, this experience has no pretense to relate to the rituals practiced by the Yawanawa to make themselves beautiful. The focus of these services is not on the stories of the product, but the makeup techniques the professional explain to the client. One of such professionals, at a salon in Minneapolis, confessed that it is difficult to transmit the message to consumers, given the little time and 
attention they have. The makeup artist, in turn, was very emotive about the importance of the partnership and of helping to make the world beautiful.

The main channels in which references to $u r u k u$ and the Yawanawa may be found are in media and events targeting the network of affiliated professionals and a select group of loyal consumers. The firm invites Joaquim to their beauty congresses, to talk to professionals about his community. Joaquim normally wears a headdress, talks about their role in the preservation of the forest and shows the snuffed tobacco, rapé, to much excitement of the audience. These gatherings are emotive moments to reassert the sharing of values, and entice the professionals. An instructor, responsible for teaching new professionals about the products and their properties, described her experience when meeting Joaquim:

"Oh, so positive, because when these people live so close to nature there is an energy that is transmitted just by their presence. Because we think that we in West are removed from it. We don't live in the forest. We live in cement buildings. We try to bring a little bit of nature where we can, but our lifestyle is not such as we are in nature as much as they are. And so, I think there is a disconnection in there that when you meet someone who lives a simple life, connected with nature, there is a presence in your energy that is tangible. And I think it reminds us of where we return to, anyway, which is really nature. For me it reminds me of my unity with nature. And, you know, we come from that. We are part of the nature. And yet we live in these artificial environments. And unless we consciously take the time to reconnect with this nature in whatever way we can, whether is walking in a park, whatever way it is, we know that, unless we do that, there is a part of us that does not feel quite fulfilled, satisfied.

And I think that when we have our indigenous partners to come, it reminds us of this connection, the power of that." (10)

The position of the speaker should be considered: she is a global trainer, training other instructors and professionals. She occupies a pivotal position in the production and diffusion of the story behind the product, creating value. Even if taken as a non-subjective statement, these words at least display the discourse the firm and its intention to provide a contact between professionals and indigenous populations. More than invoking a distant space, the indigenous carry the spirit of nature, acting as a connection between the moderns living in cement buildings and nature, considered the true human essence. Relating to the other is the way to an imagined representation of an environment that is nothing less than our essence. In 
other words, we seek in the other our own lost essence and this connection is possible because of a shared essence, the essence of nature. Other printed materials bring the message "out of the forest", equally connecting to a generic and imagined landscape (image 1).

These stories validate the substantive message of the firm, their philosophy in business jargon, amongst professionals and employees. After listing a number of problems and the additional costs of using annatto from the Amazon, I asked the R\&D team why, then, they would do it. The three members replied "because that is what the company does" (3). My contacts with professionals equally demonstrated that they are motivated and, to a variable extent, find justification to their occupation in these stories. For these professionals, beauty is, in fact, as beauty does: a cleaner environment, a more harmonious lifestyle and autonomy for different cultures.

Elements of the story of the partnership and the circulation of cultural representations of the Yawanawa might also be found in other materials. There are visual displays (image 2), brochures, articles in the firm's magazine and training material on products incorporating urucum. These texts focus on the resilience of the community after many challenges faced by the indigenous populations and the promised economic independence of the community, which was never achieved through the project. As already mentioned, after a derisive article published on the Wall Street Journal (Lyons 2011), this claim was removed of all forms of communication.

Amongst the material shared with me, the most informative is a brochure on the uruku makeup. The brochure (image 3) is the careful work of Rudy Miles, a famous makeup stylist, and previous Aveda's global makeup artist, who visited the Yawanawa to see how they used urucum in their paintings. The content can be divided in three parts, reflecting all the goals in the construction of the products and their potentials. The first deals with the products themselves and their qualities. The second offers two suggestions of looks, lists the employed products and give hints on how to use them. This is the work of Miles and Angela ContiSmith, another makeup professional. The third offers information on the Yawanawa and the partnership, including a code to understand the symbols in their body paintings. The stated benefit of the partnership is, once more, the economic independence and protection of a rainforest ecosystem ${ }^{70}$. Its cover brings an Asian woman, reflecting the new tendencies of the

\footnotetext{
70 There is clearly a gender dimension to the construction of the product and the message. After all, makeup is currently used mostly by women, almost exclusively sold to them. Therefore, the message must dialogue with expected, permitted or encouraged patterns of beauty and attitudes. In one picture, we see a woman using a blush that employs annatto with the message "be cheeky", a pun with cheek. And it continues "go ahead, break the rules, color outside the lines". First, it is an
} 
industry to de-colonize the image of women (Jones 2010). Interestingly, although the body painting is a unisex practice, and production involves members of both genders, almost all images of painted Yawanawa are of women. In fact, in all the material shared with me, there is only a residual, small corner picture of Manuel Tika. Another man, probably José Martim, is seen with a tray full of extracted seeds, but not painted. The original beauty, in its original ritual use, that allows for transportation and translation into the beauty of the makeup world is gendered, female only.

\section{Image 3: Brochure cover: Asian woman covered in bixina powder}

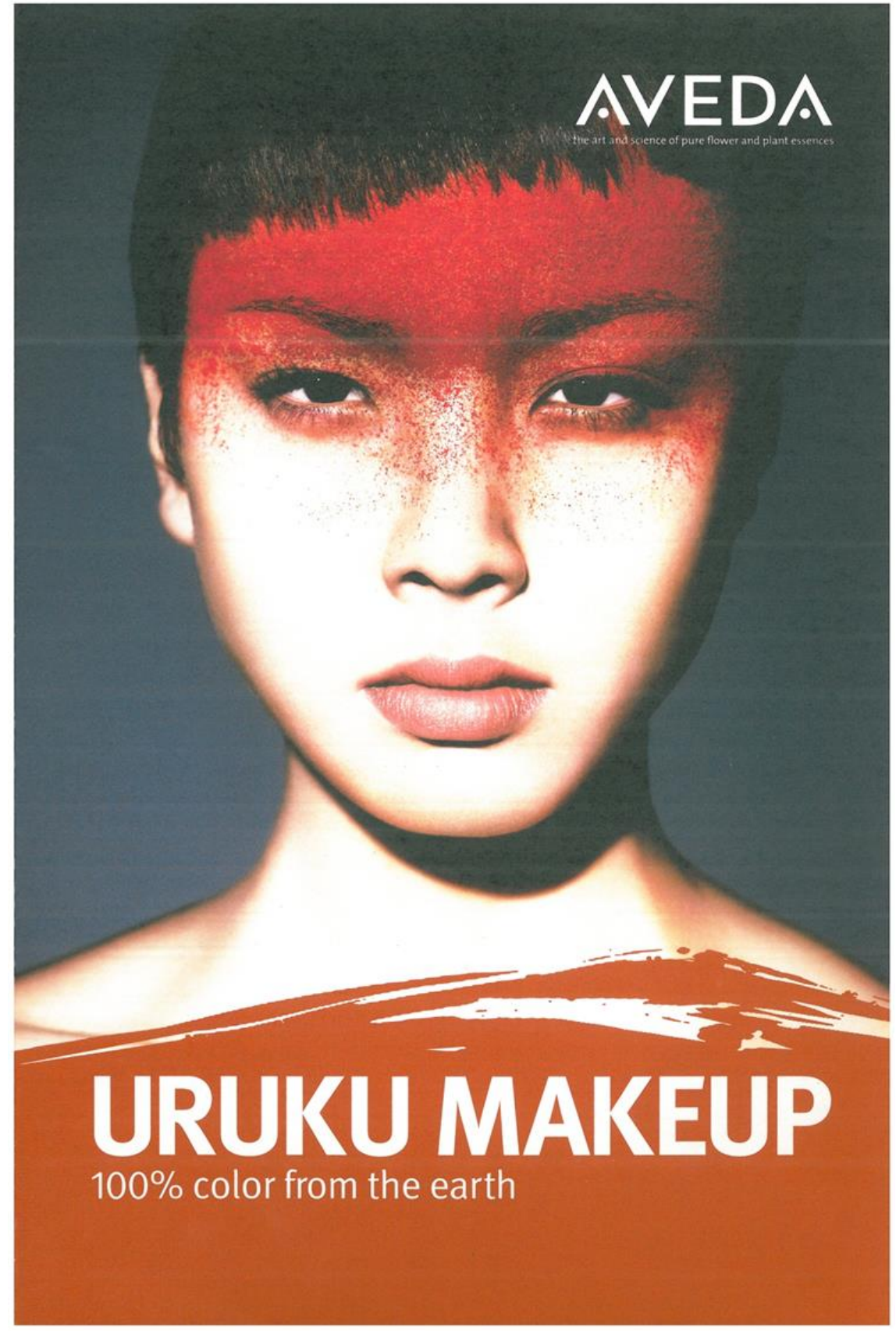

invitation to break with the expected female behavior of subservience and compliance with norms and codes. This assertiveness rests in difference, in the colors and forms of spreading them over one's face. 
Image 4: Brochure (cont.): The Yawanawa painting code

\section{explore yawanawa art}

- Uruku packaging is designed with symbols the Yawanawa paint on each other to reflect their spirit.

- Their vivid pigment-annatto-is in our Uruku makeup and the glaze on the surface of our cartons.

The diamond is inspired by the anaconda snake, believed to be a teacher of wisdom and healing.

The arrow is a symbol of courage and strength.

$\nabla$ The fish represents the sustenance of life.

We partnered with the Yawanawa to choose the best symbols for our packaging, compensating them for their ideas and design work. We hope to bring their indigenous art and culture to a new audience.

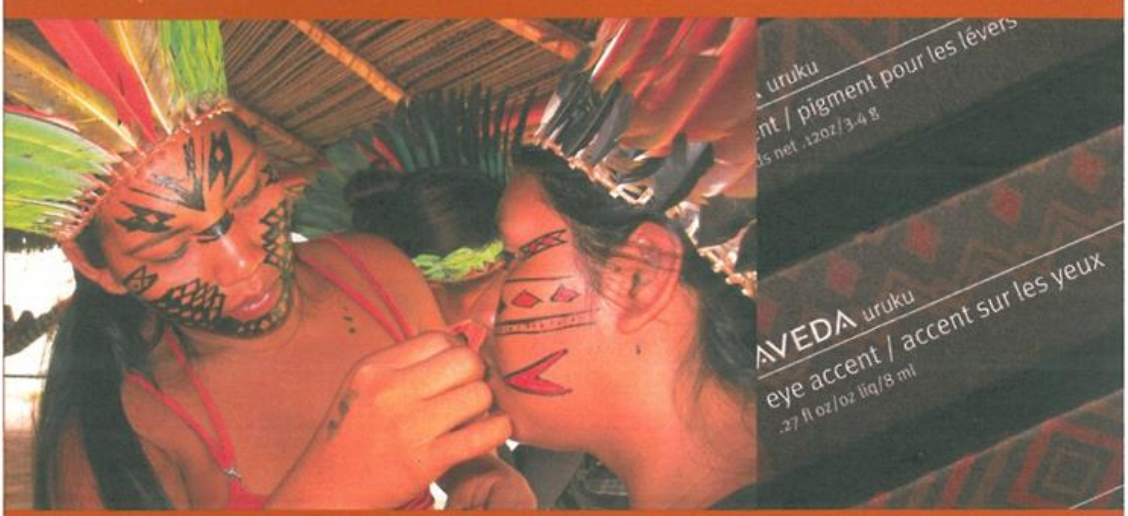

"The symbols reflect our spirit and that of the rainforest, which is sacred to our people. They also remind us of the importance of caring for the earth."

- Tashka Yawanawa, chief of Yawanawa People

OUR MISSION AT AVEDA IS TO CARE FOR THE WORLD WE LIVE IN, FROM THE PRODUCTS WE MAKE TO THE WAYS IN WHICH WE GIVE BACK TO SOCIETY. AT AVEDA, WE STRIVE TO SET AN EXAMPLE FOR ENVIRONMENTAL LEADERSHIP AND RESPONSIBILITY, NOT JUST IN THE WORLD OF BEAUTY, BUT AROUND THE WORLD. 


\section{Image 5: Brochure (cont.): Information on the partnership}

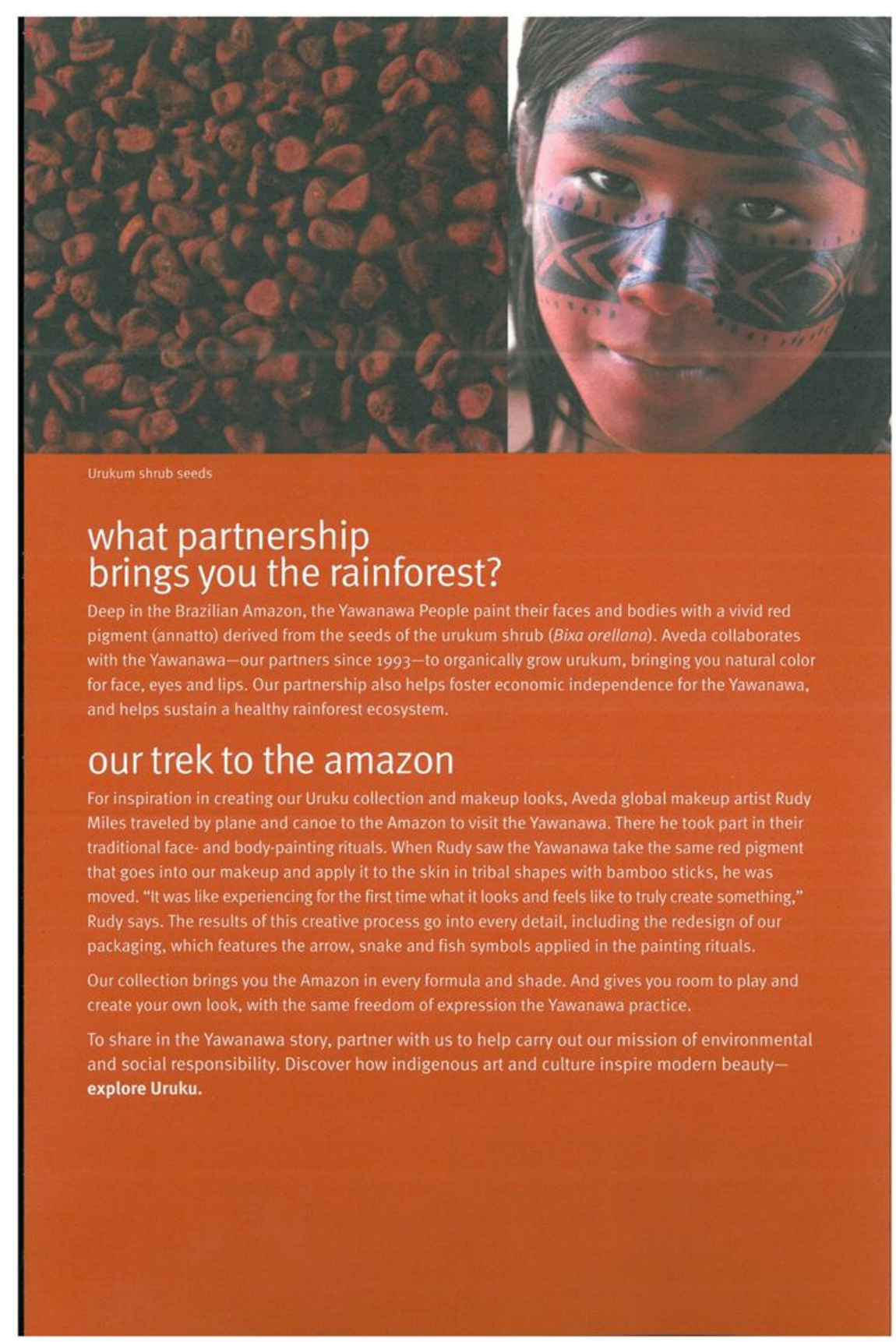

The packages of the products belonging to the $u r u k u$ line also incorporated the stylized version of two kene, patterns of body paintings, representing the jiboia (boa constrictor) and the mythical arrow (see image 1). It is written that they are symbols of the Yawanawa. Both command great mythological meaning for the Yawanawa. In short, the jiboia, the Yawanawa told me, is associated with one of the most powerful spirits. The arrow is the instrument that the Yawanawa used to defeat their enemies in legends and myths. The package states that the 
arrow symbolizes courage and strength and the anaconda snake is a teacher of wisdom and healing.

In sum, the distance between the Yawanawa and Aveda offers the ability to the firm to create the product highlighting values that are important for the consumers of makeup products in the Western world. Value is created through the quality and the performance of the product, on the one side, and through the story, the biography of uruku and its producers. More than a simple spatial transcendence, the product creates a narrative of extremely efficient makeup incorporating ingredients from an enduring and environmentally friendly population from the forest. The qualification of the product is the result of attempts to steer the value towards the former or the latter. There is an attempt to connect professionals and customers aligned to the firm's mission with the producers and remember the importance of preserving their lifestyle. Yet the performance of the product is the priority for the brand. 


\section{Selling the cure, playing Yawanawa}

The second set of economic activities analyzed here involves the traffic of ritual, mainly spiritual, elements of their "culture". Currently, there are two forms of display of Yawanawa rituals. One is the annual cultural festival, held in October in Nova Esperança. The other are presentations in towns by selected members of the community, considered legitimate representatives to perform such rituals and invited by allies from new age centers and urban cults. The Yawanawa Festival was first held in 2002, as an internal celebration of the Yawanawa traditional ritual songs and games (saites and mariris). The current leaders dispute the authorship of the idea, but it was both a product and a catalyst of initial efforts to recover cultural practices following an increased awareness about the worth of their "culture". It was an attempt to mobilize more members to the project of reinvention of traditions and the practice of rituals. The festival has been a moment in which other activities cease and the entire population may devote themselves to their "culture", teaching the newer generations the games and dances. Externally, the event also signaled the resilience of their difference despite decades of adverse conditions and attacks from religious groups against their cultural practices.

\subsection{The Product: Festivals and performances}

The Festival was born from the initiative of the leaders to revive their traditional feasts, the Mariris, celebrated in the past during the Amazonian summer, when game is abundant. The research on their cultural practices initiated by the romantics, school project and the new partnership of Aveda, which reunited the population, brought urucum back to their daily lives and led them to realize that they their difference was valued by foreigners, were all elements fostering it. The production of images and stories for Aveda's merchandising involved displaying this difference. There is no indication the firm demanded them to display traditional rites and appearance, but the interest and value bestowed by the firm upon their difference and its resilience, noticed by them, promoted a notion of self-respect linked to their body paintings, their traditional garments and ritual games. They were interested in displaying 
their traditions, because they felt valued and wanted to show their beauty to the eyes of those consuming beauty. The Yawanawa wanted to present themselves in ways they saw as matching expectations, which for many represent their true selves. Both chiefs highlight their role in staging these traditions, with the help of the elders who still remembered them.

The increasing visibility of these practices and the festival as a whole attracted an everincreasing number of external visitors, transforming it into a touristic event. Nonetheless, the commodification of the feast itself is still very incipient. On the one side, the community still regards the festival as a major exercise and display of rituals for their own population. On the other side, the event is not profitable: intermediaries who deal with travel arrangements until the river Gregorio retain some of the profits, some visitors, known by members of the community, do not pay the fees charged for tourists, and the community incurs in high costs to bring and accommodate hundreds of visitors in the village for a week. Yet the Yawanawa Festival is a venue for forging and strengthening alliances and an element of bargaining with the State government, due to the attraction of tourists and the visibility Acre gains with such events. As a matter of fact, the Government of Acre covers significant part of the costs of the Festival.

During the festival, Biraci and his group make new acquaintances, some of which offer new projects and opportunities for the population. As a display of the set of practices regarded as tradition, it is obviously a venue for the expression of identity and to formulate claims, even if more on private meetings held with authorities than during public speeches and acts, in which, as is normally the case with rituals, all interests besides the enactment of cultural customs is denied (Tambiah 1985). This is not to say rituals are not themselves important instances to celebrate alliances. They are moments in which "others" are incorporated to the community and trust is constructed, symbolically sealing alliances at the center of communitarian life and, consequently, acting as a form of justification of economic activities involving their culture.

One of these opportunities consists in invitations to the initiated in the spiritual practices to perform their rituals in urban centers. The Yawanawa are now very conscious that a fundamental aspect of their culture that attracts outsiders is the use of uni (widely known as ayahuasca), a hallucinogenic brew, in their ceremonies and the associated healing practices. Establishing alliances with urban cults that similarly employ brewed beverages made of the same vine (Banisteriopsis Caapi) and associated leaves, they are able to attract an ever- 
increasing number of visitors and resources. Attracting visitors, on the other side, they are able to attract more permanent allies.

Natives of the Amazonian South America have traditionally consumed Ayahuasca, but new cults around the brew were developed in the twentieth century, as a result of the encounter of destitute Catholic men from the Northeast of Brazil, transplanted to serve as rubber tappers in the region, and the local indigenous groups. In particular, a tapper named Raimundo Irineu Serra expressed, after trying the brew, that he was able to see Catholic imagery and received hymns, which he mixed with popular musical forms from the Northeast to form a new ritual, named Santo Daime. Much later, this and other cults attracted urban practicioners, who in turn multiplied and transformed them (Labate 2004). In the past years, members of these cults have been seeking their origins and the traditional ways of consuming the brew and the associated healing practices. New age groups, practicing alternative systems of healing are equally interested in the Brazilian native systems of spiritual cure.

To many of the Yawanawa, as to other indigenous group from Acre, those groups are perceived not as rivals, but as possible allies, not least in the respect and diffusion of the Yawanawa rituals. In an interesting and local solution to the protection of their intellectual property, instead of claiming the originality over the brew, they prefer to offer "the authentic" ritual underlying its consumption, a unique Yawanawa experience, which no one else could offer. And there is a significant market for authentic indigenous spiritual experiences, animated by these allies in urban centers of Brazil and abroad, which act as intermediaries to new visitors and audiences. The Yawanawa compete with other regional populations also offering similar services, notably the Huni Kuin (Kaxinawa). Local natives are establishing an inter-cultural dialogue centered on the brew, the inhaled tobacco (rapé) and, increasingly, the kapum, the frog secretion employed amongst the natives to improve their abilities as hunters. Above all, uni is the ticket in and out the community and all the associated resources that the inter-cultural contact provides. Kuni, an initiated member who travelled to the south of Brazil a couple of times to show their rituals, explains, in a somehow figuratively form, that the Yawanawa "travel through the beverage": "there are some people who do not drink. Those have no ways of going to other cities" (Kuni). Of course, these opportunities are restricted to those who are bestowed with the authority to speak for the Yawanawa's culture and have some degree of spiritual knowledge. 


\subsection{Politics of value: gifts from commodities}

Once more, the division of the community plays a role in the way these activities are distributed. Given the particular politics of value and the pragmatics of the culture in this area, those activities are concentrated by Biraci's group, which is more open towards this exchange. Joaquim, his siblings, among which two are initiated (Katia and Paulo), and his uncles are critical of the alliances with urban cults, although open to receiving selected visitors and performing private rituals of cure. After years planning, ASCY built in 2013 a small Center of Yawanawa Therapies and Cures in Mutum. A stronger Christian faith amongst the family nucleus of Raimundo Luis is at least partially responsible for this reserved attitude towards alliances with other cults regarded as "Satanic".

Albeit apparently contradictory, traditionalist arguments are employed by Biraci to justify and legitimize his project of increasing commodification of spiritual rituals. Due to the internal contestation of these projects, Biraci had developed a very sophisticated argumentation in an attempt to justify obtaining monetary profits out of rituals. For him, the festival and the presentations that his group offers are not originally intended to obtain financial profits, but to celebrate alliances. Displaying culture is a means of making friends, but as we know very well, friends make gifts. The material benefits that derive from these activities are justified as by-products of these social bonds. The exchange in this case is coded as a sort of gift. Due to the opacity of the negotiations, he may persuade members of the community that the resources produced staging rituals are obligations proper to friendship alliances, rooted in personal bonds that members of the community establish with outsiders. Indeed, urban performances are organized by close allies with whom the Yawanawa establish constant contact. An example of these alliances is with the group of Perfeito Fortuna, the artist Biraci first met in Rio de Janeiro (see chapter 7), members of a unit of the Santo Daime in Rio. One of the benefits of this model is that the material benefits are continuous and these partners are reliable in case of need, not limiting their contributions to a counterpart for the rituals.

For him, there is no "selling" of the sacred when a Yawanawa shaman performs a ritual for paying viewers. On the contrary, because we are in the domain of the sacred, the untouchable, he argues, there is no loss or alienation of the product in sharing it with others. It is simply a performance of a ritual that the Yawanawa retain, whilst sharing spiritual effects that helps and makes happier the external participants. Ironically, to argue that there is no 
alienation in the commercial display of rituals, he compares it with the sale of plants. With the plant, he says, "you first take the plant and do whatever you want, but with spirituality is different $[\ldots]$. No one takes it (BBY).

There are a number of characteristics of the circulation of such rituals that defy a straightforward categorization as a commodity exchange. Biraci already indicated the absence of alienation. In addition, many visitors do not pay and the festivals have never been profitable, depending on a considerable amount of resources donated by the Government of Acre and FUNAI. And yet, many Yawanawa, notably those who are critical on public performances of rituals for money, associate these events to what could be called a commodification of their culture, asserting that these events are not true cultural expressions if they are made just for money. They do not use the analytical category of commodity, but they assert that obtaining resources is the main reason, which they consider a betrayal of the sacred spirit of their cultural practices. Antonio Luis, for example, asserts:

"Our festival is not a healthy festival. Do you know why it is not a healthy festival? Because it is done intending to obtain money. It is not a festival done to strengthen our culture, our language. No! It is not like that. [...] today is everything intended for money. This makes me really sad." (ALC).

Therefore, it seems that these activities are natively, at least by some members of the community, understood as economic activities. Through these activities, they seek to maximize net receipts, a fundamental characteristic of the commodity exchange (Gregory 1982). These events involve a pecuniary contribution, paid to the organizing institution or to the community, in the case of the Festival, even if some visitors or members of the audience do no pay. And the bulk of resources that these events generate do not originate directly from the events themselves, but from the permanent relation with allies, which generates reiterated opportunities to present in different places. How then, to interpret these activities and the attitudes of Biraci?

The concept of denegation (verneinung), developed by Bourdieu over his career in relation to strategies of accumulation of symbolic capital, but particularly applied to understand the world of arts (Bourdieu 1993), seems to provide a fitting explanation for this case. Bourdieu employed the term to denote those practices in which the pursuit of reputation, or symbolic capital "can be achieved in practice - and not merely in representations - only at 
the price of a constant and collective repression of the properly 'economic' interest and of the truth of the practice that 'economic' analysis uncovers" (ibid.: 148). The time interval between these practices and the actual gains, that normally comes with future invitations or donations is the mechanism, as Bourdieu (1993: 148) asserts, that "obscures the profit promised to the most disinterested investments". The facts that many visitors are accepted to the land without paying any contribution and that not all performances are paid could indicate this logic. Obviously, not all visitors or members of the audience during performances become allies, but those who do secure contributions in a future point of time. The logic is reinforced by the fact that the contributions are not sufficient to pay the costs of the festival. Yet state and non-state allies contribute to the costs and in the forms of gifts, which correspond to the real profit. Another contributing factor is the distance separating the actors who collect contributions and the performers. Visitors and audiences pay to intermediaries located hundreds or thousands of kilometers away of the performers, either owners of the facilities where ceremonies are held or tourism agencies. The festivals and performances and not occasions to discuss prices and payment, creating a situation similar to the back room/front room division discussed by Velthuis (2005) for the case of the art market. This helps to segregate the circulation of monies and the production of cultural performances.

Nonetheless, more than a denegation, this peculiar form of obtaining symbolic and material profits through rituals seems a deep-rooted practice, and as such it has meanings in their native scheme of understanding, as I explore in the next section. This is not to say that the native repertoire of action provides a consensual view on such activities. As Leach (1954: 278) contends, "myth and ritual" are "a language of argument, not a chorus of harmony" and the Yawanawa rituals are no exception, especially when practiced with the presence of outsiders and with material gains. Despite finding a meaning in their native repertoire of action, the interpretations of ritual action are a matter of dispute, as Antonio Carioca indicates.

In general, the Yawanawa are eager to publicly display their culture and incorporate new technologies in the process. The points of contention correspond to the best forms of perform rituals and publicly display them. There is a true quest for authenticity, according to their own views of what is authentic, on the ways these performances are conducted. These rituals, for most of them, represent the true Yawanawa essence, the essentialization of their identities. Thus, any forgery is an offense against the good name of the Yawanawa collectivity. The main criticism is neither against the public character of the performances, nor against profits. Most of the criticisms I heard were against members of the community that 
present these rituals in towns without having a thorough knowledge of the healing system. In other words, these concerns involve the efficacy and quality of these performances, which are linked to the good name and reputation of the Yawanawa. In many cases, Biraci invites youngsters who, in fact, were not initiated, to join him or another healer in their trips.

There are other lines of contention as well, related to specific groups within the community. Some elders, accustomed to much more discrete rituals in different contexts contest the widespread use of uni, stating that the brew was only used in the past to perform cures, always in small groups involving the healer and the patient, secluded from the rest of the community. Others criticize the mediation of money, saying that their rituals were never intended for profit. This group is relevant to show how the community recognizes that, despite the intricate mode of articulation and justification of these performances, they recognize an economic goal. There are also Christians who reject these practices on the grounds that they are Satanic and cause of disgrace to the community, and a group that remains indifferent to cultural initiatives and critical of the excessive focus of the leadership in using culture as a means of generating resources. Due to their positions, these two latter groups are marginalized, notably by the romantics. As a consequence of such marginalization is that these groups are also denied access to resources that derive from these activities. Even amongst those who are willing to charge visitors and use performances as an income opportunity, there are different views on the best model to follow. Joaquim, for example, who organized a smaller event in Mutum, envisages these activities as ethnotourism, with direct gains obtained from the visitors.

This schematic representation clearly simplifies much more nuanced positions, but is sufficient to demonstrate how this process of engagement of the Yawanawa with outsiders is surrounded by different visions and expectations. These tensions also reveal that "culture" is not for everyone. The path to authenticity is not a consensual preference and finds opposition in those who espouse a lifestyle developed over decades of permanent contact with transplanted rubber tappers and resist to comply with traditions associated with the image of Indigeneity. All the Yawanawa seem to share a vision about what is "culture". "Isso é da cultura", or "this is from culture" is often heard in the villages. The contention is not about the practices to be included in this set of distinctive and defining features of an essentialized collective identity, but about the relative relevance of such practices as guidelines for their lives. There are different visions on the main values that should be pursued by the community and how to pursue them, especially involving the importance of "culture". Some miss the 
habits and activities of the past, currently rejected by the romantics seeking a more traditional vision corresponding to expectations of Indigeneity, in which together with non-indigenous rubber tappers, they drunk cane-distilled spirits (cachaça), danced a typically Northeastern dance, forró, and listened to the accordion ${ }^{71}$. They assert that these customs did not represent any hindrance to their own cultural expressions, including inviting outsiders to their mariris and even drinking uni together. Their healers were famous and provided services for the nonnative population in the area. A focus on cultural practices is also criticized by those who prefer productive activities bringing immediate income out of direct exchange. Disinterest in cultural practices or a lack of involvement also translate in a failure to obtain and recognize gains that emanate from these practices. Better than any description is the confession of Francisco Moacir:

"Our culture at this moment already reached a point where we are ourselves. But now I believe that what should improve is [to make available] something we want. There is nothing there [warehouse] for us to take. There is no salt... I do not even have salt here. There is not what we want: soap there is not, lighter there is not... thus I believe that this should improve. There should be more for us to work and buy. Since there is no money, we must work to buy what we need.

The worst, André, the worst is that in that period it was better. But today, we do not see anything. [...] what must improve is what they said that it was good: sugar, salt, these things. But another side too: we need some money." (FMY).

To a great extent, the failure to recognize gains that derive from cultural practices is caused by the essentially unequal nature of these gains. A note on the political economy of knowledge deserves a place on its own on the politics of value of cultural performances. Practicing cultural rituals is restricted to practitioners. These are, in turn, limited in number by the controlled access to knowledge. In the past, according to the narratives of the xinayas and older members with some knowledge on the system, alliances with the family of a healer were celebrated by those interested in obtaining lessons from him. A woman was offered to the family of a xinaya, in exchange for lessons for a member of the bride's family.

Currently, the economy of knowledge seems subordinated to the control not only of the two full-ledged xinayas, but also to the two legal organizations and their leaders. When I

\footnotetext{
71 Beyond collective positions, the dilemmas faced by individuals amidst the movement of cultural reinvention are not much different than the clashes between demands of collectivities to which they belong and the willingness to keep spaces of individual expression. The dilemmas of individuation, often studied by much of classical social theory are but intensified in the case of indigenous populations, for which collective recognition is pivotal to access rights and benefits.
} 
arrived on the Gregorio River, there were less than ten persons with some knowledge on the healing system, many of which only on medicinal plants. In 2012, each association had a true class of approximately ten persons on sacred ground (samakei) undertaking the initiation, which entails a long period of ordeal that aims at strengthening their bodies for the communication with spirits (Gil 2001). Despite the bitter taste of the knowledge, a representation of the taste of the tuber of the Muka Veine vine, which corresponds to the bulk of their diet during the initiation steps, there is an increasing number of people, especially youngsters, interested in the career. They normally voice that they want to contribute to the survival of their practices, perpetuating the knowledge of older healers. Yet the resources brought by performances and the opportunities to travel and meet "new friends", who are then expected to create new opportunities and make gifts, are probably a good reason that justifies the challenges of initiation. Biraci recognizes the appeal of this career and, to explain the challenges of the choice, he utters a true theory of value: "what is difficult is more valuable". It is currently the best project to the younger members to obtain recognition of their community. However, the access to the knowledge, given its sacred nature, must be restricted and leaders now employ this restriction as a new device to create political loyalty. Culture, once more, is not for everyone.

I argued before that money has become, albeit limitedly, a principle of social differentiation in the community. Nonetheless, since "culture" has become one of the main sources of income, symbolic and material, the differentiation is subordinated to the inequalities of the world of culture. In other words, the insertion of these performances into the market amplifies already existing inequalities that are determined by the exclusivity of the access of culture, not by the mechanisms of the market. This applies not only to those who, marginalized by their disinterest in culture, are excluded from the income cultural practices offer, but also to those who, willing to access the shamanic career, are nonetheless excluded.

\subsection{A machine of alliances: networks from markets}

This is no place to discuss the plethora of theories of ritual action or enter into the forest of symbols in the Yawanawa practice, which would require me to understand the place of each symbolic referent to words and acts in the complex system of the Yawanawa, an object far removed from my original research intent. Some fragments about the social properties of 
these acts are, nonetheless, very significant to indicate how these procedures now adopted by the Yawanawa to produce alliances find a place in the meanings they normally bestow to them. For the sake of the following discussion, I use as a working definition the notion of ritual advanced by Tambiah (1985: 128): "ritual is a culturally constructed system of symbolic communication. It is constituted of patterned and ordered sequences of words and acts, often expressed in multiple media, whose content and arrangement are characterized in varying degree by formality (conventionality), stereotypy (rigidity), condensation (fusion), and redundancy (repetition)."

The rituals that take place in performances and rituals can be approached from the logic of individual experience and collective intentionality they want to produce. Albeit focusing on the latter, I offer limited observations on the former, for understanding the experiences of consumers is important to understand the value of these rituals. One of the apparent contradictions to the external observer is that despite the mimetic aspect, the expressive flow through the chants and words of the healer, as well as the bodily and mental togetherness that they presuppose, there is no reason to believe that the experiential aspects of this encounter are all shared. People come together in the trance, but they do not experience this trance together. The rituals prompt different emotions on the Yawanawa and on the visitors, but probably also within these groups. Despite a shared intentionality in the language and acts prescribed by the ritual, even partaking in joint acts, there are individual interpretations. In these rituals, they are together to produce something collective, but without being one. These cultural performances, as other products, also seem to defy their symbolic, experiential and material stability. This might help understanding how presenting themselves to others in an objectified way serves the purpose of "recharging collective self-awareness" (Comaroff/Comaroff 2009: 26), while outsiders might experience this in their own ways.

\subsubsection{Playing at being Indian, being Yawanawa}

My contact with visitors during the tenth edition of the Yawanawa Festival was limited by the hectic nature of their activities. My short interactions with them, potentialized by the curious request of Biraci, upon my arrival, to try to make a survey of the visitors, indicated that spiritual rituals, notably those involving uni, were the main reason to attend. In fact, most of the visitors are part of groups that come from Ayahuasca-based cults or esoteric New Age centers from the Southeast and South of Brazil, as well as some foreigners. The majority of 
visitors was comprised of groups of three Santo Daime churches, two from Rio and one from Brasilia, and two New Age groups, from two cities in the South of Brazil, Curitiba and Porto Alegre. When asked about the motives of the visit, their answers had little variation: to obtain the cure, to drink the medicine, to obtain a blessing, to get the energy, to enter the spiritual side or to practice their spirituality. There are those who go seeking to know the "culture" as well, but culture is often conflated to spiritual ceremonies.

Some of these visitors are admittedly looking for the potency of the substances consumed during the rituals. I heard some visitors comparing their experience with the Yawanawa with others available in this market for indigenous spirituality, complaining that uni is not strong enough. Kuni and Nani (Fernando Luis) told me, with irony, that the Whites were too strong and drunk too much uni. In the cultural economy of this activity, it seems that visitors are appropriating these rituals mediated by the Western values of the strength and power of substances, something that has little meaning for the Yawanawa. More commonly, however, they seek an ethnomimesis (Lau 2000) provided by the experience. Visitors see a value in which one of them called "playing at being Indian". The crafts - palm skirts, necklaces and bracelets - and the paintings of their bodies with the kene, the depictions of spirits of the forest by the Yawanawa, operate a body transformation. Buying these goods and services during the festival, these visitors aim at assuming a temporary persona, diluted in the community. They become the other for five days.

They want to play at being Indians, but they do not want to be Indians. Many of them complain of the sanitary conditions in the village or other habits that they repute not just condemnable, but a peril for the local culture. In this particular sense, visitors see the other through a postcolonial gaze, claiming that the natives should have distinctive signs of nativity and reject any object and symbol that pollutes their image (the gaze ${ }^{72}$ ) of the indigenous. A group that arrived earlier and self-organized a committee to support the Yawanawa in the preparatory tasks was appalled with some practices, either considered primitive or detrimental to their "culture". Three of such practices that generated debate and action by the selforganized committee were the use of industrialized food of dubious nutritious qualities, the burning of all non-organic rubbish and the inadequacy of their cesspools. As a reaction, they decided to offer free advice on food to the population, to build a compost facility and to refurbish the existing cesspools and build additional ones (see box 6). This indicates that, albeit playing at Indians, they do not want to embrace their modes of life. They retain

\footnotetext{
${ }^{72}$ I employ the term gaze here in a sense similar to Lacan (1973).
} 
projected expectations (a gaze) and want to play this role just for a couple of days. The power of the mimesis lies in the capacity of the transformed body of the visitor, in contact with the gazed object, to connect to the imagined vision of indigenous communities in the forest. When stressing that they are playing at, the visitors indicate that the value is mediated by their representations of the other (the gaze) and that their own status should not be confused with the status they assume momentarily.

\section{Box 6: Negotiating statuses and seeking objectivity amidst personal relations}

Especially during the festival, a moment of openness and relative suspension of boundaries, maintaining the different status of researcher, and not a regular visitor, was particularly difficult, which created some problems. The reprimands by visitors of some Yawanawa women for the food they offer their children caused problems for the researcher. I had seen that the Yawanawa use instant noodles, a non-perishable and thus valuable food in the hot, humid and distant village, as the safest food for their children, especially when ill. This is clearly related to some interdicts involving most game, which besides cultural causes, find support in science: the meat of most of these animals is known to worsen inflammatory processes. As an alternative, thus, they believe instant noodles to be a better food for sick children, especially with diarrhea. During my whole period of research, I never said anything, limiting to suggest more traditional recipes to deal with such illnesses, like homemade serum. I believed that my role was not to interfere with their habits. A visitor that was staying at Biraci's house, helping in the kitchen during the festival harshly criticized other women for the solution during a moment in which I was present. Luzia (Waxy), with whom I established a close research relationship, laughed, pointed at me and said "André has been seeing this and never said anything. Bad, bad, André! Why did not you say something? You know it is wrong, do not you?" My Yawanawa friends interrogated if my attitude was a sign of indifference.

If for outsiders taking part in Yawanawa rituals is an experience of mimesis of alterity, for the Yawanawa performing is engaging in a prosopopoeia. During their regular lives, the Yawanawa wear simple clothes and have habits that do not differ fundamentally from the regional Amazonian lifestyle. It is only during rituals and the festival that they use the symbols of their Indigeneity: body paintings, headdresses, necklaces, artifacts to inhale snuff (tipis) and other objects. Yet, at the beginning of the festival, many of them came to me to say that I would finally know the real Yawanawa. They do not assume a "commodified persona" to protect aspects of their culture from the outsiders, as identified by Bunten (2008) in an 
project of ethno-tourism developed by Alaskan natives. On the contrary, they want outsiders to see the full and authentic expression of what they perceive as their "culture".

To question the authenticity in these expressions is to presuppose an essentialized alterity. There is no point in asking if these real Yawanawa are, indeed, those who present themselves in masks during the Festival. It is sufficient to assert that they believe that they dress Yawanawa, they feel Yawanawa, and they are Yawanawa through their rituals and the body preparation for them. This identity is clearly a difference mirrored in the gaze of outsiders in a process that is essentially social, as Strauss (1997) discussed. "Culture" is the product of inter-cultural contact, mobilizing selective symbols and codes of meaning of the scheme of perception (culture). Yet it is this selective set of practices, in an exaggerated form, that the Yawanawa regard their true essence. If the ritual is a representation of an ideal version of the social structure, as claimed by Leach (1954: 286), the vision of the individual is also an ideal version of the structure and her place. For visitors, without knowing the full symbolic system, rituals convey little more than indigeneity or tradition. But for natives, inserted into the symbolic system, it is possible to know and manipulate, in different levels, the positional meaning of each act, or much more simply, to build their identity, as better explored in the next section.

\subsubsection{Machines of community, machines of alliances}

More importantly are the collective intentions of these rituals. To investigate them is necessary to understand the performative acts of speech intended by the rituals. My observations endorse the contention of Naveira (1999), according to which mariris, ritual dances and games practiced by the Yawanawa during the festival are machines to produce allies. All rituals, games, dances and spiritual ceremonies alike, suppose the co-participation of producers and consumers. Neither those at Nova Esperança, nor those at urban locations are intended for passive audiences. Participation is encouraged and, in fact, the very motivation of visitors to attend. In so doing, they blur these categories, since participation turns everyone in a producer and a consumer at the same time. Some games have mainly internal purposes, as indicated by the smaller participation of visitors. This is the case of games that aim at producing matrimonial alliances, opposing men and women in a classical court/provocation dynamic. There are many games with the same trope, including the cane game, where women are able to use all physical methods to dislodge a cane stalk carried by a 
man. Other games and dances that seem, at first, intended to reassert the unity of the community, like the Yawa Yawa, in which, just as peccaries, they walk together hand by hand. Yet outsiders are invited to join and, in so doing, they are socialized in the group.

External participation is more intense and intentionality becomes more sophisticated in spiritual rituals. Talking with the elders and some initiated healers, I gathered a general opinion, sometimes with critical tones, indicating that the acts and words that constitute the rituals with $u n i$ were exclusively intended to cure a patient. In her study of the ethnomedical Yawanawa system, Gil (1999) well describes the mechanism, not distant from the parallel between healer and psychoanalyst described in the work of Lévi-Strauss (1984): the brew, or the spirit $\left(y u_{x i n}{ }^{73}\right)$ wherein, is an operational device that allow the acts of speech of a healer to guide the spirits to the ailing person and promote the cure. This is complemented by blows of air on the body of the patient. The language of the hypnotic chants intends to guide the spirits to produce visions in the patient that, once narrated to the healer, provides the diagnosis. Cure, in this system, also refers to the visions and guidance provided by the activated spirits of the brew, beyond a specific medical condition.

Currently, there seems to be a semantic displacement of spiritual healing ceremonies, using uni, towards a different collective intentionality: to produce an alliance based on a collective vision that brings together the Yawanawa and outsiders. In order to substantiate this claim it is necessary to provide a more detailed account of the social dynamic involving such rituals. For someone who saw the community during the festival and before, during their normal activities, it becomes clear that it is a special occasion, set aside from their regular lives, in which they interrupt all other activities. Actually, when asked, some Yawanawa defined the ritual as a period in which, after a great hunting campaign and much fishing, they can afford not working for some days. The interruption of the everyday flow of activities, the arrival of hundreds of visitors, the profound exchange of practices based on rituals, the permission of these visitors to dress and act like locals are all indicative of a situation that breaks with the regular dynamic of the society.

To some extent, the situation can be interpreted as a particular three-stage ritual, albeit with differences from the model devised by Turner (2008). The Yawanawa festivals with shared spiritual and cultural practices in which insider and outsider are treated as one do not display an anti-structure moment. The world is not turned upside-down, the categories of organization of the Yawanawa world are not subverted. The operation that sets the ritual in

\footnotetext{
${ }^{73}$ The Yuxin are the spiritual beings that comprise, together with the body, the person (Gil 2001: 335).
} 
motion is an openness, in which the other is invited to join their practices. This is a particular, and to some extent opposite form of liminality in relation to the work of Turner (2008). The community members do not exit the community for later reintegration, but conversely people who normally stand outside are brought into the community. The ritual socializes the other, using ritual codes to produce a shared intentionality. During this particular liminality, some rules are suspended and there is the possibility of predating aspects of their ontology through the introduction of new objects. The subversion in this case is the incorporation of these new elements. In this inter-cultural exchange, an intense cultural economy takes place: as the outsiders mimic the Yawanawa, these reassert their identity whilst incorporating practices of the culture of the outsiders. The Yawanawa can also be seen with all sort of New Age paraphernalia, with symbols like Budha, with new instruments for their songs (the guitar), new songs and new media for their paintings (oil on canvas). A curious example is the use adopted by outsiders of the curative blows, using the onomatopoeia haush as a greeting, a practice in turn adopted by some Yawanawa, but only during the festival. The last stage, following the socialization of the other, is the reintegration of the community, with the other as an ally. Rituals are, therefore, on a general level, machines to produce alliances and incorporate new persons and things. If there is a market for these rituals, this creates the opportunity to use these events as occasions to create new allies, which can be mobilized at any time without the need to offer goods.

\subsection{The seeds of "culture": assessing the projects}

In the previous sections, I dealt with the tensions and justifications surrounding the diversion of "cultural" elements. I also indicated the linkage between the ability to negotiate meanings and bring resources to the community, on the one side, and projects of individual reputation and recognition, on the other. I also discussed the potential effects of rituals. Now I turn to the perceived results of these economic activities upon collective projects of identity. The uses of the market by the Yawanawa are not just different in terms of the means, but also in terms of their results, playing with classifications of categories of action and their intentions in ways that deserve explanation. There is no form of or purpose in distinguishing the effect achieved by both projects, since they were connected. 
The annatto project was the object of some publications, mainly devoted to assessing its impacts on the community. Carlo and Drummond (2000) conducted an early appraisal of the initiative from the perspective of sustainable community development, concluding that the project would be hardly sustainable due to economic uncertainties, despite "allowing a cultural revival and reconnecting the Yawanawa with their traditional knowledge" (ibid.: 81). Lyons (2011) published a critical article on the Wall Street Journal, asserting that the project failed to secure the financial sustainability to the community that Aveda promised until then. This article was a bitter message to the firm, its parent company and some members of ASCY, leading the former to change publications and its claims about the project. Apparently, the article led Estée Lauder to call into question the partnership. Another assessment is offered by the intermediary that worked for Aveda in the project, May Waddington (Ribeiro 2005). She questions an economic-oriented vision, asserting that the project may be considered a success in terms of the project of life chosen by the Yawanawa.

Multiple reasons prevent this project of securing the financial autonomy of the entire population. The management of the project, the distribution of resources, the logistical challenges, the low value of annatto and the difficulties of the community to meet production goals are the main of such reasons. In fact, the project failed to fulfill the expectations of some members of the community that hoped to obtain sufficient income and goods. However, the project had different and unexpected results for a market project.

It is often the case that, when asked about the most important outcome of economic projects, and perhaps due to the confusions involving material resources, the Yawanawa reply that it was the awareness of the beauty and the worth of their "culture". Their ethno-history emphasizes the recent rescue of self-esteem and a renewed notion of self-worth, replacing the previous embarrassment that their cultural forms represented in the past. The economic projects developed by the Yawanawa were not the only cause of this re-awakening to their difference. The involvement in the indigenous movement since the 1970s, the participation at UNCED in 1992, the new "age of indigenous rights" inaugurated by the new Brazilian Constitution and new attitudes of the State and Federal governments towards indigenous populations all contributed somehow to offer them improved conditions to express their identity. Recognition was clearly linked to redistribution, as well: entitlements to social benefits and state policies, as discussed, helped to secure material means.

Yet the projects are regarded an important part of the processes of creative "recovery" of culture and assertion of identity. Only analytically it is possible to distinguish gains in 
recognition from gains in redistribution, for those projects brought considerable resources to the community. Even more importantly, the experience of Biraci, Joaquim, Sales and selected members of the community in the urban world made them acknowledge the links that exist between respect and income. Once they obtained some resources, they realized the dignities of the market and its system of valuation. A much paradoxical process and one of the most interesting effects of these projects, from an economic sociology perspective, is that by acting in the market displaying their difference, they were recognized for what they are. Money is a global, abstract system of valuation, which in this case did not dilute the specific qualities of the priced object, but positively influenced the societal ordinary ways of judging it. Increasing the monetary value of something may lead to an increase in the social respectability and recognition of that object. Once elements of their "culture" were monetarily valued by Aveda, visitors and new age audiences of their ritual performances, these elements also became more respected by others. Persons had to recognize that not only the Yawanawa had become productive members of the society, consuming in the market, but also that they had a market value.

Particularly, they have been able to attract political attention and negotiate state benefits, due to the fascination they exert on outsiders. The most important conquest in the terrain of state politics was the revision of the territorial limits of their land in 2004. Aveda financed this initiative, paying multiple trips to the FUNAI's office in Brasilia and putting them in contact with international authorities and celebrities that pressured the Brazilian government to recognize territories not included in the original demarcation in 1984. In recent times, the state government provided multiple benefits as well: it recently built fishponds, it covers significant costs of the Festival Yawa, a compensation for the attraction of tourists to the state and as part of Federal government policies, the villages also received electric generators and satellite internet. Since public displays of the Yawanawa may also serve to make state policies visible, the period of implementation of many benefits coincide with the Yawanawa Festival, so that political authorities can use the occasion to display their policies and achievements to a wider audience.

Additionally, they realized that money buys respect in the market society. Walking in the town of Cruzeiro do Sul with Biraci, many shop owners stopped us to adulate him, knowing that he has to buy a significant amount of goods to the village. Biraci is proud of this fact and once confided me in humorous tone: "when we gained purchasing power, the market in the towns opened its doors. We were received as good clients. We had the cars of these 
firms available for us in any place. The big traders received us with respect. They came to visit us" (BBY). In a true process of indigenization of modernity, when they started acting as market agents, they finally gained respect that enabled them to be indigenous.

The projects developed have notably contributed to strengthening their collective identity and "culture" in several other ways. More obviously, the urucum project meant the return of the pigment, or as a Yawanawa puts it, "the paint of this people" (MSF). Before the project, they no longer used to paint their faces and bodies and had lost the ability to make culturally meaningful designs. The availability of urucum and their willingness to show their beauty to Aveda led them into a quest of recreating the paintings and its stylized patterns. When Aveda's employees visited the area to understand how they employed the dye, the Yawanawa realized that their value resided in the survival of their difference. They felt elated as these foreigners commented on the beauty of their paintings, their dances and practices that they would stage to receive their new allies. As they realized that others were interested in their "cultural" heritage, they were encouraged to pursue it. The terms of the contracts celebrated with Aveda also contributed to an acknowledgment of the material and symbolic value of their "culture". Since Aveda has always paid more to use Yawanawa images showing them with their body paintings, traditional palm skirts, headdresses and sometimes during their games and rituals, they realized that their "culture", represented in those images, is worth more than any natural product. This acted as an incentive to pursue the path of reinventing traditions.

The activities involving the staging of spiritual rituals, in turn, have their own incentives to a collective rediscovery of traditional systems of cure. The interest of outsiders in their spiritual system of cure and associated rituals, or more narrowly in the substances that are consumed during these rituals, have increased the prestige and power of those members, in different stages of their spiritual formation, who can perform them to outsiders. Consequently there has been an increased interest in joining the rituals and in the shamanic career. But beyond the uses of these activities for the development of individual projects, these members tend to reinforce traditions related to these rituals and that are increasingly associated with "culture", as the set of practices that defines them. More people take part in the uni rituals, for example ${ }^{74}$.

\footnotetext{
${ }^{74}$ At this moment I can only wonder if the new wave of initiation diets will lead to a real increase in the knowledge about the cure system, but it seems likely. Since a specialization in knowledge is already present amongst those who have some training in the cure system, more plants and practices to make them active would be probably known.
} 
Finally, by prompting external judgments about the worth and beauty of their distinctive traits, all those projects influence internal judgments about "cultural" practices and entice community members to embrace them. In a similar situation described by Graham (2005) for a different indigenous group, the Yawanawa believe that outsiders consider beautiful the mere fact that they have retained their identity. Independently of the content of such identity, their history of resilience and preservation of differences is sufficiently attractive. Being recognized by outsiders, they argue, also increases the internal awareness of the worth of their "culture". This is what John and Jean Comaroff point out when they assert that "the producers of culture are also becoming its consumers, seeing and sensing and listening to themselves enact their identity" (2009: 26). 


\section{Conclusion}

"An aside on the commodification of culture. If it is true that commodification is the death of authentic culture, how come Americans still have one?" (Sahlins 1999a: 409)

"The nice thing about culture", Strathern (1995) contends, "is that everyone has it". If anthropologists are at great pains dealing with culture and trying to define it in relation to their own works on the cultures they study, the same is clearly not the case with culture as a practical category in ordinary usage. The academic skepticism about the nature and validity of the concept of culture, debunked as an essentialization of differences that, as such, do little more than revealing the analyst's own points of view and societal features, arrives too late and in the opposite direction of popular movements that have embraced "culture" as their weapon of defense. Despite its academic iconoclasts, the "culture" cult, once only practiced by anthropologists (Wagner 1981), is currently a widespread phenomenon, as these symbols of difference created in the inter-cultural relations are appropriated by their own authors to claim their space and value in modernity. It seems that everyone is talking about culture, even if to denounce the drives of cultural homogenization attributed to the global movements of capital. More often than not, this "culture" talk is part of claims to a particular identity and authentic symbols of difference. "Culture" is the air we breathe, the most basic practices and forms that result from our daily symbolic and material relations with our environment, turned into narrativized, praise and performed traditions.

A reaction to this perceived spread of cultural forms from the West to the Rest or not, "culture" has also made it into the market, as there seems to exist avid producers and conspicuous consumers of difference. On the one side, demand results from the high praise given to "culture" and the wisdom it can offer. The process here is known to sociologists: since the object of exchange, in this case, cultural representations, has an almost sacred value, it acquires a high market price. Once the price tag is appended, it increases the social worth of that object. This happens because some social categories of judgment bestow a high worth (Fourcade 2011). In this case, the powerful cosmology of the disenchantment and rationalization of the modern world, combined or not with the Western's sentimental pessimism (Greenblatt 1991: 152), animates a new romanticism that looks into these 
"cultures" and their wisdom as miraculous expressions of a lost world, to be praised and consumed against the malaises of modernity. Part of this lost world is an essential connection to nature, re-enchanted by a new political ecology. Postmodernists use the postcolonial subject to decolonize their episteme, using the native one - or the sense they, the postmodernists, make of it - to deconstruct their modernity.

The history of cultural contact and, especially, the one that followed the expansion of global capitalism since the late fifteenth century, is certainly populated with episodes of violence and genocidal cruelty. Colonialism governs, subordinates, ridicules, classifies and makes invisible different lives and knowledge, but these survive and reconstitute (Escobar 2008), with local adaptations and creative responses to modernity. And offering their "cultures" in the market seems exactly one of these creative responses of the once colonized others to reassert their place in the world, indigenizing institutions in the name of their own goals. If everyone has "culture", but nonetheless look for the vestiges of the cultures in populations imagined to have been patients in the process of modernization, these new romantics enable these others in their movements of cultural reinvention. What the natives see in the mirrors are their own interpretations of the masks that have been conferred on them. But these masks become their true being: it is during the occasions in which they wear them and, thus, are re-cognized, that they self-cognize themselves. The displayed become the authentic, the true self (Comaroff/Comaroff 2009: 27).

This should cause no surprise, given the convergence of sociological and psychoanalytical findings on the matter of identity. The self is defined reflecting the expectations of others, in the view of Strauss (1997), or become the object observed by the gazer, as noted by Lacan (1973), since you can only mean to the other. Inter-cultural encounters are experiences always mediated by the gaze. What is unique here is that the connection with the other that forges identity is mediated by the market. And to circulate as part of market transactions, cultural representations must be transformed into commodities.

\subsection{An enlarged politics of value and the Yawanawa}

This brings us to the central question of this work: the commodification of "cultures". The starting point was the rejection of a conception of commodification as an inexorable 
movement of an ever-expanding capitalism to subsume all things to monetized relations and generalized equivalence. That is not to say that the expansion of capitalism did not occur through the increase in the number of things, and decrease in number of persons, that can circulate in the commodity state (Kopytoff 1986). But research since the 1980s (Appadurai 1986; Kopytoff 1986; Zelizer 1994) reminds that things do not ontologically belong to the category of commodities. Even the most impersonal of all things, cornerstone of all capitalist relations, money, circulates under a number of regimes of exchange, as part of different social relations that promote its flow. When objects circulate as commodities, they assume this particular state during exchange, only to become a singular possession in the hands of their new owner. If we neglect this fact and continue to espouse a vision of commodification simply as a general drive of capitalist forces, we miss all the creativity and different intentions revealed by actors manipulating the movement of goods towards and from the commodity state.

The case in study here involved a peculiar circulation of cultural representations in the commodity state. This process is not imposed by outside forces, but part of a strategy of the Yawanawa to engage with outsiders, their things, rights and institutions. This called for a different conception of commodification, which may be found in the above-mentioned literature and, notably, in the work of Appadurai (1986). Whilst preferring to retain the analytically useful distinction between regimes of exchange - gift, barter and commodities -, due to their connection with different sets of social relations and primary goals, I embrace the methodological proposal of Appadurai (1986) to understand commodification as a tensional, negotiated process animated by a politics of value. In addition to the idea of politics of value, a negotiation on meanings underlying the actions of diversion of objects to circulate as commodities, the biographical approach he borrows from Kopytoff (1986) is equally useful. Appadurai provides the basis for the analysis, but a number of limitations presented in chapter 2 led me to propose an enlarged politics of value that includes a politics of production. Analyzing the Yawanawa case, the demand for their representations and the conflicts the projects promoted, this enlargement proved essential. Moreover, I proposed to understand the exchange of commodities looking not only to the discrete transaction, but to the broader societal context which informs the actions and meanings of producing and circulating objects as commodities. Not only objects produced and acquired, I contended, but also labor and the expectations it generates are informed by a native scheme of interpretation. Finally, moving to the sphere of exchange, I proposed to investigate the role of social biographies and distance (social, temporal and spatial) in the creation of value. 
A central aspect of Appadurai's (1986) work on commodities that is central to this work is that particular actors might still regard them as singular valuables and allow them to circulate. I proposed to understand how cultural representations may become commodities and what are the tensions, negotiations and translations underlying this process. The diversion of these cultural practices from their main purpose involves, as argued, a politics of value. There are general qualities of "culture" that might help to explain this process: culture is a non-depletable object and the increased demand and consumption leads not just to an increased production, but also availability (Comaroff/Comaroff 2009). The exchange of rituals and other markers of identity blurs Gregory's (1982) now classical distinction between productive consumption of the gift and consumptive production of the commodity. For even when performed for the consumption of others, culture is understood as being relived, reexperienced, re-enacted. In short, consuming culture is productive. The performative nature of these cultural practices represent that production and consumption are simultaneous and the separation will refer only to the emotions prompted by the involved actors. The increased demand, thus, leads to an increased (re)production of culture in these performances, which are not limited to market transactions. Finally, it is difficult to recognize any alienation of the exchanged cultural practice or representation, a feature that Kopytoff (1986), as well as Gregory (1982) repute fundamental to define a commodity. In effect, since the object exchanged is essentially related to the identity of its producers, something that neither they can lose, nor can the consumers effectively obtain through consumption, there seems to have no alienation in the process.

These features and the complex mechanisms and understandings developed by the Yawanawa to exchange their representations create challenges to determine whether the circulation should be considered commodity exchange. Yet it does not seem incorrect to consider at least a fragment of the process as commodity exchange. I proposed to maintain the distinction of regimes of exchange based on the main goals and the social relations they animate and animate them. I argued that commodity exchange is defined by the primary goal of obtaining a counterpart value, even if producing social relations is also an intention. Albeit calling into question the distinction between gifts and commodities, while discussing the work of Gregory (1982), Parry (1989: 86) offers a very useful element to the problem here: commodity exchange aims at maximizing net receipts and profits, to out-take, whereas gift exchange aims at maximizing net-outgoings, to out-give. I contend that the endeavors of the Yawanawa with their partners aim at bringing resources, even if in complex and indirect ways and, thus, maximizing receipts seem to be the case. 
If this is so, the question of the enlarged politics of value, or how these practices are produced and momentarily diverted into a commodity state, remains. In the last chapters, I offered a description of the processes and tensions, but now I can offer a more formalized account. The role of the intermediaries, notably the Yawanawa chiefs, in the projects analyzed is fundamental. Connected to the broader political economy of the Yawanawa and their personal projects of leadership, they monopolize the negotiation of the terms and benefits associated with these projects and other sources of resources, sharing details only with few loyal members. In the case of annatto, these negotiations took place outside the village and the project was the personal achievement of Biraci, granting him the consecration as the new leader. Controlling this new alliance in the market and generating an inflow of goods and benefits for the community, he initially managed to animate the Yawanawa and siphon their efforts while resources were sufficient for everyone.

For most of the Yawanawa, I realized, producing annatto for external sale was not just uncomplicated, but also a pleasurable activity that united the community. After decades of engagement in the rubber economy, the Yawanawa were familiar with the system: they had worked before to obtain goods they consider necessary. These activities were organized by the leader, who also brought goods for exchange, framing this system in a language of generalized reciprocity, whereby procuring goods was supposed to be exchanged by political loyalty. Workers developed different expectations regarding these activities and the insertion of money and goods in the community, but generally work was considered a means to objects they could not directly obtain from the forest. The rubber tapping activities had already scattered the population over multiple settlements and their gatherings for feasts and rituals were not always tolerated. After the demise of the rubber production, the situation worsened, with the absence of any income or goods in the region. The partnership with Aveda was, thus, a new hope, represented in the name given to their new collective village. The expectations generated by the project united the community in the new village, bringing together the scattered queixadas, allowing them, once more, to live as queixadas.

The symbolic associations with the traded object and the image they provide to Aveda did not generate contention. Urucum was wild harvested before and, according to some of them, they had lost their color. The project entailed the cultivation of better seeds, with higher concentrations of red dye. The praise of these ameliorated varieties, brought from a stateowned biotechnology research company, represents their willingness to incorporate new objects and technologies to make their rituals more lavishing. For them, nane, as they call the 
annatto seeds, is their color, their beauty, and their protection, which the project helped them regaining. It remains something singularly associated to their culture and having it available to use in their body paintings is praised. Knowing that their images were employed to sell makeup was also considered a reason for pride and an incentive to display their beauty. Amidst the recognition of new rights and implementation of new state policies towards indigenous populations, the interest of a foreign firm for their image, as well as their legacy of endurance and preservation of the forest, fostered their awareness about the worth of their identity and led them to pursue a project of cultural recreation.

The activity of producing urucum and the initial phase of the project retains consensual support from the community. This is no minor thing, given the different expectations and views about the future that are found amongst the Yawanawa. Nonetheless, the project is not praised by all and gave rise to bitter conflicts, which led to the creation of a second legal organization and a competitive setting. The real politics underlying the possibilities of continuing this project is not connected to a negotiation of values and meanings of urucum, but it is situated in the sphere of production and in the political relations. The facile interpretation would be to say that their engagement with a multinational firm, introducing vast amounts of resources in an indigenous community not used to these undertakings led to divisive spirits. Turning the Yawanawa into passive victims of their own success was, in fact, a narrative strategy adopted even by some villagers, amongst which some romantics and notable men directly involved in the management of resources (ALC, RSLY). To say that there was a threat of subjugating the community to the condition of proletarians and that this was an incipient class conflict, as May Waddington (Ribeiro 2005) suggests, also does not seem accurate. The endurance of the project under new leadership and old forms of relationship between community and leader reveals a different reality.

I argued that the conflict is, in fact, the expression of tensions on different levels. First, there is a conflict of expectations that can only be explained with reference to the role of the leader and the nature of political power amongst the Yawanawa. The role of the leader as an intermediary, forger of alliances and capable of promoting exchange that animates the community, was thoroughly discussed in chapter 4. At least since their involvement with rubber, the market became an arena to establish alliances, even if the exchange has always been surrounded by moral obligations and a high degree of personality in the relation with their partners. In any case, as part of their quests for power, leaders attempt to control the flow of resources originating from economic ventures in a centralized way and use the distribution 
for political purposes. Leaders frame the activities in terms of collective benefits and the distribution of resources in a language of generalized reciprocity (Sahlins 2008), in which the debt created imparting goods should be paid in political loyalty and reciprocation can only be expected.

Any other system would be detrimental to community bonds, both Biraci and Joaquim indicate. In practical terms, goods and money are not compensation for work, but gifts for individuals (Biraci) or improvements for the community (Joaquim). The political distribution of resources also represents the absence of any quantitative equivalence in the volume distributed vis-à-vis the effort offered. A group of loyal members can expect to receive more. Additionally, the leader retains some of the resources he thinks are indispensable for the management of the project and to be able to have more objects in his house, which in turn he donates, reasserting his authority. Most of the members of community involved directly in the productive activities, however, understand this as a work relation to obtain individual gains, in the form of money or goods brought to their territory. In the early stages of the project, according to their accounts, there were sufficient resources to distribute to all the involved. But without meeting production goals and with a more strict control over donations, coupled with a concentration of resources around the leader closest internal allies, goods became more scarce and the population involved in the project claimed their share. Leaders, in turn, claimed more resources from the firm, but the distribution was always differential, in a situation not very different than the one described by Gordon (2006) for the Xikrin. The frustrations of the population led to an eventual disinterest in the activity. Work was not offering what they expected: the desired industrial goods. This situation is often framed as a mismanagement of the leaders and their organizations. Many Yawanawa, including those involved in the legal organizations, said that there has never been a disclosure of the numbers of any project (LY, BY,RSLY).

The politics of value of the commodification of urucum and associated image of the Yawanawa is not limited to a conflict of expectations regarding the distribution of resources. Once more, the persistence of the project under a new leader that emerged amidst the conflict suggests another cause. In chapter 3, I described that the family nucleus of Raimundo Luiz maintains dynastic claims to power and to positions of prominence. During the project, the descendants of Raimundo Luiz claimed preferential access to resources and control. The return of Joaquim from the United States and his increasing involvement with the project created a competition. The new economic activity was a new avenue for the expression of 
leadership contests. Biraci had already realized that their most valuable asset was culture and amidst mounting distributive conflicts, decided to abandon the project and focus on cultural practices, initiating into the healing system. Joaquim and his newly created organization, congregating members of his dynastic family, namely his father's siblings and children, took control of the project, negotiated a new contract and began cultivating in 2008.

As argued in chapter 7, this project highlights the roles of intermediaries in promoting the circulation of goods. In the Yawanawa case, this was not an attack against the elites, as Appadurai (1986) indicates, but on the contrary, part of leadership contests between notable men. If leaders make projects, projects make leaders. The politics of value cannot be understood without reference to the importance of forging alliances that promote exchange and animate the community to the nature and role of political power amongst the Yawanawa.

On the other side of this exchange, the politics of value involve the qualification of the product. A network of actors and devices employ some elements taken from the Yawanawa to create a high performance makeup line. In this long distance exchange, small fragments of information and elements of commensurability are sufficient to attach producers and consumers. The connection amongst beauty, health and nature, the core of Aveda proposal, is recreated in relation to the Yawanawa: urucum is a natural element used to produce beautiful and healthy bodies, albeit the native conception of beauty differs from the one intended by the demanding customers of makeup. The qualification of the product faces the challenge of stabilizing its qualities and communicating the high quality and features of the product, while reasserting, especially professionals, of the connection with nature through the product of a community that leaves in harmony with it. Despite the conflicts of qualification and apparent preference of the firm to highlight the technical qualities, the professionals that work close with the firm still establish this connection. There is a core of professionals strongly associated with Aveda's message that seem to believe that, by helping a population that still lives in connection with nature, they recover their lost connection with it, not least in the way beauty is produced. The products come "out of the forest", they are informed. The situation here is not far from the spatial transcendence proposed by Beckert (2011), but the magical connection, the spirit that circulates in the product invokes an imagined entity - nature according to the Western naturalist ontology that segregates nature and culture. Nature is a generic location, an open referent to the symbol. Yet this message only reaches a core and the beauty it aims at invoking is that of the Western sophisticated women. For both sides, 
exchange is possible amidst not only very limited reciprocal knowledge, but also the described tensions within each group.

The politics of value involving the public performance of rituals during the festival or in urban locations is much more complex. Everyone has a culture (Strathern 1995), everyone talks about culture (Sahlins 1999b), but "culture" is not for everyone. At the core of the negotiations of value is the very definition of the role of "culture" in the future of society, but also the submission of these rituals to the commodity state. In order to legitimize these activities, the main performers, a group that has turned in the last years exclusively to the cultural reinvention, notably in its spiritual and healing dimensions, frames these activities as a true cultural manifestation and the gains it promotes in the language of the gift. Their culture travels around the world making friends and these, in turn, make gifts. In the domain of the ritual all interest is obscured by the prescribed acts and words. Thus, it is also a terrain for denegation: it offers the occasion to obtain material and symbolic resources, whilst denying the intention through the particular objectives of the ritual. This denegation is achieved, just as described by Bourdieu (1993), with the time lapse between the activities and their actual gains. The profits are not generated by the events themselves, but by the alliances they are able to produce. After all, the festival produces losses every year and in performances outside the land, payment is given to the facility that holds the performance, not the performer itself. The front room/back room logic described by Velthuis (2005) is also present, although the distance here is much larger: intermediaries outside the Yawanawa territory negotiate fees for visitors and arrange performances in urban centers. Any direct profit circulates in these spaces, far from the villages and the eyes of the community. That does not mean, however, that resources associated with these activities do not reach the territory or its population. Villagers do obtain income during the festival selling crafts, mostly the adornments and artifacts employed in the rituals, necessary to produce the ethnomimesis (Lau 2000) sought by outsiders.

Yet the logic of the rituals and their incipient market is more complex than a simple denegation. They aim at using the discrete transactions of commodity exchange to produce an ongoing flow of resources in the form of gifts. The intentionality of these performances and rituals is not restricted to the limited profits they produce. They are inserted in a broader strategy of a group of Yawanawa to construct a network of allies out of this market for spiritual cures, which they can mobilize permanently. There is a true competitive market in Acre for attracting the passions of esoteric, new age groups and Ayahuasca-based religions, 
well documented in the work of Labate (2004). The Yawanawa are not the only ones promoting their cultural practices and travelling to display their ceremonies of healing. In this competition, however, the Yawanawa do not seek to maximize their economic profits, but to attract the interest of visitors and forge permanent alliances they can use for material and symbolic purposes.

As explored in the next section, this existential strategy finds significance in the native repertoire of action, through which it can be understood and promoted. Nonetheless, no topic generates more contention that the forms of practice and display of their rituals and ceremonies. I argued that there is a general disposition towards sharing their rituals and ceremonies, often through new media, and that the main concern of the community is with the authenticity of the public performances. Due to a strong association between these cultural elements and their collective identity, they share the view that their reputation depends on the genuineness of the rituals. This leads to a challenge of performances by members of the community without proper training in the healing system. But there are other critics of the new forms of use of uni, the mediation of money, the excessive focus of the community on cultural practices and finally the Protestants, who reject the practices altogether. Culture is not for everyone and those who do not follow the path of cultural reinvention are marginalized and excluded from the opportunities of income represented by rituals and performances. Agents are not just the masters, but also the slaves of their own cultures.

The politics of value of cultural performances also involve the political economy of knowledge amongst the Yawanawa. Considering that these practices are the main source of symbolic and material resources, the once difficult shamanic career became very desirable amongst the youngsters. The bitter knowledge and difficult tests of endurance entailed in the long initiation process seem worthwhile in face of the opportunities to circulate showing ceremonies, making new friends and obtaining some income. However, the access to the healing knowledge must be restricted, due to its sacredness. Culture is also not for everyone because only a small number of members of a community can get access to the knowledge that enables them to perform the healing and spiritual practices that bring income. The control over the access becomes, then, a power. Only the two xinayas can teach the Yawanawa, but the leaders have realized that controlling the access to this knowledge and intermediating performances is a powerful device to maintain the debt in which leadership relies. As a result of this particular logic in which the sacred becomes the main source of income, the market becomes an amplifier of cultural inequalities. I argued that the money becomes a principle of 
social differentiation amongst the Yawanawa, but at the same time, this differentiation is subordinated to the unequal forms of access to the knowledge on healing and spiritual practices. The inequalities created by the market amongst the Yawanawa are inequalities that belong, fundamentally, to the realm of culture.

For the visitors and the audience of such rituals, the Yawanawa offer a cure against the malaises of modernity. They offer an experience of true connection with nature and its spirits, but also the potency of the vision offered by uni. Moreover, it offers the possibility of playing at being Indian. They assume a temporary role, a mimetic persona for a couple of days, transforming their bodies with the use of the Yawanawa crafts.

The politics of value of the commodification of "culture" amongst the Yawanawa indicate the tensions, negotiations and specific forms of justification mobilized by the actors to promote the circulation of their representations. However, these elements do not explain how and why the Yawanawa have been promoting the circulation of cultural representations in the market. The reasons actors go to the market and the meanings of their actions vary. In this work, I suggested an integral mode of analysis of economic action, in which exchange is inscribed in social and political relations, as well as in cultural codes. My aim is, following the suggestions of Zelizer (2010) and Sahlins (1976), to understand the market not just as a space of economic exchange, but as a cultural and social order, so that there is no contradiction between culture and economic exchange. The description of the actors in Part II of this work aimed at delineating the fundamental aspects of their society and culture that explain their uses of the market and exchange. In the next section, I situate the projects and actions of the Yawanawa into their societal features that guide the forms and meanings of economic exchange. The goal is to analyze exchange according to the point of view of the actors themselves and the meanings they bestow to their action. In so doing, it is possible to formalize the argument that cosmologies are sufficiently flexible to allow for new formulations that grant intelligibility to market processes without destroying their beliefs, relations and traditions. Moreover, to move beyond formalist positions that are still present even economic sociology, I attempt to show that all societies have some form of calculative devices and interested pursuits, defined according to their own defined goals. At the same time, all societies interpret and act upon material processes and the institutions that underpin them according to local cultural schemes. In that sense, I offer an interpretation of the native way devised by the Yawanawa to engage in the market in the next section, based on those features presented along Part II. 


\subsection{Instrumentality, dignities and perils of the market: doing business, the Yawanawa way}

Every aspect of the Yawanawa seems to impulse them toward the other and their marvelous things in a way that confirms the indications of Erikson (1996) for the Pano group and of Viveiros de Castro (2002c) for the Amazonian populations in general. Perhaps the place of the other and the importance of exchange is more a result of historical contacts than essential features, but the form the Yawanawa society organizes and projects its image transforms exchange in an essential part of its substance and life. Chapter 3 discussed the role of alterity and, consequently, exchange to the very substance of a community, both as result of myth and history. The Yawanawa were mythically produced together with other peoples, they asked for the distant other and her powers, and were historically created as an assemblage of populations. The restriction of kinship alliances and the compactness of a community descending from a common ancestor projects exchange to the exterior. The role of the leader is, thus, that of an animator of society beyond its boundaries, a producer of alterity. Operating in exchange systems belongs to a different order of action, which only assumes the form of rationally economic (and political) exchange under the current conditions. In other words, the market has been just a particular historical form through which alliances are promoted. This explains, perhaps, the instrumentality of the market for the Yawanawa.

Market activities are understood as one of the means to forge alliances, which can be equally forged with the state or private actors willing to contribute to the community. The market is understood as one of the arenas where resources may be obtained. They use the market moved by their desire to obtain goods they consider necessary. When I visited the community, I realized that Nova Esperança had replaced the resources it used to obtain producing annatto with multiple benefits obtained from the Government of Acre. Currently, the state is a major force of introduction of goods and money. Moreover, it was clear that they do not make any distinction based on the origins of resources.

During the recent past, markets had the role of introducing the other and her goods, but rituals have also played this role in their history (Naveira 1999). Their mariris, games and dances to celebrate the community, have always been understood as means to forge internal (matrimonial) and external alliances. They are machines that open the community to the other, socialize her and incorporate her as a new ally. Since the early twentieth century, at least, the Yawanawa have resorted to the market to promote alliances, which for most of the period 
were also surrounded by moral obligations. Over this period, leaders were exposed to the market institutions. Their urban experiences revealed that income was an instrument to obtain respect and that the market has some dignities. As a consequence, they used the market as part of their existential strategies to reaffirm their rights. Their involvement with a large American firm granted them respect in the region and bargaining power to fight for a revision of the limits of their territory and claim other state benefits.

Nonetheless, the conflicts produced by large economic projects also revealed the perils of the market. I argued that the Yawanawa are neither traditionalists, nor morally condemn money, goods and market practices. And yet, Biraci and some loyal men developed a "hostile worlds" vision that emphasize the divisive forces of money and have turned to "culture" as the authentic Yawanawa way of life, while promoting public performances of rituals that involve monetary resources. Curiously, there has been a process of re-ritualizing exchange, using cultural practices, in an updated form for new contexts, as machines of alliance. I propose to understand this phenomenon as an attempt of Biraci to control the effects of market exchange, especially in terms of distributive conflicts that harm his leadership. In these cultural practices and rituals, Biraci found a form of managing alliances that produce exchange without requiring permanent collective efforts that generate expectations of income and accentuate distributive conflicts. The inter-ethnic alliances forged around the use of ayahuasca offer this possibility of establishing partnerships that escape the pure logic of the market and commodity exchange. These alliances are even more powerful because the Government of Acre, due to personal links to these cults and as a strategy to forge an image of the area associated with the origins of ayahuasca-based cults, seems eager to support tourism based on the substance, as Labate (2012) shows.

As part of his role as leader, Biraci must forge alliances that promote exchange and bring resources to the community. To protect himself from the uncertainties of the market, he prefers to seek permanent allies, transforming impersonal and discrete operations of exchange into enduring relationships of reciprocity. More than a denegation, hence, cultural performances and the effects they operate in terms of producing material and symbolic resources should be understood in reference to a native repertoire of action. Rituals are understood as machines of alliances, moments of openness of the community to outsiders. The market demand for these rituals has created the opportunity for, once more, use these rituals to create a network of alliances and produce income. By putting their culture to display in the market, they expect to receive gifts in exchange for sharing their wisdom. The 
advantage in relation to regular market projects is that the Yawanawa can rely on these alliances to obtain continuous resources without depending on permanent collective productive activities. Furthermore, the leaders can justify these activities using the language of tradition and culture.

Yet there is more than a calculated, strategic decision underlying this path. As indigenous populations navigate a world of transformations, whilst seeking to retain their difference, they struggle to find forms to deal with both tradition and change. This translates into particular existential projects of insertion in modernity which are, as discussed in this research, also a matter of contestation. One of the central arguments here is that the market is not employed necessarily in the same way by all agents. Their meanings reveal creative appropriations of categories of action that defy the formalism of the analyses of economics. The Yawanawa go to the market with the aim at increasing their visibility and, thus, their capacity to mobilize resources from this wide network of allies. At the same time, it is the market for otherness that makes possible for them to resort to their traditional form of celebration of alliances.

\subsection{The Yawanawa are good to think}

The Yawanawa experience promoting the circulation of their cultural representations is good to think about a number of related theoretical questions. These questions populated parts II and III, but here I formalize the contributions of the Yawanawa case to them. In the first place, the commodification of their culture can be understood as integrating a broader strategy of indigenization of modernity. Since their initial relations with non-natives more than a century ago, the Yawanawa have introduced elements from outsiders in ways that mostly reproduce their social and cultural systems. These instruments have generally not replaced the internal relations. On the contrary, these relations are a force explaining their introduction and internal meaning. The strong relation between political leadership and the promotion of alliances with outsiders and the importance of those for the very substance of the Yawanawa are forces explaining this appropriation of goods and institutions. On the other side of exchange, consumers of the Yawanawa are also seeking indigenous forms, mediated by their own representations and understandings, to reconnect with nature, to cure them from the 
malaises of modernity and reestablish the lost connection between beauty, health and environment.

The importance of local agency and institutions in promoting and mediating the appropriation of external objects and relations also calls for a better understanding of the entanglements between local and global forces. Sahlins (1988) and Thomas (1991) offer suitable notions in that regard to replace previous conceptions in which the local was a passive and coerced subject of processes initiated on the center of capitalism, such as WorldSystem Analysis (Wallerstein 1974). The capitalism expansion does not lead to a replacement or destruction of these local structures. On the contrary, locally entrenched political and social structures mediate, if not promote, the introduction of new economic processes. Parochial intentions of local elites of reproducing their position of power and wealth often explain the insertion of peripheries into the system. I demonstrated that, despite the challenges entailed in the occupation of their land, the Yawanawa displayed enormous agency and it was their decision to engage in exchange with outsiders, since the rubber tapping years. The reliance of their leadership position in the capacity to forge alliances and procure resources is a drive to engage with outsiders. The relation between economic success and political loyalty, despite not the only element producing power, explain the involvement of the Yawanawa with activities related to the rubber extraction, and more recently, the production of annatto. Much of the inequalities and conflicts produced by these engagements are the result of the internal structure of power of the Yawanawa and the forms of distribution of resources following a political logic, supported by discourses about community bonds and the divisive effects of individual gain.

The willingness to incorporate the other and its objects leads the Yawanawa to use the market instrumentally. Without strong moral views on the market and goods, the Yawanawa are willing to engage in productive work to obtain industrialized goods or money, to be exchanged by goods. The facts that they retained their land and the possibility of using its forest resources for their subsistence secure them most of essential means, but their desire to obtain modern objects justify engaging in exchange. Recently, recognizing the high praise of their identity, related to its endurance over decades of subjugation in their own land to an economic system that is popularly equated to slavery, the Yawanawa resorted to the circulation of their cultural representations as means to obtain resources. More than ever, this action posed the dilemma of embracing modernity whilst retaining distinctive features employed to construct their identity. The means of accessing the marvelous things of 
modernity is to assert their difference, which in the eyes of many, is intrinsically related to a state of pristine tradition. The Yawanawa struggle to find forms to materialize an ideal of identity connected to the endurance and reproduction of a reified set of cultural practices that make them unique.

The insertion into the circuits of capital, even if animated by the agency and local forms of populations seeking to indigenize modernity, is not consensual or homogenous. The process of indigenization of modernity comes with different expectations, translated into a dispute over categories and meanings of these external elements. If the commodification process is understood as a tensional and negotiated process resulting from the politics of value, and the role of local institutions and relations in mediating the incorporation of external elements is recognized, culture becomes a battleground, as Wallerstein (1990) argues, in this case for the definition of the scope, role and meanings of new objects, relations and institutions. This is not, however, a functionalist process of ideological justification and domination. In concrete situations agents might mobilize their scheme of reception of new symbols and certain categories in novel and creative ways. Culture is not just an ideology to justify oppression; it is a device to make the world intelligible, according to an ever-evolving system of reception and classification of symbols. If culture is understood as an epiphenomenal ideological justification for material processes, unexpected results are overlooked. After all, market structures and foreign discourses, such as environmental concerns and preservation of cultures, may be appropriated in existential strategies of populations that still must justify their right to exist in ways that are different than those of the national societies in which they are inserted. The situation is more complicated in the Yawanawa case, because culture is the main circulated asset, generating contention over the scopes and meanings of activities of circulation of their cultural practices, which despite the tensions, continue to take place due to the power of a small group around the leaders.

I indicated that amongst the Yawanawa, despite being a small community to which unity and cohesion ensure a high symbolic value, ambivalences regarding expectations and visions about their insertions in the capitalist economy creates different positions which could be placed in a continuum from the romantics, who believe that culture should be the focus of their lives, to the workers, who believe in the necessity of large productive activities to bring the goods or income they need.

The circulation of cultural representations of the Yawanawa also allows us to think about the effects of categories of judgment on economic value and vice-versa, the effects of 
economic value on the judgment of commodified objects (Fourcade 2011). On the one side the association of indigenous populations with the protection of the forest and its diversity, with the endurance over centuries of Colonialism and with a particular wisdom about nature, its spirits and their healing powers, increased the value of their practices. Above all, the Western re-enchantment of nature bestowed increased worth to those cultures that possess a harmonious relation with nature. On the other side, the realization, amongst the Yawanawa, that their culture and forms of life were praised by outsiders, coupled with an acknowledgment of special rights related to their identity as native populations led, to an awakening to their cultural practices. Despite and because commodified, "culture" became the center of the social life amongst the Yawanawa, demanding efforts of all the community to adapt to what is perceived as authentic reinvented traditions. All this proves that capitalism and culture are not antagonistic and that the former not only has cultural roots, but also can employ cultures to reproduce capital. Yet, the result of this process is also that the market can serve the purpose of strengthening public and local perceptions of identity. The Yawanawa indicate that the market, the main transactional mode in modernity, is a possible space for pursuing individual and collective projects of identity.

Finally, the Yawanawa demonstrate that the market is an arena that is not defined by certain codes of action or a single intentionality. Their identification as an indigenous community, their reliance on distinctive cultural, social and political traits could be invoked to assume that the meanings, forms of action and goals they ascribe to the market are a remnant or an intermediary form that exists while they are not fully incorporated into the circuits of capital. Bourdieu (1977: 186) describes a similar situation in the suq, in which economic actors seek protection from the uncertainties of the market using a traditional network of relationships and asserts that this is an intermediary form of transaction. In the Yawanawa case, however, this is the result of internal mechanisms and attempts to protect themselves from the perils experienced in their transactions in the market, even when complemented by reciprocal moral obligations. Instead of an intermediary stage, it could be understood as a conscious reversion. Moreover, the use of the market for promoting their identity cannot be inscribed by any means in traditionalist strategies. As shown, it was the result of a realization that the market has also its dignities and of a market demand for these singular forms of cultural expression.

If it holds true that the market is not employed in the same forms or with the same goals by all agents, the understanding of economic action and exchange requires an investigation of 
the actors, the social relations and cultural systems of meanings in which they are situated. The dispositions to exchange are fundamental and are neither universally the same, nor represent a disenchantment of the world. On the contrary, the key to understand these dispositions rests on the enchantments with which economic action is surrounded even in capitalism. Analyzing all aspects of the Yawanawa relationship with exchange, goods and money, I sought the internal elements that bestow practical and symbolic meaning to economic action and explain their decisions to take their "culture" into the market.

The conceptual and methodological proposal of this work, which can only be achieved by means of an economic ethnography, is an integrated model of analysis in which the economic is not separated from the political, social and cultural, allowing us to apprehend forms, motivations and meanings of action within the institutional setting of markets and capture the creativity of actors operating under these constraints, capable of mobilizing different repertoires of action. The analysis of economic action, as it is purposed, executed and understood by the actors themselves must depart from the essentialist anthropology of the actor as calculative and rational. Developed by economics, this anthropology has been to a great extent uncritically imported into the sociology of economic life, most of which assumes the goals of actors without questioning the native meanings of market exchange, aiming, conversely, to explain the social determinants, the non-economic conditions that allow agents to achieve goals that are abstractly and conceptually defined.

\subsection{Finale}

June 2012, old center of São Sebastião do Rio de Janeiro. One week before the official opening of the United Nations Conference on Sustainable Development (Rio+20), and old port warehouse is filled with colorful and meticulously worked pictures of Yawanawa men and women. They wear exuberant headdresses and Jarina-straw skirts. There are also artistic pictures of the Amazonian Forest, its trees and waters. Sections of the exhibition are divided by straw curtains, mimicking the ritual skirts worn by the indigenous people. In one of such sections, there is a reconstruction of a "typical" stilt house, with a hammock and some tipi, bamboo-made, long cylindrical objects of multiple shapes employed to inhale rapé, a mix of tobacco and plant ashes, prepared with a pestle and mortar, also part of the scenography. The exhibition is titled At the Heart of the World (No Coração do Mundo) and is part of a larger 
project, which includes a book and a documentary still to be released. It is sponsored by private companies and supported by the Ministry of Culture of Brazil. The event is an official part of the Rio+20. Its opening was attended by a dozen representatives of the Yawanawa, together with the organizers of the project and the minister of culture. One of the main Brazilian daily papers based in Rio, O Globo, covered the opening, producing a hyperbolical account of the survival of the Yawanawa, from its alleged decimation in the 1970s until its current revitalization (Neto 2012). Interviewed by the journalist, the minister declared that cultural diversity is an important element to promote sustainable development and Putanny, a shaman and wife of Biraci, declared what was their goal with the exhibition: "we hope to sensitize persons to our spirituality and care for nature. We do not only live in the forest, but also made a secret oath to care for it". A couple of days later, she was invited to perform a blow ritual, part of their system of cure, in a morning show on Brazil's largest TV network. A still larger group of the same population also heads for Rio during the Rio+20. One of its leaders is attending the summit and parallel events, including meetings of native populations and prospect business meetings. Others are heading to an estate south of Rio, for a cultural festival to be held after the end of the summit. Information and pictures for each of these events are posted by the Yawanawa on Facebook.

In this rapid circulation of their cultural representations, the Yawanawa reassert their particular identity and publicly celebrate it. Even gaining distance from their ethno-history, which emphasize their survival and juxtapose the current moment of free expression with decades of hostile circumstances, it is impossible not to recognize a reassertion of their collective identity and self-awareness of their distinctiveness. Currently, they are agents in charge for their future, forging new alliances and asserting their collective identity. Yet their agency is a submission of processes initiated by Euro-American institutions to their own cultural system and experience. In other words, they must rework conditions, institutions and categories that are given. Putanny's speech demonstrates how they learned to employ the environmentalism and build upon the imagined association between traditional populations and environmental conservation to attract the attention of outsiders.

In this work I attempted to demonstrate that this reassertion of their difference and the increased capacity to claim benefits associated to their status of indigenous populations were partially made possible as a result of the circulation of cultural representations of the Yawanawa in the market. Economic activities took place in a context of increasing recognition of rights and benefits in the region that enhanced their effects. 
This is a contradictory process in which objectification reanimates subjectification (Comaroff/Comaroff 2009). The more the cultural representations, identity, or simply difference, are consumed, the more it is also produced. However, it might be that, created in the act of consumption, the appropriate practices that define any "culture", or the identity of a group, are those which are preferred and object of approval by the consumers. Is this, then, an invented and falsified version of culture, as some argue? It is obviously invented. "Culture", defined as a set of selected symbols of difference - practices, objects and relations - which define the boundaries of the group, is always invented by culture, defined as the structure of possibilities of reception of symbols and construction of meaningful relationships. The Yawanawa "culture", with its saites, mariris, uni, rapé is an invention, but not more than the French or the German "culture", as shown by Anderson (1991). People are constantly creating their culture by interpreting their world and selecting some elements, which are, then, objectified, given extreme detail. And, as in the well-known formulation of Wagner (1981), in this operation of creating culture, which is undertaken both by the population and the ethnographer, the representation also creates the subjects, which takes us to the second charge.

The risk, as always with identity, is reification, or a reduction of culture to "culture", the classification system to the staged act. At the same time, there is no empirical standard against which a version of a culture can be assessed. Especially if that version is shared and recognized by most of members of the society as defining their identity, or in other words, if they have efficacy, as a true representation. If what they are doing is deep acting and they are the only ones who know their culture, who could unveil their masks? I would like to argue, however, that in this process of enacting culture, they are indeed producing culture and its subjects, in a performance that resembles a prosopopoeia. The sometimes exaggerated, caricature-like forms of presenting themselves when displaying their "culture" is a performance in which culture is actually created and a new subject, the real Yawanawa, emerges, displaying in their body paintings, headdresses and skirts the masks of the true people of the white-lipped peccary. If the nations of Europe and North America are represented and experienced as they parade in festive military uniforms with the metallic icons of the service given to the nations, and the unity in dissent represent by regular elections and the oaths of office by elected political representatives, why cannot the Yawanawa, dancing, painted and with colorful headdresses in this brief moments of representation of the unity of the community, be the true representation of the Yawanawa? If they act as an 
objectified version of themselves, it is only to reinforce what they discover and define as their own essence and truth.

There is no goal here to produce an apology of the market and its effects on the community, but simply recognizing that market transactions gain meanings, according to the native schemes of perception and has a role in their defined goals, in consonance with their cultural dynamic. That is to say, market transactions are indigenized and serve different purposes: in a particular moral view of the market, the dignities the Yawanawa recognize are associated, by other Brazilians and foreigners, to the involvement in market transactions, are employed to increase the visibility of their culture. This does not come without certain changes in the community and effects that are common to market transactions. Ironically, the importance "culture" gains in this new scenario for obtaining resources subordinate the inequalities of income to the inequalities of access to the power of performing culture. It also imposes the observance of such practices associated to "culture" to all the members of the community, including some that do not see traditions as central or have different views of them. After all, culture is not just the glorious key to difference, but also limits that define our world and accepted practices.

Writing to Dom Lionis Pereira, former Governor of Malaca and Southern India in 1576, Pero Gandavo (1576) comments on the avidity with which the coastal natives of Santa Cruz, later baptized Brazil, desire the good things, the marvelous possessions of the colonizers. He complements that they regret the bad luck of their ancestors which had no opportunity to meet such a valuable people - and the word valuable does not seem accidental here. Would that be pure colonial mystification? I do not think so. If Viveiros de Castro (2002a) is right in his well-researched investigation into the inconstancy of their souls and central tenets, this is an acute observation into the disposition to engage with and incorporate the other. What Gandavo (1576) could not foresee, nor Viveiros de Castro (2002a) comment, is that perhaps the most valuable of all possessions brought across the Atlantic would be the notion of "culture". And to incorporate the "other" would, then, require them to assume a fundamental and rigid sameness in its difference. So valuable - again, the word matters here - became the symbols of this difference, "culture" in short, that it could actually be employed to reassert their right to exist against twentieth-first century colonizers. That is what selling "cultures" is about. 


\section{Appendix 1: Interviews at Gregorio River Indigenous Land and key}

May/June 2011; October 2011, Gregorio River Indigenous Land, Tarauaca and Cruzeiro do Sul, Acre, Brazil.

1. Manuel da Silva Filho (Tika) (N.E.) - MSF

2. Valdemir Vicente Brandão Yawanawa (Missi or Pucarassu) (N.E.) - VVB

3. Manuel de Jesus Brasil (Naynawa) (N.E.) - MJB

4. Manuel Nascimento Pequeno (Kapakuru) (N.E.) -MNP

5. Francisco Moacir Yawanawa (Yasã) (N.E.) - FMY

6. Jorge Luís Yawanawa (Vená) (N.E.) - JL

7. Raimundo Sales Luís Yawanawa - in Tarauaca - RSLY

8. Kuni - in Tarauaca (N.E.) - Kuni

9. Francisco "Chicó" (Matrinchã) - FY

10. Alderico Pequeno Yawanawa (Amparo) - APY

11. Anonymous (Amparo)-Anonymous

12. Antônio Luís Carioca (Amparo) - ALC

13. João Inácio Yawanawa (Amparo) - JIY

14. José Martim Yawanawa (Mutum) - JMY

15. Putanny Yawanawa (N.E.) - PY

16. Fernando Luís Yawanawa (Nani) - in Cruzeiro do Sul (N.E.) - FL

17. Biraci Brasil (Nixiwaka) - in Cruzeiro do Sul (N.E.) - BBY

18. Joaquim Tashkã Yawanawa (Mutum) - JY

19. Juraci Brasil Yawanawa (Juca) - Manãwãya (N.E.) - JBY

20. Biraci Brasil Junior (N.E.) _ BBJ

21. Aldaíso Luiz Vinnya (N.E.) - ALV

22. Augusto Pereira da Silva Yawanawa (Rume) (N.E.) - APSY

23. Valdemar Yawanawa Acrino (Tuinkuru) (N.E.) - VYA

24. Joao da Silva Filho (Xinu) (N.E.) - JSF

25. Pedro Conceicao Yawanawa (Shukunuha) (N.E.) - PCY

26. Esau Yawanawa Pequeno (N.E.) - EYP

27. Mariazinha Luiza Yawanawa (Naywany) (Mutum) - MLY

28. Paulo Luis Yawanawa (Matsini) (Mutum) - PLY

29. Katia Luiza Yawanawa (Hushahu) (Mutum) - KLY

30. Joao Carneiro Junior (Tuinkuru), (Tibúcio) - JCJ

31. Joao Carneiro Filho (Rara), (Tibúcio) - JCF

32. Andrelina Luiza Alberta (Ychama) (Tibúcio) - ALA 
33. Luis Brasil da Silva (and son) (Sete Estrelas) - LBS

34. Luzia Yawanawa da Silva (N.E.) - LY

35. Badu Yawanawa (N.E.) - BY 


\section{Appendix 2: Interviews with Aveda employees}

1st to 3rd of February, 2012, Blaine and Minneapolis, Minnesota.

1. David Hircock - Prospection and sourcing of raw materials - DH

2. Dominique Conseil - President - DC

3. R\&D Employee (3)

4. R\&D Employee (4)

5. R\&D Employee (5)

6. Communications Team Employee (6)

7. Marketing Employee (7)

8. Global Supplier Relations Employee (8)

9. Communications Team Employee (9)

10. Global Trainer, Aveda Institute (10) 


\section{References}

Almeida, Mauro Almeida W., 1992. Rubber Tappers of the Upper Jurua River: The Making of a Forest Peasant Economy. Cambridge, UK: University of Cambridge.

Anderson, Benedict, 1991. Imagined communities: Reflections on the origin and spread of nationalism. London: Verso.

Appadurai, Arjun, 1986. Introduction: commodities and the politics of value. In: Arjun Appadurai (ed.). The social life of things. Cambridge, UK: Cambridge University Press, 3-63. Aquino, Terri Vale de, 1983. Balanço da Situação Atual de Terras. In: Carlos Alberto Ricardo (ed.) Povos Indigenas do Brasil. São Paulo: CEDI.

Aspers, Patrick, 2010. Orderly Fashion: A Sociology of Markets. Princeton, NJ: Princeton University Press.

Aveda, 1998. Plant Aromatherapy. In: Aveda Magazine (not issue numbered).

Aveda, 2012a. Find a location. $<$ http://www.aveda.com/locator/index.tmpl>

Aveda, 2012b. Free Sensory Rituals. $<$ http://www.aveda.com/pdf/free-sensory-rituals.pdf $>$

Aveda, 2013. Ingredients. $<$ http://www.aveda.com/discover/index.tmpl\#section=ingredients $>$

Aveda (no year). The Story of Brazilian Uruku (commercial video). Aveda Sourcing Story; Aveda. United States.

Balée, William, 1993. Biodiversidade e os índios amazônicos. In: Eduardo Viveiros de Castro/Manuela Carneiro da Cunha (eds.), Amazônia. Etnologia e História. São Paulo: Núcleo de História Indígena e Indigenismo (NHII) - USP and FAPESP, 385-393.

Barreto, Carlos Alberto Lima Menna, 1995. A Farsa Ianomâmi. Rio de Janeiro: Biblioteca do Exército.

Beckert, Jens, 2011. The Transcending Power of Goods: Imaginative Value in the Economy. In: Jens Beckert/Patrick Aspers (eds.), The Worth of Goods. Oxford: Oxford University Press, 41-62.

Belk, Russell, 1988. Possessions and the Extended Self. In: Journal of Consumer Research 15, 139-168.

Biggart, Nicole Woolsey, 1990. Charismatic Capitalism: Direct Selling Organizations in America. Chicago: University of Chicago Press. 
Bloch, Maurice/Jonathan Parry, 1989. Introduction: money and the morality of exchange. In: Maurice Bloch/Jonathan Parry (eds.), Money and the Morality of Exchange. Cambridge: Cambridge University Press, 1-32.

Bohannan, Paul, 1959. The Impact of Money on an African Subsistence Economy. In: Journal of Economic History, 19, 491-503.

Boltanski, Luc/Laurent Thévenot, 2006. On justification. Economies of worth. Princeton, NJ: Princeton Univ. Press.

Bourdieu, Pierre, 1977. Outline of a Theory of Practice. Cambridge, UK: Cambridge University Press.

Bourdieu, Pierre, 1979. Algeria 1960: Essays. Cambridge: Cambridge University Press.

Bourdieu, Pierre, 1980. Le sens pratique. Paris: Éd. de Minuit.

Bourdieu, Pierre, 1986. L'illusion biographique In: Actes de la recherche en sciences sociales $62,69-72$.

Bourdieu, Pierre, 1993. The Rules of Art: Genesis and Structure of the Literary Field. Stanford: Stanford University Press.

Bourdieu, Pierre, 2005. The social structures of the economy. Cambridge: Polity Press.

Brasil, República Federativa do/Fundação Nacional do Índio - FUNAI, 2006. Relatório de Revisão de Limites da Terra Indígena Rio Gregório. Processo FUNAI 713/2006. Brasília: FUNAI.

Bunten, Alexis Celeste, 2008. Sharing culture or selling out. In: American Ethnologist 35, 380-395.

Callon, Michel/Cécile Méadel/Vololona Rabeharisoa, 2002. The economy of qualities. In: Economy and Society 31, 194-217.

Carlo, Sandra de/José Drummond, 2000. The Yawanawa-Aveda Bixa Project: A Business Partnership Seeking Sustainability in an Amazonian Indigenous Community. In: Marie D. Hoff (ed.) Sustainable Community Development: Studies in Economic, Environmental and Cultural Revitalization. Boca Raton: Lewis Publishers, 63-84.

Canedy, Dana, 1997. Estee Lauder is Acquiring Maker of Natural Cosmetics. In: The New York Times, 20.11.1997. <http://www.nytimes.com/1997/11/20/business/estee-lauder-isacquiring-maker-of-natural-cosmetics.html $>$ 
Cheal, David, 1988. The Gift Economy. London and New York: Routledge.

Clastres, Pierre, 1974. La Société contre L'État. Paris: Éditions de Minuit.

Clastres, Pierre, 1977. Archéologie de la violence. La guerre dans les sociétés primitives. Paris: L'Aube.

Clifford, James, 1997. Routes: Travel and Translation in the Late Twentieth Century. Cambridge, MA: Harvard University Press.

Comaroff, John L./Jean Comaroff, 2009. Ethnicity, Inc. Chicago: University of Chicago Press.

Conklin, Beth A. /Laura R. Graham, 1995. The Shifting Middle Ground: Amazonian Indians and Eco-Politics. In: American Anthropologist 97, 695-710.

Conklin, Beth A., 1997. Body paint, feathers, and vcrs: aesthetics and authenticity in Amazonian activism. In: American Ethnologist 24, 711-737.

Costa, Sérgio, 2012. Freezing Differences: Politics, Law, and the Invention of Cultural Diversity in Latin America. In: Kathya Araujo/Aldo Mascareño (eds.), Legitimization in World Society. Farnhame: Ashgate, 139-156.

Crewe, Emma/Elizabeth Harrison, 2005. Seeing Culture as a Barrier. In: Marc Edelman/Angelique Haugerud (eds.), The Anthropology of Development and Globalization. Oxford: Blackwell.

Cunha, Manuela Carneiro da, 1999. Populações tradicionais e a Convenção da Diversidade Biológica. In: Estudos Avançados 13, 147-163.

Cunha, Manuela Carneiro da, 2009. "'Culture" and culture. Traditional knowledge and intellectual rights, Paradigm ; 26. Chicago: Prickly Paradigm Press.

De Carlo, Sandra/José Drummond, 1998. The Yawanawá-Aveda Project: A Business Partnership Seeking Sustainability in an Amazonian Indigenous Community. In: Hoff, Marie D. Sustainable Community Development. Studies in Economic, Environmental and Cultural Revitalization. Boca Raton: Lewis Publisher, 63-84.

Dean, Warren, 1989. A luta pela borracha no Brasil. São Paulo: Nobel.

Desai, Pranav N., 2007. Traditional Knowledge and intellectual protection: past and future. In: Science and Public Policy 34, 185-197. 
Dilley, Roy, 1992. Contesting Markets: An Introduction. In: Roy Dilley (ed.). Contesting Markets: Analyses of Ideology, Discourse and Practice. Edinburgh: Edinburgh University Press, 1-33.

Douglas, Mary/Baron Isherwood, 1979. The World of Goods. Towards an Anthrpology of Consumption.

Durkheim, Émile, 1978. De la division du travail social. Paris: PUF.

Durkheim, Émile, 1983 [1895]. Les règles de la méthode sociologique, Bibliothèque de philosophie contemporaine. Paris: Presses Univ. de France.

Erikson, Philippe, 1993. Une Nébuleuse compacte : le macro-ensemble pano. In: L'Homme $33,45-58$.

Erikson, Philippe, 1996. La griffe des aïeux. Marquage du corps et démarquages ethniques chez les Matis d'Amazonie, SELAF. Leuven: Peeters.

Escobar, Arturo, 1995. Encountering Development: the Making and Unmaking of the Third World. Princeton, New Jersey: Princeton University Press.

Escobar, Arturo, 2008. Territories of Difference: Place, Movements, Life, Redes. Durham: Duke University Press.

Espeland, Wendy Nelson/Mitchell L. Stevens, 1998. Commensuration as a social process. In: Annual Review of Sociology, 24, 313-343.

Fairclough, Norman, 2001. Discourse and social change. Cambridge: Polity Press.

FAO, Food and Agriculture Organization of the United Nations, 1995. Annatto seed and its extracts. Natural Colourants and dyestuffs. Non-Wood Forest Products, 4. Rome: Food and Agriculture Organization of the United Nations. $<$ http://www.fao.org/docrep/V8879E/V8879E00.htm\#Contents> Ferguson, James, 1999. Expectations of Modernity: Myths and Meanings of Urban Life on the Zambial Copperbelt. Berkeley: University of California Press.

Fourcade, Marion, 2011. Cents and Sensibility: Economic Valuation and the Nature of "Nature". In: American Journal of Sociology 116, 1721-1777.

Franco, Mariana Ciavatta Pantoja, 2008. Os Milton: Cem anos de história nos seringais. 2nd. Auflage. Rio Branco: EDUFAC. Fundação Joaquim Nabuco. 
Furtado, Celso, 1963. The Economic Growth of Brazil: a Survey from Colonial to Modern Times. Berkeley: University of California Press.

Gandavo, Pero de Magalhães, 1576. Historia da prouincia sa[n]cta Cruz a que vulgarme[n]te chamam Brasil / feita por Pero Magalhães de Gandauo, dirigida ao muito Illsre s[e]nor Dom Lionis P[ereir]a gouernador que foy de Malaca e das mais partes do Sul na India. Lisboa: Antonio Gonsaluez: vendense em casa de Ioão lopez liureiro na rua noua, 1576.

Geertz, Clifford, 1979. Suq: The Bazaar Economy in Sefrou. In: Clifford Geertz/Hildred Geertz/Lawrence Rosen (eds.), Meaning and Order in Moroccan Society: Three Essays in Cultural Analysis. . Cambridge, UK: Cambridge University Press, 123-225.

Giddens, Anthony, 1990. The consequences of modernity. Stanford, CA.: Stanford Univ. Press.

Gemici, Kurtuluş, 2008. Karl Polanyi and the antinomies of embeddedness. In: SocioEconomic Review 6, 5-33.

Gil, Laura Perez, 1999. Pelos Caminhos de Yuve: conhecimento, cura e poder no xamanismo yawanawa. Master Thesis presented to the Department of Anthropology of the Federal University of Santa Catarina. Florianópolis: Universidade Federal de Santa Catarina.

Gil, Laura Perez, 2001. O sistema médico Yawanawa e seus especialistas: cura, poder e iniciação xamânica. In: Cadernos de Saúde Pública 17, 333-344.

Gluckman, Max, 1955: The Peace in the Feud. In: Gluckman Max (ed.) Custom and Conflict in Africa. Oxford: Basil Blackwell, 1-26.

Godbout, Jacques/Alan Caillé, 1998. The World of Gift. Montreal: McGill-Queen's University Press.

Godelier, Maurice, 1986. Making of Great Men. Male domination and Power among the New Guinea Baruya. Cambridge: Cambridge University Press.

Godelier, Maurice, 1996. L'énigme du don. Paris: Fayard.

Goffman, Ervin, 1959. The Presentation of Self in Everyday Life. New York: Anchor Books.

Gordon, Bettina, 2011. Aveda founder Horst Rechelbacher's next coup: Intelligent Nutrients goes global! <http://www.bettinagordon.com/horst-rechelbacher-intelligent-nutrients/>

Gordon, César, 2006. Economia Selvagem: ritual e mercadoria entre os Índios XikrinMebêngôkre. São Paulo and Rio de Janeiro: UNESP and NUTI. 
Gow, Peter, 1991. Of mixed blood: kinship and history in Peruvian Amazon. Oxford: Clarendon.

Graeber, David, 2001. Toward an Anthropological Theory of Value: The False Coin of Our Dreams. New York: Palgrave.

Graham, Laura R., 2005. Image and instrumentality in a Xavante politics of existential recognition: The public outreach work of Ete'nhiritipa Pimentel Barbosa. In: American Ethnologist 32, 622-644.

Granero, Fernando Santos, 1986. Power, Ideology and the Ritual of Production in the Lowland South America. In: Man 21, 657-679.

Granero, Fernando Santos, 1993. From Prisoner of the Group to Darling of the Gods: An Approach to the Issue of Power in Lowland South America. In: L'Homme 33, 213-230.

Greenblatt, Stephen, 1991. Marvelous Possessions: The Wonder of the New World. Chicago: Chicago University Press.

Gregory, Chris, 1982. Gifts and commodities. London: Academic Press.

Gregory, Chris, 2001. Exchange in Anthropology. In: Neil Smelser and Paul Bates (eds). International Encyclopedia of the Social and Behavioral Sciences. Vol. 8. Oxford: Elsevier.

Haley, Brian D., 1999. The Culture of Indigenous Rights Activism and David Stoll's Rigoberta Menchú. In: Human Rights Review 1, 91-98.

Healy, Keran, 2006. Last Best Gifts: Altruism and the Market for Human Blood and Organs. Chicago: Chicago University Press.

Hirschman, Albert O., 1986. Rival Views of Market Society and Other Essays. New York: Viking.

Hobart, Mark (ed.), 1993. An Anthropological Critique of Development: the Growth of Ignorance. London: Routledge.

Hoschchild, Arlie, 1983. The Managed Heart. Berkeley: University of California Press.

Islam, Nazrul, 2010. Indigenous Medicine as Commodity. Local Reach of Ayurveda in Modern India. In: Current Sociology 58, 777-798.

Jones, Geoffrey, 2010. Beauty Imagined: A History of the Global Beauty Industry. Oxford: Oxford University Press. 
Karpik, Lucien, 2010. Valuing the unique: the economics of singularities. Princeton: Princeton University Press.

Keifenheim, Barbara, 1990. Nawá: un concept clé de l'altérité chez les Pano In: Journal de la Société des Américanistes 76, 79-94.

Koelln, Georgann, 1995. A Breath of Fresh Hair: Beauty is more than skin deep to Horst - it's basic as Mother Earth. In: Saint Paul Pioneer Press, 1D.

Kopytoff, Igor, 1986. The Cultural Biography of Things: Commoditization as Process. In: Arjun Appadurai (ed.) The Social Life of Things. Cambridge: Cambridge University Press, 6494.

Kroeber, Alfred L., 1959. The History of the Personality of Anthropology. In: American Anthropologist 61, 398-404.

Labate, Beatriz Caiuby, 2004. A Reinvenção do Uso da Ayahuasca nos centros urbanos. Campinas/São Paulo: Mercado das Letras/FAPESP.

Labate, Beatriz Caiuby, 2012. Ayahuasca Religions in Acre: Cultural Heritage in the Brazilian Borderlands. In: Anthropology of Consciousness 23, 87-102.

Labate, Beatriz Caiuby/Edward Mc Rae (eds.), 2010. Ayahuasca, Ritual and Religion in Brazil. London: Equinox.

Lacan, Jacques, 1973. Les Quatre Concepts Fondamentaux De La Psychanalyse. Paris: Editions du Seuil.

Lahire, Bernard, 1998. L'Homme pluriel. Les ressorts de l'action. Paris: Nathan.

Lau, Kimberly J., 2000. New age capitalism: making money east of Eden. Philadelphia: University of Pennsylvania Press.

Leach, Edmund, 1954. Political Systems of Highland Burma: A Study of Cachin Social Structure. Cambridge, MA: Harvard University Press.

Lederman, Rena, 1991. 'Interests' in exchange: increment, equivalence and the limits of bigmanship. In: Maurice Godelier/Marilyn Strathern (eds.), Big Men and Great Men: Personifications of power in Melanesia. Cambridge: Cambridge University Press, 215-233.

Lemmonier, Pierre, 1991. From great men to big men: peace, substitution and competition in the Highlands of New Guinea. In: Maurice Bloch/Marilyn Strathern (eds.), Big Men and 
Great Men: Personifications of Power in Melanesia. Cambridge: Cambridge University Press, 7-27.

Lévi-Strauss, Claude, 1955. Tristes Tropiques. Paris: Plon.

Lévi-Strauss, Claude, 1962. Le totémisme aujourd'hui. Paris: PUF.

Lévi-Strauss, Claude, 1964. Mythologiques. Le Cru e le cuit. Vol. 1. Paris: Plon.

Lévi-Strauss, Claude, 1973. Anthropologie Structurale 2. Paris: Plon.

Lévi-Strauss, Claude, 1981 [1948]. Les Structures Élémentaires de la Parenté, Collection de reeditions ; 2. Paris: Mouton.

Lévi-Strauss, Claude, 1984. Paroles données. Paris: Plon.

Liep, John, 1991. Great man, big man, chief: a triangulation of the Massim. In: Maurice Godelier/Marilyn Strathern (eds.), Big Men and Great Men: Personifications of Power in Melanesia. Cambridge and Paris: Cambridge University Press and Editions de la Maison des Sciences de l'Homme, 28-47.

Liep, John, 1996. The Bigmanisation Process: Theoretical and Historical Secularisation of Power in Melanesia. In: James G. Carrier/Jonathan Friedman (eds.), Melanesian Modernities. Lund: Lund University Press, 121-141.

Lima, Antonio Carlos de Souza, 1991. On Indigenism and Nationality in Brazil. In: Greg Urban/Joel Sherzer (eds.), Nation-States and Indians in Latin America. Austin: University of Texas Press, 236-258.

Lima, Edilene Coffaci de, 1994. Katukina: história e organização social de um grupo pano do alto Juruá. Master Thesis presented to the Department of Anthropology of the University of Sao Paulo. São Paulo: Universidade de São Paulo.

Lima, Edilene Coffaci de, 2009. Katukina-Pano. Instituto Socioambiental (ISA).

Lyons, John, 2011. Skin-Deep Gains for Amazon Tribe In: Wall Street Journal, 05.05.2011.

Mahoney, James, 2010. Colonialism and Postcolonial Development - Spanish America in Comparative Perspective. Cambridge: Cambridge University Press.

Malinowski, Bronislaw, 2002 [1922]. Argonauts of the Western Pacific. An account of native enterprise and adventure in the Archipelagoes of Melanesian New Guinea. London: Routledge.

Martin, John Levi, 2003. What is field theory? In: American Journal of Sociology 109, 1-49. 
Marx, Karl/Friedrich Engels, 1990[1867]. Capital. A Critique of Political Economy. Vol. 1. London: Penguin.

Mauss, Marcel, 2005 [1923-4]. The gift: the form and reason for exchange in archaic societies. London: Routledge.

McKenna, Dennis, 2004. Clinical Investigations of the Therapeutical Potential of Ayahuasca:

Rationale and Regulatory Challenges. In: Pharmacology\&Therapeutics 102, 111-129.

Mead, George Herbert, 1934. Mind, Self and Society. From the Standpoint of a Social Behaviorist. Chicago: Chicago University Press.

Melatti, Julio Cezar, 1976. Organização social Marúbo: um sistema australiano na Amazônia. In: Anuário Antropológico 76, 83-120.

Montaigne, Michel de, 1976 [1580]. Essais Vol. 1. Geneva: Slatkine.

Myers, Fred, 2002. Painting Culture: The Making of an Aboriginal High Art. Durham: Duke University Press.

Narotzky, Susana, 2001. Economic Anthropology. In: Neil Smelser and Paul Bates (eds). International Encyclopedia of the Social and Behavioral Sciences. Vol. 6. Oxford: Elsevier.

Naveira, Miguel Alfredo Carid, 1999. Yawanawa: da guerra à festa. Master Thesis presented to the Department of Anthropology of the Federal University of Santa Catarina. Florianópolis: Universidade Federal de Santa Catarina.

Neto, Lauro, 2012. Diversidade cultural é importante para desenvolvimento sustentável, diz Ana de Holanda. In: $O$ Globo. <http://oglobo.globo.com/rio20/diversidade-culturalimportante-para-desenvolvimento-sustentavel-diz-ana-de-hollanda-5196898>

Overing, Joanna, 1975. The Piaroa, a People of the Orinoco Basin: A study in kinship and marriage. Oxford: Clarendon.

Overing, Joanna, 1992. Wandering in the Market and the Forest. An Amazonian Theory of Production and Exchange. In: Roy Dilley (ed.). Contesting Markets: Analyses of Ideology, Discourse and Practice. Edinburgh: Edinburgh University Press, 180-200.

Pantoja, Mariana C./Osmildo da Silva Conceição, 2010. The use of Ayahuasca among rubber tappers of the Alto Juruá. In: Beatriz Caiuby Labate/Edward MacRae (eds.), Ayahuasca, Ritual and Religion in Brazil. London: Equinox, 21-38. 
Parry, Jonathan, 1989. On the moral perils of exchange. In: Jonathan Parry/Maurice Bloch (eds.), Money \& The Morality of Exchange. Cambridge: Cambridge University Press, 64-93.

Parry, Jonathan/Maurice Bloch (eds.), 1989. Money \& The Morality of Exchange. Cambridge: Cambridge University Press.

Pimenta, José, 2006. Reciprocidade, Mercado e Desigualdade Social entre os Ashaninka do Rio Amônia. Brasília: Universidade de Brasília.

Polanyi, Karl, 1957 [1944]. The Great Transformation: the political and economic origins of our time. Boston: Beacon Press.

Polanyi, Karl (1968). The Economy as Instituted Process. In: George Dalton (ed.), Primitive, Archaic and Modern Economies: Essays of Karl Polanyi. Boston: Beacon Press, 139-174.

Posey, Darell/Graham Dutfield, 1996. Beyond Intellectual Property: Toward Traditional Resource Rights of Indigenous Peoples and Local Communities. Ottawa: International Development Research Centre.

Ratuva, Steven, 2009. Commodifying cultural knowledge: corporatised western science and Pacific indigenous knowledge. In: International Social Science Journal 60, 154-163.

Rechelbacher, Horst, 1999. Aveda Rituals: A Daily Guide to Natural Health and Beauty. New York: Henry Holt and Co.

Rechelbacher, Horst, 2008. Minding your own Business: Profits that Restore the Planet. San Rafael, CA: Earth Aware.

Ribeiro, Fabio Augusto Nogueira. The political economy of the green market in indigenous Amazonas: the partnership Amazoncoop-The Body Shop from the perspective of ethnodevelopment. In: Tellus, 9, 16, 57-80.

Ribeiro, May Waddington Telles, 2005. Uma Tribo vai ao Mercado - os Yawanawa: sujeitos ou objetos do processo? Thesis presented to the Department of Social Sciences of the Federal Rural University of Rio de Janeiro. Seropédica: Universidade Federal Rural do Rio de Janeiro.

Richins, Marsha, 1994. Valuing Things: The Public and Private Meanings of Possessions. In: The Journal of Consumer Research 21, 504-521.

Sacks, Danielle, 2006. It's Easy Being Green: With earth-friendly products and packaging, Aveda is putting the beauty back into the ugly world of cosmetics. In: Fast Company. $<\mathrm{http}$ ://www.fastcompany.com/75317/its-easy-being-green> 
Saez, Oscar Calavia, 1995. O nome e o tempo dos Yaminawa. Master Thesis presented to the Department of Anthropology of the University of Sao Paulo. São Paulo: Universidade de São Paulo.

Saez, Oscar Calavia, 2001. El rastro de los pecaríes. Variaciones míticas, cariaciones cosmológicas e identidades étnicas en la etnologia pano. In: Journal de la Société des Américanistes 87, 161-176.

Saez, Oscar Calavia, 2002. A Variação Mítica como Reflexão. In: Revista de Antropologia 45, $7-35$.

Sahlins, Marshall D., 1963. Poor Man, Rich Man, Big-Man, Chief: Political Types in Melanesia and Polynesia. In: Comparative Studies in Society and History 5, 285-303.

Sahlins, Marshall D., 1976. Culture and practical reason. Chicago: University of Chicago Press.

Sahlins, Marshall D., 1985. Islands of History. Chicago: University of Chicago Press.

Sahlins, Marshall D., 1988. Cosmologies of Capitalism: The Trans-Pacific Sector of the World System. In: Proceedings of the British Academy.

Sahlins, Marshall D., 1993a. Goodby to Tristes Tropes: Ethnography in the Context of Modern World History. In: The Journal of Modern History 65, 1-25.

Sahlins, Marshall D., 1993b. How "Natives" Think: About Captain Cook, for Example. Chicago: University of Chicago Press.

Sahlins, Marshall D., 1999a. Two or Three Things That I Know About Culture. In: Journal of the Royal Anthropological Institute 5, 399-422.

Sahlins, Marshall D., 1999b. What is anthropological enlightenment? Some Lessons of the Twentieth Century. In: Annual Review of Anthropology 28, i-xxiii.

Sahlins, Marshall D., 2000. Culture in Practice: selected essays. New York: Zone Books.

Sahlins, Marshall D., 2008. Stone Age economics, Routledge classic ethnographies. London: Routledge.

Sahlins, Marshall D., 2013. On the culture of material value and the cosmography of riches. In: Hau: Jornal of Ethnographic Theory 3, 161-195.

Schumpeter, Joseph A., 1968[1934]. The theory of economic development: an inquiry into profits, capital, credit, interest and the business cycle. Cambridge: Harvard Univ. Press. 
Schwimmer, Eric, 1991. How Oro Province societies fit Godelier's model. In: Maurice Godelier/Marilyn Strathern (eds.), Big Men and Great Men: Personifications of Power in Melanesia. Cambridge and Paris: Cambridge University Press and Editions de la Maison des Sciences de l'Homme, 142-156.

Simmel, Georg, 1978. The Philosophy of Money. London: Routledge and Kegan Paul.

Sivaramakrishnan, Kavita 2006. Old potions, new bottles: recasting indigenous medicine in colonial Punjab (1850-1945). New Delhi: Orient Longman.

Steiner, Philippe, 2009. Who is right about the modern economy: Polanyi, Zelizer, or both? In: Theory and Society, 38, 97-110.

Strathern, Marilyn, 1990. The Gender of the Gift: Problems with Women and Problems with Society in Melanesia. Berkeley: University of California Press.

Strathern, Marilyn, 1995. The Nice Thing about Culture is that Everyone has it. In: Marilyn Strathern (ed.) Shifting Contexts: transformations in anthropological knowledge. London Routledge, 153-176.

Strauss, Anselm, 1997. Mirrors and Masks. New Brunswick: Transaction Publishers.

Swedberg, Richard, 1999. Max Weber as an Economist and as a Sociologist: Towards a Fuller Understanding of Weber's View of Economics. In: The American Journal of Economics and Sociology 58, 561-582.

Tambiah, Stanley Jeyaraja, 1985. Culture, Thought and Social Action Cambridge, MA: Harvard University Press.

Tastevin, Constantin, 1924. Chez les Indiens du Haut-Jurua. In: Les Missions Catholiques LVI, 65-67; 78-80; 90-93; 101-104.

Taussig, Michael, 1980. The Devil and Commodity Fetishism in South America. Chapel Hill: University of North Carolina Press.

Thomas, Nicholas, 1991. Entangled Objects: Exchange, Material Culture, and Colonialism in the Pacific. Cambridge, MA: Harvard University Press.

ThomsonFinancial, 2010. ESTEE LAUDER COMPANIES INC, Thomson Financial; Nelson's Public Company Profiles. Lexis Nexis.

Turner, Terence, 1993. De Cosmologia a História: resistência, adaptação e consciência social entre os Kayapó. In: Eduardo Viveiros de Castro/Manuela Carneiro Cunha (eds.), Amazônia: 
etnologia e história indígena. São Paulo: Núcleo de História Indígena e do Indigenismo/FAPESP, 43-66.

Turner, Terence, 1995a. An Indigenous People's Struggle for Socially Equitable and Ecologically Sustainable Production: The Kayapo Revolt against Extractivism. In: Journal of Latin American Anthropology 1, 98-121.

Turner, Terence, 1995b. Neoliberal Ecopolitics and the Indigenous Peoples: The Kayapo, the Rainforest Harvest, the Body Shop. In: Yale F\&ES Bulletin, 98, 113-127.

Turner, Victor, 2008. The Ritual Process: Structure and Anti-Structure. New Brunswick: Transaction Publishers.

UN, United Nations. World Commission on Environment and Development, 1987. Report of the World Commission on Environment and Development: Our Common Future. A/42/427, United Nations. General Assembly. Forty-second Session. New York. <http://daccess-ddsny.un.org/doc/UNDOC/GEN/N87/184/67/IMG/N8718467.pdf?OpenElement>.

Urban, Greg/Joel Sherzer, 1991. Introduction: Indians, Nation-States and Culture. In: Greg Urban/Joel Sherzer (eds.), Nation-States and Indians in Latin America. Austin: University of Texas Press, 1-18.

USA/NCCAM, 2011. Ayurvedic Medicine: An Introduction. National Center for Complementary and Alternative Medicine/National Institutes of Health $<$ http://nccam.nih.gov/sites/nccam.nih.gov/files/D287_BKG.pdf?nav=gsa>

Velthuis, Olav, 2005. Talking Prices: Symbolic Meanings of Prices on the Market for Contemporary Art. Princeton, NJ: Princeton University Press.

Vinnya, Aldaiso Luiz/Maria Luiza Pinedo Ochoa/Gleyson de Araújo (Orgs.) Teixeira, 2006. Costumes e Tradições do Povo Yawanawá. Rio Branco: Comissão Pró-Índio do Acre / Organização dos Professores Indígenas do Acre.

Viveiros de Castro, Eduardo, 1992. From the enemy's point of view: Humanity and divinity in an Amazonian society. Chicago: University of Chicago Press.

Viveiros de Castro, Eduardo, 2002a. O mármore e a murta: sobre a inconstância da alma selvagem. In: Eduardo Viveiros de Castro (ed.) A inconstância da alma selvagem. São Paulo: Cosac Naify, 181-264.

Viveiros de Castro, Eduardo, 2002b. O problema da afinidade na Amazônia In: Eduardo Viveiros de Castro (ed.) A Inconstância da Alma Selvagem. São Paulo: Cosac Naify, 87-180. 
Viveiros de Castro, Eduardo, 2002c. Perspectivismo e multinaturalismo na América Indígena. In: Eduardo Viveiros de Castro (ed.) A Inconstância da Alma Selvagem. São Paulo: Cosac Naify, 347-399.

Wagner, Roy, 1981. The Invention of Culture. Revised and Expanded Edition. Chicago: The University of Chicago Press.

Wagner, Roy, 1991. The Fractal Person. In: Maurice Godelier/Marilyn Strathern (eds.), Big Men and Great Men: Personifications of Power in Melanesia. Cambridge and Paris: Cambridge University Press and Editions de la Maison des Sciences de l'Homme, 159-173.

Wallerstein, Immanuel, 1974. The Modern World-System: Capitalist Agriculture and the Origins of the European World-Economy in the Sixteenth Century. Vol. 1. New York: Academic Press.

Wallerstein, Immanuel, 1990. Culture as the Ideological Battleground of the Modern WorldSystem. In: Mike Featherstone (ed.) Global Culture: Nationalism, Globalization and Modernity. London: Sage, 31-55.

Weber, Max, 1978. Economy and Society. An outline of interpretive sociology. Berkeley: University of California Press.

Weber, Max, 1991. Science as a Vocation. In: H. H. Gerth/C. Wright Mills (eds.), From Max Weber: essays in sociology. Oxford, UK: Routledge, 129-156.

White, Harrison C., 2002. Markets from networks: socioeconomic models of production. Princeton, NJ Princeton Univ. Press.

Wilkis, Ariel, 2013. Las Sospechas del Dinero: moral y economia en la vida popular. Buenos Aires: Paidós.

Young, Lucie, 2011. Aveda founder's mission: to clean up beauty industry act. In: Telegraph, 23.04.2011. <http://fashion.telegraph.co.uk/beauty/news-features/TMG8463402/Avedafounders-mission-to-clean-up-beauty-industry-act.html>

Zaloom, Caitlin 2006. Out of the Pits: Traders and Technology from Chicago to London. Chicago: Chicago University Press.

Zelizer, Viviana, 1979. Morals and Markets: The Development of Life Insurance in the United States. New York: Columbia University Press.

Zelizer, Viviana, 1985. Pricing the priceless child. The changing social value of children. Princeton: Princeton University Press. 
Zelizer, Viviana, 1988. Beyond the Polemics of the Market: Establishing a Theoretical and Empirical Agenda. In: Sociological Forum, 3, 614-634.

Zelizer, Viviana, 1994. The Social Meaning of Money: Pin Money, Paychecks, Poor Relief, and Other Currencies. New York: Basic Books.

Zelizer, Viviana, 1996. Payments and Social Ties. In: Sociological Forum 11, 481-495.

Zelizer, Viviana, 2005. The purchase of intimacy. Princeton: Princeton University Press.

Zelizer, Viviana, 2007. Pasts and Futures of Economic Sociology. In: American Behavioral Scientist, 50, 1056-1068.

Zelizer, Viviana, 2010. Economic lives: how culture shapes the economy. Princeton: Princeton University Press. 